










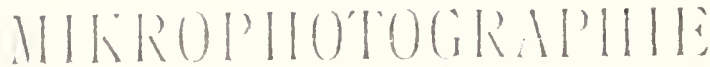

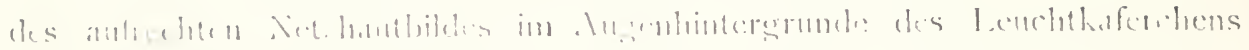

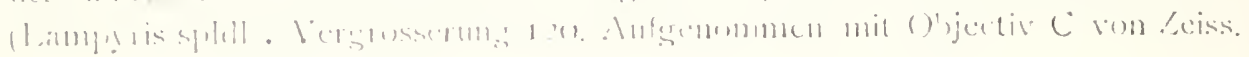

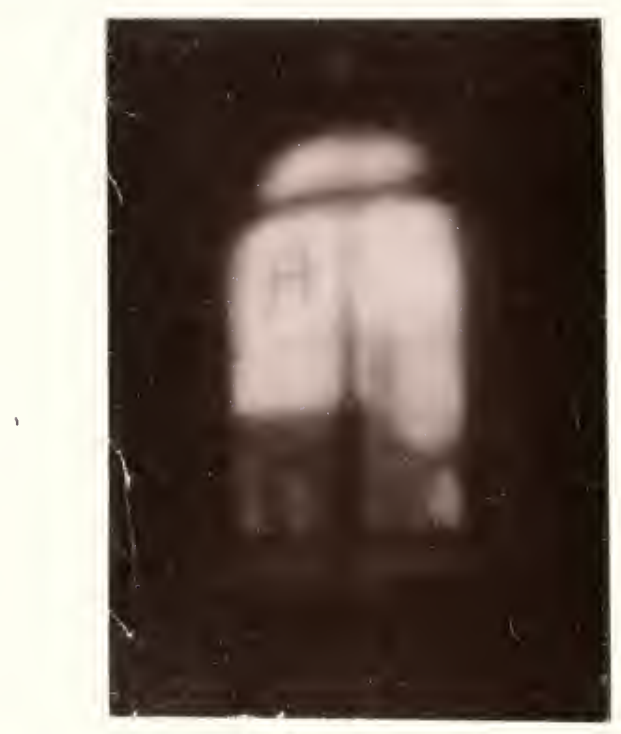

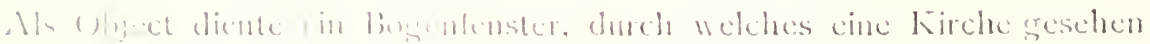

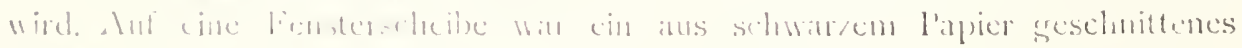

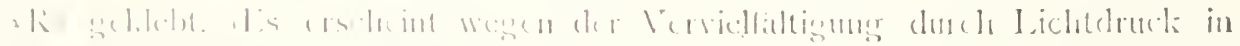

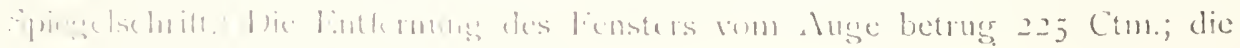

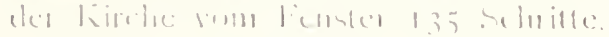

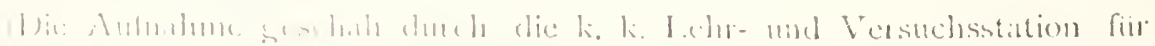

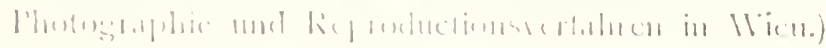






\section{DIE PHYSIOLOGIE}

1) ER

\section{FACETTIRTEN AUGEN \\ $10 N$}

KREBSEN UND INSECIEN.

EINE STUDIE

$\operatorname{VON}$

S I G M. E X N E R

FROFESSOR DER PHYSIOLOGIE AN DER UNIVERSIIÄT IN WIEN

Mit 7 lithographirten Tafeln. einem Lichtdruck und 23 Holzschnitten im Text.

LEIP'/G UND WIEN.

F R A N \% D E U 'T' I C K E.

1891. 
Alle Rechte vorbehalter.

K. II, k. Iloflsuchdruckerei farl Fromuse in Wisn. 


\section{HERRN \\ GEHEIMEN RATH \\ HERMANN VON HELMHOL'T'Z \\ ZU SEINEM TO. GEBLRTSTAG \\ DEM 31. AUGUST 1891 \\ IN ALTER VEREHRUNG}

GEWIDMET

VOM

VERFASSER. 



\section{Vorwort.}

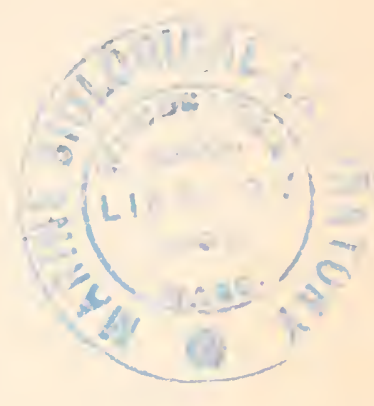

Die vorliegende Studie ist das Resultat mehrjähriger Arbeiten, welche mich stärker, als man es von einem Physiologen erwarten mag, fesselten. Das Facettenange liegt abseits von den viel begangenen Wegen unserer Wissenschaft. Einerseits aber hat es einen unzweifellaften wissenschaftlichen Reiz, nachzuforschen, wie und warum die Natur zwei so grundrerschiedene Nittel benitzt, um anscheinend zu demselben Ziele zu gelangen, ein Lebewesen mit Augen anszustatten; andererseits zeigte sich mir, einmal dem Gegenstande näher getreten, eine solche Fïlle von Formen und Erschleinungen, dass dieselben von Frage z.n Frage drängend, Antwort auf Antwort verlangten, und in ihrer Mannigfaltigkeit, indem sie anatomisches, biologisches, physikalisches und plyysiologisches Denken erforderten, das Interesse immer wieder wachriefen. Das Ange der Wirbellosen ist ein Protens im Vergleiche zum Auge der Wirbelthiere, ja letzteres könnte .Jeden langweilen, der den Reichthum des ersteren kemnen gelernt hat.

So kam es, dass ich mich mit einer gewissen Gewaltsamkeit ron meinem Studienobjecte losreissen musste, vor einer Menge Fragen gleichsam die Augen verschliessend; wie lockend wäre es gewesen, die Augen der Myriapoden und die der Arachnoideen in den Kreis der Untersuchung zn ziehen, oder die sonderbaren Angenformen der Krebse aus der Tiefseefauna zu studiren. Ans diesem Grunde ist in den naclistehenden Zeilen anch Nanches nur angedentet oder musste in der Schwebe gelassen werden; so sind die Experimente ïber den Mechanismus der Pigmentverschiebung nicht über das Stadium von Vorversuchen gediehen.

Oftmals war ich genötligt, collegiale Hilfe in Anspruch zu nehmen, um mich in den mir fremden Gebieten zu orientiren; es laten mich die Herren vom k. und $k$. Naturhistorischen Hofmuseum zu Wien anf das 
fremdlichste unterstiitat, besonder's die Jerren Custoden Prof. F. Braner, Ganglbauer, Kïlbl mul Rogenhofer', sowie Director A. Brezina; der liebenswïrdigen Vermittelung der Herren Hofrath Prof. Clans und Prof. Grobben verdanke ich die Zusendung lebender Seethiere ans 'Triest, und Prof. Ed. Sness die Ueberlassung ron petrificirten Krebsen. Ganz besonders aber füllle ich mich der Leitung der zoologischen Station zn Neapel verpflichtet, welche mich während meines Aufenthaltes daselbst, abgesehen ron der wissenschaftlichen Unterstiitzung, nicht nur auf das reichlichste mit Iaterial, sondern auch mit den zu physiologischen Versuchen nöthigen Apparaten und Einrichtungen versorgte. Der Reichthum von Formen, den ich da zu sehen bekam, gäbe wohl Arbeitsstoff für manches Jahrzehnt. Herrn Prof. Doln'n, sowie den ïbrigen Herren des Institutes meinen wiirmsten 1)ank!

Nicht unterlassen kann ich es, der Verlagsbuchlıandlung des Herrn Franz leenticke ötentlich meinen Dank dafür auszusprechen, dass sie es micht geschent hat, drm Werkchen, das anf einen grossen Leserkreis kaum rechnen darf, eine in jeder bezielnung tadellose Ansstattung zu geben und mir jeden meines Wünsthe, den ich botreffs Holzschnitten, Lithographien oder Lichtdrucken grailusert habe, in dor zurorkommendsten Weise sofort zu ertiillen.

Misn, don 22. Mïr 1891.

Der Verfasser. 


\section{I $\mathrm{n} \mathrm{h}$ a $\mathrm{lt}$.}

I. Capitel. Physikalische Vorbemerkungen . . . . .

II. Capitel. Dioptrik des zusammengesetzten Auges . . . . . . . . 11

Historische Torbemerkungen . . . . . . . . . . . . . 11

A. Das Appositionsbild von Limulus............. . . 18

Wrirkung der Sehiefstellung der Kegel . . . . . . . . . . 24

Wirkung des Kegelmantels . . . . . . . . . . . . . . 27

Das Zusammenwirken der Kegel und die Netzlaut . . . . . . . . . 2!

1) as Inge von Limulus im Vergleieh mit jenen der Trilobiteuklebse 333

l. Das Superpositionsbild yon Lampris . . . . . . . . . (3)

1. Beobaehtungen am frischen Lampyrisange. . . . . . . . . . . 35

2. Veranselaauliehung der Dioptrik des Lampyrisanges . . . . . . . . 39

3. Experimentelle Prüfung des Strahlenganges im Lampyrisauge . . . . . 47

4. Dioptrisehe Berechnung des Lampyrisauges . . . . . . . . . . 5 5

C. Katoptrisehe Wirkug der Kegel . . . . . . . . . . . . . 59

III. Capitel. Das Irispigment und seine Wirkung. . . . . . . . . . . . (33

A. Inseeten . . . . . . . . . . . . . . 67

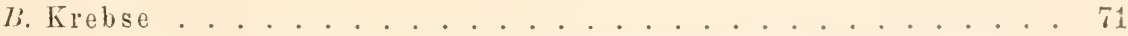

IV. Capitel. Das Netzhautbild verschiedener Insecten und Krebse . 75

A. Superpositionsbilder . . . . . . . . . . . . 76

1. Käfer . . . . . . . . . . . . . . 76

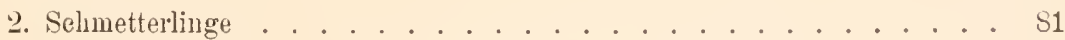

3. Krebse . . . . . . . . . . . . . . 81

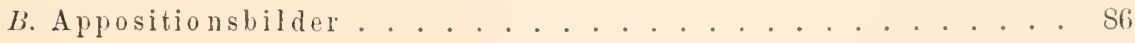

1. Insecten . . . . . . . . . . . . . . 87

2. Krebse . . . . . . . . . . . . . . . . 90

C. Augen mit doppelter Functionsweisc............ . . . . .

V. Capitel. Die Netzhaut; ihr Pigment und ihr Tapetum . . . . . 95

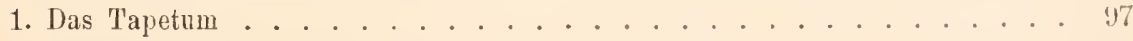

2. Das Retinapigment. . . . . . . . . . . . . . . 102

3. Die ploto-nechanische Wirkmg am Retinapigment . . . . . . . . 104

VI. Oapitel. Augen mit ungleichmässigem Bau. . . . . . . . . . . 11'

VII. Capitel. Kurze Besehreibung einzelner Augen von Insecten und Krebsen . . . . . . . . . . . . . . . 116

A. Insecten ............................ 110

1. Tagsehmetteriuge. . . . . . . . . . . . . . . 111 ;

2. Nacht- und Dämmermugsalter . . . . . . . . . . . . 117 
3. Kinfer . . . . . . . . . . . . . 118

4. Diverse lnsecten ..................... 120

b. Krelse . . . . . . . . . . . . . 122

1 Jаиgschwäне . . . . . . . . . . . . . . 122

๖. Halhschwänze . . . . . . . . . . . . . . . . . . . . . 125

3. Kurzsehwïnze . . . . . . . . . . . . . . . . . . 125

1. Direrse Crustiweer . . . . . . . . . . . . . . . 127

VIII. Capitel. Die Augen von Squilla, Phronima und Copilia. . . . . 128

a) Siquilla uantis. . . . . . . . . . . . . . . . . . . . . 128

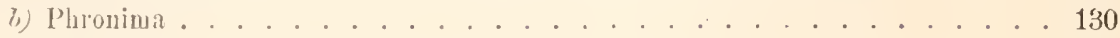

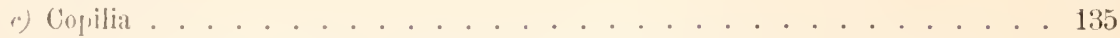

IX. Capitel. Aecessorische optische Erscheinungen an zusammengesetzten Auge . . . . . . . . . . . . . . . 141

1. 1) at A ugenlenehten. . . . . . . . . . . . . . . 141

Lie gegenseitige Lage des Comeareflexes und der Psendopupille . . . . 156

Einige weitere Beobaehtungen äber die Pigmentrersehiebungen . . . . . 160

2. Das Phänomen der P'seudopupillen . . . . . . . . . . 162

Erkiärung des Phänomens der Pseudopupillen . . . . . . . . . 166

X. Capitel. Das Sehen mit den Facettenaugen . . . . . . . . . . . 179

(1) Sehärfe des Netzhantbildes . . . . . . . . . . . . . . . . . 179

b) Terzerrungen an Netzhanthild . . . . . . . . . . . 180

c) Jas Selien ron Bewegungels . . . . . . . . . . . . . . . 182

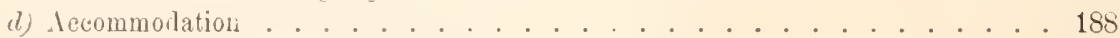

c) Das Selen in der 'Tiefendimension . . . . . . . . . . . . . . 189

XI. Capitel. Einige Bemerkungen über die Phylogenese des facettirten Auges vom functionellen Standpunkt betrachtet . . . . . . . 192 1 lulabetisches liegister . . . . . . . . . . . . 195 lifklärung der 'l'afeln . . . . . . . . . . . . . . . 19! 


\section{CAPITEL.}

\section{Physikalische Vorbemerkungen.}

Gelegentlich meiner ersten Untersuchungen iiber Insectenaugen ${ }^{1}$ im Tahre 1875 versuchte ich, den Brechungsexponenten der Hornhant des Hydrophilus zu bestimmen. Diese besteht, den einzelnen Facetten entsprechend, ans zahlreichen drei- bis viermal so langen als breiten Cylindern, deren vordere im Leben an Luft oder Wasser grenzende Fläche eine schwache kugelige Krïmmung, deren hintere, dem Inneren des Anges zugewendete Fläche aber einen sehr kleinen Krümmungshalbmesser hat (ähnlich wie Fig. 23, 'Taf. III). Man bestimnt nach allgemeinen Regeln in einem solchen Falle das Brechungsvermögen, indem man die Krümmungshalbmesser der beiden kugeligen Flächen, ihre Entfernung voneinander und die Entfernming des Bildes ron einer der beiden Flächen misst. Den hieraus berechneten Brechungsindex fand ich ganz ausserordentlich gross, nämlich $1 \cdot 8$.

Später erkannte ich mit Hilfe des Mikrorefractometers, ${ }^{2}$ dass jene Cormeacylinder nicht, wie bei jener Rechnung selbstverständlich voransgesetzt war, aus einer homogenen Masse bestehen, dass sie vielmelır aus cylindrischen Schichten anfogebant sind, deren Brechungsindex von der Axe nach der Mantelfäche allmïlilich abmimmt, ferner dass ein Stïck eines solchen Cylinders nur den Brechungsindex 1.55 (älnnlich dem des gewöhnlichen Glases) hat, und dass der Conneacylinder, anch nachdem ich die beiden gekrïmmten Endfïchen weggeschnitten hatte, noch verkehrte Bildchen äusserer Objecte entwirft.

Der früher gefundene falsche Werth für den Brechungsindex entstammt also dem Umstande, dass ich die gemessene Bildweite der die Strahlen sammelnden Kraft der gekrïmmten Endflächen allein zugeschrieben und die bis dahin umbekannte sammelnde Kraft eines geschichteten Cylinders nicht mit in Rechnung gebracht hatte.

1 Das Sehen ron Bewregungen und die Theorie des zusammengesetzten Auges. Sitzber. d. Wiener Akarl. d. Wiss. Bd. LXXII, Alth. 3.

2 Sigm. Exner. Ein Mikrorefractometer. Areh. f. mikr. Anat, Bd. XXY. 
In dieser Weise geschichtete Cylinder, deren Brechungsinlex also vou der Axe gegen die Mantelfäche continnirlich abnimmt, fungiren nun in gewisser Beziehmg ähnlich wie Linsen, ich neme sie deshalb linsencylinder; in mancher Beziehung weicht iln's Function aber von der der Linsen beträchtlich ab. Sie spielen im Facettenange, wie sich später zeigen wird, eine grosse Rolle, und es wären gewisse seiner optischen Effecte durch Linsen nicht zu erzielen. Es scheint mir deshalb nicht ïberfliissig. hier eine kurze Darstellung der optischen Wirkung von Linsencylindern zu geben, obwohl der grösste Theil derselben in einer schon mehrere Jahre alten Abhandlung enthalten ist, ${ }^{1}$ anf welche ich betreffs der genaneren Berechnungen und Ableitungen verweise. Es soll hier uur so viel von der Dioptrik geschichteter Körper besprochen werden, als zum Verständniss der Torgänge im Facettenange nöthig ist, und anch dieses soll nicht bewiesen, sondern nur anschanlich gemacht werden. Betreffs der Berechnmngen dieser dioptrischen Vorgänge verweise ich ferner anf den von meinem Bruder Prof. Karl Exner herrïhrenden Abschnitt C meiner eben genannten

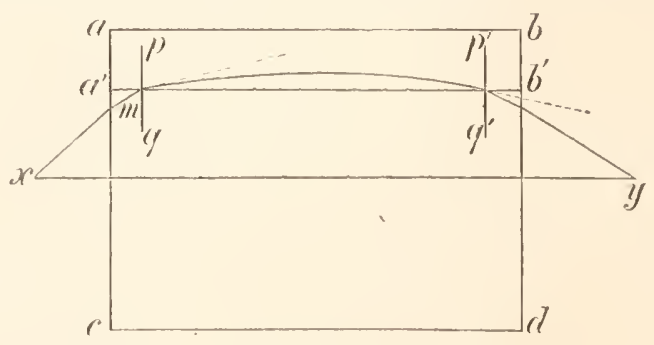

Hig. 1.

Abhandlung, sowie auf dessen Anfsatz in den Ann. f. Physik und Chemie XXVII, 1886, und anf eine einschlägige Untersuchung von Matthiessen im Repert. d. Pliysik XXII.

Es sei (Holzschnitt Fig. 1) "7, in der Axe $x y$ ein Maximmm hat und nach dem Mantel stetig abnimmt. Die beiden Grundflächen a $c$ und $b a$ seien ebene, anf der Axe senkrecht stehende Flächen, $x m$ ein Lichtstrahl; sobald dieser in den Cylinder eingedrungen ist, passirt er' T'renmungsflichen zwischen Schichten von abnehmendem Brechungsindex $n$. An jeder solchen 'Tremungsfläche, z. B. $a^{\prime} b$ ' wird er also zum Finfallsloth $(p q)$ gebrochen, so dass seine Richtung einen stetig abnelnmenden Winkel mit del Axe einschliesst, endlich wird der Winkel Null, dann negativ. Da der Strahl jetzt ans optisch dïnneren in dichtere Schichten dringt, wird er vom Einfallsloth $\left(p^{\prime} q^{\prime}\right)$ gebrochen und schneidet so wieder die Axe in $\%$. Der Symmetrie wegen werden alle ron $x$ unter demselben Winkel ansgelemden Strahlen sich in y treffen.

1 Sigm. Hxuen. Uehe" Cylinder, welehe optische Bilder entwerfen. Pflïger's Areh XXXVIII, S. 274, und Nachtrag 7.u derselhen. Ehenda XXXIX. S. 244. 
Auf' den ersten Blick mag es scheinen, dass der strahl, nachdem el r Axe parallel geworden ist, num in disser Richtung weiter verlaufen iisse, dass also alle Strahlen parallel der Axe austreten würden. Eine enauere Ueberlegung ergibt, dass dies mrichtig ist. Man brancht sich ur das einfallende Strahlenbindel in seine Elementarwellen zerlegt zu enken, so leuchtet ein, dass die der Axe nüher gelegenen geringere Fortflanzungsgeschwindigkeit haben müssen. Wir befinden uns hier eben an er Grenze der geometrischen Optik.

Ob anch Strahlen, welche unter einem anderen Winkel, von $x$ ausehend, den Cylinder treffen, in y vereinigt werden, nuss die Rechumng shren. Eine solche wurde zuerst ron meinem Bruder Prof. Karl Exner uf meine Teranlassung durchgefïlnt und ist am angebenen Orte mitgeheilt. Sie sagt aus, dass, wenn man, wie das bei den gewöhnlichen Linsenrerechnungen anch der Fall jst, nur die Centralstrahlen berïcksichtigt, sich in ier That alle diese Strahlen in $y$ treffen; sollen aber anch die Randstrahlen " $y$ rereinigt werden, dann muss $n$ jeder Schichte eine ganz bestimmte

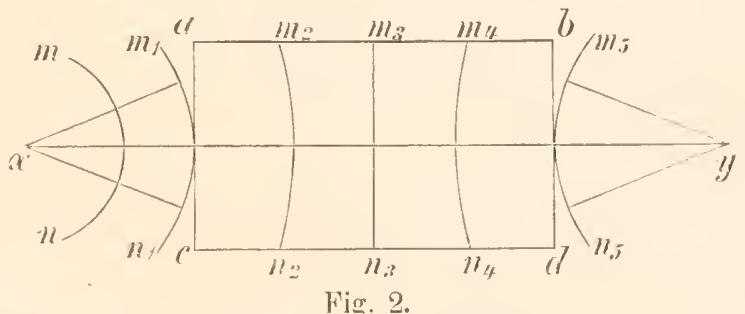

Function der Entfernung derselben von der Axe sein. Diese Function hat die Form einer Parabel.

Man kann sich den Vorgang auch so vorstellen: Es sei wieder (Fig. 2) $a b c d$ der Cylinder, in $x$ ein leuchtender Punkt, $m n$ die Oberfïche einer von ihm ausgehenden Kugelwelle. Ist dieselbe nach $m_{1} n_{1}$ gelangt, so beginnt sie eine Deformation zu erleiden, indem sie der Axe entlang die geringste Fortpflanzungsgeschwindigkeit hat. Sie geht näherungsweise iiber in $m_{2} n_{2}$. $m_{3} n_{3} \ldots$ und tritt als concave Fläche $m_{5} n_{5}$ wieder in die Luft ein, d. lı. die Strahlen treten convergent aus dem Cylinder. Man ersieht aus der Zeichnung anch ohneweiters, dass, wenn man den Cylinder in $m_{3} n_{3}$ durchschnitten und den zweiten Theil desselben entfernt hätte, die anstretende Wellenoberfläche eben sein und senkrecht auf der Axe stehen, d. h. dass dann $x$ den ersten Brempunkt des Cylinders bilden wiirde. In analoger Weise ergibt sich die Construction des zweiten Brempunktes. Fällt nämlich eine ebene, d. ı. eine von einem unendlich entfernten Punkt ansgehende Wellenoberfläche auf den Cylinder $m_{3} n_{3} b d$, so kann die Welle, zur Kugelwelle deformirt, als $m_{5} n_{5}$ austreten, d. h. es ist $y$ der zweite Brennpunkt dieses Cylinders.

Die vorgeführte Betrachtungsweise liefert anch den einfachsten Beweis dafür, dass durch den Cylinder abcd ein Bild ron " entworfen werden 
muss, falls nur die Centralstrahlen in Betracht gezogen werden (wie bei sphärischen Limsen), es möge ïbrigens das Gesetz, nach welchem $u$ ron der Axe nach aussen abninmt, welches immer sein. Von der Form dieser Abnalnme lı̈̈ngt nämlich die Gestalt der Curve $m_{5} n_{5}$ ab. Jedenfalls aber wird das an der Axe liegende kleinste Flächentheilchen wegen der allseitigen Symmetrie des Cylinders mm die Axe die Gestalt einer RotationsHäche haben, also mit Rücksicht auf seine Kleinheit nach bekamuten geometrischen Gesetzen einen Antheil einer Kugelfäche darstellen. Das Centrum $y$ dieser Kugelläche ist damn das Bild ron $x$.

Die Rechnung zeigt, dass die Brennweite $p$ eines Cylinders

$$
p=\frac{c}{1}
$$

ist, worin $c$ pine Constante mu $l$ die Tänge des Cylinders innerlalb

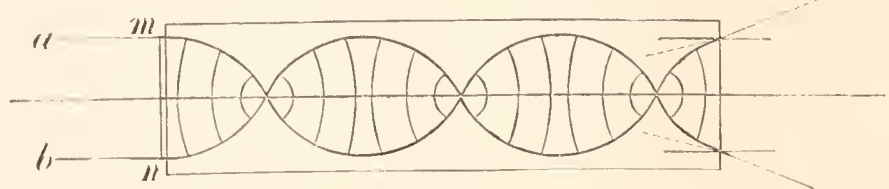

Fig. 3.

gewisser Grenzen bedentet. Da die Brennweite also mugekehrt proportional der Länge ist, so kïnnte man von einem rorliegenden Cylinder die Dioptrien nach dem Massstabe herunterschneiden.

Ich sagte, die genannte Formel für die Brennweite gelte nur innerhall, gewisser Grenzen. In der That sind anch hier die Berechmmgen nur fïr den Fall leicht durchzufülıren, dass die Länge des Cylinders bei gegrohenen Dichtigkeitsunterschieden hinreichend klein ist. Abgesehen

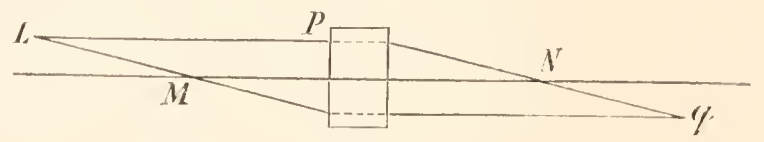

Fig. 4.

von diesem berechneten Fall ergibt die Anschaumg, dass die Bremuweite eine periodische Function der Länge des Cylinders ist. Der Verlauf eines z. B. parallel anffallenden Strahlenbiindels muss nämlich nälrerungsweise der in Fig. 3 wiedergegebene sein. wo $m n$ die einfallende ebene Wellenoberfläclie und $a b$ zwei Strahlen derselben darstellen. Die Deformation von $m u$ ist angedentet. In einem derartigen Cylinder liegt also eine Succession von Brempunkten, und er wirkt bei Wachsthum seiner Lïnge abwechselnd als Sammel- und als Zerstreuungslinse.

Hat man es mit einem verhältnissmässig kurzen oder schwachen Linsencylinder zu tlıun, und ist der abznbildende Gegenstand nicht pmnktfürmig, so geschieht die ('onstruction der Bilder wie bei den Linsen. Da die von einem Punkte der Axe kommenden Strahlen sich wieder in einem Punkte rerrinigen, werden anch die von einem der Axe benabluaren 
Punkte kommenden Strahlen sich nahezu vereinigen. Un diesen Vereingungsumkt zu finden, bedaf es nu zweier suahlen, des Focalstrahles und des Parallelstrahles. Sind $M$ und $N$ (Fig. 4) die beiden Bremumute, $L$ ein P'unkt nalıe der Axe, so wird der Strahl L I' nach $N$ gebrochen mud der Strahl $L M$ nach Q, folglich liegt das Bild von $L$ ill $Q$.

Mit Bezug anf das Insectenauge interessiren uns hauptsächlich zwei Läıgen eines Linsencylinders, erstens jene, bei welcher sein Bıennpunkt näherungsweise in der hinteren Fläche liegt, zweitens jene Länge, bei welther der Bremnumkt in der Mitte des Cylinders gelegen ist.

A. Der Brennpunk liegt in der hinteren Basis des Cylinders. Strahlen also, welche vor der Brechung parallel der Cylinderaxe verlanfen sind, schneiden sich in dem Durchschnitspunkte der Axe mit der linteren Begrenzumgstläche. Es sei Fig. 5 al c $d$ wieder ein Linsencylinder; $x$ seine Axe; ein Strahlenbiindel $m n$, das in lichtung der Axe einfällt, wird im Bremmpunkte y vereinigt. Das Bild eines anderen Punktes, dessen Stralılenbiindel durch $p$ und $q$ angedentet wird, liegt in $\approx$. Es entsteht also in der hinteren Basis des Cylinders ein verkehrtes Bild der äusseren Objecte. 1)ieses Bild mnterscheidet sich aber in einigen Punkten nicht unwesentlich von dem Bilde, das eine Linse entwerfen wiilde. Es sei z. B. in Fig. 6 yz ein ebenso grosses verliehrtes Bildchen, welches eine kugelförmige Sanmellinse von demselben Objecte entwerfen mag. Man sieht, dass die durch g gehenden Hauptstrahleu nach der Brechung noch denselben Winkel miteinander einschliessen, wie vor der Brechung; nit anderen IVorten, der Lichtkegel, welcher vou den Strahlen eines Punktes gebildet wird, hat eine andere Axemrichtung als der Lichtkegel der ron den Strahlen eines anderen Punktes gebildet wird.

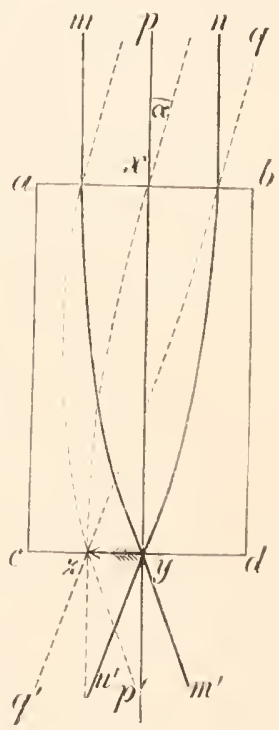

Fig. 5 . Anders ist es beim Linsencylinder Fig. 5; da sind die Axen der Lichtkegel parallel gerichtet. Es leuchtet ein, dass, wenn es sich darum handelt, Licht, welches aus einer bestimmten Richtung, z. B. $x^{2} y$ (Fig. 5), und deren nächsten Umgebung, z. B. bis zum Winkel a koumt, nutzbringend zu verwerthen (einem Nervenende zuzufïhren), der Linsencylinder also den Torzug vor der Linse verdiente.

Nennen wir beim Linsencylinder jenen Strahl, velcher, von einem Punkte des Gegenstandes ausgelınd, den Mittelpunkt der vorderen Begrenzung desselben trifft, einen Hauptstrahl (während bekamntlich bej der Linse die durch den Mittelpunkt derselben gehenden Strahlen diesen Namen fülreu), so lässt sich der uns hier interessirende Tnterschied zwischen den beiden optischen Vorrohtungen so ausdrücken: bri der Ininse divergiren die Hauptstrahlen verschiedener Objectpunkte nach der Brechung; bei den Linsencylinder vonder Länge seiner 
eigenen Brennweite verlaufen nach der Brechung alle Hauptstrahlen parallel der Axe.

Man ersieht aus der Fig. 5 mmittelbar, dass die Grösse der in $c d$ abzubildenden Fläche des Objectes eine durch die Dicke des Cylinders ( $c$ d) und seinc Höhe (ac) eng hegrenzte ist (wällrend bei der Kugellinse [Fig. 6] die Grösse des abzubildenden Objectes unbegrenzt ist) und dass für die optische Wirkung del untere äussere Antheil des ganzen Cylinders nicht iu Betracht kommt. Es kömnte dieser also fehlen, d. h. ein abgestutzter Kegel (die Glundform del dioptriscllen Bestandtleile der Facettenangen) wïrde dieselbe Wirkung laben.

Ein nacl dem Principe des Linsencylinders gebauter abgestutzter Kegel von der Länge seiner Brennweite vereinigt

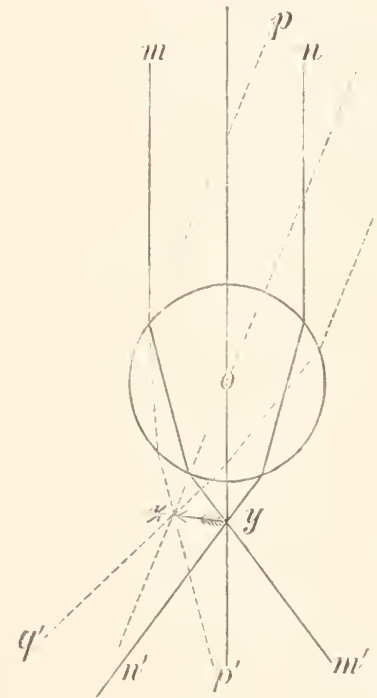

Fin. 6. alles ron einer engbegrenzten, um seine Axe gelagerten Fläche der Aussenwelt kommende Licht auf seiner hintelen Flächt of derart,dass diesämmtlichen Hauptstrahlen nach dem Austritt aus dem Kegel parallel der Axe verlaufen.

B. Der Linsencylinder ist doppelt so lang als seine Brennweite. In diesem Falle liegt das verkehrte Bild eines in grosser Entfernung befindlichen Gegenstandes natürlich in der Mitte des Liusencylinders. Es ist $y z$ in Fig. 7. IVïrde der Linsencylinder a $b c d$ in der Ebene $y z$ quer durchschnitten, so würde der eben besprochene Fall vorliegen und alle Hauptstrahlen parallel zur Axe austreten. Nun beginnt aber gleichsam in der Ebene $y z$ ein nener Linsencylinder ron derselben optischen Eigenschaft und reicht bis $c d$. In der oberen Fläche desselben liegt $y z$, welches Bild jetzt als Gegenstand für die untere Hälfte des Cylinder's aufzufassen ist. Nach dem allgemeinen dioptrischen Gesetze, nach welchem der Terlauf der Strahlen zwischen zwei conjugirten Punkten derselbe ist, es mögen dieselben ron dem ersten zum zweiten Punkte, odel rom zweiten zum ersten fortsclueiten, muss der Strahlengang in der unteren Hälfte des Linsencylinders symmetrisclı zu dem Strahlengang in der oberen Hälfte sein. Fs werden also Strahlen $(m n)$, welche in den (ylinder parallel der Axe eingetreten sind, sich in einem Punkte (y) treffen, welcher sich fül die untere Hälfte des cylinders ganz ebenso verhält, wie für die obere Hälfte. Der Weg dieser Strahlen wird in letzterer derselbe sein, wie in ersterer, nur die Richtung ilnes Fortschreitens ist nun vom Punkte $y$ weggewendet. Sie müssen aber wieder parallel der Axe austreten, so wie sie parallel eingetreten sind $\left(m_{1} n_{1}\right)$. Ein von einem anderen, dem ersten 
benachbarten Punkte ausgehendes Strahlenbuindel $(\nu q)$, das, einen Wrinkel $(\alpha)$ mit der Axe bildend, den Cylinder trifft, muss auch unter demselben Winkel $(\beta=\alpha)$ den Cylinder wieder verlassen $\left(\mu_{1} q_{1}\right)$. Daraus folgt der oben schon angenommene Satz, dass der Hauptstrahl die Ébene yz senkrecht triflt.

Ein Linsencylinder von den in Rede stehenden optischen Eigeñschaften bildet also ein astronomisches, nicht vergrösserndes Fernohr, das auf Unendlich eingestellt ist. Man kann den Effect desselben in der Hauptsache durch die Combination zweier gleicher Convexlinsen nachahmen, welche um ihre doppelte Brennweite von einander entfernt sind. Auch in diesem Falle bildet der austretende Strahl mit der Axe denselben Winkel, den er vor seinem Eintritt in die Linsencombination mit derselben gebildet hatte;Axe, eintretender und anstretender Strahl liegen in derselben Ebene und die genamnten beiden Strahlen auf derselben Seite der Axe.

Die hier besprochenen Fälle der optischen Wirkung der Linsencylinder gehören zu den einfachsten, welche denkbar sind und finden sich so wohl nirgends in den Facettenaugen ver'wirklicht. Hier trifft man vielmelı' in der Regel Effecte der Lichtbrechung, die durch die Combination von kugelig gekrümmten Flächen mit Linsencylindern erzielt sind. Jede sphärische Trennungstläche zwischen zwei Medien von verschiedenem Brechungsvermögen entwirft von einem äusseren Object ein Bild; der Linsencylinder thut das anch; falls beide im Sinne einer Sammellinse wirken und die sphärische Fläche an Stelle der Basis an Linsencylinder selbst angebracht ist, so unterstützen sich die beiden Arten der Strahlenbrechung, ähnlich wie die Strahlen sammelnde Kraft einer Convexlinse durch die einer zweiten unterstïtzt wird. Dies ist natürlich auch der Fall, wenn der Linsencylinder beiderseits durch sphärische Flächen begrenzt ist, und ist

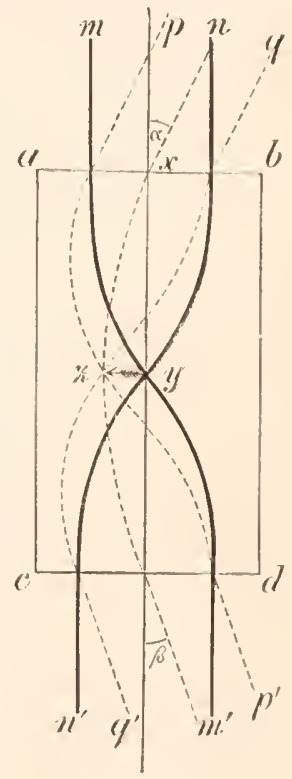

Fig. 7. ähnlich der Fall, wenn der dioptrische Apparat, wie das bei den meisten Arthropoden zutriftt, aus zwei Stiicken, der Cornea und dem Krystallkegel, besteht, von denen wahrscheinlich jedes einen Linsencylinder bildet, dessen beide Basen durch kugelig gekrümmte Flächen ersetzt sind.

Noch in anderer Weise weichen die Verhältnisse im Eacettenauge von den hier geschilderten einfachen physikalischen Vorgängen ab. In Fig. 7 ist vorausgesetzt, dass die über $y z$ gelegene und die darunter gelegene Hälfte des Cylinder's vollkommen gleichen optischen Bau haben. Dadurch entsteht die Wirkung eines nicht vergrössemden astronomischen Fernrohres. In der Natur aber scheint es Regel zu sein, dass die beiden Antheile von ungleichem optischen Ban sind, wie dieses bei einem vergrössernden Fermolne der Fall ist. Es liegt dann das Bild yz nicht mehr in der geometrischen Mitte des cylinder's, sondern der einen Basis näher; 
doch aber kömnen die strahlen eines Punktes parallel ans dem optischen Systeme austreten.

Es ist nicht unwahrscheinlich, dass noch eine weitere Art optischer Bilderzengung in Insectenauge eine Rolle spielt. Matthiessen ${ }^{1}$ hat in jüngster \%eit die Aufmerksamkeit darauf gelenkt, dass ein Satz ron an einer Axe angereihten Kugelschalen, von denen jede parallele Begrenzungsflächen hat, auch die Wirkung einer Sammellinse zeigt, wenn der Brechungsindex der Kugelschalen in der Richtung des Ganges der Lichtstrahlen abnimmt und die Concavität derselben dem einfallenden Lichte zugewendet ist. Diese Linsenwirkung ist auch dann noch vorhanden, wenn das ganze System an beiden Enden mit planen Flächen schliesst. Es bildet dann auch einen Cylinder.

Matthiessen fiuhrt einige Insectenangen an, von deren Cornea er; da sie nach den Untersuchungen Grenache r's eine Schichtung mit nach hinten

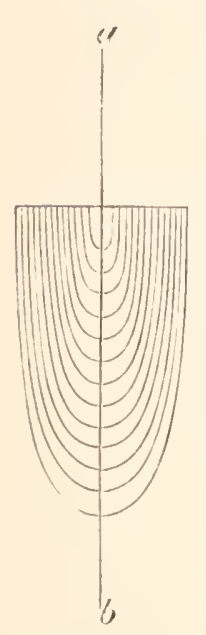

Fig. 8 . gerichtetel' Convexität zeigen, auch volauszusetzen ist, dass die hinteren Corneaschichten, als die jüngeren, ron geringerer optischer Dichtigkeit sind, rermuthet, dass sie nach diesem Principe, das er das der Etagenlupe nenut, wirken.

Bei der Häufigkeit des Torkommens einer solchen Schichtung ist es, wie gesagt, nicht muwahrscheinlich, dass dits Princip anch in Insectenauge zur Geltung kommt; doch kömuen 11u verhältnissmässig kleiue Wirkungen durch dasselbe erzielt werden. Die starken Brechungen, die wir im Insectenange beobachten, wiirden nach dem Principe der Etagenlupe so grosse Differenzen im Brechungsvermögen der aufeinanderfolgenden schichten erfordern, dass diese sofort unter dem Mikroskone erkennbar sein miissten. Das ist aber nicht der Fall. Anders ist es mit einer Mischform von Etagenlupe und Linsencylinder, welche auch Matthiessen ${ }^{2}$ terange 8. handelt sich um hyperbolische Schichten, welche schalenartig ineinander stecken, und deren Brechnngsindex in der Richtnng des eindringenden Lichtes (ab) abninmt. Nan sieht sofort, diss dadurch zugleich die Structur eines Linsencylinders elzengt wird, iudem an jedem Querschnitt das Brechungisrermögen vom Centrum gegen die Peripherie abnimmt. Es ist gerade diese Art der Schichtung, die z. B. beim Auge des Limulus auffällt; ich halte es deshalb für sehr wahrscheinlich, dass sie auch anderen Ortes eine Rolle spielt. Wie wir beim Studium des eben gemanıten Anges bemerkeu werden, ist die Wirkung dieser Schichtung, wie zu erwarten war, wesentlich die eines Linsencylinders.

1 ientralbl. 1. Opt. II. Meuh. VII, Nr. 10 und Repert. d. Physik XXII, S. 3333.

2 Repert. d. Plıysik 1886, \$. 350. 
Leh habe oben anf die Terschiedenheit in dor optischen WVirkung kugelig-gekıtimmıter 'T'renumgstlïchen und der Linsencylinder hingewiesen. Es scheint den Lebensbedüfnissen verschiedener Arthopodenfanilien zu entsprechen, dass eimmal die Linsenwirkmg, das anderemal der Ellect des Linsencylinders iiberwiegt, und dadurch erklïlt sich die grosse Mannigfaltigkeit in der Construction der zusammengesetzten Augen, eine Mannigfaltigkeit, gegeniiber welcher das Auge, das ein verkehrtes Netzlautbild erzengt, eine armselige Einförmigheit anfweist.

Es ist mil nicht bekannt, dass in einem zusammengesetzten Auge das Princip des Linsencylinders allein zu Geltung liommt, obwohl das Auge ron Limulus hart an dieser Grenze stehen diifte, und es ist mir auch kein zusammengesetztes Auge bekannt geworden, in welchem nu' das Princip der Linse die optischen Torgänge beher'scht. Ist ja sellst im Ange der Wirbelthiere und des Menschen das Princip des Linsen"ylinders verwerthet, ${ }^{1}$ indem die Linse geschichteten Bau und in ihrem Kiern ein cylinderähnliches Gebilde trägt, dessen Axe mit der Augenaxe (gauz oder näherungsweise) zusammenfällt.

Die optische Wirkung des Linsencylinders ist nahezu unabhängig von der denselben ungebenden Flüssigkeit, die optische Wirkung der kugeligen Flächen ist im lıöchsten Grade von der Ungebung abhäugig. Damit laangt es zusammen, dass jene Thiere, welche theils im IVasser, theils ausserhalb desselben leben, wie z. B. die schwimm- und Wasserkäfer, eine vorderẹ Begrenzungsfläche der Corneafacetten haben, deren Krïmmung kaum in Betracht kommt, wälıend z. B. bei vielen Schmetterlingen diese Flächen einen sehr kleinen Kriimmungshalbmesser liaben. In der 'That, die Wirkung des dioptrischen Apparates wiirde bei starker Krimmung der Corneafacetten sich gänzlich änderı, wenn das 'Thier' aus dem Wasser' steigt, wählend sie sich nahezu gar nicht ändert, wenn die Corneafacette aus einem Linsencylinder besteht. Bei Krebsen, die das WVasser zeitweilig verlassen, waltet ein analoges Terhältuiss ob.

Ein anderer Umstand, durch welchen die Mannigfaltigkeit der Angenformen bedingt ist, liegt darin, dass für verschiedene Lebensweisen jene vben besprochene Art des Linsencylinders nicht immer am zweckmässigsten sein muss. Ich habe nämlich der Einfachheit wegen angenommen, dass der Linsencylinder in seiner ganzen Länge genau denselben optischen Bau hat. Er könnte aber, und das kommt thatsächlich vor, in seinenı hinteren (dem Augeninnern zugewendeten) Antlieile eine raschere Abnahme des Brechungsindex von der Axe gegen die Peripherie haben, als im rorderen 'Theile, wobei aber zwischen den beiden Antheilen ein allmählicher Uebergang stattfindet. Fl entspricht damn, wenn er wieder ein anf TTn- 
endlich eingestelltes astronomisches Fermrohr bildet, einem solchen, das vergrössert, d. l. das verkehrte Bildchen liegt jetzt nicht mehr in der Nitte seiner Länge, sondern ist meln nach hinten geriickt, liegt aber immer noch in der zweiten Bremnebene des ersten Linsencylinder's, und in der ersten Brennebene des zweiten, wenn wir uns wieder den ganzen Cylinder durch einen Schnitt in der Ebene des verkehrten Bildchens in zwei Theile getheilt denken. 


\section{CAPITEL.}

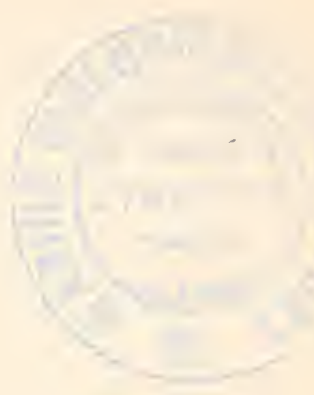

\section{Die Dioptrik des zusammengesetzten Auges.}

\section{Historische Vorbemerkungen.}

J. Nïller liatte in Jalne 1826 eine 'Theorie iiber die Functionsweise des Auges der Insecten aufgestellt, ${ }^{1}$ nach welcher diese Thiere ein aufrechtes Netzhautbild haben sollen, das, im Gegensatze zu den Netzhautbilde des Wirbelthierauges, nicht so sehr durch Sammlung der von je einem Punkte des Objectes ausgehenden Strahlen, als vielmehr durch 'l'renumg der von verschiedenen Punkten des Objectes ausgehenden zu Stande kommt.

In der That hatte .J. Müller erkannt, dass die sogenamnten zusammengesetzten Augen aus einer grossen Anzahl von Elementen bestehen, deren jedes, wir wollen es ein Facettenglied nenmen, eine schwar\% pigmentirte Röhre darstellt. Diese Röhren sind in radiärer Stellung auf einer melır oder weniger vollkommenen Halbkugel aufgesetzt. Was immer die Röhre sonst noch enthalten mag, wemn ihr Jnhalt nur durchsichtig ist, so muss an der Oberfläche der Halbkugel ein, wemn auch unvollkommenes aufrechtes Bild eines äusseren Gegenstandes entworfen werden, denn es leuchtet ein, dass auf den Grund jeder Röhre nur Lichtstrahlen gelangen können, welche näherungsweise in der Richtung jenes Kugelradius einfallen, um welchen diese Röhre eben aufsitzt. Strahlen, welche mit grösserer Neigung gegen den Radius, d. i. gegen die Axe der Röhre in dieselbe eindringen, treffen, ehe sie ihren Boden erreicht haben, die Wand derselben, und werden von dem Pigmente, das hier liegt, absorbirt. Befindet sich aber auf dem Boden jeder Röhre ein nervöses Endorgan, d. h. ist die Kugeloberfläche von einer lichtempfindlichen Nervenausbreitung gebildet, so fungirt diese gegen das eindringende Licht convexe Netzhant, wie die concave des Wirbelthierauges.

Dies in ihren wesentlichsten Zügen die Müller'sche 'Theorie vom musivischen Sehen und dem aufrechten Netzhautbilde.

Griiel und Gottsche ${ }^{2}$ hahen den Anstoss dazu gegeben, dass diese 'Theorie wieder fallen gelassen wurde, ja fast in Vergessenheit gerieth.

1 Kur vergleichenden Physiologie des Gesichtssinnes. Leipzig 1926.

2 II üller's Arch. 1852. 
Letzterer hatte die leicht zu bestätigende Beobachtung gemacht, dass man bei einem Fliegenange unter passenden Unstïnden, entsprechend jeder Facette der Hornhant, mit dem Mikroskope ein verkehrtes Bildchen eines änsseren Gegenstandes zn sehen bekommt, weløhes Bildchen übrigens schon Leeuvenhök und Anderen bekannt war. Eine Bemerkung, welche J. Mïller zu der Nittheilung Gottsche's hinzufïgte, mochte in den Lesern den Eindruck erweckt haben, dass der Schöpfer der Theorie des anfrechten Bildes angesichts der sichtharen verkehrten Bildchen seine Theorie fallen lasse; es folgte eine Anzahl vergleichend anatomischer und physiologischer Untersuchungen iiber das zusammengesetzte Ange, welche, jenem verkehnten Bildchen Rechnung tragend, die Miiller'sche Theorie bei Seite liegen liessen. Es muss das um so auffallender erscheinen, als die Forscher, welche sich mit dem Gegenstande beschäftigten, fast ausschliesslich Mikroskopiker waren, denen die Thatsache, dass jeder Fetttropfen, jede Luftblase n. s. w. ein mikroskopisches Bildchen entwirft, geläutig sein musste; es wäre also zu erwarten gewesen, dass dem Nachweise eines solchen in jeder Facette kein so grosses Gewicht, der einlenchtenden Miiller"schen Theorie gegeniiber, zugewiesen werde, umsomehr, wenn man erwägt, mnter welch bedenklichen L'mständen Gottsche sein Bildchen demonstrinte. '

So kam es, diss im Jahle 18 sis Max Schultze in seinen "Untersuchungen iiber das zusammengesetzte Alge der Kriebse mnd lnsecten" 2 mit Bezug anf die Versuche von Gottsche und Zenker sagen konnte, ..die physikalisch nicht haltbare Theorie von dem musivischen aufrechten Bilde in Auge der Insecten ist dem auch durch das Experiment widerlegt", und dass er sich num der undankbaren Aufgabe unterzog, zu dem voransgesetzten verkehrten Netzhautbilde jedes Facettengliedes die zugehörige Retina aufzufinden.

Erst 19 Jalne nach der Publication Gottsche's trat eine Wendung in der Angelegenheit eim, indem Fr. Boll, der Schüler Max Schultze's, angeregt durch die Beobachtung, dass anch die Stäbchen der Tritonenretina rerkehrte Bildchen entwerfen, die functionelle Bedentung der Facettenbildchen in Frage stellte, und zur Müller'schen Theorie zurïckzukehren mahnte. ${ }^{3}$

Später haben, in verschiedener Richtung arbeitend und unabhängig voneinander, znerst Grenacher, ${ }^{1}$ dann ich eine Lanze für die Miiller'sche

1 Ioh bin auf diese Verhältnisse in meiner ersten Abhandlung über das Faeettenange näher eingegangen und verweise hier auf jene. (Ueber das Sehen von Bewegungen und die Theorie des zusammengesetzten Auges. Wiener akad. Sitzber. LXXII, Abth. IHI, Juli 1875.)

2 Bom 1868.

"Du Bois-lieymoud's u. Rejehert's Areh. f. Anat. u. L'hysiol. 1871.

"Sinine erste, mir leiler unlekannt gehliehene "Kurye Noti\%", wie Grenacher sie nennt, in den Gïttinger Nachrielsten ersehien 1874. Dann kan in Jahre 1875 meine oben eitirte Abhandlung, anf welehe ane anslührlichere Yittheilung Grenaeher's in den Klin. Monatsb. I. Augenheilkunde 1877 folgte, und sein IVerk: Untersuchungen ïber das Sehorgan der Arthroporlen, Göttingen 1579, erschien. 
Theorie vom aufrechten Bilde gehrochen. Grenather war anf Glund seiner ausgedehnten und erfolgreichen Untersuchungen iiber die einfachen und zusammengesetzten Angen einer grossen Anzahl niederel 'T'hier', und insbesondere durch seine grundlegenden Erfahrungen ïber den nervösen, der Netzhaut entsprechenden Antheil derselben zn der Veberzeugung gelangt, dass die 'Theorie von den Einzelbildchen unhaltbar sei, dass selbst, wem solche Bildchen da wäıen, die Netzhaut fehlen wïrde, welche zur physiologischen Verwerthung derselben nöthig wäre, und dass die anatomischen Verhältnisse durchaus für die Miiller'sche Theorie sprächen. Ich habe in gewissem Sinne den entgegengesetzten Weg eingeschlagen. Indem ich von dem Gedanken ausging, dass die wesentlichen optischen Vorgänge in ähnlich gebauten Augen auch wesentlich ähnlich sein würden, untersuchte ich eingehend das Ange nur eines Thieles (des Hydrophilus piceus), und komnte zeigen, dass bei diesem das Gottsche'sche Bildchen zwar' sehr schön zu sehen ist, wenn man so verfährt, wie Gottsche es gethan, dass dieses Bildchen im Leben aber nicht zu Stande kommen kann, dass iiberhaupt unmöglich ein Bildchen da liegen kann, wo es nach jener Theorie liegen miisste, um percipirt zu werden. Hingegen glaubte ich gezeigt zu haben, dass der doch ziemlich complicirte dioptrische Apparat des Facettengliedes seine Bedeutung darin hat, dass er die näherungsweise in der Richtung der Axe derselben einfallenden Lichtstrahlen, theils durch Brechung, theils durch Reflexion bis an die Spitze des Krystallkegels leitet, wo sie dann in viel intensiverer Weise das Nervenelement zu reizen vermögen, als wenn dieser dioptrisch-katoptrische Apparat fehlte. Es wird durch denselben die Helligkeit des aufrechten Netzhautbildes erhöht, was schon J. Mïller, freilich in anderer Weise, vermuthet hatte, wie aus folgendem physikalisch etwas unklarem Passus hervorgeht: "Die Convexität. der einzelnen Facette der Cornea wird das in der Richtung der Axe einfallende Licht als brechendes Medium der Axe zulenken und in der Tiefe des Auges zu grösserer Einigung bringen. So mag es kommen, dass das den ganzen Kegel durchleuchtende Licht an der Spitze desselben, wo es die Sehfaser afficirt, punktföımig vereinigt wird, wodurch die Bestimmtheit des Bildes sehr gehoben werden muss. Die von der äusseren convexen Fläche der Cornea bedingte Brechung ist aber nicht so gross, dass es zur Entstehung besonderer kleiner Bilder von jeder Facette aus kommen kïnnte." 1

Die Concentration der Strahlen an der Spitze des Frystallkegels konnte ich durch Versuche am Auge von Lampyris splendidula mit roller Bestimmtheit nachweisen, nur kommt sie nicht, wie .J. Miiller meint, allein durch Brechung an der Corneafläche - in diesem Falle miisste wenigstens ein undeutliches verkehrtes Bildchen entstehen -, sondern. wie ich damals meinte, duch totale Reflexion an der Mantelfläche des Krrystallkegels zu Stande. Auf diese Weise wiirde das Licht, wie man das

1 Zur vergl. Physiol. d. Gesiehtssinnes, S. $36 \%$. 
mit jedem ansezogenen Glasstabe machmachen liann, ist es einmal im Kegel gelangen, bis an seine Spitze fortgeleitel. Ich habe später, für das Auge des Leuchtkäferchens in den geschichteten Linsencylindern einen optischen Torgang gefunden, der im Effect bezïglich der Concentration der Strahlen an der Spitze des Krystallkegels dasselbe leistet, wie die totale Reflexion, aber doch auf einer Brechung berult. Dass ich das Auge des Leuchtkïferchens zu diesen Tersuchen benutzte, hatte darin seinen Grund, dass bei diesem Thiere die Krystallkegel mit der Cornea rerwachsen sind, man also in die glïckliche Lage versetzt ist, Pigment und die übrigen Weichtheile des Auges abpinseln und den ganzen dioptrischen Apparat bei normaler Lagerung der Krystallkegel zu den Corneafacetten untersuchen zu künnell.

Anch latte ich darauf hingewiesen, dass die Resultate meiner dioptrischen Untersuchung des Insectenauges geeignet sind, den Schliissel zu der Erklälung der Erfahrungsthatsache zu geben, dass diese Thiere ilıre Feinde und Freunde vielmehr durch deren Bewegungen, als durch deren Gestalt erkennen.

Ferner ist zu erwähnen, dass Oskar Schmidt ${ }^{1}$ bei gewissen Thieren Krystallkegel gefunden, welche nicht symmetrisch um eine Axe geformt waren, sondeln die mannigfache Unvegelmässigkeiten, vor Allem Biegungen nach Art eines Hormes, zeigten. Er kommt dadurch merkwürdigerweise zu dem Ausspruch, dass nicht nur die 'Theorie von den verkehrten Bildchen mllaltbar ist - worin ihm, falls seine Beobachtungen richtig sind, jedermamn beistimmen wird -, sondern dass damit auch die Theorie rom musivischen Sehen unvereinbar ist. Es hat schon Grenacher gezeigt, dass er in letzterer Beziehung im Irrthum ist, so dass ich mich auf die folgende Bemerkung beschränken kann. O. Schmidt hat selbst in der Art der von ihm gefundenen Krystallkegel gebogene Glasstäbe mnd Glaskegel angefertigt und sich davon ïberzeugt, wie in solchen das Licht fortgeleitet wird. ${ }^{2} \mathrm{Er}$ glaubt auch, dass eine derartige Fortleitung bei den ron ihm besprochenen Augen stattfindet. Er scheint aber nicht darauf aufmerksam geworden zu sein, dass auch unter diesen Umständen eir musivisches Selıen möglich ist. Wenn die Licht aufnehmenden Antheil der Krystallkegel in radiärer Anordnung ein Mosaik bilden, und dif Spitzen der Kegel ein Mosaïk, in welchem dieselbe Anordnung herrscht

${ }^{1}$ I) Fe Form der Krystallkegel in Arthropodenange. Zeitschr. f. wiss. Zool. XXX. Supp:

2 Jeh zeige seit meinen ersten Untersuchungen über das zusammengesetzte Auge ein Anzahl solcher theilweise complicirt verbogener Glasstäbe und Glaskegeln in meiner Vor lesung, nm die Art, wie das Licht darinnen fortgeleitet wird, zu demonstriren. In neneste Zeit ist dieser ibrigens selır alte Versuch praktisch verwerthet worden. Dil, wo es sich darm: laandelt, das licht "um eine Ecke" gu leiten, und wo man mit Spiegel und Linse nic zukann, mag dieses mit kirfolg gesehrehen. Zur Belenehtung mikroskopiseher Ohjecte ( wurde eine derartige Lampe in llandel gehracht) wirl wohl immer Linse und Spingel vo zuziehen sein. 
so muss unter den entsprechenden Bedingungen nach dem Mïller'schen Principe ein Bild entstehen, es mögen die Kegel zwischen ilner Basis und ihrer Spitze gebogen sein oder nicht, sie mögen alle in der gleichen Weise, oder es mag jeder in besonderer W'eise verbogen sein.

Anch Notthaft : tritt betreff's des anfrechten Netzhantbildes anf die Seite der Miiller'schen 'Theorie und stellt eine Ansicht ïber die Functionsweise des Facettenauges auf, die wesentlich in Folgendem bestelit: „Es fällt anf jede Retinula ein cylindrisches Lichtbüschel oder eine Lichtlinie genau in der Richtung der optischen Axe des Augenelementes. Die einzelnen, dieses Büschel zusammensetzenden Lichtstrahlen halten im strengen Sinne die gleiche Richtung ein. Das Stiick des Gegenstandes, von welchem dieselben ausgehen und welches ein einzehnes Elementarsehfeld erfïllt, ist somit füi alle noch so verscliedenen Entfernngen durchaus gleich gross; es ist nämlich genan gleich lem Querschnitte des hinteren zugespitzten, nicht pigmentirten Endes des Erystalikegels, oder gleich demjenigen der Retinula." 2 Da die Strahlen dieses Lichtbïschels streng parallel sind, so wird weiter ausgeführt, kommen sie immer von der gleichen Anzahl von nebeneinander stehenden lenchtenden Punkten der Aussenwelt, welche in ihrer Gemeinschaft ein Elementarselrfeld bilden, es mag das geseliene Object nahe oder ferne sein. Nun nimmt die Helligkeit eines Lichtpunktes mit dem Quadrate der Entfermung ab, es muss also auch die Helligkeit des ganzen Elementarsehfeldes mit dem Quadrate der Entfernung abnelimen. Das Insect orientire sich also dadurch in der Aussenwelt, dass es alle nahen Objecte lıell, alle fernen dunkel sieht, ja es werde dadurch in die Lage gesetzt, ohne Angenlider seine Augen dem directen Sonnenschein auszusetzen, da die Somne so weit ist, etc.

Abgesehen davon, dass das Insect mach dieser 'I'heorie jeden dunklen Gegenstand für einen entfernten halten muss, ist dieselbe aus physikalischen Gründen nicht annehmbar. Denn entweder ist unter jenem Lichtbüschel, das auch Lichtlinie genannt wird, wirklich ein unendlich dünner Strahl gemeint, dann geht er auch von einer unendlich kleinen Fläche des Objectes ans, einem Punkte. Ist aber die Helligkeit des Objectes keine unendliche, sondern nur eine endliche, wie bei allen beleuchteten Objecten, so geht von einem Punkte desselben nur unendlich wenig, d. i. kein Licht aus, das Insect könnte also nicht sehen. Oder es ist nuter dem Lichtbüschel eine Anzahl parallel nebeneinander verlaufender Strahlen, deren Querschnitt eine endliche Grösse hat, gemeint (wie die obigen Angaben wahrscheinlich machen), dann können dieselben niemals parallel bleiben, wenn sie durch gekrümmte Trenuungsflächen verschiedener Nedien lindurchdringen, wie solche im Facettengliede des Insectenanges vorkommen, und natïrlich auch von Notthaft anerkannt werden. Werden die Tichtstrahlen

1 Ueber die Gesichtswahrielımungen rermiltelst des Faceltenanges. Frankfurt a. M. 1880.

2. e. S. 61. 
aber gebrochen, dam treten auch die Gesetze in Geltung, welche derartige Strahlenbrechungen beherrschen, die Helligkeit nimmt nicht mehr ab mit dem Quadrate der Entfernung. Notthaft hat ansführliche Messungen iiher die Grösse der Hornhantfacetten bei zahlreichen Insecten ausgeführt, die all und für sich werthroll sind. Ob er mit Recht die Grösse einer Facette als Massstab für die Selischärfe des Thieres betrachtet, muss wohl dahingestellt bleiben, ich vermag die Berechtigung dazu nicht einzusehen.

Eine eigenthümliche Modification der Miiller'schen Theorie rïhrt von Thompson Lowne her. ${ }^{1}$ Nach ihm ist jenes Gebilde, das man den Sehstab nannte und allgemein zu dem nervösen Antheile des Sehorganes rechnet, ein Theil des dioptrischen Apparates, und erst hinter den Sehstäben liege eine bisher ïbersehene Retina. Der Sehstab sei nun thatsächlich von anderer Gestalt und von anderem Habitus als er gewöhnlich abgebildet wird, er stelle nämlich einen nach vorne convexen, ziemlich roluminösen Körper dar, der vermöge dieser couvexen Fläche ein Bild eines vor ihm gelegenen Gegenstandes auf der Netzhaut entwerfen kann. Als der Gegenstand zu diesem Netzhautbildchen fungire aber das Gottsche'sche, im Krystallkegel liegende verkehrte Bildchen, das jedes Facettenglied unter dem Mikroskope zeigt. Es entstiinde demnach auf der präsumptiven Retina ein zweimal umgekehrtes, d. h. ein aufrechtes billchen eines äusseren Objectes. Jedes dieser Bildchen enthält nur einen kleinen Theil des Sehfeldes, so dass sich ein aufrechtes Netzlnantbild znsammensetzt, dessen einzelne Theile, die so zalılreich wie die Facetten des Auges sind, selbst aufrecht stehende Bildchen der betreffenden einzelnen Antheile des Sellfeldes sind.

Auch dieser Hypothese vermag ich nicht zuzustimmen. Denn erstens kann ich in dem Sehstab kein optisches Medium erkennen, das im Stande wäre, ein Bildchen zu entwerfen; schon die Anwesenheit des Rhabdomes in demselben mit seinem starken Brechungsindex und dem complicirt gestalteten Querschnitt scheint mil das unmöglich zu machen. Zweitens kann ich nicht zugeben, dass die Retina hinter den Sehstäben da liegt, wo Thompson Lowne sie annimmt. Es ist natïrlich selu misslich, ron der Lage der Retina im zusammengesetzten Auge Bestimmtes aussagen zu wollen. Es fällt diese Frage dem Sime nach zusammen mit der auch für das Wirbelthierauge noch nicht sicher beantworteten Frage nach der empfindlichen Schichte der Nervenausbreitung. Doch glaube ich, dass aus dem später zu schildernden Verhalten des Retinapigmentes und hauptsächlich des 'Tapetums im Insecten- und Krebsange mit an Gewissheit grenzender Wahrscheinlichkeit hervorgeht, das Licht bewirke seine Nervenerregung in ciner vor den centralen Enden der Sehstäbe gelegenen Schichte. Denn Niemand wid amehmen wollen, dass sich bei Nachtthieren, sobald die Dunkelheit eintritt, eine dicke Schichte stark reflec-

\footnotetext{
1 'T'ratsact. of ther Limmean Soe. Zonol. 1884.
} 
lender Tapetumsubstan\% zwischen dem dioptrischen Aplatat und der chtempfindlichen Schichte enthïltt. Man wird es viehnehr selbstrerstiindlich unden, dass, wie beim Sängethier, das 'Tapetum in simne des Ganges der' Eichtstrahlen hinter der empfindlichen Schichte liegt. Anf die IBilder, relche Thompson Lowne zur Ammane seiner Retina bestimmten, komme cch später zuriick.

Im Grossen und Ganzen scheint es, dass Max Schultze der Letzte war, der mit iiberlegenem Lächeln auf die Mïller'sche 'Theorie von anfrechten Netzhantbild herabsehen konnte, die Forscher der letzten Jahre neigen unzweifellıft dieser 'Theorie zu; ich elwähne z. B. der schönen biologischen Beobachtungen Forel's, ${ }^{1}$ der entschieden auf dem Boden dieser 'Theorie steht, sowie jener Plateal's' ${ }^{2}$ und der Darlegungen von Sharp. ${ }^{3}$ Auch C. Claus ist auf Grund seiner Untersuchungen des Phronimaauges gegen die Leydig-Gottsche'sche Theorie und für die Mïller'sche eingetreten." Blos Patten " hat in nenester Zeit anatomische Befunde veröftentlicht, die der Müller'schen Theorie nicht giüstig sind die aber wohl noch sehr der Bestätigung beduirfen.

Endlich habe ich der Vollständigkeit wegen noch zu bemerken, dass ich auf der 61. Vel'sammlung deutscher Naturforscher und Aerzte in Köln am Auge des Lenchtkäferchens das aufrechte Netzhautbild unter dem Mikroskope demonstrirt habe. ${ }^{6}$

Nach meinen Erfahrungen lassen sich die zusammengesetzten Augen ihrer optischen Wirkung nach in drei Typen theilen; alle entwerfen ein aufrechtes Netzhautbild, aber in verschiedener Weise. Zwei dieser Typen wirken dioptrisch, eine hanptsächlich katoptrisch. Die Netzhautbilder der beiden ersten 'Typen, von denen zunächst die Rede sein soll, will ich ihrer Entstehungsweise nach als das Appositionsbild und als das Superpositionsbild unterscheiden. (Letzteres ist identisch mit dem - früher von mir Summationsbild genannten Bilde des Lampyrisauges; seit mir das Appositionsbild bekannt geworden ist, halte ich es, nm Missverständnisse zu vermeiden, für zweckmässiger, den Namen Summationsjild fallen zu lassen.)

Um den dioptrischen Apparat eines Auges zu studiren, ist es liöchst vïnschenswerth, dass derselbe ein Ganzes darstellt, mit dem man hantiren iann. Die meisten Augen entsprechen dieser Anforderung nicht, die zahl-

1 Sensations des Insectes. Recueil zoolog. Suisse, Bd. IV, $18 S 6$ u. 1857.

${ }^{2}$ Rech. expérim. sur la vision chez les arthropodes. Acad. d. sciences zu Briissol SS7 น. $188 S$.

3 Adress read before the Entomological Society of London, 16. Jänı. 1889.

4 Der Organismus der Phronimiden. Arbeiten aus dem zoolog. Institnte d. Universitït ien. Bd. II, S. 71 .

5 Journ. of Morphology I, Nr. 1, $18 S 7$.

6. T'agblatt der 61. Vers. deutscl. Naturf. u. Aerzte in Kölı. Kölı 18s9, S. 71. 
reichen Kiystallkegel, die durch Weichtheile an die Cornea geheftet sind, kommen leicht aus ihre lage, sobald man das Auge exstirpirt hat, das Pigment thut das Uebrige, um ein genaneres Studium des optischen Terhaltens ummöglich zu machen.

Es gibt aber 'Thiere, bei welchen die Krystallkegel oder solche cuticulargebilde, welche ihnen, wenn anch vielleicht nicht morphologisch, doch functionell entsprechen, mit der Hornhant rerwachsen sind; hier hat man dann den ganzen dioptrischen Apparat in einem Stiick vereinigt, kann denselben vom Pigment befreien und in seinem Terhalten gegen Licht studiren. Jeh wählte zum Studium des einen dioptrischen Typus das Auge eines Krebses, des Schwertschwanzes (Limulus), das ausserdem den Vortheil hat, sehr grosse Elemente zi besitzen; nud zum Studium des anderen 'lypus das unseres Leuchtkäferchens. Letzteres ist zwar' recht klein, doch in hinlünglicher Anzahl leicht zu beschatfen.

\section{A. Das Appositionsbild von Limulus.}

Das grosse, ganz unbewegliche Auge des Schwertschwanzes, das in seinen Dimensionen und Umrissen unserer Lidspalte nicht unähnlich, mit der Längsansdehnung ron vorne nach riickwärts gerichtet ist, hat einen sehr grossen Krïmmungshalbmesser. Seine Oberfläche ist derb, chitinös; es lässt schon mit freiem Ange Facetten erkennen. Selbst an getrockneten Exemplaren, schöner an Spirituspräparaten und am besten am lebenden Thiere gewahrt man im Ange einen schwarzen Fleck, der vollkommen den Eindruck einer grossen Pupille macht, auch in der Tiefe zu liegen scheint. Diese "Pseudopupille" ist aìer nur ein optisches Phänomen, wie man sich sofort iiberzengt, weun man das ganze Thier hin und her wendet. Dic Pupille behält dann nämlich ihren Platz, indem sie stets dem Beschauer zugewendet ist. Diese Psendopupille ist bei zahlreichen Thieren zu beobachten und ihre Erklärung wird uns später noch beschäftigen. Sie wurde schon von Leydig bemerkt und als optisches Phänomen erkannt.

Führt man senkrecht zur Oberfläche einen Schnitt durch das Auge von Limnlıs, so sieht man an die Cornea angewachsene zahlreiche Zapfen aus Chitinsubstanz in die Tiefe ragen. Einer derselben ist Taf. III, Fig. 20, dargestellt. Die Cornea selbst lässt kanm gewölbte Facetten erkennen, die Spitze des Kegels ist abgestuzt, und diese Endfläche erscheint sogar, wenigstens an manchen Stellen des Auges, geradezn schwach concav. Das Ganze besteht, wie Grenacher ${ }^{2}$ dieses schon abbildet, aus Lamellen, welche sich anssen der älsseren̊ Oberfläche, in der' 'T'iefe aber mehr und mehr der inneren, Zapfen bildenden Obertläche anschliessen und diese Oberfläche auch bilden. Dabei heben sich gewisse Schichten

1 MÏ̈ller's Arch. f. I'hysiol. 1855, S. 431.

2 Sehorgan der Arthropodeu. Güttingen 1879, Taf, XI, Fig. 123. 
durch ihr optisches Verhalten ron ihrer Nachbarschatt ab, eine ober1lächliche, welche aber schon dentliche Zapfen zeigt, und eine wahrscheinlich in jedem Kegel enthaltene, aber nicht iiberall g]eich dontliche, mit den Chitinlamellen nicht parallele Schichte, welche einen Kegelmantel von dem Kegelinner'n tremnt. (S. Holzschnitt Fig. 10, S. 27.) Es macht den Eindruck, als stäicu in den Kegeln noch Kegeln anderen optischen Verhaltens, und es ist anch so. Der Kegelmantel ist aber nicht anatomisch vom Ker'n getremnt, sondern nur durch sein Lichtbrechungsvermögen von diesem verschieden. An den Stellen, welche den Zwischemräumen der Kegel entsprechen, ist die ganze Chitinmasse durch feinste Porencanäle senkrecht zur Oberfläche durchsetzt (bei a der Tafel), die man am besten an Horizontalschnitten sieht, und die meines Wissens nirgends beschrieben sind. (Tn der Abbildung: sind nur wenige als mit Luft gefiillt dargestellt; die meisten sind mit Flïssigkeit erfïllt und dadurch undeutlich geworden.)

Ich muss bemerken, dass ich sowohl die Tremungsfläche als die Scheidung der Kegel in zwei Bestandtheile an vielen Schnitten vermisst. habe, so dass ich vermuthe, es möchten die optischen Differenzen, um die es sich da handelt, in rerschiedenen Antheilen des Auges ungleich stark ausgeplägt sein.

Eine auffallende Eigenthiimlichkeit des Limulusauges, die das Studium des optischen Verhaltens recht erschwert, besteht darin, dass die Kegel mit ihren Axen nur in der Gegend der Mitte des Auges senkrecht zur Hornhantoberfläche stehen. Denkt man sich durch die Mitte des Auges eine auf der Oberfläche senkrecht stehende Linie gelegt, so convergiren die Kegelaxen nicht nach dem anf dieser Linie gelegenen Kriummungsmittelpunkt der cornea, sondern nach Punkten, die zwischen diesem und der Hornhant liegen. Je näher also an der Peripherie des Anges, desto schiefer sitzt der Kegel der Hornhant auf; der Winkel, den seine Axe mit der Hornhautoberfläclıe bildet, kann von einem Rechten bis um 40 Grad abweichen und wohl noch mehr. (Vgl. Holzschnitt Fig. 9, S. 25.)

Der ganze Kegel ist, abgesehen von seiner abgestutzten Spitze, in schwarzes Pigment gehiillt, und der Spitze gegenuiber befindet sich nach meinen Schnitten in einer Entfernung vou circa 0.04 Nillimeter die Retinula $(R)$ mit dem am Querschnitte sternförmigen Rhabdom. (S. Fig. `1.) Die Elemente der Retinula sind verglichen mit der Grösse der Facettenglieder und mit jenen anderer Augen ganz besonder's kurz. Anch die Retinula ist noch eingehïllt in Pigment, das fast in Continnität mit jenem des Kegels steht, so dass nur die kurze Strecke zwischen der Kegelspitze und den nervösen Elementen pigmentfrei ist.

Die Spitzenfläche des Kegels — so will ich die Abstutzungsfläche an der Spitze nemnen - pflegt nicht kreisrund, sonder'n elliptisch zu sein Ich fand den längeren Durchmesser in einem speciellen Fall 0.09, den kïrzereu 0.07 Millimeter. Doch mögen anch da Variationen. vorkommen. So gibt Grenacher den Durchmesser mit 0.065 Millimeter an. 
Um nun die dioptrischen Eigenschalten des Auges zu studiren, war es natiollich wiinschenswerth, frische 'Thiere zu' Verfügung zu haben. Ich bekam zwei Exemplare von Limulus polyphemus aus dem Berliner' Aquarium lebend nach Wien. Exstirpirt man das Auge, so gelingt es leicht, den ganzen dioptrischen Apparat von seinen Weichtheilen abzuschälen, ein zartes Abpinseln bringt die Reste des Pigmentes, wenn solche an einzelnen Stellen fester haften, hinweg.

Will man sich von der Wirkung eines solchen dioptrischen Apparates eine richtige Vorstellung bilden, so ist die Regel geboten, seine Flächen mit Medien in Berührung zu bringen, welche denselben Brechungsindex laben, wie jene Medien, welche diese Flächen im Leben berüln'en. Hat ja doch eine Linse eine andere Brennweite unter Wasser, eine andere in der Luft. Die vordere Fläche des Auges ist normalerweise bei Limulus mit Wasser oder mit Luft in Beriihrung, da er sein Leben theils im Meere, theils am Strande verbringt. Ich wählte bei meinen Untersuchungen Luft als erstes Medium. Die hintere Begrenzmngsfläche des dioptrischen Apparates, d. i. die Manteloberfläche der Kegel und deren Spitzenflïche, stossen an Zellen, welche mit Blntflüssigkeit getrïnkt sind. Obwohl der grüsste Theil dieser Zellen pigmentirt ist, ist ihr Brechungsindex, oder jener der Flïssigkeitsschichte, welche zwischen diesen Zellen nnd dem Kegel anznnehmen ist, nicht gleichgiltig, wegen einer etwa vorkonmenden totalen Reflexion.

Ich hatte schon frïher für derartige Untersuchungen am Insectenauge den Brechungsindex des Käferblutes (von Hydrophilus) bestimmt und $n=1.346$ gefunden; eine sehr verdiunte Glycerinlösung ron demselben Brechungsvermögen diente mir da als Benetzungsflïssigkeit für die hintere Fläche. Es war voranszusetzen, dass das Krebsblut keinen nemnenswerth verschiedenen Brechungsindex hat, weshalb ich bei der Untersuchung von Limulus dieselbe Glycerinlösmng anwendete. Ich durfte dds umsomehr, da ich mich ïberzeugt hatte, dass die Leistungen des dioptrischen Apparates bei diesem Thiere merklich gleich waren, ob ich denselben in der geschilderten Weise richtig montirte, oder ob ich iln ganz in Wasser eintrug, oder in selur stark lichtbrechende Flïssigkeiten, selbst in Anilin, legte. Letzteres hat den Brechungsindex $n=1.5803$, bricht also stärker wie die gebränchlichen Glassorten. Dieses beweist, dass bei Limulus merklich alle Brechung im Inneren des dioptrischen Apparates stattfindet und die Tremnungsflächen nahezu keine Rolle spielen.

Nichtsdestoweniger habe ich die Bestimmungen und Messungen, die alsbald mitgetheilt werden sollen, alle bei correcter Nontirung des dioptrischen Apparates gemacht. Es wurde also das ron allen anhaftenden Weichtheilen befreite Ange an seiner vorderen Fläche mit verdünntem Glycerin befenchtet, danit diese nicht durch Anstrocknen raulı wird und die Srhönheit des Bildes stört. Dieses komnte olıne Gefahr geschehen, da bekanntlich eine hinlänglich diime schichte eines wie immer brechenden 
Mediums keinen Einfluss anf den Gang der gebrochenen oder zu brechen. den Strahlen hat. Dann wude las Ange ant einen durchbohrten Objectträger gelegt, seine nach oben gerichtete Concavität mit einem Tropfen Glycerin des genannten Brechungsvermögens erfüllt und auf diesen ein Stiickchen eines Deckgläschens gelegt. Letzteres, damit der Gang der' Strahlen bei ihrem Austritt ans der Fliissigkeit nicht durch eine Wölbung dersellen beeinflusst wird.

So kann man das Präparat unter das Nikroskop bringen, wobei man natürlich ohne Belenchtungsapparat und mit dem Planspiegel arbeiten muss, oder noch besser, man legt das Mikroskop, nachdem das Auge vorsichtig befestigt wurde, horizontal und richtet es direct nach den Objecten, deren Bilder beobachtet werden sollen. So verfulır ich gewölınlich.

Das erste, was bei Einstelhng anf die Kegel auffüllt, ist die schon genamnte starke Convergenz ihrer Axen. Hat man in der Mitte des Sehfeldes einen Kegel eingestellt, dessen Axe mit del des Mikroskopes zusammenfällt, so weichen die sechs Nachbarkegel schon merklich von dieser Richtung ab, und am Rande des Selıfeldes - man arbeitet natïrlich mit schwacher Vergrösserung - sind die Kegel schon im Halbprofil zu selien.

An den SpitzenHächen liegeu nun die Bilder äusserer Objecte. Dieselben sind viel grösser als man sie etwa an den Hornhïuten der Insecten zu sehen pflegt und sind nicht sehr scharf. Stellt man den Balken eines Fensterkreuzes ein, so erkennt man leicht, dass dieser Mangel an Schärfe daher rïlırt, dass das Bild schon in der Ausdehnung der Spitzentläche recht starke Krïmmung lat. Hat man den Balken in der Mitte dieser Fläche scharf eingestellt, so muss man die Stellschranbe recht nennenswerth gebrauchen, um an der Peripherie das Maximum der Schärfe zu erzielen.

Was die Lage des Bildes betrifit, so ist dieselbe schon aus diesem Grunde natürlich nicht genau anzugeben. Ansserdem aber kommen kleine Verschiedenheiten in derselben bei verschiedenen Kegehn vor. Ich überzeugte mich in manchen Fällen, dass das Bild in der Mitte der Spitzenfläche gerade mit dieser Fläche zusammenfällt, bei anderen Kegeln sah ich dasselbe etwas hinter der Spitzenfläche. Dass es vor derselben liegt, dürfte kaum vorkommen.

Richtet man das Auge nach einen als Gegenstand wirkenden Lichtpunkt (ein Gasrundbrenner ist mit einem weissen Thoncylinder und einem schwarzen Blechcylinder ungeben, welche beide an einer ror'respondirenden Stelle ein Loch von circa 1 Centimeter Durchmesser haben), so sieht man natürlich in den Spitzenflächen jener Kegel, deren Axe nahezn parallel zur Mikroskopaxe stehen, die hellen Bildpunkte. An den Mantelflächen dieser Kegel, sowie in der Tiefe zwischen ihnen sieht man nirgends Licht austreten, ein Beweis, dass alles Licht, welches näherungsweise in der Sehrichtung ïberhaupt das Auge trifft, an die Spitzenflächen gelangt, und keines zwischen denselben anstritt. Anders ist es mit den Kegeln, welche 
mit ilner Axe von der selnichtung nemenswerth abmeichen. An diesen sieht man ejne in der Iantelläche oder in deren Nähe gelegene Brennlinie. Die Entstehungsweise derselben ist leicht einzusehen. Ein Linsencylinder wirkt fïr Strahlen, welche auf denselben senkrecht zu dessen Längsaxe fallen, wie eine Cylinderlinse, el sammelt die Strahlen in einer Brennlinie. Die schief gegen die Einfallsrichtung des Lichtes stehenden liegel nehmen eine Mittelstellung ein zwischen jener, bei welcher ein Bildpmkt in der spitzenfläche und jener, bei welcher eine Bremlinie entsteht, die parallel der Axe liegt. In der 'That kam man liänfig selı' schön rerfolgen, wie die Lichtpmnte des centrirten Kegels in den Nachbilliegel schon in radiärer Richtung ansgezerrt sind und so in den peripherer gelegenen Kegeln allmählich in die Bremnlinien iibergehen, die erst nahe der Spitze, dann länger' werdend, immer innerhalb oder doch in nächster Nälı der Mantelfläche liegen.

Macht man dicke Querschnitte durch die Kegel, so dass eine Schnittfläche das rordere, die andere das hintere Ende eines solchen abtrennt, so wirkt der zuriickbleibende mittlere Theil immer noch wie eine Convexlinse, nur liegt das verkehrte Bildchen, das el entwirft, in grösserer Entfernung; als beim unverselnten liegel.

Es geht aus dem Mitgetheilten hervor, dass ein Kegel des Limulusanges, natiulich von der Hornliantoberfläche bis an die Spitzenfläche gerechnet, ein dioptrischer Apparat ist, del ausschliesshich oder doch hauntsächlich als Linsencylinder wirkt, und zwar als einel näherungsweise ron der Länge seiner Brennweite. 1)a el im Telgleiche zu den Linsen'ylindern anderer zusammengesetzter Augen sehr lang ist, so muss auch sein Bild entsprechend gross sein.

Ich bestimmte die Grösse desselben, indem ich zwei Lichtpunkte als Objecte verwendete und die Entfernung ihrer Bildchen mass. Es ergab sich: Das Bild eines 150 ('entimeter rom Ange entfernten, 22 Centimeter messeuden Objertes ist 0.043 Millimeter gross.

Tou functioneller Bedentung ist mun die folgende Beobachtung. Hat man auf die beiden in der Ebene der Spitzenfläche liegenden Bilder der Lichtpunkte eingestellt und verschiebt damn durch Schranbeneinstellung die Focalebene des Mikroskopes nach rïckwärts (gegen den Augenhintergrumd), so guht jeder der beiden Bildpunkte in einen Zerstreungskreis anseinander, die rentren der beiden Zurstreunugskreise rïcken dabei gegenmnd ineinander, so dass bald nur meln ein nällerungsweise kreisförmig hegrenzter Zerstrenumgsheis zu sehen ist. Der Zerstrenumgsreis hatte dam in einem speciellen Falle einen Durchmesser von 0.13 Millimetel.

Auch bei anderen, geringeren Entfermungen des Objectes konnte ich mich vou der r'onvergenz der austretenden Strahlenkegel überzengen. 1)och kann ich nicht mnerwähnt lassen, dass ich bisweilen Fegel traf, an welchen diese Convergenz weniger ansgesprochen war, ja bei denen man zweifoln konnte, ob die beiden austretenden Liclitkegel mit ihren 
Axen nicht parallel stehen. Divergenz derselben kommit nath meinen Elfahrungen nicht vor. Bei den rollkommen tirishen Angen sah ich das farallele Anstreten freilich nie, so dass es dahingestellt bleiben muss, ob man es hier mit Verschiedenheiten der liegel intra ritan oder nur jost mortem zu thun hat. Fuir die physiologische Deutnng sind diese kleinen Variationen ïbrigens von untergeordneter Wichtigkeit.

Die optische Winkmig eines Kegels ron Limulus entspricht also anch in Bezug anf die Richtung der gebrochenen Hauptstrahlen, somit in allen wesentlichen Punkten der eines Linsencylinders ron der ungefähren Länge seiner Brennweite. (V'gl. d. plyssik. Einleitung.) Da, wo dis Hauptstrallen die geschilderte Convergenz zeigen, ist eine etwas grössere Länge vorauszusetzell.

Lm mo die Entstelımg des Netzhantbildes im Grsammtange klar zn machen, haben wir jetzt zu fiagen, wie gross jener Theil des Sehfeldes ist, ron dem ans das Licht an mo duch die Spitzenfläche eines Krystallkegels dringt, somit genal oder mu anmähernd - das möge vorlänfig noch unerörtert bleiben - die Richtung zur Retinula eines Facettengliedes eingeschlagen hat.

Meine Messungen ergaben, dass das Bildchen eines Lichtpunktes die Spitzenfläche durchwandert, wemn der Lichtpunkt in einer Entfermung ron 63 Centimeter rom Auge eine Verschiebung um S.5 Centimeter erfälnt. Rechnet man das der Anschaulichkeit wegen fiir ein object rm, welches sich in 1 Meter Entfernung vom Auge befinclet, so geht daraus hervor, dass ein Kegel des Limulusanges durchsetzt wird ron Licht, welehes ron einer Kreisfläche des Ohjectes, deren Durchmesser 135 Centimeter betrïgt, ausgestrahlt worden ist.

Oder in Winkelgraden ansgedrïckt: Fallen anf die Corneafläche eines liegels Lichtstrahlen aus den verschiedensten Richtungen, so passirt von allen diesen nur jener Theil die Spitzenfläche, welcher ror dem Eintritt in das Ange einen Lichtkegel gebildet hat, dessen in der Eintrittsstelle gelegener Spitzenwinkel nälıerungsweise acht Winkelgrade hat.

Ich bestimmte weiter an demselben Auge, an welchem diese ILessungen gemacht waren, den Krümmmngsradius der vorderen Fläclı. Es geschah das mit Hilfe des Ophtialmometers. Ich fand denselben $\mathrm{r}=7 \cdot 4$ Millimeter. Endlich mass ich an dem Auge die Entfernung der Mittelpunkte je zweier benachbarter Basen der Chitinkegel. Dabei wurde das Ange mit der Vorderfläche nach oben unter das Mikroskor gelegt und theils aus den allerdings kam erkenubaren Wölbungen, theils mnd hanptsächlich ans dem optischen Effect der ganz oder nällerungsweise senkrecht stelenden Kegel deren Entfermung beurtheilt. Dieselbe war nicht gleicll, schwankte bis zu $1 /$ oder $1 / 10$ ihnel (irizse und gal als Mittelwertl 0.28 Millimeter. 
Alle diese gemessenen Werthe kömnen theils wegen der Schwankungen, welche die Objecte selbst zeigen, theils wegen der Schwierigkeit der Messungen nur den Anspruch machen, als Näherungswerthe betrachtet zu werden. Sie genïgen aber auch als solche zur Orientirung über die Leistungen des Auges.

Bei dem genannten Kriimmungstadius des Anges ron $7 \cdot 4$ Millimeter und bei dem Oeffunngswinkel des Lichtkegels ron 8 Grad, welcher für jeden Chitinkegel als verwerthbar in Betracht kommt, wïrde es, damit jeder Punkt des Objectes Licht in den Angenhintergrund entsenden kann, nahezu ansreichen, wenn die Kegel in einer Entfernung von 1 Millimeter der Cornea anfsässen. Wir sahen aber ans der Entfernung der Kegelbasen von 0.28 Millimeter, dass drei bis rier Kegel auf einen Millimeter kommen, woraus hervorgeht, dass ein Punkt des Gegenstandes sein Licht zugleich in mehrere Kegel so entsendet, dass es optisch verwerthet werden kann.

Damit stimmt auch die directe Beobachtung ïberein. Gab ich dem Lichtpunkt eine solche Stellung, dass sein Bild in die Mitte der Spitzentiäche eines senkrecht gestellten Kegels fiel, so war es auch in den sechs rund $n$ m den ersten gestellten Nachbarkegeln noch im Bereiche der SpitzenHäche, freilich stark excentrisch gelegen, zu sehen; in einem Durchschnitte des Anges wïrden also, wie die Berechnmng erwarten liess, je drei Kegel die Strahlen eines äusseren Punktes durch die Spitzenfläche leiten und ihnen jene Richtung geben, in welcher sie empfindende Elemente finden diirften.

Wirkung der Schiefstellung des Kegels. Ich habe bisher die Verhältnisse so besprochen, als wenn die Axen der Chitinkegel alle radiär anf der Hornhantoberfläche stünden. Wie oben hervorgehoben, ist das nicht der Fall, sie sitzen um so schiefer der Oberflïche anf, je peripherer sie im Auge stehen. Das hat in Bezug anf die bisher dargelegten Verhältnisse keinen wesentlichen Einfinss; sicherlich nicht für die mittleren Antheile des Anges, wo die Schiefstellung eine geringe ist. Als Gianzes bildet diese Lager'ung der Kegel eine Eimrichtung, durch welche das Sehfeld jedes Anges erweitert wird. Bei der geringen Wölbung, welche das Auge von Limulus zeigt, dürfte diese Eimrichtung in der That recht nützlich sein, und dürfte seinen Grund darin haben, dass die Thiere bei ihrer Lebensweise ein stark gewölbtes Ange nicht branchen künnten. Sie graben sich nämlich in Sand ein, ${ }^{1}$ wobei das gewölbte Körperschild, in dem sich die gänzlich umbeweglichen Angen eingesetzt finden, die steinigen Nassen bei Seite schieben muss. Fs war in der'That bei den Exemplaren, die ich sah, die Mehrzahl der Angen zerkratzt, und wäre das gewiss

1 Virl. Brehm's Thierleben, 1. Aun. VI, S. 656. 
in lö̈lerem Grade, Wenn die Amgen sich in ihıer Wölbung von der Kriümmung des Körperschildes stälker abheben wiurden.

Wieso das Sehfeld auf diese Weise erweitert wird, lenchtet ein, wemn man erwägt, was für eine Brechung jene Lichtstrahlen bein Eintritt in deu dioptrischen Apparat erleiden miissen, welche zur lietimula gelangen. Ith habe in Holzschnitt Fig. 9 die Stellung eines centralen und rines peripheren Kegels schematisch angedeutet, wobei natiirlich die wahren Dimensionen des Anges nicht beibehalten werden honnten.

Der Kegel A, der der Gegend des Augencentrums entspricht, vereinigt als Linsencylinder die Lichtstrahlen $(s, t)$, welche senkrecht auf die cornea fallen, in einem Punkte (a) nahe der Spitzenfliche anf der Axe des Kegels, und strahlen, die unter geringtr Neigung zur Axe, z. B.

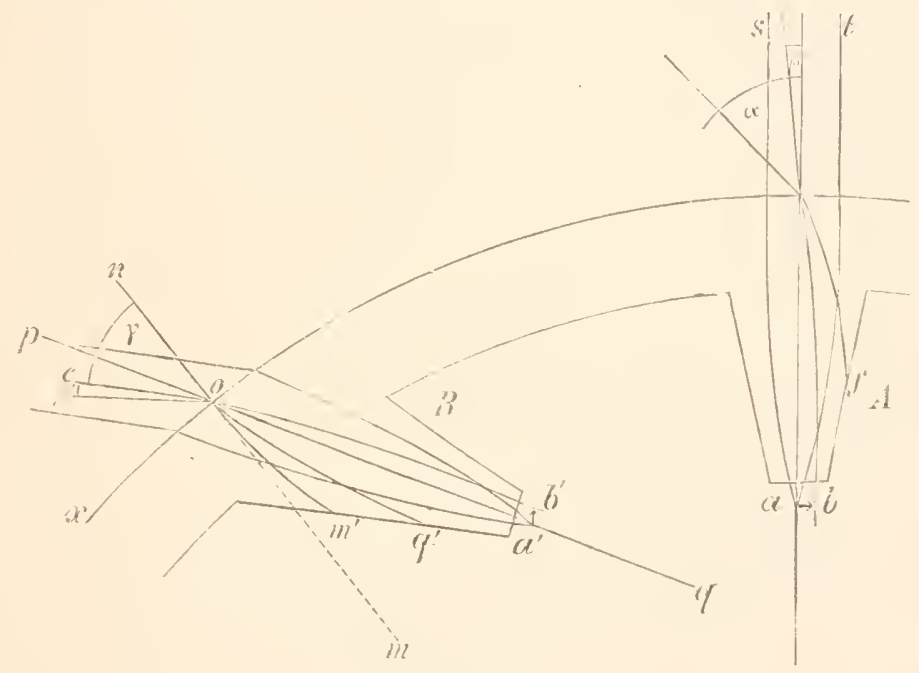

Fig. 9.

muter dem Winkel $\beta$ einfallen, in derselben Ebene neben der Axe (in b). So entstelıt, wie wir sahen, das verkehrte Bildchen. Strahlen, die unter stärkerer Neigung gegen die Oberflärhe, beziehungsweise die Kegelaxe auffallen, z. B. unter dem Winkel $a$, werden schon nicht mehr zur Bilderzeugung verwendet, sondern rom Pigmente absorbirt (in $f$ ).

Ander's beim Kegel $B$, der der Peripherie des Auges angehürt. Hier füllt die Axe des Kegels $p q$ nicht melır zusammen mit dem ant der Corneabertläche errichteten Lothe $n \mathrm{~m}$. Es dringt deshalb anch ein Lichtstrahl, der die Oberfläche senkrecht trift, nicht mehr durch die Spitzenfläche, sondern wird ungefälı den durch o $m_{1}$ ingegebenen Weg machen, und bei $m_{1}$ vom Pigment absorbirt werden. Aber auch Lichtstrahlen, die parallel der Kegelaxe pq einfallen, werden kam mehr die Spitzenflïlle erreichen, sondern an der Nantellärche durch Pigment alsorbirt werden, indem sie den durch poq angedenteten Weg zurïcklegen. Erst Strahlen, welche, wie oc mit der Kegelaxe einen Wiukel von mäs- 
siger, mit dem Oberflähenloth einen Winkel von bedentender Grösse (Minkel $\gamma$ ) bilden, sind nach den Eintritte in die Cornea der Kegelaxe farallel, verlalten sich also wie Strallen, welche fïr den centralen Kegel (A) von einem Objectpunkte kommen, der in seiner Axe liegt. Und die strahlen, welche mit oc einen kleinen Winkel $\left(\beta_{1}\right)$ bilden, gelangen nach $b_{1}$ und entwerfen mit den ersteren zusammen das verkehrte Bildchen $a_{1} b_{1}$. Ich will den Strahl co die optische Axe des Kegels nennen, zum Untelschied ron del anatomischen Axe $p o a_{1}$.

Bringt also im simne der Müller'schen Theorie jerles Facettenglied eines zusammengesetzten Auges fast mul das Licht zur Empfindung, welches nällerungsweise in seiner Axe einfäll, was, wie wil noch sehell werden, fiil viele Augen nu in seln wenig strengem Sime richtig ist, und stehen die Axen der Facettenglieder senkrecht zur Corneaobertläche, Jamn gibt die Stärke der Hornlantwölbung bei gleicher Basis des Anges (genanel gespl'ochen die Grösse des Bruchtheiles der Kugeloberfläche, den die Hornhant darstellt) ein Mass für die Grösse des Selıfeldes. Durch die geschilderte Eigenthïmlichkeit des Limnlnsanges ist das Selıfeld nicht mur bis zu jener Grösse elweitert, die es liätte, wenn die fegel alle ihre lichtung beibehielten und die Corneabertäche in Fulge stärlieler Kriummung ïberall anf den Kegelaren senkrecht stiunde, sondern die Erweiterung des selnfeldes geht nicht unbedentend über dieses Mass hinans: in der That eine schöne physikalische Lösung des Problemes, ein durch seine Form ror Insulten geschüitzes Auge mit grossem Sehteld herzustellell.

Wir kömen uns ïber den Grad dieser Erweiterung des Selnfeldes auch ein Maass bilden. Der Kreisbogen, den die Cornea auf ihrem längsten (horizontalen) Meridian zeigt, beträgt circa 90 Grad. Icl bestimmte an einem Schnitte den Winkel, den die Axe des Kegels mit dem anf dessen corneafläche errichteten Einfallsloth bildet. Er betrug; obwohl der Kegel noch lieiner von den äussersten war, 40 Grad. Ferner ermittelte ich den Brechungsindex eines Stiickchens aus den rordersten Schichten des Auges mit Ililfe des Mikrorefractometer's und fand iln

$$
\begin{aligned}
& n<1.5381 \\
& n>1.5327
\end{aligned}
$$

Wir liömen den brechungsindex also $=1.535$ annelmmen. Daraus der teinfallswinkel eines strahles berechnet, der nach dem Eintritt in die Colnea in del Axe des Kegels rerlanfen soll, ergibt 79 bis 80 Grad. Das lueisst also, das Selifeld ist nach beiden Seiten und ähnlich nach unten (denn oben steht eine Lamelle des Kürres'schildes ror) un circa 80 Grad "weitert, umfasst also in der Horizontalebene 2.80 - $90=250$ Winkelgrade. J)iese Wrweitermog scheint fast ïberflissig gross, wird aber sogleich verständlich, wemn man bedenkt, dass sie bedeutend leducirt, wird, sobald das 'J'hier' ins Wrassel ceht. 
Ich habe diese Eigenthiimlichkeit in Bau des Auges, wie ich später zu besprechen haben werde, noch hei anderen Thieren gefunden. Ws wiurde sich lohnen, derselben bei den rerschiedenen Thierchssen nachongehen und das biologische Verhalten der betreltenden Species zu beachten.

Wirkung des Kegelmantels. Auch eine andere optische Einlichtung des Limulusanges und ihre Bedeutung kann ich nicht unerörtert lassen. Oben habe ich erwähnt, dass man, wie schon Grenacher beschrieb, in den Kegeln durch eigenthümliche Lichthrechung zwei Theile unterscheiden kamn, den kegelfürmigen Kern und den umgebenden Mantel (Taf. III. Fig. 20 zeigt diese Zweitheilung nur uwvolliommen. doch ist sie in Holzschnitt Fig. 10 angedentet). Untersucht man die Lichtbrechung dieser T'heile mit dem Mikrorefiactometer genaner, so überzengt man sich, dass der Kern, den Ban eines Linsencylinder's anfweisent, in seinen äusseren Schichten den geringsten Brechungsindex hat, und dass der llantel ron höherem Brechungsindex ist. die nicht scharfe T'rennungsfläche zwischen beiden also einen raschen Tebergang von schwach zu stark brechenden Schichten darstellt. Ja ich habe Kegel ror mir gehabt, bei welchem ich nicht im Zweifel bleibeu komnte, dass der Mantel selbst wieder aus Schichten verschiedenen Brechungsvermögens bestehe, dass aber hier der Brechungsindex von immen nach aussen zunehme. Doch ist das optische Verhalten verschiedener Kegel nicht ganz gleich, auch sind die Dentungen der Schattirungen, welche man mit dem Mikrorefractometer sieht, für den Fall, dass zwei Linsencylinder verschiedener Art ineinander

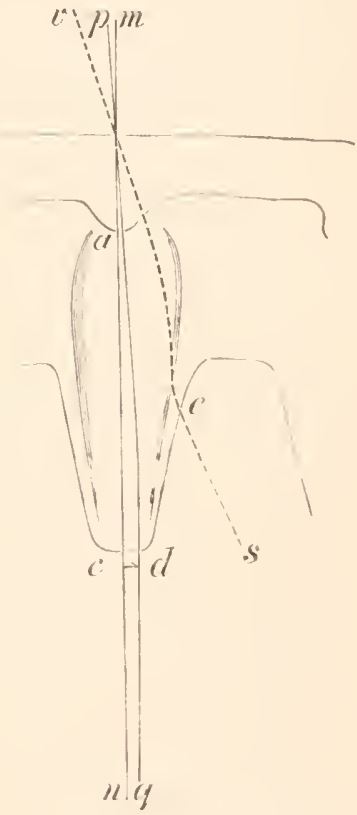

Fig. 10 stecken, so schwierig, dass ich es anfgeben musste, ïber den optischen bau auch in dieser Beziehung ins Klare zu kommen. Darïber aber kann kein Zweifel sein, dass der Kern des Kegels ein Linsencylinder der oben geschilderten Art ist, und dass seine schwach brechende äussere Lage an stärker brechende Schichten stösst, welche die inneren Schichten des Mantels bilden. (Ich will hier erwälmen, dass ich anch bei Schmetterlingen ähnliche Complicationen im Ban des K'rystallkegels und seiner Hüllen gefunden habe. T'af. T, Fig. 57, 2 und 3, zeigen den optischen Effect eines solchen, wenn man ihn unter dem Mikrorefractometer betrachtet.)

Das Mikrorefractometer lehrt auch, dass die waryenartige Vorwölbung, welche die äussere Lage der ganzen Hornmasse, jedem Kegel entsprechend. zeigt (Fig. 10 bei a), als Sammellinse wirkt, l. h. dass die nach hinten anstossende sthichte von geringerem Brechungsindex ist, als die Warze selbst 
Was bedentet nun die optische - nicht anatomische - Trennung ron Kegelkern und Kegelnantel? Ich glaube, die Deutung ist eine einfache und liasst sich durch Fig. 10 versinnlichen. $m n$ ist ein Axenstrahl, $p q$ zeigt den schon oft besprochenen Verlauf eines Hauptstrahles, der von einem in der Nähe des Axenstrahles liegenden Punkte ausgegangen ist; $c d$ ist das Bild des Objectes. Ein Strahl $v s$, der, ron einem seitlicher gelegrenen Punkt ausgehend, das Facettenglied triftt, wird durch die Wirkung der gekrümmten Fläche bei $a$ und des Linsencylinders nicht mehr so stark ans seiner Richtung abgelenkt, dass er die Spitzenfläche erreicht. Er gelangt vielmehr durch die Randschichte des Kegelkernes in die daranstossende, stark brechende Schichte des Mantels, verändert so, da er bei diesem Uebertritt zum Einfallsloth gebrochen wird, seine Richtung im Sinne einer Divergenz von der Axe und gelangt in das anliegende Pigment, wo el absorluirt wird.

Durch diese Einrichtung ist zweierlei erreicht.

1. Der Einfallswinkel, unter welchem ein so abgelenkter Strall die Grenze zrischen der Iormmasse und den Weichtheilen (bei e) trifft, ist nennenswerth verkleinert, und dadurch die Gefahr, dass dieser an der'selben eine totale Reflexion erfähnt, herabgesetzt, thatsächlich offenbar ganz rermieden. Als Gefahr muss dies in Bezug anf die Schärfe und die Begrenzung des Bildes $c d$ bezeiclmet werden, denn die total reflectirten Strahlen wïrden wenigstens zu einem beträchtlichen Theil die Spitzenfläche passiren und als fremdes, von entlegenen Stellen kommendes Licht das Bild stören.

Man wird num freilich fragen, warmm gerade der Limulus eine solche Einrichtung zur Vermeidung der totalen Reflexion lat, warum man die Einschachtelung eines Kegels in einen anderen, stärker brechenden nicht anch anderweitig findet. Es scheint mir nicht sicher, dass diese selbe Bildung nicht ziemlich allgemein in den zusammengesetzten Augen rorhanden ist; bei manchen ist sie, wie erwälnt, sicher vorhanden. Thatsache aber ist, dass ich bei keinem Ange optische Erscheinungen gefunden habe, die mit Bestimmtlıeit anf das Stattfinden einer totalen Reflexion lıätten schliessen lassen, ja gewöhnlich war das optische Verhalten so, dass totale Reflexionen an der Mantelfläche des Kegels geradezu ansgeschlossen erschienen, wenigstens solche Refiexionen, die das Bild in der angedenteten Weise stören wïrden. Und gerade solche müsste man erwarten, gerade diese sind es, welche man in reichsten Masse beobachtet, wem man die Form eines hrystallkegels aus Glas nachahmt und seine Axe nach einer Lichtquelle richtet. Nun ist das Glas freilich nicht rom optischen Ban eines Linsencylinders, aber trotzden mïsste man anch beim Krystallkegel im Allgemeinen totale Reflexionen erwarten. Deshalb zeigte ich, wie sie bei Limnlus vermieden sind, und werde in Folgenden Augen zu besprechen haben, bei denen ich eine weitere Ursache des Ausfalles totaler Reflexionen angebon zn kömnen glaule. Bei allen Augen kann ich das freilich nicht. Es ist auch bei der Mamnigfaltigkeit der Formen nicht zu erwarten, dass 
man bald ïber derartige Details in der Wirkmosweise jedes Auges muterlichtet sein wird.

2. bine andere Wirkmng dieser optischen binlichtung besteht darin, dass zwischen Strahlen, welche vernöge ihrer Finfallsichtung die stark brechende Mantelschichte nicht erreichen, sondern durch die Spitzentläthe austreten, und jenen, welche die Mantelschichte durchsetzt haben, keine Mittelstufen vorhanden sind. Die ersteren werden in ihrem ganzen Verlanfe der Kegelaxe zugelenkt, die letzteren schlagen friblier oder suäter, regen der Formation des ganzen Facettengliedes, aber niemals erst in ler nächsten Nähe der Spitzentläche, eine ganz andere Richtung ein. Hs treten also unter den entsprechenden Beleuchtungsverhältnissen iiberall an der Mantelfläche des Kegels die schädlichen Strahlen ans, nur nicht in nächster Nähe der Spitzenfläche. Bedenkt man, dass die Retinula gleich hinter den Spitzenflächen liegt, so erscheint es, obwohl schützendes Pigment vorlıanden ist, zweckmässig, diese strahlen, die ihrer Richtung nach etwa die Retinula des Nachbarkegels treffen künnten, zu beseitigen.

Das geschilderte Verhalten füln’t zu sehr' schönen und auffallenden Bildern. Wenn man das abgepinselte Limulusange als Ganzes nnter dem Mikroskope betrachtet, die Spitzenflächen nach oben gewendet, so sieht man bei entsprechender Belenchtung (durch das Fenster) die Spitzenflächen, welche horizontal liegen, hell, ihre Umgebnng dunkel, wie ich das schon geschildert habe. Bei anderen Kegeln aber', welche einen gewissen Grad der Neigung laben, sieht man anch noch die Spitzenfläche hell, ebenso den grössten Theil der Mantelfäche, nur der hinterste, an die Spitzenfläche grenzende Gïrtel derselben ist vollkommen dunkel, so dunkel, dass man glauben kann, es hänge ihm noch Pigment an, und sich dur(lı eine weitere Neigung des Kegels ïberzeugen muss, dass den nicht so ist, mmsomehr, als gerade hier das Pigment seln' fest zu haften ptlegt. Dieser dunkle Gürtel also ist der Ausdruck der besprochenen optischen Einrichtung.

Das Zusammenwirken der Kegel und die Netzhant. Naw diesen Anseinandersetzungen über die optische Wirkung der winzelnen Krystallkegel ist es nun möglich, von ihrem Zusammenwirken zu hindeln, ron der Art des durch sie entworfenen Netzhantbildes. Dazu ist vor Allem nöthig, die Lage und Ausdelmung der Retimnla ins Ange zu fassen. An die Spitzentläche setzen sich, den Kegel gleichsam fortsetzend, mpigmentirte Zellen an (Taf. III, Fig. 20). Grenacher lässt die Frage offen, ob diese Zellen schon der Retinula angehören und Fortsetzungen der darunter liegenden unzweifelhaften Retinulazellen sind. Dieses pigmentlose Zellenbïndel wird nach hinten schmäler und rämmt den Stäbchenbildungen den Platz; diese, identisch mit Grenacher's Rhiblom, bilden am Querschnitt eimen vielstrahligen, zierlichen Stern von selı' geringer Grösse (Taf. 11I, Fig. "21). Die gamze pigmentlose Masse ist kegelfürmig', 
die Spitze des Kegels, das Rhabdom enthaltend, ist eingehiült in dichtes Pigment, das von der Mantelflïche des Chitinkegels sich fast continuinlich bis herab fortsetzt. Ein 'Theil dieses Pigmentes ist nach der Auffassmg von Grenacher in den Retinulazellen selbst enthalten, deren axiale Flächen eben das Rhabdom bilden. In diese Zellen sah Grenacher die Nervenfasern direct ïbergehen.

C'nsere Vorstellung von dem zur Perception kommenden Netzhautbild wird num in erster Linie daron abhängen, wo wir in der unpigmentirten Strecke hinter dem Kegel die empfindende Schichte amelmen wollen, gleich hinter der Spitzenfläche, oder erst da, wo die Stäbchenbildung liegt, ferner daron, ob wir die Retinula als ein einheitliches Ganzes, das nur ein Localzeichen liefert, ansehen wollen, oder als Netzhant im Sinne der Wirbelthierretina. Letzteres halte ich für falsch, werde aber diese Frage später noch besprechen. Zumächst wollen wir die Retinula als Seheinheit atuffassell.

Sind schon die pigmentlosen Zellen lichtempfindlich, welche sich an die Spitzenfläche ansetzen, so werden dieselben getroffen von allen Strahlen, die von einem auf der optischen Axe des Kegels gelegenen Punkt ansgehen und die Corneafläche in jener Ansdehnung treffen, welche einem Facettenglied entspricht. Sie bilden zusammen einen Lichtkegel von der Basis einer Corneafacette, deren Spitze in dem Objectpunkt liegt. Wäre keine das Licht sammelnde Einrichtung vorhanden, so würde nur eine viel kleinere Zahl der von jenem Punkte ausgehenden Strahlen die Retinula erreichen, nämlich ein Lichtkegel, dessen Basis von der Retinula gebildet wird. Ferner exreichen sie gleich grosse Lichtkegel, welche von allen Punkten ausgehen, die mit dem ersten eineu Sehwinkel von nicht mehr als 4 Graden bilden, also bei gegebener Entfermung in einem Umkreis von bestimmtem Radius 1 m jenen Axenpunkt angeordnet sind. I)ie Hauptstrahlen dieser Lichtkegel sind nach dem Austritt aus der Spitzenfläche parallel der Kegelaxe gerichtet oder convergiren nach derselben. Vürde keine lichtsammelnde Eimrichtung getroffen sein, so wäre natiirlich wieder die Basis der Lichtkegel kleiner, und wären als sammelude Vorrichtung eine oder mehrere kugelige centrirte brechende Flächen verwendet, so wiirden die Hauptstrahlen divergiren und somit unter den siimmtlichen in Betracht kommenden Strahlen ceteris paribus viel grössere Verschiedenheiten in der Richtung vorhanden sein. Sollte die Grösse der Nervenerregung mit davon abhïngen, wie gross die Strecke der empfindenden Zellen ist, welche vom Lichte durchlanfen wird, oder wäre die empfindliche Schichte nicht hart an der Spitzenfläche, sonder'n weiter hinten gelegen, so leuchtet ein, mu wie viel der Linsencylinder den kugeligen Flïchen ïberlegen ist.

Es ist mun viel wahrscheinlicher, dass die Lichtempfindung erst da stattfindet, wo die Stïbchenbildungen sind. Hat doch Grenacher geretgit, dass diese das constanteste Element in Ange simmotlicher 'Thiere. 
sind, ınd wissen wir, dass die schichte del stäbchen und Zanfen des Menschenanges an nächsten nit der empfindenden Schichte zusanmmfällt. Ist also das Rhabdom Velmittler der Lichtemphindung, dann ist eine parallele Rielitung der Hauptstrahlen von auffillendem Nutzen. Man sieht dann aber weiter, dass nicht alle Punkte, welche dem Elumentarselıfeld (um mit Notthaft zu sprechen) eines Facettengliedes angelıören, gleich viel Licht dem Rhalodom zuwenden. Je weiter peripher, dusto "reniger Ticht gelangt von jedem der Punkte zur P'erception, da ein 'T'heil des ihn zugehörigen Zerstreungskreises fï̈ die Perception verloren geht. Anders ist es, wenn, wie ich ausgeführt liabe, die Hanptstralnlen hinter der Spitzentlïche convergiren. Hier liegt der Nutzen der Verwendung des Linsencylinders bei den obwaltenden Dimensionen der brechenden Modien noch meln zu l'age. Es werden damn eben alle Haupstrahlen und damit auch zum grossen Theile die Strahlen der zugehörigen Zerstremugskreise dem Rhabdom zugeleitet. Tmmer noch wird aber der Axenpunkt las Maximum der Erregung erzengen, es mïsste dem die empfindliche Schichte unendlich dimn sein und gerade da liegen, wo sich die /erstreumgskreise aller Punkte des Elementarsehfeldes decken, oder es uniisste bei dickerer empfindlicher Schichte die Ebene dieses Zusammenfallens gerade in der Mitte der Dicke gelegen sein. Selust dam wiude eine Gleichwerthigkeit aller Punkte des Elementarsehfeldes bei den obwaltenden anatomischen Verhältnissen noch nicht in strengsten Sinne vorhanden. sein, weil ja das Rhabdom in einem engen Canal von Pigmentmasse eingebettet liegt.

Ich muss lier in Bezug auf die Functionsweise des Rlıabdoms an das erinnerm, was zuerst E. Brïcke für deren Analoga in der Wirbelthiernetzhaut, den Stäbchen, hervorgehoben liat. IVegen des starken Lichtbrechungsvermögens, im Vergleiche zur Ungebung nämlich, ist ein Lichtstrahl, der einmal unter spitzem Winkel ins Rhabdom eingedıungen ist, darin gleichsam gefangen, er wird durch totale Reflexion bis ans Ende geleitet, am Ende kann er wenigstens zum Theil reflectirt und wieder in derselben Weise zuriickgeleitet werden. Wie immer die Nervenerregung: durch die Lichtwirkung zu Stande kommt, dieses Eintreten der Strahlen in die Stäbchenbildungen, die sich ja auch an den Zapfen der Sängethiernetzliant finden, scheint von wesentlicher Bedeutung. Und eine coustruction des Auges, bei welcher der Eintritt des Liclites in das Riliabdom, wenn auch nur an einem Ende, ermöglicht ist, genügt, es kamn damm, wic las beim Limulusauge der Fall ist, der grösste Theil der Stäluchen in Pigment eingegraben sein oder nicht.

Aus alldem geht hervor, dass wir uns das percepirte Netzhautbild des Limulus aufrecht volzustellen haben und von einer Schärfe, deleu untere Grenze dadurch gegeben ist, dass ein Gitter', dessen stäbe circa 13 Centimeter voneinander abstehen und ebenso dick sind, in einer Entfernung rou 1 Meter norls als Gitter erkannt wird, wobei abes die Grenzen 
der Stäbe nicht mehr scharf erscheinen. Die Helligkeit des Netzhanthildes, verglichen mit der des Objectes - wir wollen dieses Verhältniss die "relative Helligkeit des Netzhantbildes" nemnen - ist insofern recht gross, als jedes Retinaelement mehr Licht bekommt, als bei den meisten anderen Artlıropoden. Dafür ist allerdings die Anzahl der Netzhautelemente, auf die Flächeneinheit bezogen, sehr gering. Auch die „relative Grüsse“ des Netzhantbildes ist entsprechend den Limensionen "des Auges sehr bedeutend. Nit Rücksicht auf den Kriümungshalbmesser der Cornea von 7·4 Millimeter und der Entfernung der empfindlichen Schichte der Retinula von der vorderen Corneafläche $=0.92$ Hillimeter (nach Angaben und Zeichnungen von Grenacher als Näherungswerth angenommen) lässt sich die Länge des Netzhautbildes eines in 1 Meter Entfernung befindlichen, 1 Meter langen Objectes mit 6.5 Millimeter angeben. Das Netzhautbild desselben Gegenstandes und bei gleicher Entfernung wïrde im menschlichen Ange 15 Villimeter gross sein. Die Ausdehnung des Netzhautbildes, beziehungsweise des Sehfeldes, ist nemnenswerth grösser als der Wölbung des Anges entspricht, und wird, wie wir sahen, in der Horizontalen circa 250 Winkelgrade umfassen, wenn das 'Thier in der Luft ist.

Kann man das Netzhautbild sehen? Nach der dargelegten Theorie desselben muss das, wenigstens in unvollkommener Weise, der Fall sein. Und so zeigt es anch der Versuch. Wemn man ein abgepinseltes Auge oberflichlich mit wenig Glycerin befeuchtet, un die, wenigstens an meinen Augen immer vorhandenen, durch Lädirungen entstandenen Rauhigkeiten der Corneabberfläche auszugleichen (ich tauchte die Augen zu diesem Zwecke in Alkohol, dem etwas Glycerin zugesetzt war), und richtet dasselbe gegen das Fenster, so sieht man zunächst kein deutliches Bild desselben, wenn man es ron hinten betrachtet. Nimmt man nun die Lupe zu Hilfe, so erkennt man, dass eine grössere Gruppe von Spitzenflächen hell leuchtet, während die nächste Umgebung einer jeden dunkel ist. Es sind das die Spitzenflächen jener Kegel, deren Axen nach dem Fenster gerichtet sind. Der helle Fleck, welchen diese leuchtenden Spitzenflächen in ihrer Gesammtheit bilden, ist das anfrechte Netzhautbild, es wandert bei Drehung des Anges im Simne eines solchen; ein Gegenstand, der zwischen Auge und Fenster bewegt wird, lässt die Spitzenflächen der Reihe nach dunkel werden, wie es dem anfrechten Bilde entspricht.

Unvollkommen ist dieses Bild, weil einerseits die ganze Spitzenfläche hell gesehen wird, nicht, wie es der Function des Anges entsprïiche, nur jene viel kleinere Fläche, die dem Querschnitt des Rhabdoms angehört; andererseits, weil die Ungebung des geschilderten Fensterbildes nicht dunkel erscheint. Es treten nämlich, wie oben besprochen, die Lichtstrahlen, welche unter einem ziemlich grossen Winkel mit der optischen Axe in den Kegel gelangen, aus dessen Mantelfliche wieder aus. Unter normalen Verhältnissen werden sie bei ihrem Austritte vom Pigment absorbirt, am aligepinselten Auge aber und bei der eben geschilderten Betrachtungsweise 
desselben erhellen sie die ganze Ungebung des eigentlichen Netzhantbildes, mit Ausnahme einer engen Zone um dasselbe, die sich auch aus dem oben Mitgetheilten erklürt. Ignorirt man, indem man den Augenhintergrund mit der Lupe betrachtet, alles Licht, das in Form von Lichtstreifen aus den Mantelfïchen der Kegel tritt, als physiologisch bedertungslos, so wird man das Netzhautbild und seine Bewegungen mit Bequemlichkeit beobachten und studiren können. Ich habe mit riemlich gutem Erfolg versucht, das abgepinselte Pigment durch einen schwarzen Alkohollack zu ersetzen, der sich durch Capillarität in die Vertiefungen zwischen die Kegel hineinsangte, die Spitzenflächen aber fiei liess. Die Angenfälligkeit des Netzhautbildes nahm dadurch bedentend zu.

Ich werde im Folgenden davon zu sprechen haben, dass bei Insecten Verschiebungen des Pigmentes in Folge von Lichteinwirkungen auftreten, so dass dessen Anordnung eine verschiedene ist, wenn sich das Thier einerseits im Hellen, andererseits, wemn es sich im Dunkeln befindet. Es ist nicht unmöglich, dass dieses auch bei Limulus der Fall ist, doch habe ich keime Versuche oder Beobachtungen hierïber angestellt, kann also nur Vermuthungen aussprechen. Es könnte nämlich geschehen, dass die Pigmentliille, welche die Retinula umgibt, mit der Beleuchtung ihre Weite ändert, oder auch, dass ihre Entfernnng von der Spitzenfläche variirt, indem der unpigmentirte Kegel, der sich an die Spitzenfläche anschliesst, an Basis und Höhe oder an einem von beiden abnimmt. Die Verengermng der Pigmenthïlle entspräche der Lichtstellung, Erweiterung der Pigmenthiille wiirde die relative Helligkeit des Netzhantbildes erhöhen, allerdings wahrscheinlich auf Kosten seiner Schärfe.

\section{Das Auge von Limulus im Vergleiche mit jenem der Triboliten- krebse.}

Unter allen Augen lebender Insecten und Krebse, die ich untersuchte, oder die ich anf anderem Wege kennen lernte, ist keines der GrïelGottsche'schen Hypothese güustiger, als das von Limulus. Freilich wäre auch dieses nur eine sehr schwache Stïtze für dieselbe. Aber wenn man annehmen wollte, dass die an die Spitzenfläche angesetzten durchsichtigen Zellen Retinaelemente sind, wenn man die geringe Anzahl der Nervenfasern, die Grenacher mit den Retinnlazellen in Verbindung treten sah, für ausreichend zur Aufnahme eines verkehrten Netzhautbildes der Aussenwelt in jedem Facettengliede halten will, wemn man von der Nutzlosigkeit, ja dem Schaden absehen wollte, den die Verwendung des Linsencylinder's statt der kugeligen brechenden Medien mit sich brächte, ebenso von den gerechten anderweitigen Bedenken, die so vielfach gegen jene Theorie erhoben worden sind, dam könnte man das verkehrte Bildchen, das in 
oder linter der Spitzentläche entsteht, so unvollkommen es ist, als Netzlatutbild, jene Zellen als lietina auffassen und sagen, der Limulus sehe mit zahlreichen Angen, deren jedes nach dem Typus des Wirbelthieranges fungirt. Ich glaube selbst, dass Max $\mathrm{Sch}$ lltze gefrolılockt hätte, wemn er das verkehrte Netzhautbild und die verhältnissmässig zahlreichen Retinaelemente (Grenacher schätzt sie anf 14 bis 16) gesehen haben wïrde.

Ich bin über die Functionsweise anderer Meinung, obwohl ich dip Annäherung an den Typus des Wirbelthieranges eben hervorgehoben habe und in der Lage bin, noch ein Bindeglied zwischen diesem und dem Limulusange einzuschalten.

Bekanntlich ist die Stellung des Limulns im zoologischen System unsicher; frïher rïckte man ihn nahe an die fossilen Trilobiten, in nenerer Zeit sind Stimmen laut geworden, welche sich gegen diese Verwandtschaft wehren. Herr Professor Eduard Sness hatte die Giite, mir ein Paar Trilobiten zn überlassen, deren mit freiem Ange bequem sichtbare grosse facettirte Angen mein lebhaftes Interesse erweckten. Ich glaubte in diesen längst ansgestorbenen Verwandten des Limulus dessen Auge nur in noch viel grösserem Massstabe wiederzufinden.

Ich fertigte nach der Methode der Mineralogen, deren Erlernung ich der freundlichen Unterweisung des Custos nnd Leiters der mineralogischpetrographischen Abtheilung des $\mathrm{k} . \mathrm{k}$. naturhistorischen Hofmuseums in Wien, des Herrn Dr. A. Březina, verdanke,. Dünnschliffe aus den Augen an, theils senkrecht, theils tangential zur Oberfläche. Das mikroskopische Bild der Tangentialschliffe (Taf. II, Fig. 18) zeigte schon ein von Limulus sehr abweichendes Terhalten, indem hier in regelmässigen Abständen und durch Scheidewände voneinander getrennt, kreisrunde Felder zu sehen waren. Diese lätten noch den Querschnitten von eigenthümlichen Kegehn entsprechen können, umsomehr, als sie in ihrer Stellung dieselbe Regelmässigkeit zeigten, wie sonst die Facettenglieder. Die Scheidewände waren freilich kaum als in einer zusammenhängenden Chitinmasse eingelagert zu betrachten. Die senkrecht auf die Oberfläche gefiilırten Schliffe aber liessen nichts von Kegeln erkennen, sondern wiesen sehr schöne und regelrechte Linsen anf, wie wir sie als Chitinbildungen bei den einfachen Augen der Insecten zu sehen gewohnt sind. Ein Paar solcher ist in Fig. 19 der 'Taf. II von Phakops fecundus abgebildet. Leider konnte ich von den tieferliegenden Theilen des Auges an den Versteinerungen nichts melır erkennen. Doch was ich sah, zeigte, dass hier, ob ansschliesslich oder nur theilweise muss dahingestellt bleiben, das optische Princip der linse rerwendet war, und das Auflıören des zwischen je zwei Linsen eingeschobenen Septums in einer' geringen 'J'iefe liess vermuthen, dass hier anch bald die Grenze des ganzen Anges, die Netzlıant also nahe der Linse, lag. Mit einem Worte, wir haben das Bild eines einfachen Anges ror ms, und ein solches sielıt mzweifelhaft mit rerkehrtem Netzhautbild. 
Bekanntlich kommen bei spimnen partweise gestellte einfache Angen ror'; bei den 'Tribobiten sind es nicht zwei, sondern viele, dis in einer Grupe beisammen stehen, miteinander ein Gesanmtange bilden, das als solches eine recht geringe Krïmmung hat, geringer als die des Limulusauges. niese Thiere haben also, wenn man mach diesen dïrftigen Pefunden urtheilen will. wirklich so gesehen, wie die Theorie ron Gottsche, Grïel und deren Tachfolgern verlangte: viele agorregirte Angen, deren jedes ein kleines rerkehrtes Bildchen entwarf, wirkten znsammen als Sehorgan, und wemn man nu die Strahlen in Betracht zöge, welche jedes Netzhautcentrum treffen, so entstünde ein grosses anfrechtes Bild in jedem Gesammtange. Schon der grobe Unterschied im Ban dieser Angen und jener von Limulus weist auf die Veränderung in der Functionsweise, das Verkümmern der kleinen rerkehrten, die Vervollkommnung des grossen anfrechten Bildes hin.

\section{B. Das Superpositionsbild von Lampyris.}

Nachdem ich im Vorstehenden an einem Beispiele den optischen Ban oiner Angenform besprochen habe, gehe ich zu einem zweiten Beispiele ïber, das uns einen zweiten Typus des zusammengesetzten Anges verstehen lehren soll. Das anfrechte Netzhautbild des Limulusanges entstand dadurch, dass die je einem Facettengliede angehörigen Lichtmassen neb eneinander die Ebene der Netžlant treffen. Ich suchte dies durch den Namen Appositionsbild auzudeuten. Bei dem jetzt zu besprechenden Auge fallen die den einzehen Facettengliedern zugehörigen Lichtmassen in der Ebene der Netzhaut zu einem grossen Theile ïbereinander. Ich nenne diese Art des Netzhantbildes deshalb das Superpositionsbild. Bei der Klarlegung desselben halte ich mich aus naheliegenden Grïnden wieder zunächst an das Ange eines Thieres als Beispiel für diesen Typus. Es ist das Auge unseres Lenchtkïferchens (Lammyris splendidula), das sich, wie jenes von Limulus, zum Studium dadurch eignet, dass der ganze dioptrische Apparat ein Stïck bildet. Ich benitzte nur die Angen der fliegenden Männchen, da jene der flügellosen Weibchen gar zn rudimentär sind.

1. Beobachtungen am frisclien Lampyrisange.

Tch kappe mit einer gut schneidenden Staarnadel den grössten Theil des Anges, welches nahezu eine Halbkugel darstellt, ab, bringe ihn in ein Schälchen und pinsele die concave seite so gut als möglich ab, indem ich das Ange mit einer Nadel oder einer feinen Pincette festhalte. Im frischen Zustande geht das Pigment leicht weg; an Spirituspräparaten hat man dabei schon mit einigen Schwierigkeiten zu liämpfen. Nun bringe ich anf ein Deckgläschen oder auf eine diinne Glimmerlamelle einen 'Tropfen des rerdünnten Glycerins, dessen Brechungsindex

$$
n=1 \cdot 346
$$


ist. Das ist, wie erwähnt, der Brechmngsindex des Käferblutes, den ich bei Hydrophilns picens bestimmt hatte. Bei diesem Thiere ist es, wenn man ihm den Kopf abschmeidet, leicht, genug Blut zu gewinnen, um den Brechungsindex desselben mit Hilfe des Abbe'schen Refractometers zu elmitteln. Ich wähle diese Flïssigkeit, um Verhältnisse lıerzustellen, welche dem normalen Zustande, in dem die Krystallkegel mit Gewebsfliissigkeit benetzt sind, so nahe als müglich kommen. Aus demselben Grunde bringe ich num in diesen 'lopfen das abgekappte Auge in eine Lage, dass es mit der Concavität dem Tropfen aufliegt, die Convexität aber unbenetzt an Inft stüsst. Es geht dies leicht, weil die frische Corneafläche eine Schwerbenetzbarkeit anfweist, fast als wäre sie eingefettet, sich also das Ange fast von selbst in die gewïnschte Lage begibt. Ich ziehe Glimmer den gewölınlichen Deckgläschen vor, weil sich der Tropfen auf diesen besser ausbreitet.

Nun lege ich den Glimmer oder das Deckgläschen in der gewölınlichen Weise mit dem Präparate nach unten anf einen Objectträger, der eine Oeffnung rou circa 1 Centimeter Durchmesser lat, natürlich so, dass das Auge in die Oeffnmng fällt, und bringe das Ganze untel das Mikroskop. Fs sind also jetzt, wie beim normalen Sehen der Thiere, die vordere Hornhautfläche mit Lnft, die Krystallkegel mit einer Flïssigkeit von $n=1.346$ in Berïlnung. Am bequemsten bei schwacher Vergrösserung von 60 bis 100 sieht man num bei hoher Einstellung ein anfiechtes Lnftbild (abgesehen von der Unkelıung durch das Mikroskop und der Wirkung des Mikroskopspiegels) der äusseren Gegenstände. Ein solches ist mikrophotographisch aufgenommen und durch Lichtdruck (selbstverständlich ohne jede Retouche) vervielfältigt, diesen Zeilen als Titelbild beigegeben. Das Auge befand sich einem Bogenfenster gegenübel, durch welches eine Kirche sichtbar war; auf eine del Fensterscheiben hatte ich ein ans schwarzem Papier geschnittenes $R$ geklebt. Es erscheint im Bilde in Spiegelschrift, wegen der Tervielfültigung durch Druck.

Um sich vor Täuschungen durch die Wirkung des Hohlspiegels oder anderer Reflexionen und Brechungen zu schiitzen, kann man den Planspiegel anwenden, das abzubildende Object, z. B. eine Staarnadel, zwischen Spiegel und Präparat bringen; kann den Spiegel durch Papier ersetzen; das Mikroskop umlegen, mnter Beseitigung des Spiegels gegen das Fenster ricliten und ein Object vor dem Präparat anf und ab bewegen; man kann unter diesen Umständen das Bild auch mit dem einfachen Mikloskop oder der Brïcke'schen Lupe als anfrechtes erkemnen, ja ich zweifle nicht, dass es ein sehr kurzsichtiges Auge anch olme optische Hilfsmittel sehen wird. Ich führe das an, weil wohl Jedermann, wenn er das Bild das erstemal sieht, so wie es auch mir geschehen ist, denkt, es möge doch noch irgendwie durch doppelte Reflexion von den Mikroskoplinsen hel u. dgl. ein dem Präparate selbst fremdes Bild dahin gelangen. Das Weitere wird iibrigens diese Bedenken vollständig beseitigen. 
Ich benützte zum 'Theil anch hohl geschliftene Objectträger, gab dieses aber später aut, erstens weil deren Schlift, als Concavlinse wirkend, eine Brechung einfïhnte, die ich bei der genaneren Untersuchung der optischen Eigenschaften zu vermeiden hatte, aus welchem Grunde ich anch mit dem Planspiegel oder ohne Spiegel untersuchte, zweitens weil durch das verdampfende Wasser eine Bethaung der concaven Fläche des Objecttrïger's eintrat, welche das Bild bald trïbte, oder ganz zum Verschwinden brichte.

Andererseits hat anch die Beobachtung in der freien Luft, wie ich sie eben beschrieb, den Nachtheil, dass sich der Brechungsindex der Flüssigkeit ändert, was bei den genaneren Prüfungen des optischen Verhaltens nicht zulässig ist. Man muss sich dann eben dadurch vor Irrthümern schützen, dass man häufig den Tropfen erueut. Uebrigens ist die Schönheit des Bildes nur in geringem Grade ron dem genauen Einhalten jenes Brechungsindex abhängig. Es ist bei Benützung ron Wasser merklich ebensogut; concentrirtes Glycerin allerdings darf man nicht nehmen.

Was die Schärfe des Bildchens betrifft, so ïbertraf dieselbe meine Erwartungen. Forel hat (l. c.) vermuthungsweise die Schärfe eines Netzhautbildes abgebildet, das eine Biene von einem kleinen Iusecte bekommen mag, das an ihr vorbeitliegt. Ungefähr ron dieser Schärfe hatte auch ich mir die Bildchen nach meinen früheren Untersuchungen gedacht. Sie sind aber beim Lampyrisauge schärfer, und es ist alle Ursache, anzunehmen, diss die Augen anderer Insecten noch rollkommener gebant sind. Ich sah eine Staarnadel, zwischen Spiegel des Mikroskopes und das Präparat gehalten, in ihrer Gestalt sehr gut, erkannte den weissen Grift, den Reflex bei Drehung der Nadel. Ich sah — da ich diese Studien theilweise während der Sommerferien auf dem Lande machte - das verkleinerte Bild des Mikroskopspiegels, das als Rahmen fiir eine kleine Landschaft diente, in der ich die weissen gemanerten Pfeiler einer meinem Fenster gegenüberliegenden Scheume, deren rothes Ziegeldach und die braunen Bretterwände unterschied, und in der sich die einzelnen schwächlichen Zweige kleiner Zwetschkenbäume vom blauen Himmel abhoben. Ich komme auf die Schärfe des Bildes später nochmals zu sprechen.

Die Grösse des Bildes ist seiner etwas verwaschenen Grenzen wegeu nicht mit Sicherheit zu messen. Die Läuge desselben betrug in einem Falle circa 0.24 Millimeter, in welchem der Gegenstand 32 Centimeter lang und in einer Entfernung von 52 Centimetern war.

Ehe ich ïber die Lage des Bildchens in der Tiefe des Auges, also seine Entfernung vou der vorderen Corneafläche spreche, wird es angezeigt sein, das Nothwendigste über die Anatomie dieses Anges mitzutheilen.

Ich habe in Taf. I, Fig. 1, einen meridionalen Schnitt durch ein Lampyrisange mit Hilfe der Zeichenkammer abgebildet. Das Auge war' in Celloidin eingebettet und mit Safranin gefürbt. Die Zeichnung zeigt denselben in 120facher Vergrösserung. 
Die convexe vordere c'orneatläche (c) trägt entsprechend je einem Krystallkegel eine gekrimmte Facette, deren Krimmungshalbmesser ich im ('entrum grösser', an der Peripherie kleiner', 0.09 bis 0.02 Millimeter fand.

Rechnet man die Conea bis dahin, wo die chitinartige Substanz zu den einzelnen Kegeln alseinanderweicht, so ist sie bei diesem Thiere von sehr geringer Dicke und macht sich am Schnitte des nicht abgepinselten Alıes durch ihre Pigmentlosigkeit kenntlich. Die mit der Cormea ver'wachsenen Krystallkegel (k) sind dicht von Pigment (J.P.) umliült, mit Ausnahme inres inneren Endes, das frei in die dalnintel gelegene Zellemmasse lineinragt. Die Form der Kegel ist nur an abgepinselten Augen genaner zu erkemnen. Ich labe einen solchen in Holzschnitt. Fig. 12, S. 44 , seiner Gestalt nach, so getreu es mir möglich war, sammt der Corneafacette wiedergegeben. Nun folgt eine ziemlich breite Zone langgestreckter, kernlraltiger Zellen $(G)$ in radiärer Anordnung, die walnscheinlich mit ähnlichen Gebilden von Schmetterlingen identisch sind und deren Bedentung später besprochen werden soll. Bei $R$ beginnt die Retina, von der man freilich an Neridionalschnitten selı wenig sielıt. An Flächenschnitten erkennt man hier eine kelmeiclue Zelllage, deren Mosaik gegen die retinale Pigmentschichte $(R . P$.$) hin alsbald in jenes überaus zierliche Bild iibergelıt, das$ aus velgissmeinnichtartigen Figulen zusammengesetzt und noch in- und jenseits der retinalen Pigmentschichte, wenn ancl in modificirter Form, zu erkennen ist. Immitten jedes der blïthenförmigen Querschnitte sieht man eine ungefärbte Stelle, das Rhabdom Grenacher's. Noch weiter gegen den Krimmungsmittelpmnkt des Anges gewahnt man die dïmne Schichte, in welcher sich die Nelvenzüge verlieren ( $m . f$.$) , die vom Ganglion opticum$ (G. o.) kommend, in dieselbe einstralılen.

Was nun die Lage des Bildes anbelangt, so ist es sehr schwer, dieselbe genau zu messen. Es muss natürlich mit der Stellschraube geschehen und die Lage aus der Höhe eines Schraubenganges und den Winkelgraden der Schrambendrehung berechnet werden. Die stellnng, bei weleher das anfrechle Netzhautbild das Maximum der Deutlichkeit hat, ist zienlich genan zu hestimmen, ander's aber steht es mit dem zweiten, tiefer gelegenen Punkt. Man kamn auch hier recht genan eine Stellung finden, bei welcher jedes fatcettenglied als lieller Krejs und die Räume zwischen den Facetten dunkel elsclieinen, und zwar anch, wenn das Pignent alygepinselt worden ist. Es dringt eben zwischen den Facettengliedern in Folge von Brechungen liein Jicht durch die andisichige substanz, wie ich dies schon beim Limulusange genaner erläutert habe. Auf' welche Ebene aber hat man eingestellt, wenn das Hacettenglied als schar begremzter heller hreis erscheint? Bestimmt weiss ich es nicht, vielleicht anf die Basis der hiystallkegel, vielleicht auf die Basis der Hecttenwölbung, vielleicht aber anch auf einen writer hinten golegenen (,uersohuit durch den Krystalliegel.

Bei einer etwas höheren Einstellung komnte ich mich wiederholt mit Hilfe del noch anlaftenden Pigmentkürner so weit orientiren, dass ich 
glaube, richtig anf die Spitze der Krystalliegel eingestellt zu haben. Wie Entfermung zwisehen der erstgemanten Einstellung und dem Netzhantbilde fand ich 0.23 Millimeter. Es wïrde demmach dis Bild un die genannte länge hinter dem dioptrischen Apparat liegen.

Würden wir dieses Bild in die Zeichnung Fig. 1, Taf. I, eintragen, so wiilde es demmach nicht unbeträchtlich hinter die lietina fallen. Es mag das danin seinen Grund laben, dass meine Zeichnung einem Meridionalschnitt vom seitlichen 'Theile des Auges angehört. Ieh wählte diesen Theil, weil ich hier, olne die Zeichmmg zn gross machen zu müssen, den ganzen schnitt abbilden konnte. Nun sieht man aber' an duch das centrum der Cornea gelegten Meridionalschnitten, diss gegen den Rand hin nicht ıแr, wie schon erwälnt, die Krïnmung der Corneafacetten zunimmt, sonder'n anch, diss die Krystallkegel kïrzer werden (ich mass \%. B. 0.055 gegenuiber 0.082 Hillimeter im (entrum), der ganze dioptrische Aplarat also stärker wird, das Bild näher liegt.

Ls ist ïbrigens nicht ansgeschlossen, dass noch ein anderer Unstand in spiele ist. Jedernam weiss, um wie viel z. B. ein weisses Blutkörperchen, das wir im Blutgefässe eines durch Alkohol gehı̈rteten Präprarates finden, kleiner erscheint als ein firsches. Die Schrumpfung ist eine sehr bedentende; eine Tolumabnahme liamn also wohl trotz der stïtzenden Chitingerïste anch durch die Präparirung des Auges bis zur Schnittfähigkeit stattgefunden hiben, wemn sie allch nicht so hochgradig ist, wie bei einem weissen Blutkörperchen.

Ich führe diese Dinge hier an, weil es mahe gelegen wäre, alls der Lage des Bildchens einen Schluss anf die Lage der empfindlichen Schichte innerhalb der dicken Retina zu ziehen und diese auf' solche Weise genaner zu bestimmen. Mag sein, dass es einmal gelingen wird.

Obwohl physiologisch olne Bedentung, will ich doch das in. theoretischer Beziehung nicht belauglose optische Curiosum hier noch hervorheben, dass das in der geschilderten Weise zugerichtete Auge, von der verkehrten Seite betrachtet (d. h. die mit der Glycerinlösung bedechte concave Seite ist dem Objecte, die an Luft grenzende convexe dem Mikroskope zugewendet), anch ein Bildchen zeigt. Es liegt merklich an derselben Stelle, wie das normale Netzhautbild, also vor dem optischen Alparate, hat dieselbe Grösse, ist aber verkehrt.

2. Veranschanlichung der Dioptrik des Lampyrisanges.

Zunächst will ich die Dioptrik des Lampyranges, wie ich sie in meinen Studien gefunden labe, darlegen, der Nachweis für die Richtigkeit dieser meiner Anschaumg und der Weg, wie ich zu derselben gelangt biu, soll im nächsten Abschnitte mitgetheilt werden.

Wrürde die Müller'sche 'Theorie in ihrer ursprünglichen Form fï̈r das Lampyrisange richtig sein, so mïsste man bei Eụstellung des Mikroskopes auf die Spitze der Krystallkegel das aufrechte Bild des Objectes 
zu sehen bekommen. Nun ist das andeutungsweise allerdings der Fall, das Bild in seiner weit rollkommeneren Form liegt aber, wie wir sahen, beträchtlich hinter den Spitzen der Krystallkegel. Dieses liesse sich unter einigen Voraussetzungen noch mit der Theorie vereinigen.

Gänzlich unvereinbar mit dieser aber ist das Resultat folgenden Versuches. Ich wähle als abzubildenden Gegenstand zwei Lichtpunkte (z. B. zwei Kerzenflammen), und richte das horizontal gestellte Mikroskop, auf dessen Objecttisch sich das Lampyrisange, in der oben angegebenen Weise zugerichtet, befindet, gegen deu Mittelpunlit der Verbindungslinie der beiden

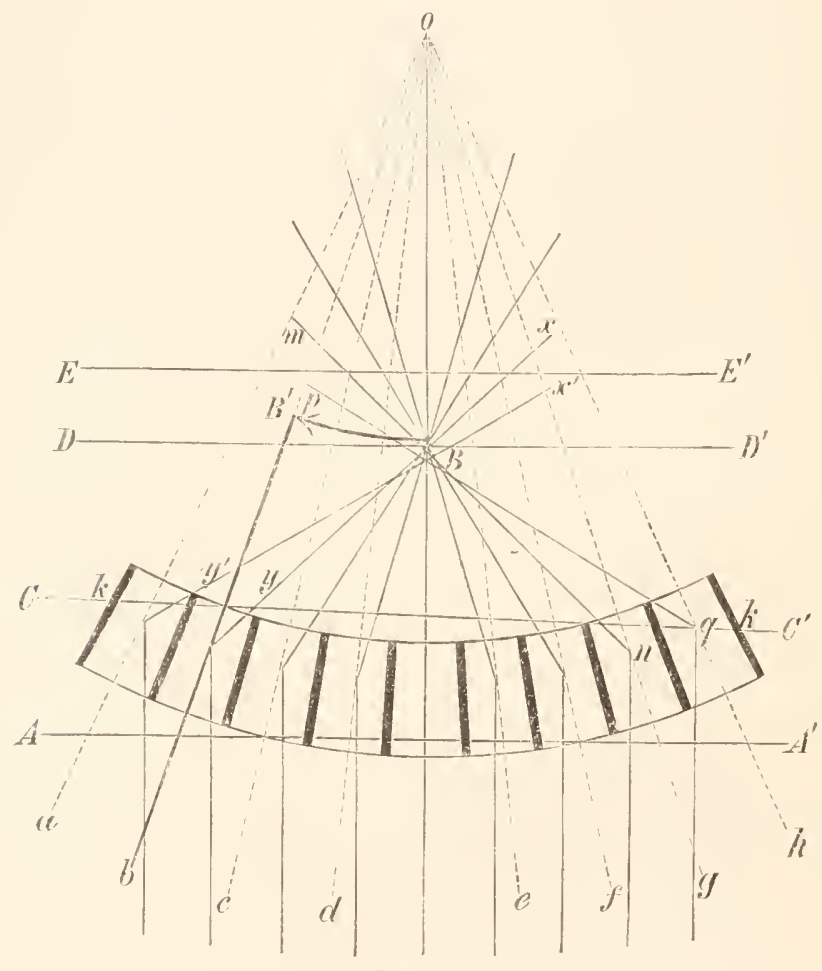

Fig. 11.

Kerzen. Es befindet sich kein brechendes oder reflectirendes Medium zwischen dem Objecte und der convexen Corneatläche. Stelle ich auf die Ebene des Netzhauthildes ein, so sehe ich natiirlich zwei Lichtpunkte, die Bilder der Kerzenflammen. Nähere ich die Focalebene des Mikroskopes der Cornea, so gewahre ich die optischen Querschnitte der Strahlenliundel, welche bei ihrer Vereinigung die beiden Bildpunkte gaben. Und zwar gehört jedem Punkte eine Schiar von Strahlen an; jeder dieser Strahlen kommt aus einen Krystallkegel. Sind die beiden Ker"yenflammen in der passenden Entfernung, so gewahrt man, dass aus der Mehrzahl der beleuchteten Krystallkegel je zwei Strahlen hervordringen, von denen der eine dem einen Bildpunkte, der andere dem anderen Bildpunkte zustrebt. Ein vom 
rechten Objectunkte in den Krystalleegel eindringender strahl wird also nach dem lechten Bildpunte abgelenkt, einvom linken Objectpukte eindringender strahl wird in demselben Krystallkegel dem linken Bildpunkte zugelenkt. Mit anderen Worten: Ein nnter einem Winkel gegen die Axe des Krystallkegels in denselben eindringender Strahl schliesst bei seinem Austritt wieder einen Winkel ein; eintretender, austretender Stralıl und Axe liegen in einer Ebene; der austretende aber anf derselben Seite der Axe, wie der eintretende.

Hiernach sollte man glauben, es handle sich mm eine heflexion im Krystallkegel. Dieses trifft aber nicht zu, vielmelı beruht der geschilderte Effect auf Brechung. Elıe ich auf die Art dieser näher eingehe, will ich an der Hand der Abbildungen das Gesagte anschanlicher zu machen suchen.

Benützt man als Object einen Lichtpunkt, der in grosser Entfernung ist, so dass die von ilm ausgelıenden Strahlen, wem sie ans Auge gelangen, als parallel betrachtet werden kömnen (was wegen der Kleinheit des Krïmmungshalbmesser's der Cornea sclon fïr kurze Distanzen der Fall ist), so lässt sich der geschilderte optische Vorgang durch Holzschnitt Fig. 11 versimnlichen. Derselbe zeigt Auge und Stralilen in der Stellung, wie sie sich bei Untersuchung unter dem Nikroskope und horizontaler Stellung des Objecttisches befinden. $k_{i} k$ stellen schematisch die einzelnen Facettenglieder dar, wie ich das "Einzelange" der Autoren lieber nennen will, oa bis oh ihre Axen, die ansgezogenen senkrechten Limien die einfallenden Strahlen, welche in jedem Facettenglied in der geschildèten Weise aligelenkt werden und sich in $B$ zu dem Bildpunkte vereinigen. $O$ ist der Kriummungsmittelpunkt des Auges. Man sielit, dass ein ginz analoges Bild $\left(B^{\prime}\right)$ ron einem zweiten Objectpunkte entstehen muss, der z. B. in der Verlängelung von $O b$ liegt und an dem sich theilweise dieselben Krystallkegel betheiligen werden, die das Bild $B$ entworfen-haben. Man sieht zugleich auch, dass das Bild auflecht ist, wovon seine Grösse abliängt u. s. f.

Stellt man das Mikroskop auf eine Ebene $\left(A A^{\prime}\right)$ ein, die (im Sinne des Ganges der Lichtstrahlen) vor der Cornea liegt, dieselbe tangirt, oder vielleicht schon in die vorderen Antheile der Krystallkegel fällt (es ist das, wie oben hervorgehoben, nicht mit Sicherheit zu bestimmen), so bekommt man das in Fig. 2, l'af. I, wiedergegebene Bild zu sehen. Es ist dasselbe Bild, das ich schon in meiner ersten Abhandlung beschrieben labe, und stellt die optischen Querschnitte der von dem leuchtenden Punkte ausgehenden Strahlen in der Focalebene des Mikroskopes diu: Selbstrerständlich sind es nicht die einfallenden Strahlen selbst, sondern die Verlängerungen jener Strahlen $p q, m n \ldots$. Fig. 11), welche, nachdem sie den Krystallkegel passirt haben, das Bild zusammensetzen.

1 Doch verlegte ieh damals die Ebene, in der man es sicht, etwas weiter nach rückwärts. 
Bewegt man die Stellschnabe anf und ab, so bleibt das Bild eine rerhältnissmässig grosse strecke wesentlich vou der gleichen Art, nur erkennt mall an der gegenseitigen Annäherung oder Entfermung der lichtpunkte, dass man es in der That mit convergirenden Strahlen zn thun hat. Hat man zwei Liehtpunkte als Object verwendet, so ist jeder der Punkte doppelt. Die Fig'. 2, 'T'at. T, zeigt weiterhin an den meisten der' Punkte Andentungen von Bengungselscheinnngen, wie solche mnter den obwaltenden Umständen zu erwarten sind.

Terschiebt man die Focalebene des Mikroskopes nach riickwärts $\left(C^{\prime} C^{\prime}\right.$ Holzschnitt Fig. 11) bis in die Nähe der Spitzen der líystallkegel, so greht das Bild der Fig. 2 allmählich in das der Fig. 3, Tat. I, über. Aus den hellen Punkten sind Kreise geworden, die meistens ein besonder's helles Innere und einen oder zwei mehr oder weniger deutliche Höfe haben. Auch hier zeigen sich Interferenzerscheinungen, die in der Zeichnung nur angedentet sind. Terwendet man bei dieser Einstellung zwei Lichtpunkte als Gegenstand, so tritt keine Verdoppelung der hellen Kreise ein.

lch glaube, dass der helle Kern jedes dieser rundlichen Flecken den physiologisch wichtigen Strahlenintheil enthält, und dass die hellen Höfe durch das Licht gebildet sind, welches normalerweise im Pigment absorbirt wird, wenn es iiberhant in solcher Menge aus dem hrystallkegel heransdringt. Bei rerschiedener Einstellung kamn man nämlich bemerken, dass sich das licht der Höfe nach allen Richtungen diffus zerstrent. Auch habe ich mich überzengt, dass dieses falsche Licht an ganz firisch präfarirten Angen in weit geringerem Masse vorlanden ist, so dass Fig: 3 der Fig. 2 sehr ähnlich wird, und mu die Lichtpunkte näher stehen.

Bei weiterer Verschiebung der Focalebene nach rückwärts trifft dieselbe die Strahlen zwischen dem dioptrischen Apparate und dem Bildpunkte. 1)abei rücken die Kreise der Fig. 3 immer enger zusammen und bilden zierliche Interferenzfiguren. Wemn man jetzt wieder zwei Lichtpunkte als Gegenstand verwendet, so gewahrt man wieder die Verdoppelung an ihnen. Schliesslich nähert sich das Bild bis zur Einstellung $D D^{\prime}$ (Fig. 11) mehr'und melı dem Bildpunlite, der in Fig. 4, 'Taf. I, dargestellt ist. Auch an ihm sieht man, entsprechend der regelmässigen Sechseckstelhng der Krystallkegel, noch Bengungserscheimngen, welche an die Streifung ron Plenrosygma angulatum erimner'n. Stellt man endlich anf eine linter dem Bilde gelegene Ebene $E E^{\prime}$ (Fig. 11) ein, so geht der Bildpunkt in einen Zerstreungskreis anseinnnder, Fig. 5, T'rf. 1, der die Interferenzfigur eines dreistrahligen Sternes, sowie andere Andeutungen von Diffirationsspectren erkennen lässt.

Ich muss bemerken, dass die Abbildungen Fig. 2 bis 5 alle ron einem Auge stammen, dessen Meridian in Bezug auf die Scchseckstellumg der Krystallkegel bei jeder Zeichnung dieselbe lage hatte, und dass das Ange sich moter den genannten, der Norm entsprechenden Verhältnissen befand. Als Lichtquelle diente ein 1 Centimeter grosser, runder Aus- 


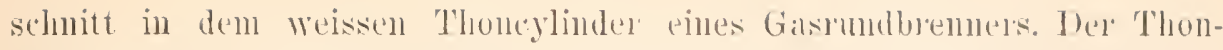
cylinder wall mit einen schwarzen Blecheylinder, dor einell entsplechenden Alssclunit latte, ïberkleidet.

Fs entwint also das Lampyrisillge ein antiechtes bild anch durch simminng der stıahlen, we das Wirbelthierange; nelmen wir die Geradu, welche einen beliebigen Plnkt des Gegenstandes mit sejnem bille verbindet, als Axe des Anges an, so wird anch hier der parallel der Are einfallende Lichtstruhl nmsomehr von seiner lichtung abgelenkt, je weiter er rou der Axe entfernt ist (jenseits einer gewissen Grenze nimmt el ïberhanpt an der Bilderzengung nicht melı theil), anch hier bheibt der gebrochene Strahl in der durch den einfallenden Strahl und das Finfallsloth (Krystallkegelaxe) gegebenen Ebene u. s.. f. Del dioptrisclue Aploarat, der das bewirkt, ist die Smme der mit der Cornea rerwachsenen Krystallkegel in ilner radiären Anordnmg anf einer Kugeloberfläche.

Es flagt sich nun, welchen dioptrischen Ban ein Krystallhegel (mit Eimschluss seiner Corneafacette) lraben nuss, um jene Wirkung zu elzielen.

Toh elinnere dalan, dass eine in wesenthichen Punkten goleiche Wirkung wie del Fiystallkegel jedes Palal conrexliusen ansiibt, das, um die summe ihrer Bremmeiten roneinander entfernt, an derselben Are angeordnet ist. Strahlen, welche, ans grosser Entfelmung kommend, geueigt gegen die Axe anf die erste Linse auffallen, treten ans der zweiten Linse unter einem Minkel mit der Axe ans, der un so grousser ist, je grösser der Winkel war, unter dem sie eingetreten sind. Sie liegen dabei in der durch die Linsenaxe und den einfallenden Strahl bestimmten Ebene und sind unteremander parallel. Als solche bilden sie nach der gewölulichen Auffassung natïrlich in endlicher Entfernoung kein Bild; denkt man sich das parallelstrahlige Bündel aber von mikroskonisch kleinem Querschnitt, so begreift man, dass duch /usammentritt vou vielen solchen ein Bildpunkt entstelıen kann, da dann die anderen Dimensionen des Bildes gross gegenïber jenen Querschnitt sind.

So einfach wie bei dieser Linsencombination sind nun die Terhältnisse bei den Kirystallkegeln wohl nicht; ich hatte anfangs geglanbt, dass die convexe Corneafacette die Rolle der ersten Linse jenter Linsenconbination, und die Wölbung der hrystallkegelspitze die liolle der zweiten Linse sprelt. Es ist das aber nicht der Fall, wie nich ein ringelendes Studium gelehrt lat. Vielmelı berulit die Wirkung des lirystallkegels, wenigstens grossentheils, auf seinel Schichtung, die ihn zum Linsencylinder stempelt. Selbstrerständlich werden die gekrimmten Flächen diese Winkung unterstitzen. Und zwal handelt es sich hier mu einen Linsencylinder, dessen Länge gleich ist der Summe seiner Bronnweiten.

Tch liabe in Holzsclmitt Fig. 12 den jedenfals sello nalıe lichtigen Verlanf zweier Strahlenbiindel in cinem Facottengliede gezeiclınet. Derselbe gestaltet sich stwas anders, als ich dies iu meinel Mblandlung 
(Das Netzhautbild des Insectenauges) dargestellt hatte. Schon damals musste ich die Vermuthung aussprechen, dass die Divergenz der homocentrischen Strahlen nach ihrem Austritte aus dem Facettengliede im Leben nicht vorhanden sei; ich hatte sie damals bei einem Ange, das lange in Alkohol gelegen war, gefunden, und konnte nur aus der Erinnerung mittheilen, dass ich sie an frischen Augen nicht bemerkt hatte. Seitdem hatte ich Gelegenheit, wieder frische Augen zu untersuchen, und

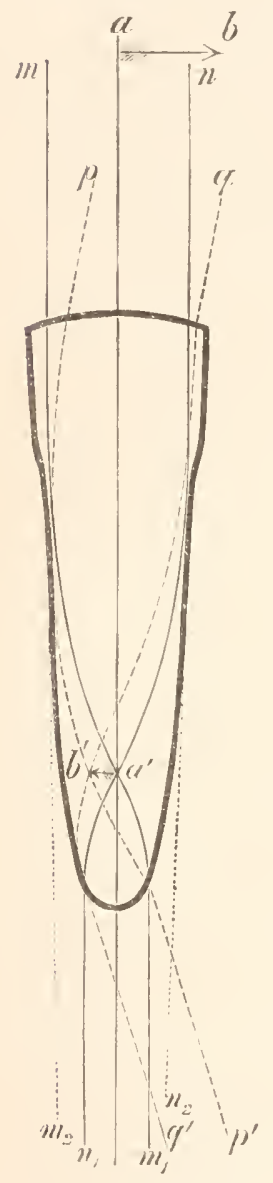

Fig. 12 . hiernach ist die Zeichmung Fig. 12 angefertigt. Jene Divergenz hatte bewirkt, dass man im vorderen Theile des Krystallkegels ein, natürlich virtnelles, verkehrtes Bildchen der äusseren Objecte zu sehen bekam; es beluhte offenbar daranf, dass durch das Liegen im Alkohol die Differenzen der Brechungsindices im Linsencylinder vermindert, die ganze Brechkraft also eine geringere geworden war. Ich erwähne dieses Anftreten von verkehrten Bildern im Innern der Kegel bei abgelegenen Augen, mit Rïcksicht auf etwa vorkommende Nachuntersucliungen.

Sei $a b$ ein Gegenstand in grosser Entfernung, so dass die von einem Punkte desselben ansgehenden Strahlen gegeniiber den im Krystallkegel vorkommenden Winkelmassen als parallel betrachtet werden können. Die Strahlen $m$ und $n$ mögen die Grenzstrahlen des vom Fusspunkt (a) des Pfeiles ausgehenden und in das Facettenglied eindringenden Bündels sein. Sie würden nach der Messung, die ich in einem speciellen Fall über die Krïmmung der Hornhautfacette gemacht habe, und unter Zugrundelegung des an der Hornhant des Hydrophilus ${ }^{1}$ gefundenen Werthes für den Brechungsexponenten sich in Folge der Brechnng an der gekrïmmten Fläche erst beträchtlich weit hinter dem Krystallkegel zu einem Bilde vereinigen (siehe die punktirten Linien $m_{2}$ und $n_{2}$ ). Vem ich in anderen Fällen anch kleinere Krïmmungshalbmesser der Corneafacette gefunden habe, so kommt das hier nicht in Betracht. Die durch diese erste Brechung schwach convergent gemachten Strahlen werden dann in Folge der Linsencylinderwirkung bei $a^{\prime}$ zu einem Bilde vereinigt. Die vom Punkte $b$ des Pfeiles ansgehenden Strahlen $p$ und $q$ werden in anloger Weise im Punkte $b^{\prime}$ vereinigt. Das Bild $a^{\prime} b^{\prime}$ kann aber als solches nicht gesehen werden, da zwischen ihm und dem Mikroskope noch der Lintere Theil des Krystallkegels liegt. Wäre $a^{\prime}$ nicht genau der erste Brempunkt dieses letzten Antheiles des Krystallkegels, sondern läge diesel'

1 Den Brechungsindex der Lampyriscornea konnte ich wegen ihrer Dünnheit nicht mit genügender Genauigkeit messen. 
etwas weiter vorn, so verlassen die von $a^{\prime}$ weiter verlanfenden strahlen $m_{1} n_{1}$ den Kegel schwach divergent, so dass das oben 'rwähnte virtuelle, der Beobachtung zugäingliche Bild entstiinde. Jie Lage des Bildes a' $b^{\prime}$ kamn ich natürlich nicht genau angeben, die Zeichmug soll vielmelı nur zeigen, dass es in der linteren Hälfte des Kegels liegen miisse. Uebrigens habe ich dieses Bild auch, wie ich später des Näheren mitheilen will, der directen Beobachtung zugänglich gemacht, indem ich die Spitze des Krystallkegels abschnitt. Es ist ja klar, dass man das Bild sofort sehen muss, wenn man den Kegel in der Ebene $a^{\prime} b^{\prime}$ abkappt und un von hinten darauf sieht.

Man sieht demmach an der Zeichmung die Ablenkung des unter einem Winkel einfallenden Strahlenbündels ( $(q)$ nach derselben Seite der Axe, von der es gekommen ist, man sieht, dass der Winkel, den es nach der Brechung mit der Axe einschliesst, $1 \mathrm{~m}$ so grösser ist, je grösser der Winkel war, den es vor der Brechung mit dieser gebildet lat. Dass sich unter diesen Umständen die Strahlenbïndel, welche von einem Punkte ausgehen und verschiedene Krystallkegel passirt liaben, wieder in einem Punlite vereinigen mïssen, geht hieraus freilich noch nicht hervor, wird aber in einem der folgenden Abschnitte gezeigt werden. Man sieht weiter unmittelbar, welche Bedeutung es hat, dass die Natur die Wirkung des kleinen, auf Unendlich eingestellten astronomischen Fernrohres, als welches sich ein solches Facettenglied demmach herausgestellt hat, nicht nur auf den zwei brechenden gekrümmten Flächen bernhen liess, sondern das Princip der Linsencylinder zu Hilfe nahm. Wïrde die Corneafacette und die Spitze des Krystallkegels von hinlänglich kleinem Krïmmungshalbmesser sein, so könnte der in Fig. 12 abgebildete Krystallkegel im Wesentlichen dasselbe wirken, aber man erkennt sofort, dass Stralılen, die unter so grossem Winkel gegen die Axe wie der Strall $p$ einfallen, für die Erzeugung des Bildes schon nicht mehr in Betracht kämen, es muisstc den der Brechung:sindex eine ganz enorme Grösse haben. Kurz, es verhalten sich in diesem Facettenglied die Dinge so, wie ich es in der physikalischen Einleitung von einem Linsencylinder geschildert habe, der die oben gemannte Länge liat.

Ich will hier noch liervorheben, dass ich nach den angegebenen Principien ein Schema eines Insectenauges angefertigt habe, das die dioptrischen Vorgänge veranschaulicht, und das ich zur experimentellen Prüfung der später zu entwickolnden Formeln ïber Grösse, Ia ge etc. der Bilder verwendet habe. 1 Es besteht aus zeln Paaren von Convexlinsen (Brillengläser'n). Jede Linse hat eine Brennweite ron 2 \%oll und ist mit ihrem Partner in einer gegenseitigen Entfermung von 4 Zoll auf einem Brettchen befestigt. Dieses Paar repräsentirt den dioptrischen Apparat eines Facettengliedes. Die zehn Paare sind in einem Kreisbogen von 75 Centimeter Radius (bis zum gemeinschaftlichen Brennpunkt je zweier Linsen gemessen)

${ }^{1}$ Dasselbe ist in etwas modifieirter Form känflich zn hahen hei Juenoir u. Forster, Wien, IT. Waaggasse 5. 
angeordnet. Das schema entwirft anfrechte Bilder, deren Schärfe freilich nicht gross ist, da das ans jeder Linse anstretende Lichtbündel den Querschnitt der Linsenfläche hat, und an denen sich für jeden Punkt des Gegenstandes etwa fünf Linsenpaare betheiligen. Man kann an dem Schema die Aenderung in der Lage und Grösse des Bildes für verschiedene Entfermungen des Gegenstandes demonstriren u.s.w., kann die Schärfe des Bildes erhöhen. wenn man vor die Linsen Diaphragmen setzt. Nur nimmt dann die Anzahl der Linsenpaare ab, die sich an der Erzengung eines Bildpunktes betheiligen.

Was endlich das erwähnte virtnelle, rerkehrte Bildchen betrifft, das man sieht, wenn man das normal zugerichtete ausgepinselte Auge mit seiner concaven Seite dem Gegenstande zuwendet und von der Cornea-

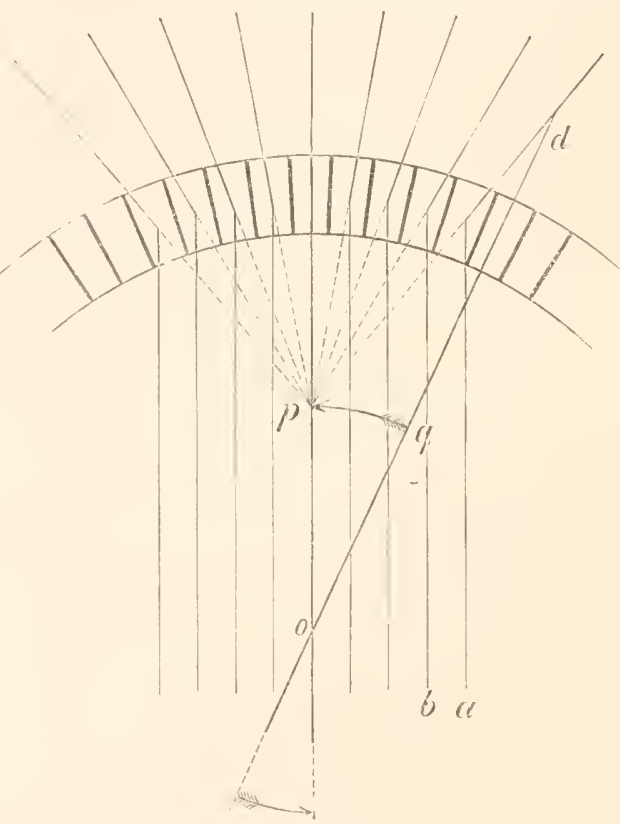

Fig. 13.

seite betrachtet, und welches an der Stelle des normalen Netzhantbildes liegt, so erklärt sich dessen Zustandekommen ans der Fig. 13 mmittelbar. Alle homocentrischen, auf die Krystallkegel einfallenden Strahlen $(a, b \ldots)$ werden eben im Krystallkegel in der geschilderten Weise ron ihrem Wege abgelenkt, so dass dieselben divergirend austreten und ihre Verlängermugen sich in einem Punkte (p) schneiden. Strahlen, die, von einem anderen Punkte des Gegenstandes ansgehend, in einer anderen Richtung (z. B. $\left.o{ }^{\prime}\right)$ anf das Auge fallen, vereinigen sich in einem anderen Punkte $(q)$. Die beiden Punktpare bilden mit dem gemeinschaftlichen Trimmnngsmittelpunkte des Anges zwei ähnliche Dreiecke mit Scheitelwinkeh.

Beniitzt man anch in diesem Falle als Gegenstand einen lenchtenden Punkt, der also, in grosser Entiermung vor den Spitzen der Krystallkegel liegend, sein bild in der Gegend der Netzhant entwirft, nnd stellt das an der 
Conneaseite belindliche Mikroskop zo tief ein, so dass die Ebene des dentlichen Sehens (im simne des Ganges der lichtshahlen) vor die Netzlautebene fällt, so sicht man wieder den dreistrahligen stern der Fig. 5, 'Taf. I. Bei allmählicher Hebung des 'Tubus taucht das virtuelle Bild des Lichtpunktes anf (Fig. 4, l'af. 1), dam das Bild der Fig. 3 und endlich die optischen Querschnitte durch die Strahlenbindel der einzelnen Krystallkegel, wie sie in Fig. 2, Taf. I, dargestellt sind. Man sielt also dieselben Bilder wie bei der normalen Functionsweise des Anges, jedes anch an demselben Orte, soweit dies beurtheilt werden kann.

\section{Experimentelle Prüfung des Stralılenganges im Lampyrisauge.}

Im Nachstehenden sollen jene Thatsachen angeführt werden, durch welche ich mich iiberzengt habe, dass die mitgetheilte Auffassung der Dioptrik des Lampyrisanges zutreffend ist oder, richtiger gesagt, durch welche ich auf die mitgetheilte Deutung der optischen Vorgänge geleitet worden bin.

Bei den folgenden Versuchen ist, wenn nicht ansdritcklich etwas Anderes gesagt wird, vorausgesetzt, dass das abgepinselte Lampyrisange, mit der vorderen Fläche an Lnft grenzend, mit der linteren Fläche in eine Glycerinlösung vom Brechungsindex 1.346 tauchend, direct nach dem abzubildenden Gegenstand gerichtet war, so dass das Licht nur durch Luft und, olne eine Reflexion zu erleiden, vom Objecte bis zur cornea gelangte. Das Bild wurde durch ein Deckgläschen oder eine Glimmerplatte hindurch bei Horizontalstellung des Mikroskopes beobachtet. Es wurden also die Verhälmisse hergestellt, welche den normalen so nahe als möglich kamen.

Beniitzt man als Gegenstand einen hellen Punlit, stellt auf dessen Bild (Fig. 4, Taf. I) ein und schiebt einen undurchsichtigen Schirm ron einer Seite her ïber das Auge, so verschwindet das Bild, indem es in allen seinen Theilen gleichzeitig dunkler wird; thut man dasselbe, während man auf eine vor dem Bildpunkte gelegene Ebene einstellt (entsprechend Fig. 2 und 3, Taf. I), so verschwinden die hellen Flecken oder Punkte. welche den einzelnen Facettengliedern entspreclen, zuerst anf der Seite, von welcher der Schirm kommt; stellt man aber anf eine hinter dem Bilde gelegene Ebene ein, so verschwindet der Zerstrenungskreis (Fig. 5, Taf. J) zuerst auf der dem anriickenden Schirm entgegengesetzten Seite. (Tc/s beschreibe hier das thatsächliche Verhalten, indem ich ron der Umkelırmg des Bildes durch das Mikroskop absehe.) In diesen Bezichungen also verlält sich Bildpunkt und Zerstreumgskreis ganz so wie bei einer Consexlinse, nur dass man beim Insectenange die einzelnen strahlen unter dem Mikroskope sehen kann, wie sie convergirend den Bildpmnkt bilden. Wir pflegen dieses sonst durch eine Zeiolnung oder in einem Schema durch Fäden anschaulich zu machen, hiep sieht, man es mmittelbar. 
Hierans, sowie aus der obeu beschriebenen directen Beobachtung durch Einstellung geht hervor, dass der Bildpunkt in der That dadurch entsteht, dass die durch eine Gruppe von Krystallkegeln hindurchgeleiteten Strahlen sich in einem Punkte schneiden.

Verschiebt man den Objectpunkt, so wandert der Bildpunkt im gleichen Sinne, woraus folgt, dass der Ort, an welchem sich die Strahlen, die durch verschiedene Krystallkegel gegangen sind, schneiden, nicht etwa der Krümmungsmittelpunkt des Gesammtanges ist, wie dies nach der ursprünglichen Mïller'schen Theorie der Fall sein miisste. Dabei ist noch Folgendes zu bemerken. Stellt man auf die den Spitzen der Krystallkegel naheliegende Ebene der Fig. 3, Taf. I, ein, so gewahrt nan bei der Verschiebung des Objectpunktes ein successives Erlöschen der einzelnen hellen Flecke, wobei diese selbst aber keine Verschiebung in der eingestellten Ebene erleiden. Verschiebt man die Focalebene des Mikroskopes von da aus nach rorne (Fig. 2, Taf. I), so bewegen sich die einzelnen Lichtpunkte entgegengesetzt der Bewegungsrichtung des Objectes; lühlert man hingegen von der erstgenannten Stellung aus die Focalebene dem Bildpunkte (so dass ein zwischen Fig. 3 und 4, Taf. I, liegendes Bild sichtbar wird), so verschieben sich die den Facettengliedern entsprechenden lellen Flecken im gleichen sinne mit dem Objecte.

Ich hatte zuerst hierans gefolgert, dass in der Ebene von Fig. 3 oder in ihrer nächsten Nähe eine Spiegelung stattfinde, etwa durch totale Reflexion in dem Sinne, wie ich das in meiner ersten Abhandlung mitgetheilt habe. Dem ist aber nicht so. Vielmehr begegnet man hier dem Unterschiede wieder, der von den optischen Phänomenen der Atmosphäre her bekannt ist. Ein von einem Punkte der Erdoberfläche ansgehender Lichtstrahl kamn an oberen Schichten der Atmosphäre reflectirt werden und so in das Auge des Beobachters gelangen. Dann sieht dieser das Object löhher, als es wirklich liegt und verkehrt („Luftspiegelung"). Der Strahl kann aber auch dadurch, dass mit der Höhe der Luftschichte ihr Brechungsindex abnimmt, im Bogen gebrochen und schliesslich auch dem Auge des Beobachters zugefühnt werden. Dieses sielit dann das Object auch höher gelegen, aber aufrecht ( "Kimmung"). ${ }^{1}$ Benützt man nämlich als Object zwei Lichtpunkte, so sieht man in der Ebene der" Fig. 3 dasselbe Bild wie bei Beniitzung eines Lichtpunktes. Dreht man die Mikrometerschraube im Sinne der Einstellung naclı vorne, so geht jeder lichte Kreis der Fig. 3 in zwei helle Flecken anseinander, welche die Querschnitte zweier Strahlen darstellen, die nach vorne untereinander divergiren. Verdeckt man nun den linken Objectpunkt, so verschwindet

1 Vgl. Joh Mïller, Kosmisele Physik. 4. Anfl. 1875, S. 372 u. ff. Zur Erkliumng dafïr, dass ein Beobachter die Kimmung eines Objectes sehen könne, das mit ilım in derselhen Horizontalebene liegt, glaubte Müller (S. 375) Iuftsehichten anuehmen z.n miissen, die nach unten convex sind. Diese Anmahme wird nach dem, was wir num vom Strahlengang in Linseupylindern nnd ïhnlich geschichteten Körpern wissen, iiberflüssig. 
der rechte helle Fleck und ungekehrt. Bewegt man die Mikrometerschraube im Sinne einer Annäherung der Focalebene von der Ebene der Fig. 3 nach dem Bildpunkte der Fig.4, so gewahrt man dasselbe Plïnomen des Auseinanderweichens je zweier Strahlen, von denen jeder seinem Bildpunkte zustrebt. Verdeckt man jetzt den linken Objectpunkt, so verschwindet der linke Strahl.

Daraus gelıt hervor, dass man es hier mit einem Phänomen der Brechnng, nicht mit einer Reflexion zu thun hat. Man kamn dasselve an meinem Schema des Lampyrisanges sehr gut demonstriren, indem man zwischen die beiden Linsen eines Facettengliedes seitlich von der Axe und parallel zu derselben einen Spiegel anfstellt, nnd nun die aus dem Linsenpaare austretenden Lichtbiindel beobachtet, eimmal unter Hitwirkung des Spiegels, das anderemal ohne diesen.

Soviel über die Zusammensetzung des aufrechten Netzhautbildes durch die aus den Krystallkegeln austretenden Strahlen. Ich labe nun noch meine Erfahrungen über den optischen Bau des einzelnen Krystallkegels mit Einschlnss seiner Cornea zu besprechen.

Legt man das abgepinselte Ange in einen Flüssigkeitstropfen hinein, so dass es allseitig von Flïssigkeit umgeben ist, und beobachtet unter gewöhnlicher Verwendungsweise des Mikroskopes, so bekommt man das aufrechte Netzhantbild nicht zu sehen. Es ist das selbstverständlich, da ja jetzt die Brechung an den beiden Endflächen geändert ist, das eingetretene Strahlenbïndel also anch nicht mehr annähernd parallelstrahlig den einzelnen Krystallkegel verlässt. Wohl aber sieht man jetzt in ganz ausgezeichneter Weise die verkehrten Bildchen der Facettenglieder, die man unter normalen Verhältnissen nicht sieht. Hat man eine schwach lichtbrechende Fliissigkeit gewählt, so können diese Bildchen immer noch von der Brechung an den Endflächen herrïhren.

Lege ich aber das Ange in Anilin, dessen Brechungsindex =1.58 ist, so ist wohl nicht daran zu zweifeln, dass eine sammelnde Wirkung der Endflächen ausgeschlossen ist. Ich bestimmte seinerzeit, ehe ich das Princip der Linsencylinder gefunden hatte, den Brechungsindex der Krystallkegel von Hydrophilus zu

$$
n=1.559 \text {. }
$$

Falls auch bei diesem Thiere der Krystallkegel einen geschichteten Bau hat, ist diese Angabe noch zu gross, so dass wohl anch beim Lampyrisange durch Anilin die Brechung an den Endfiächen sicher beseitigt ist. Trotzdem entwirft aber noch immer jedes Facettenglied sein verkehrtes Bildchen. Liegt das Ange mit den Spitzen der Krystallkegel nach oben gerichtet (es ist mit einem gestiitzten Deckgläschen bedeckt und ruht auf einem gewöhnlichen Objectträger), so sieht man das Bildchen oberhalb jener Ebene, die man dem Aussehen nach als die Spitzen der Krystallkegel tangirend betrachten muss. Es wohnt also dem Facettenglied, abgesehen von seinen Endflächen, noch eine bilderzengende Wirkung inne, die wohl nur auf einen geschichteten Bau desselben bezogen werden kann. 
Stellt mall unter den genanuten Verlältnissen anf eine Ebene ein, welche vor (bei der gewöhnlichen Betrachtmgsweise mit dem Mikroskope unterlialb) der Cornea liegt, so gewalut man zu seiner Ueberraschung abelmals, anscheinend jeder Facette entsprechend, ein Bildchen. Dasselbe ist fieilich viel weniger dentlich als das elste, doch ist an seiner Existenz, insbesoudere wem man einen bewegten Gegenstand zwischen Auge und Mikroskopspiegel bringt, nicht zu zweifelı. Dieses Bildchen ist nun aber ein aufrechtes. Die Art, wie es zu Stande kommt, zu kennen, scheint mir nicht von grosser Wichtigkeit, da es physiologisch bedeutungslos ist. Walnscheinlich ist sie die folgende. Bei der Aufsicht auf ein Facettenglied sieht man den optischen Querschnitt des Krystallkegels als kleinen Kreis, und bei etwas tieferer Einstellung den der Colneafacette als grösseren concentrischen Kreis. Zwischen den Peripherien der beiden Kreise liegt eine Zone, die ihrem Aussehen nach keine starken Brechungen hervorruft. Sie entspricht der Mantelfläche des breiteren Kegelantheiles. Als solche kann sie ihrer Gestalt nach, und da sie von einem stärker brechenden Medium umgeben ist, als Zerstreumngslinse wirken und so das aufrechte, vorne liegende Bild erzeugen, während der eigentliche Krystallkegel das rerkelnte hinten liegende Bild als Sammellinse entwirft. Es schien mir wenigstens, dass beim Einstellen des Mikroskopes die ersten Spuren des aufrechten Bildes in jener Zone, die des verkehrten im inneren Kreise zu sehen waren. Nicht mmöglich wäre es auch, dass die in der Nähe der Cormeaebene gelegënen Stellen, an welchen je drei Facettenglieder zusammenstossen, dadurch als Concavlinsen wirken, dass schon hier an der Axe jedes Facettengliedes das liöchste Brechungsvermögen herrscht, so dass von der Mitte eines solchen Zwischenlaumes aus der Brechungsindex allmälılich (freilich nicht in Kreiscylinderschichten ansteigt. Bei der Undentlichkeit des Bildes und seiner Lage unter der Cornea ist seine Stellung zu den einzelnen Facettengliedern nicht sicher zu bestimmen. Ich halte die erste Auffassung fïr die wahrscheinlich richtige.

Die Ueberzeugung davon, dass im Innern des Krystallkegels das in Holzschnitt Fig. 12, S. 44, abgebildete verkehrte Bildchen der äusseren Objecte liegt, gewann ich ausser durch das Mitgetheilte auf folgende Art. Ein Auge wird in der aus der histologischen Technik bekannten Weise in Celloidin eingebettet und von demselben parallele Schnitte angefertigt, deren erster dio Cornea tangential triff. In einigen der folgenden Schnitte hat man näherung: weise kleisrunde Abschnitte des Auges vor sich, in deren Centrum oder in dessen Umgebung nu die hinteren abgestutzten Enden der Krystallkegel liegen (durch das Celloidin in sitı erhalten), weiter nach aussen kommt dann immer melır und melur von vorderen Theile des Krystallkegels dazu; bei passender Dicke des Schnittes ist das lintere Ende desselben aber schon abgestutzt, wenn die Corneafacette des Kegels an demselben erhalten ist. An der Peripherie des Schnittes sind also nur die 
vordersten Theile der Facettenglieder als runde, durch ihren optischen Effect erkennbar'e Scheiben zu sehen.

An dem mikroskopischen Schnitte, von dem ich hier als von einem ausgewählten Beispiele spreclien will, war kein vollständiger Kegel volhanden, da die Dicke desselben geringer war als die Länge eines Krystallkegels. Da das Auge iiberdies in Celloidin lag, dessen Brechungsindex ich zwischen den Werthen von 1.561 und 1.565 fand, ${ }^{1}$ konnte die Brechung an den Grenzflächen vernachlässigt werden, wenigstens sofern es sich um eine Sammelwirkung handelte (sie ist wohl schon durch eine Zerstreuungswirkung ersetzt).

Richtete ich diesen Angenabschnitt gegen zwei Lichtflammen, die in einer gegenseitigen Entfernung von 85 Millimeter und in einer Entfernung vom Auge $=585$ Millimeter anfgestellt waren, so entwarf jedes der Facettenglieder ein verkehrtes Bild. Es war nicht möglich, die Entfernung desselben von den einzelnen Facetten zu messen, doch habe ich die Grösse der Bilder mit dem Mikrometer annähernd bestimmen können. 1)ie am äusseren Rande des Augenabschnittes gelegenen Facettenquerschnitte entwerfen Bilder, deren Grösse (d. i. die Entfernung der beiden Lichtpunkte im Bilde)

\subsection{Millimeter}

beträgt. Sie liegen eine bedeutende Strecke hinter den Facettendurchschnitten (im Sinne des Ganges der Lichtstrahlen) und kommen nur durch den vordersten Antheil (Cornea) des Facettengliedes zu Stande. Die dem Centrum des Augenabschnittes näher gelegenen Bilder, welche von längeren Abschnitten der Facettenglieder entworfen werden, nehmen rasch an Grösse $\mathrm{ab}$; ich mass die Grössen

$\begin{array}{cc}0.011 & \text { Millimeter } \\ 0.004 & " \\ 0.002 & \end{array}$

Dabei rücken die Bilder, wie selbstverständlich, dem Facettenabschnitte immer näher, und das letztgenannte, das fünfzehmmal so klein wie das erst. genannte ist, liegt, so weit man das beurtheilen kann, in der hinteren Begrenzungsebene des Schnittes, also in der Schnittfläche des augenscheinlich abgestutzten Krystallkegels. (Von dieser Lage ïberzeugt man sich besser, wenn man die gewöhnliche Beleuchtung mit Tageslicht beniitzt und das Bild des Fensterkreuzes beobachtet.)

Es folgen dann noch weiter nach dem Centrum des Augenabschnittes Kegeln, denen man ansielit, dass der vordere Theil, wohl auch schon der mittlere Theil, fehlt, denn sie erscheinen nur mehr als kleine Kreise. Die Bilder derselben werden wieder grösser, z. B.

0.005 Nillimeter

und entfernen sich von dem brechenden Medium. Es ist also möglich, auch

1 Natürlich in dem Quellungszustand, in dem es im Schnitte enthalten war. 
mit Ausschluss der Brechung, an den kugeligen Begrenzungstlïchen ein Bild im Durchschnitt eines Krystallkegels zu sehen, die Wirkung der normalen vorderen Corneafläche muss dasselbe noch etwas weiter nach vorne schieben. In welchem Antheile des Kegels es im Leben liegt, wage ich nicht mit grösserer Bestimmtheit, als das oben gethan wurde, anzugeben, aber darüber, dass es in seinem Tnnern liegt, kann nach dem Vorgetragenen kein Zweifel sein und ebensowenig, dass es wesentlich durch die Schichtung der Medien zu Stande kommt.

Ich brauche kaum zu elwähnen, dass die oben mitgetheilten Messungen bei der Kleinheit der Bilder keinen Anspruch auf grosse Genauigkeit machen können, vielmehr sollten sie nur zeigen, dass die Bilder in der Richtung eines Radius des Tangentialschnittes erst an Grösse ab-, dann wieder zunehmen, wodurch auch schon die Variation der Bildweite illustrirt ist. Die Bilder also, deren Grösse mit 0.002 Millimeter angegehen wurde, lagen in der Abstutzungsfläche des Kegels, im Leben demnach im Innern desselben.

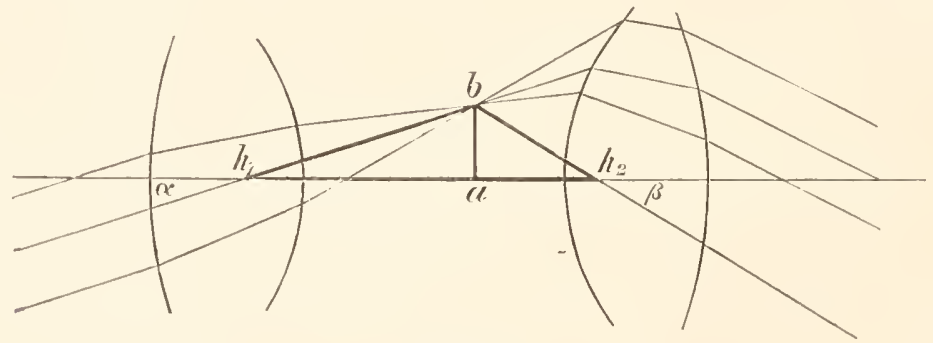

Fig. 14.

4. Dioptrische Berechnung des Lampyrisauges.

Wir haben gesehen, dass ein Krystallkegel mit Einschluss der Cornea wie ein astronomisches Fernrohr wirkt, das anf unendliche Entfernung eingestellt ist. Die Ablenkung, die ein Strahl durch ein solches erleidet, ergibt sich aus Holzschnitt Fig. 14:

$$
a b=a h_{1} \operatorname{tang} \alpha=a h_{2} \text { tang } \beta \text {. }
$$

Nennen wir die beiden Brennweiten $a h_{1}$ und $a h_{2}, \varphi_{1}$ und $\varphi_{2}$, so ist

$$
\frac{\operatorname{tang} \alpha}{\operatorname{tang} \beta}=\frac{\varphi_{2}}{p_{1}}=\text { Const. }
$$

eine Formel, die dem Brechungsgesetze ähnlich ist und von ihm sich dadurch unterscheidet, dass statt der Brechungsindices der beiden Medien die beiden Brennweiten, und statt der Sinuse der Winkel die Tangenten eingetreten sind.

Denken wir uns nun das kugelig gekrümmte Auge von Lichtstrahlen getroffen, deren jeder (wenigstens wenn er iiberhaupt zur Verwerthung gelangt) in einem Krystallkegel nach dem genannten Gesetze abgelenkt wird, so lässt sich die Construction des Bildes in ganz analoger Weise wie bei einer kugelig gekrümmten Trennungsfläche zweier Medien aus 
fïhren. Was bei dieser Radius oder Einfallsloth ist, ist beim Insectenange Radius des Auges oder Axe des Facettengliedes; nur liegt bei dem letrteren der gebrochene Strahl mit dem eintretenden auf derselben Seite des Einfallslothes, und miïssen wir die Dicke der optisch wirkenden Schichte, das ist die Länge der Krystallkegel + Cornea, vernachlässigen.

Hiernaclı habe ich den in Fig. 16, S. 54, versinnlichten Strahlengang geometrisch construirt, und zwar für den Fall, dass die Winkel nicht sehr klein sind, sondern bis 60 Grad reichen und

$$
\frac{\operatorname{tang} \beta}{\operatorname{tang} \alpha}=1.5
$$

ist. Man sieht, dass die Vereinigung der Strahlen in einer kaustischen Kegelfïche, ähnlich wie bei sphärischen Flächen und beim Sinusgesetze stattfindet. Die ausgezogenen Linien zeigen den Strahlenverlanf und die kaustische Curve für das Tangentengesetz, die gestrichelten Linien dasselbe für das Brechungsgesetz.

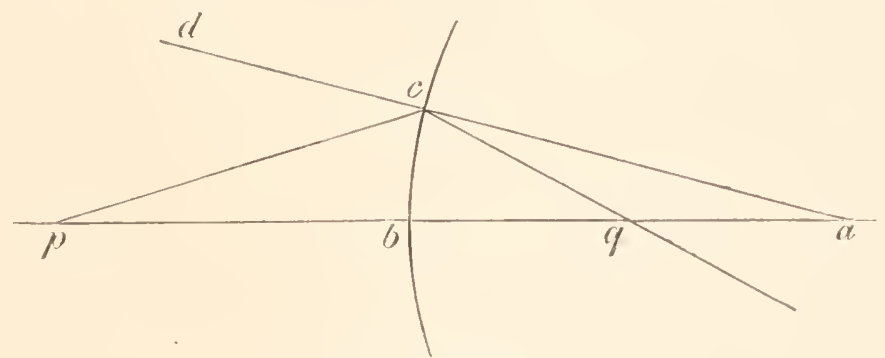

Fig. 15.

Für kleine Winkel, 1 m die es sich hier allein landelt, kann man, wie auch, abgesehen von dieser Construction, selustverständlich ist,

$$
\frac{\operatorname{tang} \alpha}{\operatorname{tang} \beta}=\frac{\sin \alpha}{\sin \beta}
$$

setzen, was im Folgenden auch geschehen ist. So habe ich die Rechnung ganz im Anschlnsse an die Berechnung der Brechung an einer Kugelfäche, welche v. Helmholtz in seiner physiologischen Optik ${ }^{1}$ gibt, durchgefuilirt. Es ergeben sich, wie zu erwarten war, abgesehen von den Vorzeichen, ganz analoge Formeln; ich suchte dies durch Beibehaltung der iiblichen Bezeichumngen hervortreten zu lassen.

Es sei $b c$ (Fig. 15) die Wölbung des Gesammtauges, a $p$ eine durch den Krümmungsmittelpunkt $a$ derselben gehende Gerade, $p$ ein Punkt, ron dem aus ein Strahl nach $c$ gelangt, ad ist das Einfallsloth für diesen Strahl, der gebrochene Strahl schneide a $b$ im Punkte $q$. Nach Gleichung 1) und der obigen Substitution ist dann

In dem Dreieck $p c a$ ist

$$
\varphi_{1} \sin p c d=\varphi_{2} \sin a c q .
$$

12. Aufl. S. 60 u. ff. 


\section{$-54-$}

$$
\frac{\sin p c a}{\sin c p a}=\frac{a p}{a c}
$$

und im Dreiecke acq

$$
\frac{\sin q c a}{\sin c q} \frac{a q}{a c}
$$

Durch Division der ersten dieser beiden Gleichungen durch die zweite und unter Beriicksichtigung von

$$
\sin p c a=\sin p c d
$$

erhält man

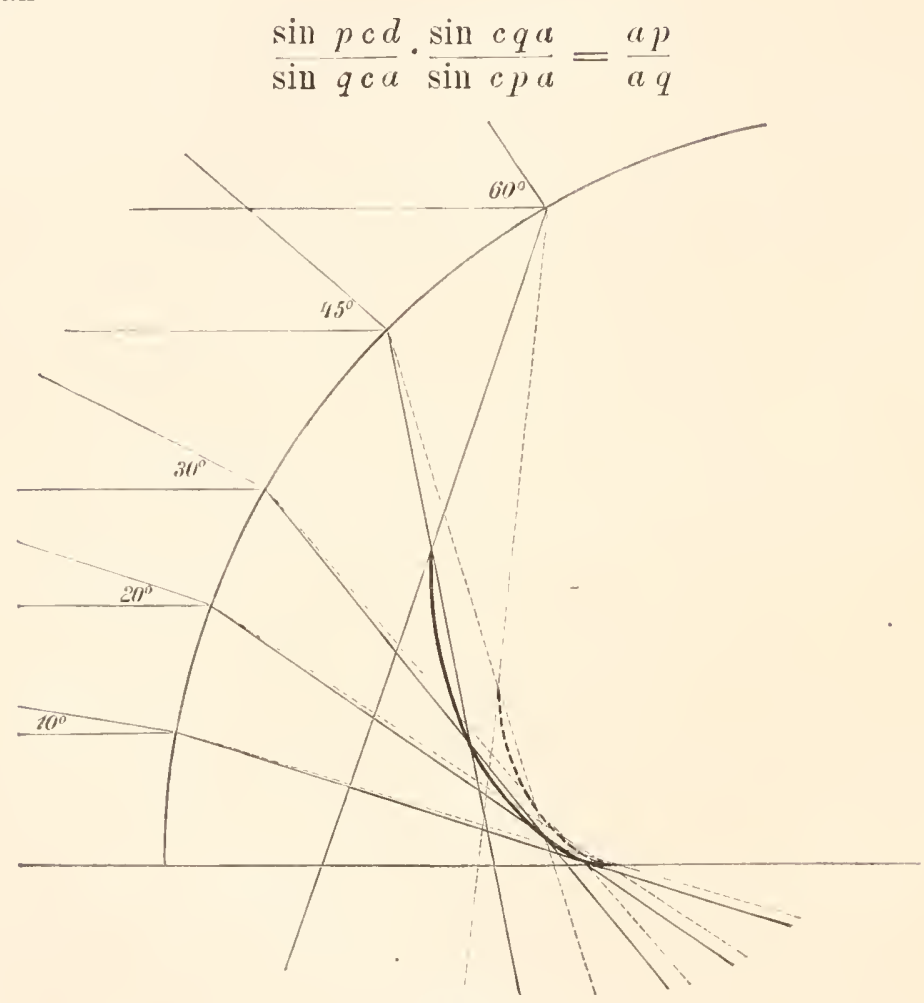

Fig. 16.

Nun ist nach Gleichung 1)

$$
\frac{\sin p c d}{\sin \frac{p c a}{q c a}}=\frac{\varphi_{2}}{\varphi_{1}}
$$

und im Dreiecke $p c q$

$$
\frac{\sin c q b}{\sin c p a}=\frac{c p}{c q}
$$

so dass man die obige Gleichung mit Rücksicht auf $\sin c q a=\sin c q b$ auch schreiben kann:

$$
\frac{\varphi_{2}}{p_{1}} \cdot \frac{c p}{c q}=\frac{a p}{a q}
$$

Wenn die Strahlen nahe bei $b$ das Auge treffen, so ist 
und Gleichung g) latutet

$$
\frac{c p}{c q}=\frac{b p}{b q}
$$

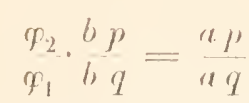

Es mögen nun für die Entfernungen der beiden conjugirten P'unkte $q$ und $p$ ron dem dioptrischen Aplarate einerseits und von dessen Mittelpunkte andererseits andere Zeichen eingefüht werden, die alle positiv zu rechnen sind, wenn sie von den genannten Orten nach der Richtung des Objectes liegen.

Man ersieht ans der Zeichnung:

$$
\begin{aligned}
& a b=r \\
& b p=f_{1} \\
& b q=-f_{2} \\
& a p=g_{1} \\
& a q=g_{2}
\end{aligned}
$$

$$
\left.\begin{array}{l}
f_{1}+r=g_{1} \\
-f_{2}=r-y_{2}
\end{array}\right\}
$$

Gleichung 3) fühl dann zu

oder

$$
\left.\begin{array}{l}
\frac{\varphi_{1}}{f_{1}}+\frac{\varphi_{2}}{f_{2}}=\frac{\varphi_{1}+\varphi_{2}}{-r} \\
\varphi_{1}+\frac{\varphi_{2}}{\varphi_{1}}=\frac{\varphi_{1}+\varphi_{2}}{r}
\end{array}\right\}
$$

Bezeichnet man, wemn $f_{1}=\infty$ mnd $y_{1}=\infty$ werden, die betreftenden Werthe ron $f_{2}$ und $y$. mit grossen Buchstaben, so ergibt sich aus 5)

$$
\left.\begin{array}{l}
F_{2}=\frac{-r \varphi_{2}}{\varphi_{1}+\varphi_{2}} \\
G_{2}=\frac{r \varphi_{1}}{\varphi_{1}+\varphi_{2}}
\end{array}\right\}
$$

und entsprechend, wenn $f_{2}$ und $g_{2}$ unendlich werden

Woraus folgt

$$
\left.\begin{array}{l}
F_{1}=-\frac{-r \varphi_{1}}{\varphi_{1}+\varphi_{2}}=-G_{2} \\
G_{1}=\frac{r \varphi_{2}}{\varphi_{1}+\varphi_{2}}=-F_{2}
\end{array}\right\}
$$

$$
\frac{F_{1}}{F_{2}}=\frac{\varphi_{1}}{\varphi_{2}}=\frac{G_{2}}{G_{1}}
$$

Alls Gleichung 6) geht hervor; dass, wemn

$$
r_{1}=\varphi_{2}
$$

ist, d. I. Wenn das astronomische Fermröhrchen, das das Facettenglied ersetzen kömnte, ans zwei gleichen Linsen bestiinde, der zweite Bremlpunkt des Lampyrisauges in del Hälfte seines Radius läge, also da, wo der Brenupunt eines Convexspiegels liegt. Nur ist das Netzhauthild ein 
reelles Bild. Aus den Gleichmngen 7) ersieht man, dass an derselben Stelle auch der erste Brempunkt des Auges liegt.

Aus diesen beiden Gleichmigen geht weiter hervor

$$
r=G_{1}+G_{2}=-\left(F_{1}+F_{2}\right)
$$

Auch kam man durch dieselben die Werthe $\varphi_{1}$ und $\varphi_{2}$ eliminiren, indem auf Grumd derselben die Gleichung 5) in die bekannte Formel ïbergeführt wird:

woraus folgt:

$$
\left.\begin{array}{l}
\frac{F_{1}}{f_{1}}+\frac{F_{2}}{f_{2}}=1 \\
\frac{G_{1}}{g_{1}}+\frac{G_{2}}{g_{2}}=1
\end{array}\right\}
$$

$$
\left.\begin{array}{l}
f_{1}=\frac{F_{1} f_{2}}{f_{2}-F_{2}} \\
f_{2}=\frac{F_{2} f_{1}}{f_{1}-F_{1}}
\end{array}\right\}
$$

Kommen, entsprechend dem oben S. 39 angefülıten Versuche, die Lichtstrahlen von der Seite der Retina, so wird in der Formel 5)

$$
\begin{array}{rrrr}
\varphi_{1} & \text { zu } & \varphi_{2} \\
\varphi_{2} & & \varphi_{1} \\
f_{1} & & -\frac{-}{f_{2}} \\
-f_{2} & & f_{1}
\end{array}
$$

so dass diese Formel die Gestalt annimmt:

$$
\left.\begin{array}{l}
\frac{\varphi_{1}}{f_{1}}+\frac{\varphi_{2}}{f_{2}}=\frac{\varphi_{1}+\varphi_{2}}{r} \\
\frac{\varphi_{1}}{g_{2}}+\frac{\varphi_{2}}{g_{1}}=\frac{\varphi_{1}+\varphi_{2}}{-r}
\end{array}\right\}
$$

d. I. die Formel bleibt, wie bei der gewöhulichen Brechung (vergleiche Gleichung 5) bestehen, nur ist das Vorzeichen des Radius zn ändern. Es liegt also das verkehrte Bildchen, das man beim nmgekehrten Strahlendurchgang sieht, gerade an dem Orte, wo das normale Netzhautbild liegt, welın der Gegenstand jedesmal in grosser kutfernung ist.

Was nun die Berechnung der Bildgrösse betriftt, so geht aus Fig. 17 hervor:

Setzt man

$$
\frac{p s}{r t}=\frac{a p}{a r}=\frac{g_{1}}{g_{2}}
$$

$$
\begin{aligned}
p s & =\beta_{1} \\
r t & =\beta_{2}
\end{aligned}
$$

so erhält man

$$
\frac{\beta_{1}}{\beta_{2}}=\frac{g_{1}}{g_{2}}
$$

und unter Berücksichtigung der Gleichmngen 4) bis 7) 


$$
\begin{gathered}
-57- \\
\frac{\beta_{1}}{\beta_{2}}=\frac{g_{1}-G_{1}}{G_{2}}=\frac{G_{1}}{g_{2}-G_{3}} \\
\beta_{1}=\frac{F_{1}-f_{1}}{\beta_{1}}=\frac{F_{2}}{F_{2}-f_{2}}
\end{gathered}
$$

Erwägt man, dass in Fig. 17 rt gegen $b$ riickt, wenn $s p$ siclí $b$ nähert, so sieht man, dass sie in $b$ bei gleicher Grösse und Richtung zusammentreffen miissten.

Aus der letzten Gleichung geht nämlich hervor, dass, wenn

$$
\beta_{1}=\beta_{2}
$$

sein soll, $f_{1}=0$ ist, d. h. die beiden Hanptpunkte liegen in der brechenden Fläche, oder mit Rücksicht auf die Verlä̈ltnisse des Insectenauges: in jedem Facettengliede liegt ein vereinigter Hauptpunkt des Aụges, und diese sämmtlichen Hauptpunkte sind in einer Kugelfläche um den Krümmungsmittelpunkt angeordnet.

Es ist leicht, sich experimentell von dem Zutreffenden dieser Berechnung im Allgemeinen zu überzeugen, z. B. von der geforderten Annäherung des Bildes an den dioptrischen Apparat, bei Näherung des Objectes

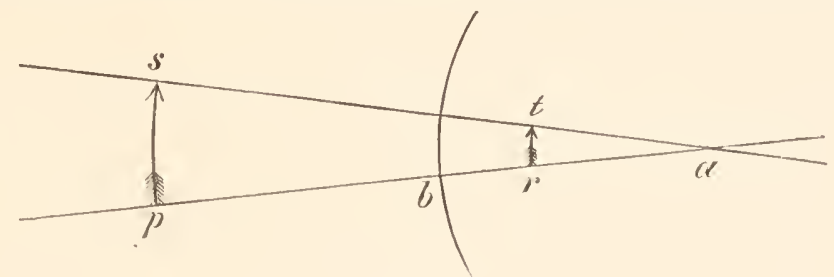

Fig. 17.

und Anderem mehr, was schon aus der obigen Schilderung des optischen Verhaltens unseres Auges bekannt ist. Doch ist es mir nicht gelungen, eine befriedigende Uebereinstimmung der berechneten mit den gemessenen Zahlenwertlen zu bekommen. So mass ich z. B. die Entfernung des Bildes ron den Krystallkegeln fiir die drei Entfernungen des Objectes von 810, 12 und 1.2 Millimeter. (Die geringen Entfernungen erhielt ich, indem ich ein vom Abbe'schen Beleuchtungsapparat entworfenes Bild als Olject benützte.) Hieraus liess sich nach Gleichung 3) das Verhältniss $\frac{\varphi_{1}}{\varphi_{2}}$ berechnen. Ich fand in jedem Falle einen Werth zwischen 1.1 und 1.9 gelegen, so dass dies mit den Beobachtungen und der obigen Darstellung insofern ganz wohl iibereinstimmt, als es anch zeigt, dass das verkehrte Bildchen, das in jedem Krystallkegel liegen muss, in der That in dessen rïckwärtiger Hälfte gelegen ist. Doch eine gute Uebereinstimmung der Werthe erhielt ich nicht. Aehnlich ging es mir bei der Prüfung jener Formeln, in welche die gemessene Brennweite eingeführt wurde. Die Ursache der mangelhaften Uebereinstimmung liegt, wie mir scheint, auf der Hand. Alle experimentelle Prüfung beruht auf der Messung der Entfernung zwischen dem verhältnissmässig dicken dioptrischen Apparat und dem Bilde. Wie 
oben schon erläutert, lässt sich die Einstellnng auf eine bestimmte Stelle des dioptrischen Apparates nicht genal ausführen, man denke nur, dass man Bilder vor sich hat, welche jenen der Fig. 3, Taf. I, ähnlich sind. Wenn man aber hierin nur einen kleinen Fehler macht, so kommt er natürlich im Resultat schon sehr in Betracht. Auch ist die Dicke des dioptrischen Apparates ja in der Rechnung vernachlässigt worden, und konnte ich meine Messungen nur an Alkoholpräparaten ausführen. Das erwähnte Schema des Insectenauges, das ich mir herstellte, ergab mit der Rechnung recht gut stimmende Resultate.

Ich have bisher rorausgesetyt, dass der Ban eines Facettengliedes beim Leuchtkäferchen der eines Linsencylinders ist; in der physikalischen Einleitung labe ich abel erwähnt, dass Matthiessen's Etagenlupe ähnliche optische Wirkungen erzeugen kiun.

Es fragt sich also, ob die Wirkung des Facettengliedes nicht etwa auf dem Principe der Etagenlupe beruht? Ich glaube. man muss das verneinen, denn um die Wirkung zweier Convexlinsen von so kurzer Brennweite nach diesem Principe zu erzielen, wären Differenzen im Brechungsindex der verschiedenen Schichten von einer so enormen Grösse vorauszusetzen, wie dies für die Chitimmassen verschiedener Dichtigkeit unmöglich angenommen werden kann, und wie sie weiter auch anf den er'sten Blick unter dem Mikroskope geseheñ werden mïssten.

Es ist hier der Ort, darauf aufmerksam zu machen, dass man die ganze Bilderzeugung in Lampyrisange auch anders, und zwar in folgender Weise auffassen kamn. Jedes Facettenglied hat sich als ein astronomisches Fermohr herausgestellt. Es entwirft also jedes derselben ein aufrechtes Bild auf der Netzhaut. Wenn, wie wir sahen, das Fermrohr auf Unendlich eingestellt ist, d. h. die austretenden homocentrischen Strahlen parallel verlaufen, wird das Bild, wo immer man es auf einen Schirm auffinge, bei der Kleinheit des Qnerschnittes eines solchen Strahlencylinders gegenüber den Dimensionen des Bildes, immerhin ziemlich scharf sein. Diese aufrechten Netzhautbilder der einzelnen Facettenglieder decken sich aber in der Art, dass laut Abbildungen 2 und 3, Taf. I, ungefülır dreissig Netzhautbilder für jeden Punkt des abzubildenden Gegenstandes iibereinander liegen. Fïr einen zweiten Punkt desselben sind es wieder dreissig andere, oder je nach der Entfernung vom ersten Punkte nur theilweise andere Facettenglieder, deren aufrechte Bilder das definitive Netzhautbild zusammensetzen. Diese dreissig Bilder sind - abgesehen voll den Aender'ungen der optischen Constanten an der Peripherie des Auges und ron anderweitigen kleinen Abweichungen - rongruent und unterscheiden sich nur durch die Lage ihrer Begrenzung, indem die mehr rechts gelegenen Hacettenglieder noch Theile des Objectes enthalten, welche in diesem melir rechts liegen, die nach links gelegenen mehr von den linksseitigen An- 
theilen des Objectes. Ih habe deshalb zur Charakterisirung dieser Art der Bilder, und zum Untersehied des definitiven Net\%hautbildes von den einzelnen dasselbe zusammensetzenden Bildern der Facetten, ein in der geschilderten Art entstandenes Bild ein Superpositionsbild genannt.

\section{Katoptrische Wirkung der Kegel.}

Ueberblickt man die beigegebenen 'Tafeln, welche den Bau einzelner Facettenglieder bei verschiedenen Gliederthieren wiedergeben, so gewahrt man, dass nicht nur läufig, sondern bei Insecten fast in der Regel die vordere basale Fläche des Krystallkegels recht nemnenswerth kleiner ist, als die hintere Begrenzungsfläche der Corneafacette. Es ist hier also die Möglichkeit gegeben, dass Strahlen, welche die Cornea durchsetzt haben, aus dieser so austreten, dass sie nicht in den Kegel gelangen, sondern seitlich von diesem verlaufen. Ja es ist kein Zweifel, dass solche Strahlen existiren müssen, es sind die, welche vor dem Eintritt in das Auge einen Winkel mit der Axe des betreffenden Facettengliedes einschliessen, der eine gewisse bedentende Grösse iiberschreitet.

Ebenso unzweifelhaft ist es, dass diese Strahlen in der Regel von dem zwischen den Kegeln liegenden "Irispigment", von dem später noch die Rede sein wird, absorbirt und dadurch unschädlich gemacht werden. Ob das aber immer der Fall ist, mag wohl fraglich erscheinen, ja es wäre bei gewissen, unten zu besprechenden Stellungen dieses Pigmentes (den Lichtstellungen) nicht recht einzusehen, warum diese Strahlen nicht zunächst in die benachbarten Krystallkegel eindringen sollten. Vgl. die Abbildungen Taf. II, Fig. 16 , oder von einem Krebse Taf. V, Fig. 52.

Es kommt hier ein Umstand in Betracht, del wahrscheinlicherweise eine wichtige Rolle bei der Abblendung schädlicher Strahlen im Insectenauge spielt und auf den ich nun aufmerksam machen will. Er ist zugleich geeignet, Aufklärung ïber das fast constante Vorkommen eines der wichtigsten Bestandtheile des Facettengliedes, nämlich des Krystallkegels, zu geben. Ich meine die möglichen Reflexionen der in den Kegel eingedrungenen Strahlen.

Ich erinnere daran, dass jeder Lichtstrahl an der Grenzfläche zwischen zwei optischen Medien eine Reflexion erleidet, welche in der Regel nur einen Theil des Strahles betrifft, in dem Falle aber, dass der Strahl, in einem optisch dichteren Medium verlaufend, an die Grenze nach einem optisch dünneren gelangt, auch eine totale sein kann. Die Reflexion ist total, wenn der Einfallswinkel eine gewisse, durch die Brechungsindices der beiden Medien bestimmte Grösse iiberschreitet. Immer wird der Strahl, sei er nun total reflectirt oder nur theilweise, nnter demselben Winkel zurïckgeworfen, unter dem er auf die Grenztläche anfgefallen ist. 
Die Krystallkegel haben ihren Namen von ihrer kegelförmigen Gestalt Ein Kegel aber verhält sich in Bezug auf die Reflexion eines in ihn eingedrungenen Lichtstrahles ganz eigenthïmlich. Es sei Fig. 18 ein Kegel im geometrischen Sinne des Wortes und $a$ ein in ihn unter einer mässigen Neigung zur Axe einfallender Lichtstrahl. Er trifft bei $b$ das erstemal die T'rennungsfläche nach einem optisch dünneren Medinm. Hier ist der Einfallswinkel so gross, dass er wohl total reflectirt werden diurfte. Dasselbe gilt wohl auch noch für den Punkt $c$. Vielleicht wird hier aber nur mehr ein 'Theil von ihm nach $d$ reflectirt; indem man ihn immer unter seinen Einfallswinkel reflectirt werden lässt, kommt man zu der Construction des Weges $d, e, f, g, h, i$ der reflectirten Antheile des Strahles. Der Strahl wird also, so weit er der Reflexion unterliegt, aus dem Kegel wieder herausbefördert. Ein grosser Theil des Strahles aber wird bei $d, e, f, y$ nicht

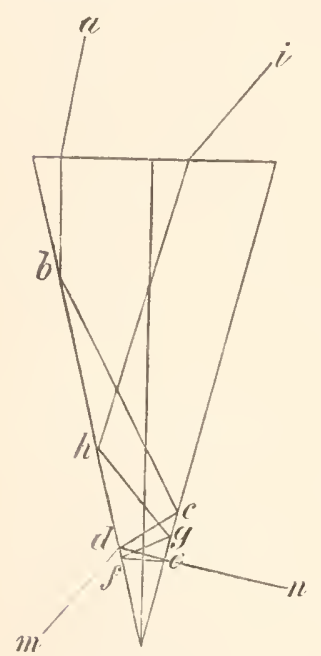

Fig. 18. reflectirt, durchdringt vielmehr die Tremnungstläche der beiden Medien. Diese den Kegel verlassenden Strahlenantheile ( $d m, e n$ u. s. W.) aber haben nul eine sehr bedeutende Neigung gegen die Axe des Kegels, es ist jetzt kein Strahlentheil vorhanden, welcher auch nur näherungsweise die Richtung der Kegelaxe hat.

Uebertragen wir diese Anschauungen von dem geometrischen Kegel auf den Kegel des Facettenauges, der eben keinë geometrische Spitze, sondern statt der Spitze eine gekrimmte Fläche hat, der auch nicht homogen, sondern als Linsencylinder geschichtet ist, so leuchtet ein, dass nur an der Spitzenfläche, wie wir hinlänglich besprochen haben, Strahlen austreten könnell, was beim geometrischen Kegel, abgesehen von dem nnendlich dünnen Axenstrahl nicht der Fall ist. Es ist aber durchaus nicht ansgeschlossen, dass gewisse Strahlen auch im Krystallkegel des Facettenauges ein ähnliches Schicksal erleiden, wie jene im geometrischen Kegel. Was von Licht auf dem Wege $a, b, c, d, e, f, g, h, i$ aus dem Facettenglied, in das es eingedrungen ist, wieder zurïckgeworfen wird, dürfte kaum in Betracht kommen. Wohl aber kömnen jene Strahlen ins Gewicht fallen, welche wie $d m$ und $e n$ aus dem Krystallkegel austreten nud nun eine Richtung haben, in welcher sie entweder vom Irispigment absorbirt werden (vgl. die ebengenannten Abbildungen), oder in einen Nachbarkegel eindringen müssen. In letzterem Falle verlaufen sie schon anfangs in dem zweiten Kegel unter einem selır grossen Winkel mit der Kegelaxe und fallen deshalb hier sofort demselben Schicksale in die Arme, dem sie eben im ersten Kegel entronnen sind. Sie werden auf diese Weise vielleicht noch viele Kegel durchsetzen, endlich aber doch wie $h i$ des geometrischen Kegels ans dem ganzen optischen System ausgestossen werden. Es wirkt 
dabei die Ablenknug mit, welche die Strahlen an dem Uebertritt aus einem Kegel in die umgebende Substanz und umgekeln't erfahren. (Schematisch wïrde ja ein Durchschnitt die Kegel wie einen Satz nebeneinanderstehender, mit ihrer brechenden Kante nach hinten gewendeter Prismen erscheinen lassen, welcher natïrlich einen sie passirenden Strahl nach vorne ablenkt.)

Von den Lichtstrahlen, für welche diese Betrachtungen zutreffen, sind natürlich alle jene ausgenommen, von denen wir im dioptrischen Theile gehandelt haben. Diese erleiden nirgends eine Reflexion. Aber es ist selbstverständlich: wemn Strahlen, die von einem gewissen Theile des Sehfeldes ansgehen, im Facettenglied so gebrochen werden, dass sie, olıne dessen seitliche Begrenzung zu berülıren, aus demselben wieder austreten, wie dies die oben behandelten Strahlen thun, dass damn andere Strahlen existiren müssen, welche die seitlichen Grenzflächen wohl berühren, somit daselbst reflectirt oder gebrochen werden. Das sind dann eben die unter stärkerer Neigung gegen die Facettenaxe auffallenden, somit wohl auch jene, von denen wir zu diesen Betrachtungen geleitet wurden: die zwischen Cornea und Krystallkegel in das umgebende Gewebe dringenden Strahlen.

Es erklärt sich, glaube ich, durch das Vorstehende eine Erscheinung, die ich mir lange nicht zu denten gewusst labe. Viele Insecten, z. B. Hydrophilus, besonders aber Krebse zeigen einen eigenthümlichen diffusen Schimmer an ihren Augen, der recht oberflächlich seinen Ursprung zu haben scheint. Derselbe wird besonders dentlich, wenn man die Thiere ins directe Sonnenlicht bringt. Es sind dann eben die auf die genannte Weise aus dem Auge herausbeförderten Strahlen intensiver. Am schönsten sah ich diesen Schimmer bei den grossen Krebsen, Langusten und Hummern. Bei diesen zeigt sich in demselben noch eine durch Steigerung und Verminderung des Glanzes markirte Zeichnung eines rechtwinkeligen Kreuzes, das sich über einen grossen Theil des Anges ausdehnt. Ich irre wolll nicht, wenn ich dasselbe mit der rechtwinkeligen Corneafacette und dem vierkantigen Krystallkegel dieser Thiere in Verbindung bringe.

Es ergibt sich weiter durch das Mitgetheilte eine Deutung für gewisse, wahrscheinlich auch in Zellen eingelagerte, stark das Licht reflectirende körnige Massen, welche bei manchen Krebsen und Insecten der vorderen Schichte des Irispigmentes anfgelagert sind und die Verschiebmngen desselben in Folge ron Lichtwirkung mitmachen. (Vgl. Taf. V, Fig. 51 it.) Sie gleichen vollständig der später zu beschreibenden Substanz des Tapetums bei diesen Krebsen. Im durchfallenden Lichte unter dem Mikroskope betrachtet, erscheinen sie fast so schwarz wie das Irispigment, und scheinen zu diesem zu gehören. Blendet man aber das durchfallende Licht ab, dann erkennt man, dass man es mit einer opaken, sehr stark reflectirenden Masse zu thun hat. Ich sah dieselbe bei Nica edulis, Sicyonia sculpta, Crangon, Palaemon und, wenn auch nicht so dentlich, bei Palinurus. Es 
sind diese Massen, ich will sie das Iristapetum nemen, analog den farbigen Pigmentzellen, die man bei Insecten so hänfig am rorderen Abschnitte des Facettengliedes findet.

Die Bedentung des Iristapetum liegt nun wohl ziemlich klar. Da es zwischen den Kegeln oder ihren Scheiden liegt, so reflectirt es die Lichtstrahlen, welche, wie eben besprochen, in die Räume zwischen die Kegel gelangten. Es unterstiitzt also die dioptrische und katoptrische Einrichtung, die ich geschildert liabe, in ihrer Bestimmung, das zu schief in das Facettenglied eindringende Licht unschädlich wieder herauszubefördern. Bei Insecten sowohl, wie bei Krebsen bildet es die Ursache der oft so prächtigen Farben der Augen, und die Reflexionen an demselben erklären den schönen metallischen Glanz, der, besonders in der Insectenwelt, keine Seltenheit ist.

Das Iristapetum scheint bisher nur von Leydig bemerkt worden zu sein (Müller's Arch. 1855, S. 410), und zwar am Flusskrebse. Er sagt: "Ausser dem schwarzen Pigment trifft man aber auch ungefähr halbwegs zwischen dem Ende der Krystallkegel und der oberen Spitze der spindelförmigen Anschwellung ${ }^{1}$ ein bei auffallendem Lichte weisses Pigment an, das ebenfalls aus kleinen Körnchen zusammengesetzt sich zeigt." Er hatte also ein Auge in Lichtstellung des Irispigmentes und des Iristapetums vor sich, ${ }^{2}$ wie ich alsbald zeigen werde.

1 Sel. der Selıstäbe.

2 Aehnlich spricht sich Leydig in seiner Histologie, S. 255, aus. 


\section{CAPITEL.}

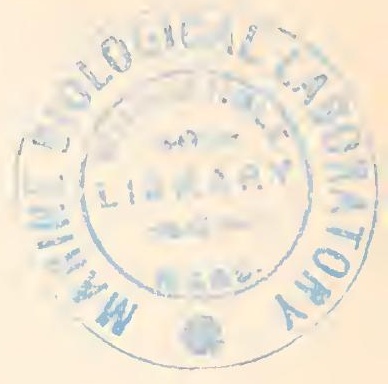

\section{Das Irispigment und seine Wirkung.}

Es hat gewiss eine tiefere Bedeutung, und dieselbe soll durch das Nachstehende wenigstens einigermassen aufgeklärt werden, dass das alsbald zu besprechende Phronima-Ange, das sein Bild nach katoptrischen Principien entwirft, kein Pigment enthält, während mir kein dioptrisch wirkendes Facettenauge bekannt geworden ist, das nicht zwei wohlcharakterisirte Lagen von Pigment enthielte. Ich verstehe hier unter Pigment das körnige schwarze, gewöhnlich oder immer in Zellen liegende Pigment, wie es ja auch in Wirbelthierange rorkommt, und sehe von den farbigen und diffusen Pigmenten, sowie von abnormen albinotischen Zuständen, die auch bei Krebsen ${ }^{1}$ und Tnsecteu vorkommen sollen, ab. "Die erste oder vordere Pigmentlige liegt innerhalb oder in der Nähe des dioptrischen Apparates, ich will sie, der Aehnlichkeit der Function wegen, das Irispigment nennen. Die zweite Lage liegt an oder zwischen den Elementen der Netzhaut, wohl anch hinter derselben, ich will sie das Retinapigment nennen. Dieses soll lins erst später beschäftigen.

Die Abbildung Fig. 1, Taf. I des Lampyrisanges, zeigte uns das Irispigment als die Zwischenräume zwischen den Krystallkegeln ausfüllend; nur die Spitzen derselben sind frei geblieben und ragen in die durchsichtige Masse, die zwischen dem dioptrischen Apparate und der Retina gelegen ist, hinein. Höchst wahrscheinlich ist das körnige schırarze Pigment hier, wie an den analogen Stellen anderer Facettenaugen, in Zellen eingeschlossen - ich habe das nicht näher untersucht, sah abèr wiederholt Bilder, die wenigstens für den betreffenden Fall keinen Zweifel darüber bestehen lassen - und so lelirt es auch Grenacher. Dieser unterscheidet hier zwei Arten morphologisch unterscheidbarer Pigmentzellen, die er mit Pg. I und Pg. II bezeichnet. Ich habe keine Ursache, an der Richtigkeit der Grenacher'schen Darlegung zn zweifeln. Da mein Augenmerk weniger den morphologischen als den physiologischen Verhältnissen zugewendet war, so habe ich die Lage und Anordnung des Pigmentes untersucht, ohne mich darum zu kümmern, ob und in welchen Zellen dasselbe liegt.

is. unter Peneus membranaceus. 
Die genaunte Abbildung des Lampyrisauges gehört einem im Dunkeln getödteten Thiere an. Ich habe nun die Erfahrung gemacht, dass das Irispigment eine andere Lage zeigt, wenn man das Auge eines Thieres untersucht, das in der Sonne gesessen hat, und in der Sonne getödtet worden ist. Ich liess die Thiere auch, nachdem sie bewegungslos geworden waren, noch 1 bis 2 Stunden in der Sonne, um sicher zu sein, dass auch die inneren Organe ihre Reactionsfähigkeit verloren hatten, ehe ich sie in andere Beleuchtung brachte.

Im Lichtauge des Leuchtkäferchens liegt nämlich das Irispigment, der Hauptmasse nach hinter einer Ebene, welche die Spitzen der Krystallkegel berührt, und zwischen den Kegeln sind nur spärliche Reste des Pigmentes zurückgeblieben. Es hat also das Pigment eine Localveränderung erlitten, eine Verschiebung nach hinten, näherungsweise um die Länge des

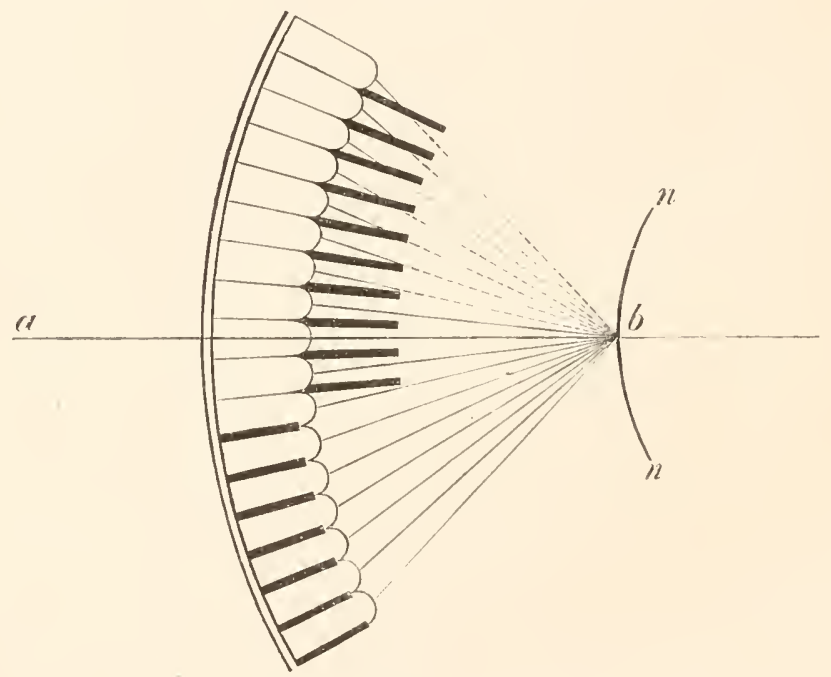

Fig. 19.

Krystallkegels. Es umhïllt aber jetat den Kegel nicht etwa auch an seiner Spitzenfläche - es würde dann gar kein Licht durch denselben auf die Netzlıaut gelangen - sondern die Verlüngerung der Kegelaxe und deren nächste Umgebung bleibt frei von Pigment, wie man an Schiefschnitten und Querschnitten leicht sehen kann. Das Pigment zieht sich demnach als mehr oder weniger cylindrische Scheide über den Krystallkegel nach rïckwärts, und die Scheiden der verschiedenen Kegel bilden miteinander eine zusammenhängende Pigmentmasse.

Die functionelle Bedeutung dieser Pigmentverschiebung kann nicht zweifelhaft sein, wenn wir uns an den oben geschilderten Strahlenverlauf im Lampyrisange erinnern. Es sei Holzschnitt Fig. 19 das Schema eines solchen Anges, in dessen unterem Theile die Dunkelstellung, in dessen oberem die Lichtstellung des Irispigmentes obwaltet. Aus der Richtung $a$ falle von einem Punkte ausgehend Licht auf das Auge, so werden die durch die 
einzelnen Facettenglieder gebrochenen Strahlen sich in $b$ zum Bilde anf der Netzhaut nn vereinigen. Man sieht nun, dass ein 'Theil dieser Strahlen (der obere der Zeichnung) durch das in der Lichtstellung befindliche Pigment absorbirt werden muss, also gar nicht zum Bildpunkte gelangt. Nan ersieht auch weiter, dass beim allmählichen Uebergang des Pigmentes aus der Dunkelstellung in die Lichtstellung von dem ganzen Strahlenkegel, dessen Spitze $b$ ist, immer mehr und mehr Strahlen abgeblendet werden müssen, und zwar von aussen nach innen fortschreitend, so dass die Basis des Kegels immer kleiner und kleiner wird und dadurch die relative Helligkeit des Bildes proportional der Basis des Kegels abnimmt. Genau ebenso verkleinert die Iris der Säugethiere bei fortschreitender Verengerung der Pupille die Helligkeit des Netzhantbildes in deren Auge, indem sie, an der Peripherie der Basis des Strahlenkegels beginnend, Strahl auf Strahl abblendet und die Helligkeit des Punktes $b$ proportional der Kegelbasis verkleinert. Eben wegen dieser Analogie in der Function möchte ich vorschlagen, diese Pigmentlag"e "Irispigment" zu nennen.

Es scheint, dass das Facettenange sich in höherem Grade durch sein Irispigment den verschiedenen äusseren Helligkeiten anpassen kann, als es das Wirbelthierauge durch seine Iris thut. Ich werde alsbald Beispiele anführen, durch welche es wahrscheinlich wird, dass jener Lichtkegel durch das Irispigment bis auf vielleicht nur den Strahl eines Facettengliedes reducirt werden kann, während die Pupille des Wirbelthierauges wenigstens nur in den seltensten Fällen eine analoge Verkleinerung zeigt. Nur von den Haien ist es mir bekannt, dass sich die spaltförmige Pupille bei Tage bis auf zwei den Enden entsprechende Lücken zu schliessen scheint, denn auch die engste Pupille der Katze dürfte immer noch an Wirkung der Wirkung des Irispigmentes zahlreicher Gliederthiere nachstehen.

Der geschilderte Effect des Irispigmentes ist natürlich nur möglich bei Augen, welche nach dem Principe des Lampyrisauges gebaut sind, also ein Superpositionsbild entwerfen. Es muss, wie bei diesem, zwischen dem dioptrischen Apparate und der empfindlichen Netzhautschichte ein namliafter Zwischenraum sein, durch welchen die Lichtstrahlen verlaufen und in welchen hinein sich das Irispigment schieben kann. Denn bei einem Auge, das, wie jenes von Limulus, kein Superpositionsbild hat, würde eine derartige Pigmentverschiebung sinnios sein. Andererseits wird man aber aus dem Vorhandensein der Pigmentverschiebung auf Belichtung in zweifelhaften Fällen einen Fingerzeig dafür entnehmen können, dass man es mit einem Superpositionsbild, nicht mit einem Appositionsbild zu thun hat.

Interessant und für die dargelegte Bedeutung des Irispigmentes von Wichtigkeit ist die Thatsache, dass unter den zahlreichen Gliederthieren, welche ich auf die photomechanische Reaction des Irispigmentes gepruift habe, mit nicht einer unzweifelhaften Ausnahme nur die Nachtthiere eine solche zeigten, jene Thiere, die ihre Augen also sowohl bei 'Tage als bei Nacht zu beniitzen haben. Nachtschmetterlinge siud bei Tage nicht 
blind, die meisten Krebse sind Nachtthiere, sehen aber gan\% gut auch bei Tage. Diese zeigen die photomechanische Wirkmug. Fliegen, Tagschmetterlinge. Libellen etc. sind des Nachts vollkommen hilflos, zeigen keine Lichtwirkung auf das Irispigment und haben, wie noch ausfülılich besprochen werden soll, auch kein Superpositionsbild, sondérn ein Appositionsbild. Anch Larven von Libellen habe ich untersucht und keine Lichtwirkung auf das Irispigment finden können.

Ich habe die Mülıe nicht gescheut, zahlreiche Thiere auf das Spiel des Irispigmentes zu prüfen, und gehe daran, meine Erfahrungen hierübel mitzutheilen. Torher will ich jedoch daranf hiuweisen, dass sich manche Differenz in den Angaben und Abbildungen des Irispigmentes bei verschiedenen Autoren dadurch erklären wird, dass der Eine ein Lichtauge. der Andere ein Dunkelauge untersucht hat. In Leydig's "Tafeln zur vergleichenden Anatomie" findet sich auf Taf. X, Fig. 1, die Abbildung eines Anges rom Windenschwärmer (Sphynx convolvuli), welches das Irispigment auf der einen Seite in der Dunkelstellung zeigt, nach der anderen Seite aber geht es allmählich in mässige Lichtstellung über. Es ist mit Bestimmtheit zu sagen, dass das Thier in einer Lage abgestorben ist, wo der erstgenannte Theil des Auges ein duukles Netzhautbild entlalten hatte, das nach der anderen Seite hin lichter wurde. Ich lıabe mich nämlich überzeugt, dass die photomechanische Wirkung auf das Irispigment eine locale ist; ich komnte die eine Hälfte des Auges in Lichtstellung, die andere in Dunkelstellung versetzen, wenn .ich die eñre Hälfte des Sehfeldes hell, die andere dmukel machte. Nan kann also auf das Irispigment photographiren, wie Kühne mit dem Netzhantpigment der IVirbelthierangen "Optogramme" gemacht hat. Ich erwälne dies hier nur und werde bei Gelegenheit des Augenlenchtens mehr davon sagen, da diese Verhältnisse am lebenden Thiere studirt werden können, und dies mit Hilfe des Augenleuchtens viel bequemer geschicht, als durch mikroskopische Untersuchungen.

Dort werde ich anch die zeitlichen Terhältnisse der Pigmentverschiebung besprechen; hier sei nur noch hervorgehoben, dass ich die Thiere, um iiber die Pigmentverschiebung etwas zn erfahren, eine bis zwei Stunden oder auch über Nacht in vollkommen dunklem Raume hielt und sie daselbst tödtete, indem ich sie mit Alkohol oder dergleichen ïberschïttete, und dass ich andere, ihnen womöglich an Lebensfrische, Stärke u. s. w. gleiche Exemplare derselben Species an die Sonne stellte und da geradeso behandelte wie die ersten. Ohne über eingehende Versuche dariuber zu verfügen, scheint es mir, dass sowohl die Lichtstellung, als die Dunkelstellung ausgesprochener ist, wenu man die Thiere nicht zu lange der Emwirkung des Lichtes und der Dunkelheit aussetzt. Es dürfte sich insbesondere bei tagelanger Einwirkung der Dunkelheit eine mittlere Pigmentstellung entwickehn. Es wïrde das mit den Erfahrungen übereinstimmen, dic E. Fick

1 Ueber Liehtwirkung anf die Netzhant des Frosehes. Ber. d. ophthahmolog. Gesellseh. an Hoidelberg 1SS9. 
kïmlich am Netzhantpigment des Frosches gemacht hat. Ein weiterer Umstand, auf den zu achten ist, liegt in dem Gesundheitszustand der 'Thiere. Ich habe die Erfabrung gemacht, dass matte, dem Absterben nahe Thiere keine P'igmentrerschiebung mehr zeigen.

\section{A. Insecten.}

1. Käfer. Ausser bei unserem Lenchtkäferchen habe ich noch bei Cantharis fusca (Telephorus) die Pigmentverschiebung beobachtet. (Vgl. Taf. I, Fig. 9, $A$ von einem Dunkel-, $B$ von einem Lichtthiere.) Dieser Käfer hat auch ein unzweifelhaftes Superpositionsbild, und die Lage des Irispigmentes ist am Dunkelauge ganz ähnlich der des Dunkelauges von Lampyris. Bei den besonnten Augen ist das Pigment zwischen den Kegeln fist ganz verschwunden und ist nach hinten gerïckt, während beim D) unkelauge die Zwischemäume zwischen den Kegeln ganz mit Pigment erfüllt sind.

Iclı untersuchte zwei Lichtaugen und ein Dunkelauge des Rosenkäfers (Cetonia) und fand keinen Unterschied in der Lage des Irispigmentes, obwohl der Ban des Auges im Uebrigen einen solchen erwarten liess. Das Pigment hört nämlich mit einer auffallend scharfen Grenze, etwa in der Ebene del Kegelspitzen anf und erfuillt die Räume zwischen den Kegeln. Da ich, als ich diese Thiere untersuchte, ïber den Unterschied der 'Tagund Nachtaugen noch nicht klar war, so glaubte ich den Mangel an Pigmentverschiebung individuellen Eigenthümlichkeiten der Thiere zuschreiben zu müssen, umsomehr, als ich eine so scharfe rückwärtige Grenze des Pigmentes nur bei Dnnkelaugen anderer 'Thiere gesehen hatte. Ich schnitt deshalb noch die Augen eines nahen kleineren Verwandten des Rosenkäfers, nämlich die von 'I'ropinota hirtella (Fig. 23, Taf. III), fand die Augen ganz ähnlich gebaut jenen des ersteren, aber, obgleich ich drei Licht- und drei Dunkelthiere untersuchte, keine Spur einer Verschiebung des Irispigmentes. Nun sind die Rosenkäfer, sowie ihre kleineren Verwandten exquisite 'Tagthiere, fast möchte ich sagen Sonnenthiere, denn sie fliegen im hellsten Sonnenschein und bringen die Nacht in Blumen u. dgl. eingegraben, anscheinend schlafend zu. Damit hängt es wohl zusammen. dass sie keine Pigmentverschiebung zeigen. Anffallend ist nur, dass sie dabei den Ban des Auges haben, der für ein Superpositionsbild spricht, nämlich einen pigmentlosen Zwischenraum zwischen der Retina und den Kegeln. Freilich kann hier wieder die Frage anfgeworfen werden, wo die empfindliche Schichte der Netzhaut ist, ob im oberen, verdickten, knopfartigen Ende des Sehstabes, oder in der unteren, langen Anschwellung desselben. Nur im letzteren Falle könnte von einem Superpositionsbild die Rede sein. Nun sind aber sehr nahe Verwandte der in Rede stehenden Käfer Nachtthiere, z. B. die Juni- und die Maikäfer. Ich möchte daraus den Schluss ziehen, dass wir es bei Cetonia und Tropinota mit Augen zu thum laben, welche 
vol vieleu Generationen Nachtalugen walen, wie jene des velwandten Maikäfer's. Erst suät sind die Thiere Tagthiere geworden, das Auge hat sein Superpositionsbild behalten, hat aber die Fähigkeit, durch das Irispigment die relative Helligkeit des Netzhautbildes stark zu variuren, eingebuisst.

So kann man dem Auge gTeichsam die Geschichte der Cetonien ablesen, die andererweise wiedergespiegelt wird, z. B. in den Worten, mit denen Taschenberg in Brehm's Thierleben das Capitel ron diesen Käfern einleitet:

"Die letzte... Sippe" (der Lamellicornia) „bilden die honigliebenden Cetoniden... Thiere, welche nicht scheu vor dem Lichte das nächtliche Dunkel abwarten, um aus ihren Verstecken hervorzukommen, sonderu als Frennde desselben die Kinder des Lichtes, die duftenden Blumen und blühenden Sträucher aufsuchen, um in Gesellschaft der bunten Schmetterlinge, der' lustigen Fliegen und ewig' geschäftiger Immen den Pollen zu verzehren."

Ferner habe ich zwei Schwimmkäfel und einen Wasselkäfel mit positivem Erfolg auf die Pigmentverschiebung untersucht. Es waren diese Versuche die ersten, die ich iberhaupt gemacht habe, um meine Vermuthung von einer Pigmentwanderung zu priifen.

Sie sind bereits kury publicirt worden.' Bei Dyticus marginalis füllt das Irispigment am Dunkelange, Fig. 7, Taf. I, die Rämme zwischen den Krystallkegeln und lässt die Spitzen derselben soweit frei, dass Strahlen auch in nenwenswerther Neigung gegen die Axe aus derselben austreten können. Am Lichtauge Fig. 6, Taf, I, ist der Raum zwischen den Kegeln immer noch reichlich mit Pigment versehen, aber ein grossel Theil desselben lrat sich nach rïckwärts geschoben und ïberzieht den Sehstab circa auf die Länge eines Krystallkegels. Jetzt können nur melır Strahlen, welche fast parallel der optischen Axe den Kegel verlassen; weiter verlaufen, ohne von den Pigmentscheiden absorbirt zu werden. Nahezu genau so zeigen meine Präparate die Verhältnisse bei Colymbetes fuscus (Fig. 16, Taf. II, A Dunkelauge, B Lichtauge).

Im optischen Effect gleichwerthig; in Aensserlichkeiten etwas abweichend, ist das photomechanische Verhalten des Irispigmentes bei Hydrophilus piceus. Ich habe zahlreiche Licht- und Dunkelaugen geschnitten, da dieses Thier eine Eigenthümlichkeit zeigt, die geeignet ist, den mechanischen Vorgang der Pigmentverschiebung verständlicher zu machen. Im Dunkelange (Fig. 13, Taf. II) ist das Pigment in compacte Massen zwischen den Kegeln, ihrer ganzen Länge nach, so angehäuft, dass man recht dïnne Schnitte vor sich haben muss, will man ïberhaupt die Kegel zu Gesicht bekommen. Horizontalschnitte aber zeigen, was man an Verticalschnitten kaum zu vermuthen wagt, dass jeder Kegelspitze eine runde Pigmentöffnung entspricht, durch welche das Licht zu der ziemlich entfernten

1 Durch Lieht bedingte Versehiobung des Pigmentes im Insectenange, und deren physiologische Bedentung. Sitzber. d. Wiener Akal. d. Wissensch. NUTII. Abth. III, M̈̈z 1889. 
Netzhant gelangt und ein Superpositionsbild zn entwerfen vermag. Der Raum zwischen Netzhaut und den Krystallkegeln ist bei den Facettenaugen der meisten 'Thiere ron dem Sehstab, beziehungsweise dessen schmaler' vorderer Fortsetzung durchzogen, welche sich an die Kegelspitze ansetzt. Von diesen radiär verlaufenden Gebilden ist im Hydrophilusauge nichts zu sehen; die Netzhant hängt mit dem dioptrischen Apparat gar nicht zusammen (ich konnte wenigstens keine solche Verbindung finden), hingegen ist hier der genamnte Raum durch zahlreiche mehr oder weniger parallel der Oberfläche oder schief gegen dieselbe ansteigende Fäden durchzogen, welche ein succulentes Aussehen haben und deren musculöse Natur nicht ausgeschlossen erscheint.

An der Peripherie des Auges ptlegen diese Fasern fächerförmig gegen die Pigmentschichte auszustrahlen; ich habe auch Stellen gefunden, wo sie radiär von der Netzhaut direct gegen das Irispigment aufstiegen. Lch halte es aber nach meinen Präparaten für ausgeschlossen, dass alle Faseru urspriinglich so verlanfen, und dass sie erst duch die Präparation des Auges in die schrägen und der Cornea parallelen Lagen gekommen sind; dazu wäre schon ihre Länge zu gross. Ceberall num sieht man die Fasern vorne in das Pigment übergehen, und zwar stehen sie hier mit kleinen kegelförmigen Fortsätzen der Pigmentlage in continuirlichem Zusammenlıange. Das Schicksal des anderen Endes der Faser habe ich nur an solchen Stellen erkannt, wo sie mehr oder weniger direct zur Pigmentlage anfsteigen. Da hängen die sentralen Enden mit der Netzhaut zusammen, und zwar, wie es scheint, cellr imnig und fest.

Im Lichtange (Fig. 14, Taf. II) fehlt das Pigment zwischen den Krystallkegeln bis auf wenige, wie es scheint in verzweigten Fortsätzen von Pigmentzellen liegende Reste, so dass man jetzt auch an dicken Schnitten bequem die Kegel zu sehen bekommt. Das Pigment liegt nun in der Höhe der Kegelspitzen angeliäuft und reicht eine nennenswerthe Strecke nach rückwärts. Da die Dimensionen nicht nur des Gesammtanges, sondern auch der Netzhaut dieselben geblieben sind, so muss der Raum zwischen der Pigmentlage und der Netzhaut, also der Raum, in welchem die fraglichen Fasern verlaufen, kleiner geworden sein, die Fasermasse ist zusammengedrängt. Die kegelförmigen pigmentirten Enden der Fasern sind mit der Pigmentschichte nach rïckwärts gerückt. Es fragt sich nun: Will man ammehmen, dass die Pigmentzellen, indem sie etwa die Krystallkegel als Stiitzpunkt beniitzen, sich nach rïckwärts schieben und die mit ihmen verschmolzenen Faser'n vor sich her drängen, oder will man annehmen, dass die Fasern sich contrahiren und, da sie nach längerem oder kürzerem, directerem oder schrägerem Verlauf doch vou der Netzhaut entspringen, ihre Insertionspunkte an den Pigmentzellen nach rückwärts ziehen? Die letztere Annahme wird sehr wesentlich unterstützt durch die Verhältnisse an Schmetterlingsaugen, von denen alsbald die Rede sein soll. Acceptirt man sie, dann muss man diese Fasern wohl als organische Muskelfasern betrachten. 
Hat ja schon Leydig bei Schmetterlingen solche beschrieben und 1. c. abgebildet.

Es scheint mir also wahrscheinlich, dass das Irispigment in Folge der Lichtwirkung durch organische Muskelfasern nach rïickwärts gezogen wird, wenigstens bei gewissen Thieren. Doch will ich nicht unerwähnt lassen, dass es Thiere gibt, bei denen man grosse Schwierigkeiten hätte, die fraglichen Muskeln anatomisch nachzuweisen, und doch ist die Lichtwirkung vorhanden. Es sind das insbesondere die Krebse, bei denen ich trotz der schönsten photomechanischen Wirkung Muskelfasern durchaus nicht aufzufinden vermag.

2. Schmetterlinge. Die Verschiebung des Irispigmentes fand ich, wie zu erwarten war, nur bei Nachtschmetterlingen, hier ist sie aber ron ausgezeichmeter Dentlichkeit. Die fragliche Muskelfaser setzt sich im Dunkelauge an eine langgestreckte Pigmentzelle, die zwischen den Kegeln liegt und die Spitze derselben kaum oder wenig iiberragt (Taf. IV, Fig. 29), indem sie mit dieser eine continuirliche Masse zu bilden scheint. In Lichtauge ist die Pigmentzelle in die Länge gestreckt und weit nach hinten gezogen, so dass nu ihr vorderes Ende noch zwischen den Kegeln liegt, die Hauptmasse aber in dem Raum zwischen Netzhaut und dioptrischem Apparat (Taf. IV, Fig. 2S).

An der Kupferglucke Lasiocampa (Gastropacha) quereifolia habe ich folgenden Versuch zweimal mit demselben Erfolg ausgeführt. Das Thier wurde in Dunkeln gehalten, dann bei möglichst geringem Lichtscheine der Kopf halbirt, die eine Hälfte mit dem daran befindlichen Ange in Alkohol gelegt und num das Thier, dessen Leben kanm geschädigt erschien, in die Somme gesetzt. Nach Verlauf von circa einer lablben Stunde wurde es in Alkohol getödtet; die gehärteten Augen zeigten nun auf Schnitten die ansgiebigste Pigmentverschiebung (Fig. 28, 'Taf. IV von dem zweiten Ange, Fig. 29 vom Dunkelauge). Einen ganz ebensolchen Versuch mit demselben Erfolg habe ich noch an einem anderen Abendschmetterling (wahrscheinlich Lencoma) ausgefïhrt.

An einer ganzen Reihe kleinerer Nachtschmetterlinge (Spilosoma oder Porthesia und ihren bramen Verwandten) habe ich mich von der I'igmentverschiebung in der gewöhnlichen Weise überzengt, indem ich von zwei gleichen Exemplaren das eine im Dunkeln, das andere in der Sonne tüdtete und damn die Augen schnitt (vgl. Fig. 30 ı. 31, Taf. IV). Ueberall finden sich jene in die Pigmentzellen iibergehenden Fasel'n, die als Muskelfaser'u anfzufassen sind und die Analoga zu den Muskelfasern bilden, welche die Chromathophoren der Cephalopoden alszerren und dadurch Farbenveränderungen in deren Hant herrorrufen; dieselben, schon längere Zeit bekinnt, wurden von Britcke ${ }^{1}$ zuerst elektrisch gereizt, und in newerer Zeit von Klemensiewic:z genaups studirt. ${ }^{2}$

1 Sitzber. der Wiener Akad. d. Wiss. 1852, Bu. WII

${ }^{2}$ Ebenda, Bd. IXXXVIII, Abth. JiI. 
Mit der erwähnten localen Wirkung des Lichtes hängt es zusammen. dass man, wemn allf den Belenchtungsanstand des luges bei der l'ödtumg des schmetterlings nicht geachtet wude, gelegentlich einen 'Theil des Irispigmentes in der Licht-, einen anderen in der. Dunkelstellung findet. So salt ilh es z. B. bei einem rothen Ordensband (Catocala nupta), Taf. II, Fig. 15.

\section{B. Krebse.}

Nicht weniger sicher lässt sich die Lichtwirknng auf das Irispigment bei einer Reihe von Krebsen nachweisen. Ein Aufenthalt an der zoologischen Station in Neapel machte es mir möglich, eine nemnenswerthe Reilse von Krabben und Langschwänzern in dieser Richtnng zu untersuchen. Bei der grössten Mehrzahl der Thiere fand ich muweifelhafte photomechanische Wirkung, bei einigen aber rermisste ich dieselbe. Dass diese Verschiedenloejt auch mit der Jebensweise zusammenhängt, ist zwar kaum zu bezweifeln, den Nachreis dafiir kann ich aber schon deshalb nicht bringen, weil ich in Büchern nahezn keine Angaben dariiber finde, ob diese oder jene Species Tag-oder Nachtthier ist. Die Sache wird hier noch dadurch complicint, dass die Helligkeiten, für welche das Ange eines Seekrebses eingerichtet sein muss, anch mit der 'Tiefe, in der er lebt, variirt, und dass zu erwarten ist, das Ange rermöge sich verschiedenen Helligkeiten zu adaptiren, wenn der Krels, selbst als ansschliesshrohes 'Tagthier, die Fähigkeit hat, abwechselnd in verschiedenen Tiefen zn leben und seine Bente zu erjagen.

Versehiebung des Irispigmentes durch Lichtwirkung liabe ich beobaclitet bei:

Palämon (Taf. V, Fig. 51 u. 52). Im I)nnkelauge liegt das Pigment gänzlich zwischen den Krystallkegeln. Als solche bezeichne ich die stark lichtbrechenden Antheile des Facettengliedes, die ilırer Lage und wohl anch ilırer Function nach den Kegeln der Insecten entsprechen; sie sind die Altheilmngen, welche Max Schultze mit K"“ bezeichnet. ${ }^{1}$ Dieser Autor fasst nämlich das ganze zwischen Cornea und Retina gelegene, allerdings näherungsweise kegelförmige Segment als Krystallkegel anf und unterscheidet mehrere Abschnitte desselben.

Das Irispigment hat bei Palaemon eine recht scharfe vordere und hintere Grenze, und liegt den Kegeln in dünner Lage hart an. Schon mit freiem Ange kann man an Schuitten die selı beträchtliche Lageveränderung des Pigmentes am Lichtauge erkennen. T)asselbe bildet jetzt eine dunkle Zone, die weit hinter dem Krystallkegel liegt, ja geradezu in die Nähe der Retina gewandert ist. Die Kegel sind ganz pigmentfrei. Auch in dieses nenen Lage ist die vordere und hintere Grenze des P'igmentes eine scliarfe. An Quer- und Schiefschnitten gregen die Axen des Facettengliedes erkennt man, dass die Pigmentlage bienenwabenartig durchlöchert ist. Inuch diese Bolnungen gehen die eigenthimmlichen Stränge hindurch, die, zu je vieren

1 Cnters. über die zusammengesetzten Augen der Krebse und Insecten. Bomn 1868. 
vereinigt, die Fortsetzung der selbst aus vier prismatischen Stücken bestehenden Krystallkegel bilden.

Zur Ergänzung der genannten Abbildungen, von denen die eine einem iiber Nacht im Dunkelzimmer gehaltenen, die andere einem Thiere angehört. welches längere Zeit dem directen Sonnenschein ausgesetzt war, steht mil ferner das Ange eines Palämon zur Verfügung, von dem ich eine Abbildung: nicht gebe, und der im Hintergrunde eines von der Somne nicht beschienenen Zimmers gehalten und getödtet worden war. Dieses Dämmerungsange zeigt das Irispigment in einer Mittelstellung, wie das zu erwarten war.

Es liegt auf der Hand, dass die physiologische Wirkung dieser Art der Pigmentverschiebung, die sich von der bei Insecten beobachteten quantitativ und qualitativ unterscheidet, doch wesentlich dieselbe sein muss. Je näher das Pigment an die Retina riickt, desto spitziger wird der von dem centralen Ende eines Krystallkegels - diesen im oben angegebenen Sinne genommen - ausgehende Lichtkeg*el, der die Netzhant noch erreicht, und es mag woll sein, dass bei der extremsten Lichtstellung des Irispigmentes ïberhaupt fast mu ein Sehstab oder doch nur eine kleine Gruple derselben von dem Lichte, das durch einen Kegel gegangen ist, getroffen wird. Falls es nur einer ist, so wäre dies eine wahre Lichtsonderung im Simne von Joh. Mïller, wobei der Kegel aber immer noch eine lichtsammelnde Wirkung dadurch ausiibt, dass die von dem in seiner Axe gelegenen Punkte des Gegenstandes ausgelıenden und in ihn eindringenden Strahlen näherungsweise parallel gerichtet werdelı, das schmale Netzliautelement also in concentrirterem Zustande treffen, als wenn der Kegel niclit vorhanden wäre.

Bei der Languste (Palinurus, Taf. V, Fig. 50) fand ich keine unzweifelhafte Verschiedenheit in der Lage des Irispigmentes bei einem Thiere, das im diffusen Tageslicht getödtet wurde, und einem anderen, das im Dumkeln gehalten war. Doch ist zu bedenken, dass ersteres eben nicht im directen Somnenlicht gewesen war, und dass die Tödtung des letzter'en eine, wemn auch sehr schrache Beleuchtung erforderte, und bei der Well'kraft dieser grossen Thiere nur mit einiger Vorsicht, also nach Verlanf von mindestens melreren Secunden zu bewerkstelligen ist. Ich zweifle kaum, dass unter günstigeren Verhältnissen Differenzen am Irispigment zum Ausdrucke zu bringen sind.

Sehr schlagende Resultate ergab Nica edulis, deren Auge so viel Aehnlichkeit mit dem ron Palämon einerseits mnd Sicyonia andererseits liat, dass ich eine Abbildung zu geben unterlasse. Das Dunkelauge zeigt das Irispigment zwischen den Kegeln, deren hintere kinden frei nach hinten herauslagen; im Lichtange lingegen ist dasselbe rollständig hinter die hinteren Enden der Kegel gerïickt, und verhält sich da ähnlich wie bei Palämon, abgesehen davon, dass einzelne Pigmentfüden noch weiter nach hinten ragen.

Ueberaus lehreich ist das Bild bei Sicyouia sculpta ('Taf. V, kig. 53 u. 54). Das Pigment wandert in Folge der Lichtwirkng, man möchte 
sagen, durh das halbe Ange. Bei schwahen Vergössernugen scheint es deshalb, als wären die Schichten des Auges ganz andere. I(h halue ('Taf. IV, Fig. 39) drei Angensegmente dieses Thieres bei geringer Tergrösserung gezeichnet. $D$ zeigt das Dunkelange, $L$ das lichtange und $A$ dasselbe in auffillenden Lichte. In dem letzten Segmente sieht man also auf dunklem Grunde nu die Tapetmischichten und erkennt, dass das Iristapetmu, wie dieses anch bei den anderen Krebsen der Fall ist, die Wanderming des Irispigmentes mitmacht.

Auch unser Flussliebs (Astacus fluviatilis) zeigte nu schöne photomechanische Wirkung am Irispigmente, wenn er in gutem Zustande getödtet wurde. Hier riickte aber anf Lichtwirkung nicht alles Pigment, das im Dnukelange zwischen den Kégeln lag, aus den Zwischenkegehäumen nach hinten, sondern es blieben da spärliche Reste zuriick, während der grösste Theil in Form langer Hosen den Kegelscheiden entlang bis in die Nähe der Retina wanderte.

Keine Verschiebung des Irispigmentes zeigten von den Lallgschwänzer'n mur der Bärenkrebs (Scyllarus, Taf. III, Fig 25 und 26), und Peneus, dessen von mir untersuchte Exemplare iiberhanpt kein oder fast keiu Irispigment besassen. Bei letzterem 'Thiere kann ron einer Hhotomechanischen Wirkung also nicht die Rede sein, bei Scyllarus aber dürfte eine solche wohl auffindbar sein, wenn man nenerdings Versuche darïber anstellen wollte. Da ich alle Augen der Seekrebse in Neapel conservirte und erst in Wien mikroskopisch untersuchte, so war mir eine Ueberpriifung meiner Resultate, die vielleicht durch besondere Empfindlichkeit oder Unempfindlichkeit einer Thierspecies gegen Licht oder andere hier in Betracht kommende Factoren theilweise getriibt sind, unmöglich.

Der Einsiedlerkrebs (Pagurus) zeigte sehr dentliche Verschiebnng des Pigmentes. Während es im Dunkelange ausschliesslich zwischen den Kegeln liegt, mit der Hauptmasse in der Flucht vor deren hinteren Hälften, und die Spitzen frei nach rïckwärts ragen lässt, hat es sich im Lichtauge um die Kegellänge nach der Netzhaut gezogen, allerdings olne seinen Platz zwischen den Kegeln vollständig zu rämmen. Es steht anch in dieser Beziehung Pagurus zwischen den Lang- und den Kurzschwänzer'n, demn, wie ich gleich zu schildern haben werde, kommt eine Pigmentwanderung in geschlossenter Masse, wie das bei den meisten Langschwänzern der Fall ist, bei den Krabben nicht vor. Hier tritt vielmehr eine nach riickwärts gerichtete l'igmentausbreitung ein.

Ein Blick anf die Abbildungen der Licht- und 1)unkelaugen von Kurzschwänzern zeigt, was ich mit dieser Pigmentansbreitung nach riickwärts meine. So ist Fig. 55, Taf. T, einem Dunkelange ron D romia entnommen. während Fig. 56 einem Exemplar derselben Species angehört, das in difínsen Tageslicht gehalten war. Also schon bei dieser mässigen Lichtrinwirlinng rïickt das Pigment weit nach rïckwärts, lässt aher Reste da zurück, wo es in toto im Dunkelauge gelegen war, und - was fiir diese Kurzschwänzer 
so charakteristisch ist - das nach rïckwärts wandernde Irispigment rerschmilzt mit dem nach vorne gewauderten Retinapigment zn einer contimuirlichen, wenn auch nicht dichten Pigmentscheide des Sehstabes und seiner Fortsetzung.

Bei IIaja (Taf. IV, Fig. 41 und 42) ist eine Pigmentverschiebung im selben Simne vorhanden, aber von geringem Grade. Die Kerne, welche dem vorderen Ende des Sehstabes angehören, sind im Lichtange von Pigment umhiillt, im Dunkelange nicht oder doch viel weniger dicht.

Ganz ähnlich wie Dromia verhält sich Galathea (Taf. V, Fig. 45 n. 46). Anch hier ist eine Pigmentwanderung rorhanden, die zu einer Terschmelzung ron Iris- und Retinapigment gefiilnt liat.

Anch bei Pisa (1'af. V, Fig. 48 und 49) tritt eine soluhe Velsclmelzung ein, doch unterscheidet sich das Auge dieses Thieres rou dem anderer Lírbben dadurch, dass - wie bei Langschwänzern alles Jrispigment in Folge von Lichtwirknng die Zwischenkegelıäume verlïsst. Diese I'igmentrerschiebung wird noch anfiallender dadurch, dalss anch die rordere Anschwellung des Selıstabes eine beträchtliche Strecke nach hinten rïckt. Man sieht dann einen langen Verbindungsfaden zwischen Kegelspitze und Sehstab, der im Dnukelange nicht sichthar ist. Da ich bei keinem anderen Thiere Derartiges beobachtete, so läge der Gedanke nahe; dass man es hier mit dem Ausdrucke einer Quellung oder Schrumpfung beim Härten oder einer Zer'rung beim Schneiden zu thun habe. Es scheint mir das aber nicht der Fall zu sein, wie ich aus verschiedenen Umständen, auf die ich hier nicht näher eingehen zn sollen glaube, vermuthe.

Eigenthümlicher ist die Verschiebung des Irispigmentes bei Pol'tum us (Taf. IV, Fig. 37 und 38). Hier zielit es sich als ziemlich compacte Nasse eine kurze Strecke weit den Sebstab entlaug, seine vordere Anschwellung einhiillend.

Anch Carcinus maenas zeigt muweifelhafte photomechanische Erscheinumgen am Trispigment.

Squilla mantis liess mich keine Verschiebungen des Pigmentes erkemnen. 


\section{CAPITEL.}

\section{Das Netzhautbild verschiedener Insecten und Krebse.}

Die zwei geschilderten Formen zusammengesetzter Augen ron Limulus und Lampyris bilden 'Typen, auf' welche sich fast alle vou mir anatomisch und optisch studirten zusammengesetzten Sehorgane der Arthropoden zurïckführen lassen, trotz der enormen llannigfaltigkeit derselben. In den unten zu besprechenden Mischtormen, welche man vielleicht als besonderen 'Typus auffassen könnte, sehe ich gerade eine Bekräftigung dafiir, jene beiden als Urtypen betrachten zu sollen.

Der wesentlichste und anatomisch lercht festmustellende Unterschied del beiden Augenformen ist die in der geschilderten Functionsweise begründete Lage der Netzhaut, wenigstens insoferne, als 1. ein Superpositionsbild nur möglich ist in Augen, in denen sich zwischen dem dioptrischen Apparat und der empfindlichen Schichte der Netzhaut eine dickere Lage durchsichtigen Gewebes in einer solchenAnordnung findet, dass ein Netzhautelement von Strahleu, die aus mehreren Kegelspitzen austreten, getroffen werden kann, und 2. ein Auge, dessen Netzhantelemente sich in nächster Nähe der Kegelspitzen befinden, ein Appositionsbild entwerfen kann.

Nun sind die Netzhantelemente, als welche ich das betrachte, was nan früher Sehstab nannte, und was Grenacher das Rhabdom mit den Retinulazellen nennt, bei sehr vielen Thieren lange, und reichen rom Kegel angefangen so weit nach hinten, dass ihre vorderen Antheile einem appositionellen Bilde, die hinteren aber ganz wohl einem superponirten entsprechen können. Sie thun dies wohl theilweise in der That, wie ich unten besprechen werde. Hier genügt uns vorläufig der Satz, dass eine an die Kegel sich anschliessende Retinula anf ein Appositionsbild, eine entfernte anf ein Superpositionsbild hindeutet.

Auch im optischen Verhalten gibt es Merkmale, die beiden Augentypen ohne eingehende Untersuchung zu muterscheiden. Kappt man ein frisches oder ein gehärtetes Auge al, so hindert gewölnlich das hinter dem dioptrischen Apparate gelegene Gewebe und besonders das Pigment am Anblicke des Netzhautbildes. Doch pflegen dann wenigstens ein Paar 
Kegelspitzen so frei zu liegen, dass man die aus ihnen tretenden Strahlen beobachten kann. Hat man dann als Lichtquelle zwei lenchtende Punkte aufgestellt, so weichen 1 . die ihnen zugehörenden Strahlenbündel hinter den Kegehn auseinander, kreuzen sich in der Gegend der Kegelspitze, un vor derselben wieder scheinbar zu divergiren; hinter der Kegelspitze verschwindet das rechte Strahlenbiindel, falls man den rechten Lichtpunkt abblendet: wenn dem Aıge ein Superpositionsbild angehört. 2. Die Strahlenbiindel oder die Axen der Strahlenkegel divergiren aber wenig oder gar nicht und es verschwindet hinter dem Kegel das rechte Lichtbiindel, falls man den linken Lichtpunkt verdeckt: wenn man es mit einem Appositionsbild zu thun hat. Oder, falls dieses Mittel, was bei gewissen Augen vorkommt, im Stiche lässt, beniitzt man einen Lichtpunkt als Object, sieht damn unter dem Nikroskope jedem Kegel entsprechend einen hellen Punkt näher mngsweise in der Ebeve des dioptrischen Apparates und erkennt bei I) relrung der Stellschraube im Sinne einer Annäherung an die Netzhant die ron diesen Punkten weiter verlanfenden Strahlenbündel als untereinander stark convergirend oder nur kanm merklich convergirend, je nachdem man es mit einem Superpositionsbilde oder einem Appositionsbilde zu thum lat. Tie Ursache dieses Verhaltens ergibt sich aus dem oben für die beiden Augentypen dargelegten Stralılenverlanf.

Am besten ist es natïllich, wenn ein das Bild deckendes Gewebe nicht hinter dem optischen Apparate liegt, und man die Frage nach dem Angentypus dadurch beantworten kann, dass man sich von der Abwesenheit oder Anwesenheit des superponirten Netzhautbildes direct unter dem Mikroskope iiberzengt. Das Thier wird ein bis zwei Stunden im Dunkeln gehalten, dann das Auge in einer solchen Tiefe abgekappt, dass das Netzhautpigment im Aıgenhintergrund zurïckbleibt, das Auge am längenden Tropfen unter das Mikroskop gebracht. Man sieht dann die hellen Spitzenflächen der einzelnen Facettenglieder. Hebt man nm den Tubus, so fliessen die Zerstreungskreise dieser Lichtpunkte zu dem Superpositionsbild zusammen, wenn ein solches vorhanden ist. Dasselbe pflegt bei dieser Präparationsweise freilich nicht selı dentlich zu sein, da abfallendes Pigment, Unordnung in den losen Krystallkegeln, wohl auch 'Trübung des dahintergelegenen Gewebes das Bild stört; aber als solches wird es docll, falls es iiberhanpt existirt, häufig zu erkeunen sein, besonder's wemn man zwischen Ange und Spiegel des Mikroskopes einen Gegenstand (Stift) hin und her bewegt. Hat man es mit einem Appositionsbilde zu thun, so gewahrt man bei Verschiebung eines dunklen Objectes vor dem Ange, wie die hellen Stellen, welche den einzelnen Facettengliedern entsprechen, der Reihe nach verschwinden, und zwar in dem Sinne eines aufrechten Netzhautbildes.

A. Superpositionsbilder.

1. Käfer. Da sind zunïchst jene Käfer anzufühnen, welche, wie das Lenchtkäferehen, hirstallkegel haben, die mit der Hornhant verwachsen 
sind. An ilnen ist der Narhweis des Superpositionshildes leicht, da del ganze dioptrische Apparat abgepinselt werdeu kanu.

Es ist schon bekannt, dass ansser bei Lampyris anch bei T'elephorus und Elater noctilucus diese Verwachsung rorkommt. Ich ïberzengte mich ron der Richtigkeit dieser Angabe für Elater an einem getrockneten Exekplare, das mir ron dem k. k. naturhistorischen Hofmuseum zur Verfügmng gestellt worden war; zu optischen Untersuchungen war es nicht meln' geeignet. Doch verdanke ich meinem Bruder Prof. Franz Exner cin Exemplar eines anch den Elateren zugehörigen Käfers, Agrypnus moertus, das er in Indien fing und in Alkohol conservirte. Dieses zeigt natülich auch den vereinigten dioptrischen Apparat, und sein Auge, obwohl nun seit mehr als einem Jahre in Alkohol, entwirft das vollkommenste Superpositionsbild, das ich je gesehen habe. Es ist qualitativ in allen wesentlichen Punkten identisch mit dem Bilde von Lampyris, nur sind bei Erzeugung eines Bildpunktes viel mehr Kegeln in Verwendung wie bei diesem, das Bild also lichtstärker. Entsprechend der Grösse des Käfers ist anch die des Anges und demnach des Bildes, so dass ich bei diesem Kü̈fer das aufrechte Netzhantbild mit freiem Auge sehe, ebenso das virtuelle verkehrte Bildchen, das an dem Orte des Netzhantbildes entsteht, wenn man das Licht in umgekehrter Richtung hindurchgehen lässt. Es ist selbstverständlich, dass das Auge abgepinselt und in der oben beschriebenen Weise montirt war. Ich zweifle, nach dem was ich von den Augen des amerikanischen Elater noctilucus gesehen habe, nicht, dass dieser Käfer ähnlich schöne Netzhautbilder haben wird.

In Amalfi habe ich ein Exemplar eines Leuchtkäferchens gefangen, das sich als Luciola italica lierausstellte. Dasselbe zeigte mir anch ein Bildchen, das vielleicht etwas vollkommener als das unserer Lampyris spendidula war, übrigens ganz in derselben Weise zu Stande kam.

Von den Telephorus- oder Cantharisarten untersuchte ich Cantharis fusca, fand auch hier die Angabe von der Vereinigung des dioptrischen Apparates richtig und sah ein schönes Superpositionsbild, das sich ron dem des Lampyris nicht nemnenswerth unterscheidet. Nur sind etwas weniger Krystallkegel bei der Entwerfung eines Bildpunktes betheiligt. Anch ron der Anwesenheit des verkehrten Bildes beim ungekehrten Strahlenverlaut ïberzengte ich mich wieder; es ist dies der einfachste Beweis für dip Gleichartigkeit der optischen Vorgänge; doch verabsämunte ich nicht, auch hier wieder die Untersuchung mit dem punktförmigen Objecte vorzunehmen.

Gerade dieselben Verluältnisse fand ich bei Cantharis rustica. Auch bei einem Verwandten dieses Käfers Rhagonycha melanura fand ich dieselben anatomischen Verbältnisse; dass die Verwachsmog von Cornea mud Kiystallkegel bei ihm schon bekannt ist, weiss ich nicht. Selbstrerständlich latte die optische Untersuchung das gleiche Resultat. Bei diesem sehr kleinen Thiere mit stark gekrimmter Cornea ist natürlich die Zahl der einem Bildpunkte zugehörigen Facettenglieder anch zirmlich klein. 
Viel schwieriger ist es, das Superpositionsbild bei jenen Insecten zu sehen, deren Kegel frei sind. Hier handelt es sich darum, diese beim Abkapren des Auges in ihrer natiirlichen Lage zu erhalten und keine störenden Gewebe zwischen den Spitzen der Krystallkegel und dem Mikroskope zu lassen. Was speciell das Pigment betrifft, um das es sich hier hauptsächlich landelt, so geht aus dem oben über die Verschiebung des Irispigmentes Mitgetheilten hervor, welches Mittel anzuwenden ist, dasselbe bei der Beobachtung des Superpositionsbildes unschädlich zu machen.

Ich verfuhr demnach z. B. bei Hydrophilus piceus folgendermassen: die Thiere wurden aus ihrem erhellten Käfig in den dunkeln Raum gebracht (in Wasser), nach Ablauf von ein bis zwei Stunden wurde der Kopf abgeschnitten, und von directer Berührung geschïtzt in eine Kältemischung eingetragen. Wenn ich annehmen konnte, dass das Auge gefroren war, brachte ich das Ganze ans Licht, kappte mit einem gekühlten Rasirmesser das Auge in geringer Tiefe (damit vou der Netzhant nichts am Präparate bleibt) ab und brachte es in der oft geschilderten Anordnung, an einem Tropfen des Käferblutes hängend, unter das Mikroskop. Da thaut es natïrlich auf. Unter solchen Umständen kounte ich mich von der Anwesenheit des Superpositionsbildes ïberzeugen, ebenso von der des virtuellen verkehrten Bildes, beide waren allerdings nicht schön, doch war das unter den gegebeneu Verhältnissen nicht anders zu erwarten.

Das Ange des Hydrophilus unterscheidet sich recht bedeutend von dem der bisher besprochenen Käfer; es hat andererseits viele Aehnlichkeit mit dem anderel Insecten, so dass ich hier etwas näher auf dasselbe eingehen muss. ${ }^{1}$ Der Unterschied liegt vor Allem in der Dicke der Cornea und der Grösse ihrer optischen Wirkung. Ich lrabe die Cornea in Fig. 13 und 14, Taf. II, welche dem Hydrophilus gewidmet sind, nicht gezeichnet und bitte den Leser, sich Corneafacetten daran zn denken, etwa von den Dimensionen der in Fig. 23, Taf. III, abgebildeten. Die Corneafacette ist ein Linsencylinder, der vorne und hinten eine kugelige Begrenzung hat. Da die vordere Corneafläche glatt ist und nicht wie bei vielen anderen Thieren jeder Facette eine Vorwölbung entspricht, so ist der Krïmmungslialbmesser der vorderen Facettenfläche identisch mit dem der vorderen Corneafläche. Er ist in verschiedenen Abschnitten allerdings nicht genau derselbe und misst nach ophthalmometrischen Messungen, sowie nach Cirkehmessungen 1.4 Millimeter. Der Krümmungshalbmesser der hinteren Begrenzungsfläche beträgt nach Cirkehmessung an einem projicirten mikroskopischen Bilde 0.013 Millimeter. 1)iese Corneafacette entwirft, wenn sie vorne mit Luft, hinten mit Wasser in Berührung ist, ein ungekehrtes Bildchen, das 0.037 Millimeter hinter der zweiten Begrenzungsfläche liegt. Es treten also die Strahlen stark convergirend in den Krystallkegel ein.

1 Vgl. meine Abhandlung: Das Sehen von Bewegungen und die Theorie des zusammengesetaten Auges. Wiener akad. Sitzber. Bd. LXXII, Abth. III, 1875. 


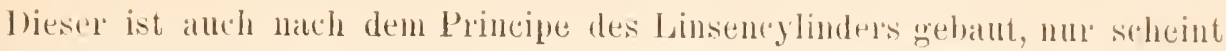
er von geringerer brechender Kraft zu sein, als die Cornèil.

Ich habe mich davon iiberzelgt, inden ich sah, dass el auch nach Abtragung der Spitze noch deutliche Bildchen entwarf, dass er bei Untersnchung mit dem Mikrorefractometer das Licht, welches senkrecht auf seine Axe lindurchdringt, so stark ablenkte, wie es ein gleichgeformter hörper thun wïrde, wenn er den Brechungsindex von 1.559 hätte. (I)ie verschiedenen Kegel zeigen nicht ganz gleiche optische Eigenschaften, so dass ich einen Mittelwerth wähle). Erinnern wir uns, dass die überaus compacte Chitinmasse des Limulusanges einen Brechungsindex von 1.535 hat, so wird man lieber annelmen wollen, dass jene starke Brechung einer Schichtung nach Art eines Linsencylinders zuzuschreiben sei. Ferner zeigen abgestntzte Stiicke der Kegel, ohne die Spitzentläche mit dem Mikrorefractometer geprïft, noch deutliche Strahlen - sammelnde Wirkung; ja entwerfen schöne Bildchen, so dass ein Zweifel ïber ihre Natur als Linsencylinder nicht melır bestehen kann.

Die Corneafacette und der Krystallkegel zusammen bilden also auch hier ein astronomisches Fermrohr, und die brechende Kraft desselben wird theils durch die kugelig gekrümmten Flächen, theils durch den geschichteten Ban aufgebracht. Die Hauptrolle dabei spielt die Corneafacette, denn dieselbe wirkt, wie gesagt, als Linse ron sehr geringer Brennweite. Unter den natürlichen Verhältnissen schliesst sich hart an die hintere Corneafläche der Krystallkegel an. Dieser hat eine vordere concave Fläche, welche das Bildchen also nach hinten verschieben muss. So entsteht es zweifelsolne im Krystallkegel wie bei Lampyris, und der Ort desselben entspricht dem Brennpunkt in einem Linsencylinder ron der doppelten Länge seiner Brennweite. (S. die physik. Einleitung.) Die Function der zweiten Hälfte dieses Linsencylinders ïbernimmt bei diesem Käfer wohl zum grossen Theile die sogenannte Spitze des Krystallkegels als gekriimmte Flächr. Da sie eine kugelige Begrenzungsfläche von sehr kleinem Radius darstellt, so muss ihr eine so starke Wirkung zugeschrieben werden, umsomehr, als die Linsencylinderwirkung des Kegels nicht bedentend ist.

Der Querschnitt durch den hinteren Theil der Corneafacette ist ein sehı nennenswerth grösserer, als der Querschmitt durch den vordersten Theil des Krystallkegels. Es ist also die Möglichkeit gegeben, dass Lichtstrahlen durch die Randtheile der hinteren Begrenzungsflïche der Cornea austreten und gar nicht in den Kegel gelangen. Es sind das also jenc Strahlen, die theils vom Irispigmente absorbirt, theils aus dem Auge zuriickreflectirt werden, und diesem dadurch jenen eigenthïmlichen S'himmer verleihen. Es war oben gelegentlich der katoptrischen Wirkung der Krystallkegel von ihm die Rede.

Kehren wir nun zu den Superpositionsbildern, die bei Käfern beobachtet werden kömnen, zuriick. Fin wenigstens muweifelhaft erkennbares Netzhautbild dieser Art sah ich bei Rosenkïfer'n, und zwal bei Cetonia 
aftinis, cetonia metallica und deren Verwandten Tropinota hirtella. Ich sah es im frischen Zustande, wenn es mir gelang, das Ange olme die Kiegel in Unordnung zu bringen, gerade in einer solchen Tiefe aluzukappen, dass das Retinapigment nicht mehr im Präparate enthalten war. Der Augenabschnitt wurde dann in der ïblichen Weise im hängenden Tropfen aus Glycerin rom Brechungsindex des Fäferblutes unter das Mikroskop gebracht. Bei manchen Exemplaren des letztgenannten Käfers stand das Bild an Schönheit nicht nennenswerth dem von Lampyris nach. Die Fasermasse, welche zwischen Kegehn und Retina ausgespannt ist und die an dem Präparat zwischen dem dioptrischen Apparate und Bild liegt, muss natürlich im Allgemeinen letzteres schädigen, da dieses Gewebe die Durchsichtigkeit verliert, die es unzweifelhaft im Leben hat. Trotzdem gelang es mir z. B. bei Tropinota alle jene Bilder der Reihe nach zu sehen, die ich in den Fig. 2 bis 5, Taf. I, von Lampyris abgebildet habe. Man sieht die Vereinigung der Strahlen in dem freilich etwas verwaschenen Bildpunkt, der aber sogar anch dieselbe Interferenzzeichnmng lat wie beim Leuchtkäferchen. Es waren die Rosenkäfer die ersten Insecten, an denen ich nach Lampyris das aufrechte Netzhautbild fand. Jetzt glaube ich zu wissen, woher das rïhren dürfte. Bei Besprechung des Irispigmentes habe ich darauf aufmerksam gemacht, dass dasselbe bei diesen 'Thieren ungefähr in der F'lucht der Kegelspitzen mit scharfer Grenze aufhört. Diese ragen also in den ganz pigmentlosen "Glaskörperraum" hinein, wie dies bei anderen Insecten nur in der Nachstellung des Irispigmenteš der Fall zu sein pflegt. Das ist offenbar ein gïnstiger Umstand zur Wahrnehmung des Netzhantbildes unter dem Mikroskop.

Die Rosenkäfer und ihre Verwandten haben verhältnissmässig selır dicke Corneafacetten, welche dementsprechend als starke Linsencylinder wirken. Pinselte ich das Auge einer Cetonia ab, so sah ich bei normaler Montirung natïrlich auch wieder ein verkehrtes Bildchen der äusseren Objecte in jeder Facette. Dasselbe liegt in nächster Nähe der hinteren Corneafläche, vielleicht noch etwas vor derselben. Benïtzte ich als Object zwei Lichtpunkte, so konnte festgestellt werden, dass die Axen der beiden sehr spitzen Strahlenkegel, die von den Bildpunkten nach hinten verlaufen, nicht merklich divergirten. Es entspricht demnach die optische Wirkung der Corneafacette näherungsweise einem Linsencylinder von der Länge seiner Brennweite (selbst in Damarlack eingebettet liegt das Bild der Comeafacette in nächster Nähe ihrer hinteren Fläche), mnd es ist sehr wohl möglich, dass der Rest der noch nöthigen optischen Wirkung fast ausschliesslich von der kugelig gekrïmmten Spitzenfläche des seln kleinen, man möchte fist sagen, rndinentären Krystallkegels aufgebracht wird. Dieser kleine Krystallkegel bewirkt es auch, dass der Rosenkäfer, obgleich er ein Superpositionsbild hat und sein Irispigment einer photomechanischen Wirkung merklich muzugänglich ist, anch in der grellen Sonnenbelenchtung keine zu starke Netzhantreizung prleidet. Ich habe ja gelegentich der optischen Wirkmngen 
der Kegel (S. 59) auf die Bedeutung des Grössenverhältnisses von Corneafacette und Krystallkegel hingewiesen. Ganz ähnlich wie bei Cetonia und 'Tropinotal fand ich sowohl den bau des Anges, als anch die optischen Verhältnisse bei Oryctes rhinoceros (Lin.).

2. Schmetterlinge. Superpositionsbilder sind hier nur bei Nachtthieren zu erwarten. Versuche, die Augen von im Dunkeln gehaltenen Thieren gefrieren zu lassen, dann abzukappen und das Netzhautbild so direct zu beobachten, habe ich nicht genacht. Es schien mir überflüssig, da ich an Spiritusexemplaren von im Dunkeln gelıaltenen Schmetterlingeu, wenn auch nicht schöne, so doch ihre Existenz hinlänglich beweisende Netzhanthilder sah. Ich verfuhr dabei in der iiblichen Weise und hellte das trübgewordene Gewebe des Glaskörperrammes durch Glycerin etwas auf.

Sthön sind die Bilder freilich nicht, die ich so erhielt, ich musste mich begnïgen, den verwaschenen Lichtpunkt, der das Bild einer Kerzenflamme war, bei Verschiebung der Kerze in den Sinne eines anfrechten Netzhautbildes wandern zu sehen oder mich davon zu überzeugen, dass bei Verwendung eines lenchtenden Punktes als Gegenstand die aus einigen Krystallkegeln austretenden Strahlen nach hinten convergiren, oder dass bei Verwendung zweier Bildpunkte die beiden ans einer Iegelspitze austretenden Strahlen nach hinten im Sinne des Superpositionsbildes divergiren, u. s. w.

Ich sal dieses bei Sphinx convolvuli und bei vier kleinen Nachtfaltern: Porthesia, Ocneria rubea, Leucoma salicis und Cnophria quadra.

Es scheint mir demnach der allgemeine Satz gerechtfertigt, dass jene Nacht- und Dämmerungsfalter mit eukonen Augen, deren Selıstäle wenigstens in ihren breiten Antheilen (vgl. Fig. 15, Taf. 1I, Fig. 28, 30, 31, Taf. IV) eine wohl ausgebildete und vom dioptrischen Apparat abstehende Retina bilden (z. B. auch der am 'Tage fliegende Abendfalter Macroglossa), ganz allgemein Superpositionsbilder haben. Nur so wird die hier besonders stark entwickelte Verschiebbarkeit des Irispigmentes verständlich, jede andere Auffassung dieser Augen stellt uns, soviel ich selien kann, vor ein Räthsel, so dass ich, wie schon einmal hervorgehoben, den Nachweis dieser eigenthümlichen Pigmentresschiebung als TVahrscheinlichkeitsgrund für die Annahme eines Superpositionsbildes anselıen muss. Schwerer wiegt überdies die Erscheinung des Augenleuchtens, auf die ich erst später zu sprechen komme, und wehche auf die optischen Vorgänge, die in Auge stattfinden, sichere Schlüsse gestattet. Wir werden sehen, dass auch diese für ein Superpositionsbild spricht. Anatomisches, photomechanisches Verhalten, sowie die directe Beobachtung des Superpositionsbildes lassen also über den Augentypus dieser Nacht- und Abendfalter keinen Zweifel.

3. Krebse. Ich luabe keinen Krebs gefunden, an dem ich das Superpositionsbild sehen konnte. Die Ursache davon liegt offenbar darin, dass nicht nur die Krystallkegel mit der Hormhant nicht verwaclisen, sondern 
anch im höchsten Grade vergänglich, weich, fast zerfliessend sind. Schon viele Forscher haben bei der anatomischen Untersuchung mit diesen Schwierigkeiten zu kämpfen gehabt. Es ist deshalb nicht wunderbar, dass es mir trotz Gefrierens u. dgl. nicht gelang. den dioptrischen Apparat eines der hier in Betracht kommenden Krebse abgekappt und in genïgend erhaltener Anordnung unter das Mikroskop zu bringen.

Trotzdem halte ich es für zweifellos, dass es auch viele Krebse gibt, deren Auge ein Superpositionsbild entwirft. Andere allerdings haben kein solclies, sondern ein Appositionsbild, wie das von Limulus schon besprochen wurde. Es gibt aber Krebse, deren Auge so viele Aehnlichkeit mit dem jener Insecten hat, an denen ein Superpositionsbild theils nacligewiesen, theils sehr wahrscheinlich gemacht wurde, dass an eine andere Functionsweise schwer zu denken ist. Ich erwähne die wohl ausgebildeten Kegel, das Irispigment und seine charakteristische Verschiebbarkeit, die rom dioptrischen Apparate entfernte Retina mit ihrem erst später zu besprechenden Pigment und Tapetum, sowie das auch erst unten zu behaudelnde charakteristische Augenleuchten.

Die Krebse, ron denen ich hier spreche, und deren Ange ich durch eigene Untersnchnng kennen gelernt habe, sind: Unser Flusskrebs (Astacns fluviatilis), Palinurus, Palämon, Peneus membranaceus, Crangon, Seyllarus; Sicyonia sculpta, Nica edulis, Pagurus, Carcinus maenas, Dromia vulgaris, Maja, Pisa, Portunus und Galathea.

Es sind also Langschwänze, Halbschwänze und Kurzschwänze, Vertreter aus den drei Familien der Dekapoden, deren Augen jenen Typus tragen, während Squilla mantis als Tertreter der Stomatopoden, und wie wir sahen, Limulns Appositionsbilder haben.

Die Cornea spielt bei den hrebsen eine weit geringere Rolle als lichtbrechendes Organ wie bei Insecten, zumal bei Käfern. Sie ist dünn und mit un schwach gekrïmmten Endflächen versehen. Die Hauptrolle fällt angenscheinlich den Kegeln zn, mnd zwar jenem stark lichtbrechenden, aus vier Stïcken hestehenden 'Theile derselben, der' schon öfter's mit einer aylindrischen Lupe verglichen worden ist. Freilich sieht man an vielen Präparaten die brechenden Flächen derselben nicht kugelig gekrïmmt, sondern mit vier, len vier Stïcken angehörigen, kuppeligen Wölbungen versehen. Da man aber andererseits schöne kugelige oder hyperbolische Endflïchen sieht (vgl. z. B. Fig. 46, 47, 50, 55 der Taf. V) und man derartige Infferenzen in Bane sonst ïhnlicher Angen nicht wohl annehmen kann, so wird man eines der Bilder für Kinnstproduct halten mïssen, mmsomehr, als wir ja die starke Quellharkeit schon kennen. Dann kamn es aber keinem Zweifel muterliegen, welches das kunstproduct ist. Es ist sehr wahrscheinlich, dass jedes der vier stücke für sich quillt, und demnach für sich Kuppen bildet, es ist aher sehr mwahrscheinlich, dass vier Kuppen durch (Qncllnng so verschnolzen, dass sie eine schöne Rundung bilden unı gerade an der optischen Axe das Maximm der Länge roigen, oder dass sie, 
wie das an anderen Angen vorkommt, mit einer gemeinschaftlichen ebenen Grundfläche abschliessen.

Dieser aus vier Stücken bestehende Krystallkegel wirkt als Linsencylinder. Ich komnte mich allerdings am frischen Ange davon nicht überzeugen wegen der leichten Vergänglichkeit der Gebilde, wohl aber an in Alkohol erhärteten. An Palämon nämlich sind die beiden Endflächen des Linsencylinders eben begrenzt (Fig. 51 u. 52, 'Taf. V). Trotzdem entwarfen selbst noch Abschnitte derselben, welche in Damarlack engebettet sind, und deren Axe in der Richtung der Mikroskopaxe stand, ganz hïbsche verkehrte Bildchen, wie ich solche bei Lampyris nach Entfermung der gekrümmten Endflächen schon beschrieben habe. Dabei vereinigen sich die von einem in der Axe gelegenen Lichtpunkte alisgehenden Strahlen in einem Bildpunkte so, als wären die vier Stücke, aus denen der Keg'el zusammengesetzt ist, eine homogene Masse. Auch noch in anderer Weise komnte ich den geschichteten Ban nachweisen. Bringt man die Kegel in eine Flïssigkeit, die schwächer (Wasser) oder die bedentend stärker (Monobrommaphthalin) bricht, wie die äussere Schichte des Kegels, so sieht man mit dem Mikrorefractometer ein ïberaus plastisches Bild des vierseitigen Prismas. Diese Gestalt haben nämlich in Wirklichkeit die recht uneigentlich "Kegel" genannten Körper. In schwacl brechenden Flïssigkeiten scheint das Prisma scharf beleuchtet zu sein von der Seite her, auf welcher der Schirm des Mikrorefractometers steht, und die Fläche der anderen Seite liegt im tiefen Schatten. In stark brechender Flïssigkeit scheint die Beleuchtung von der entgegengesetzten Seite zu kommen. Es ist das der Effect, der bei der Benützung des Mikrorefractometers mnd der Gestalt des mutersuchten Objectes selbstverständlich anftreten muss. Legt man die Krystallkegel aber in Flüssigkeiten, deren Brechmngsindex zwischen den genamnten liegt, so schwindet mehr und mehr das kantige Aussehen der Kegel, sie erscheinen wie runde Säulen, die vou der einen oder der anderen Seite her beleuchtet sind. Das kann nur daher rühren, dass nun die Schichtung, durch welche sie beim Durchgang des Lichtes senkrecht zu ihrer Längsaxe wie Cylinderlinsen wirken, in ihrem optischen Effect iiber den Effect der ämsseren ebenen Flächen iiberwiegt, letzteres deshalb, weil diese eben an eine Flïssigkeit von ähnlichem Brechungsindex stossen. Sucht man endlich jene Flïssigkeit anf, in welcher der Krystallkegel weder anf der Seite des Schirmes noch auf der anderen hell erscheint, so findet man eine, die den Brechnngsindex $u=1.622$ hat. Genaner lässt sich derselbe nicht angeben, weil manche Kegel otwas stärker, andere etwas schwächer brechen.

biesen genannten Brechungsindex miisste also ein Krystalliegel haben, wenn er homogen wäre. Er ist aber so enorm lıoch, dass er mmöglich richtig sein kann. Er ïberșteigt weit den brechungsindex des gewöhmlichen Glases. Es kann die starke Brechnmg also nur dureh den geschichteten ban zn Stande gekommen sein, der den Kegel znm linsonsylinder stempelt. 
Ich will bei dieser Gelegenheit bemerken, dass man mit dem Mikrorefractometer läufig im Innern des Kegels noch einen kleinen Körper' liegen sieht, der ungeführ gleiche Gestalt mit dem Kegel hat; derselbe zeigt einen optischen Effect im Sinne einer geringeren Brechkraft, als seine Umgebung. Er ist schon bisweilen gesehen worden. Ich kann ihm eine nennenswerthe Bedeutung nicht zumessen, da man ihn in nebeneinanderliegenden Kegehn sielıt und auch vermisst, und halte es nicht für ausgeschlossen, dass er Kunstproduct ist.

Da also auch bei den in Rede stehenden Krebsen Linsencylinder einen Hauptbestandtheil des dioptrischen Apparates bilden, düıfen wir wohl auch hier ein Superpositionsbild annehmen, selbst wenn wir es nicht direct gesehen haben.

Es muss hier hervorgehoben werden, dass es zum Zustandekommen eines Superpositionsbildes nicht nöthig ist, dass jedes Facettenglied ein auf Unendlich eingestelltes astronomisches Fernrohr darstellt. Es kann auch für geringere Entfernung eingestellt sein. Wir sahen, dass bei einem Linsencylinder von der Lünge seiner Brennweite (wie der Kegel des Limulusanges einen solchen darstellt) die von zwei Punkten eines Gegenstandes ausgehenden Hauptstrahlen untereinander parallel austreten. Der Kegel braucht demnach nur um ein Geringes länger zu sein, oder es braucht nur noch eine convexe brechende Fläche hinzuzukommen, so werden die Hauptstrahlen jene Neigung mit der Facettenaxe bilden, die beim Superpositionsbild vorhanden sein muss. Es könnten dabei noch ganz wohl die ron einem Punkte des Gegenstandes ausgehenden Strahlen untereinander mässig divergiren. Das Netzhautbild wiirde dann weniger scharf sein, als im idealen Superpositionsbild, doch würde dieser Mangel wenigstens im Lichtange durch das Dazwischentreten des Irispigmentes, wie aus dem Obigen hervorgeht, selı wesentlich corrigirt. Man könnte sich also vorstellen, dass die Augen der in Rede stehenden Krebse oder eines Theiles derselben ein Superpositionsbild von einer derartigen oder ähnlichen Modification entwerfen.

Ich zweifle bei diesen Krebsen deshalb nicht an der Existenz des Superpositionsbildes, weil der Bau des Anges, sowie die Lichtrerschiebung des Iris- und des Retinapigmentes in hohem Grade für ein solches sprechen und die anderen Möglichkeiten nahezu ausschliessen. So lıätte man daran denken künnen, dass man es hier mit katoptrisch wirkenden Augen zu thun hat, nach dem 'Typus ron Phronima (siehe Cap. VIII). Damit würde allenfalls Cornea und Kegel stimmen. Es ist aber ummöglich, dass die durchsichtigen, flüssigen, bei Hürtung in kugeligen Massen gerinnenden, und vor Allem keinen höheren Brechungsindex aufweisenden Bestandtheile, welche sich hinten an den Kegel anschliessen, das Licht durch totale Reflexion zu leiten vermögen. Gerade bei den Krebsen würde die alte Bezeichnung des Glaskörpers für diese 'Theile am besten passen; denn wenn auch jeder Kegel in eine Scheide eingeschlossen ist, die sich bis an 
die Netzhant fortsetzt, und wenn diese Scheide auch noch hinter den Kegeln einen Inhalt hat, so bildet die Smmme alles dessen im Leben doch eine rollkommen durchsichtige Masse, die, wie es beim Superpositionsbild gefordert wird, das Licht in jeder Richtung gleichmässig durchlässt. Bei Phronima setzen sich die Krystallkegel bis zur Retina fort und sind im Leben deshalb so leicht zu sehen, weil sie eben einen viel höheren Brechungsindex haben als ihre Ungebung.

Kann ein Appositionsbild von der Form, wie wir es bei Limulus kennen gelernt, angenommen werden? Die grosse Entfernung der Retina vom dioptrischen Apparate, wo dieselbe besteht, spricht nicht fïr ein solches, schliesst es aber im Principe nicht ans. Was aber lätte die enorm ansgiebige Lichtverschiebung des Irispigmentes für eine Bedentung, wemn ein Appositionsbild oder auch ein katoptrisches Bild vorhanden wäre? Beim katoptrischen Bilde hätte sie gar keinen Sinn. Für das Appositionsbild könnte man beim Rückwärtsgehen des Pigmentes eine relative Verdunkelung des Netzhantbildes bei zunehmender Schärfe desselben zugeben. Die Eimrichtung wäre zwar kamm eine zweckmässige zu nemnen, demn es ist klar, dass auf diese Weise auch viele Strahlen, welche von dem in der Facettenaxe des Gegenstandes gelegenen Punkte ausgegangen sind, abgeblendet wiirden. Doch könnte man auch von diesem Standpunkte ans eine Art Mittelding zwischen Superpositionsbild und Appositionsbild - das war ja die eben geschilderte Modification - annehmen.

Es kommt aber nun noch ein Umstand in Betracht, nämlich das Ergebniss der Untersuchung mit dem Augenspiegel. Das Dunkelauge der meisten Krebse verhält sich ganz ähnlich dem Dunkelauge der Nachtschmetterlinge. Wie sich unten ergeben wird, ist das Augenleuchten, das man mit dem Augenspiegel sieht, nur durch einen Bau des Anges zu erklären, bei welchem ein Bildpunkt auf der Netzhaut durch Strahlen gebildet wird, die durch zahlreiche Facettenglieder hindurchgegangen sind. Das ist aber nur beim Superpositionsbilde der Fall.

Wenn also die Dekapoden ein Netzhautbild haben, welches dem Typus des Superpositionsbildes entspricht, so kann doch nicht gelengnet werden, dass anatomische Uebergangsformen zu dem Auge von Squilla, dessen Bau einem Appositionsbilde entspricht, vorhanden sind. Und gerade diese Uebergangsformen, sowie das Verhalten des Irispigmentes in ihnen ist ron Interesse.

Die eigentlichen Langschwänzer haben in der That jene vom dioptrischen Apparate weit entfernte, und nach rorne wohl begrenzte Netzhaut, wie solche die Nachtinsecten zeigen. Ich verweise auf die Abbildungen von Palinurus Taf. V, Fig. 50; von Sicyonia Taf. T, Fig. 53 und 54, von Peneus Taf. T, Fig. 47; von Scyllarus Taf. III, Fig. 25 und 26, wohl auch noch von Palämon 'Taf. V, Fig. 52. Auch ist, wie wir salıen, bei diesen Langschwänzern - in voller Analogie mit den Nachtfaltern die Wanderung des Irispigmentes am vollkommensten ausgebildet. Dem 
gegenïber haben viele Krurzschwänzer eine Netzhant, die aus langen Sehstäben besteht, und wo der von dem dioptrischen Apparat abgelegene Theil jedes Sehstabes, das Analogon des Netzhantelementes eines Langschwänzers, sich nur durch seine besondere Entwickelung auszeichnet. Die Selıstäbe bilden eben die bekannten der Membrana fenestrata aufsitzenden spindelförmigen Anschwellungen. Ich rerweise auf die Abbildungen von Portunus 'Taf. IT, Fig. 37 und 38; von Pisa Taf. V, Fig. 48 und 49, und Galathea Taf. V, Fig. 45 und 46. Hier scheint in der 'That die Anschwellung zwar ein Netzhantelement zu sein, aber nicht mehr das ga n ze Netzhantelement, und dementsprechend ist auch die Pigmentwanderung auf Lichtwirkung eine diffuse, von dem Typus, der bei Langschwänzern her'seht, abweichende.

Noch ein Schritt weiter fülnt nus zu anderen Kinrzsthwänzern, deren Netzhantelemente keine spindelförmigen Anselıwellungen mehr haben, sondern als cylindrisehe Sehstäbe von der Membrana fenestrata bis an den dioptrischen Apparat verlanfen. Ich verweise anf die Zeichnungen von Maja Taf. IV, Fig. 41 und 42, deqen sich noch Carcinus maenas anschliessen liesse. Hier sind wir schon bei Augen angelangt, die jenen vou Squilla mantis und ron Tagschmetterlingen (Fig. 40) ähnlich sind, sich von diesen aber noch durch die, wenn auch nicht mehr selır ausgiebige Pigmentwanderung auf Lichtwirkung unterscheiden. Doch wäre dieser letzte Rest von Pigmentwanderung nicht verständlich, wenn diese Augen nicht anch noch einen letzten Rest rom Superpositionsbild lätten. Erst Squilla, die den Dekapoden nicht mehr angehört, hat ein Auge, welches betreffs der in Rede stehenden Beziehungen vollkommen dem der 'Tagschmetterlinge gleicht, also wohl auch ein reines Appositionsbild birgt, und keine Lichtverselicbung an Irispigment mehr aufweist.

Das sind die Grïnde, aus welchen ich oben von der Möglichkeit gesprochen habe, dass es Uebergänge von Superpositions- zu Appositionsbildern gebe. Diese Uebergänge scheinen in der lieihe der Dekapoden verwirklicht, und die Selıstäbe mit hinten gelegener spindelförmiger Anschwellung ein schöner Ausdruck der doppelten Functionsweise des Anges, eimmal als Organ für ein Appositionsbild (lange, bis vorne reichende Sehstäbe), das anderemal als Organ für ein superpositionsbild (kurze, hinten gelegene Sehstäbe) zu sein, je nachden dieses die Helligkeit der Belenchtung, beziehungsweise die Stellung des Pigmentes erheischt.

Ich komme bei Besprechung der Nutzhat nochmals anf' die Bedentung dieser spindelförmigen Anschwelhung zurtick, wobei sich in dem Terhalten des Retinapigmentes eine weitere stätze für die hier vorgetragene Ansicht zeigen wird.

\section{B. Appositionsbilder.}

Limulus, dessen Appositionsbild wir genauer kennen gelernt hahen, besitzt eine sich an den dioptrischen Apparat ummittelhar anschliessende 
Retina. Es ist das ein Chankterzug jener Augen, welehe auf ein Appositionsbild angewiesen sind. Die physiologiscle bedentung des dioptriscinen Ayparates konnte auch bei Limulus an genanesten studin und ann sichersten erkannt werden, es wird nus also genïgen, wenn wir die liauptsaichlichsten Eigenthümlichkeiten desselben bei anderen Angen wiederfinden, un anclı bei diesen ein Appositionsbild anzmehmen, besonders wenn die Lage der Netzhant hiermit ïbereinstimnt. Dass die Elemente der Retina (Sehstäbe) bei den meisten Arthopoden absolut mod relativ länger sind wie bei Limulus, kommt in dioser Bezichung nicht in Behracht; es handelt sich viehnehr lier in erster Linie un den directen Anschluss an den diopurischen Aplarat.

\section{Insecten.}

Ich kappte bei einer firschen Hummel (Bombus terrestris) einen 'Tlheil des Allges in einel solchen 'Tiefe alb, dass dasselbe, in liängenden 'l'ropfen untersucht, vollkommen schwal\% elschien, abgeselıen von regelmaissig gestellten kleinen hellen stellen. welche den spitzen der kegel entspiechen und die Pforten dastellen, durch welche das Jicht zu den Sehstäben gelangen kann. Bei einer gegebenen stellung des Mikroskopspiegels ist immer nur eine Gruppe derselben erhellt. Fïhrt man einen mudmehsichtigen Körper vor dem Auge vorbei, so versehwinden die hellen Flecke der Reihe nach in den simne, dass, wenn jeder helle Fleck von einem Netzlautelement pereipint wiirde, ein aufrechtes Netzhantbild vorhanden wäre.

Nimmt man als Lichtquelle einen Lichtpunkt, so erscheint abermals eine Gruppe von liellen Punkten, die aber kleiner ist, als sie froulher bei Beleuchtmng durch ein Stïck Himmel war. Verschiebt man den Jichtpunkt, so wandert jene Gruppe im simne eines anfrechten Bildes. Die Einstellung des Mikroskoyes, bei welcher die hellen Flecke am kleinsten und hellsten ersclieinen, ist jene, welche der Einstellung auf die spitzenfläche des Limuluskegels entspricht, und fällt zusammen mit der Spitze der Krystallkegelzellen, welche Durchschnitte durch das Auge zeigen, zugleich mit den engen Oeffumngen, die das Irispigment (da maln doch anch bei diesen Angen von einem solchen, durch seine Lage kenntlichen, sprechen kaun) an dieser Stelle bildet. Rïckt man mit del Einstellung des Mikroskopes weiter nach ruickwärts, so geht jeder lelle Punkt in einen 'berstreumgskreis auseinander; die Axen derselben zeigen aber keine nennenswerthe Convergenz. Sic bilden zusammen einen grossen Zerstreungskreis, del anch im sinne eines aufrechten Bildes wandert, wenn der äussere Lichtpunkt verschoben wird.

Die geschilderten Lichtpunkte in Grunde des dioptrischen Appanates entsprechen den Brenmpunten der einzelnen Facettenglieder. Ws muss also hier auch ein kleines verkehrtes Bildchen liegen. Das ist in der 'That ebenso der Fall wie bei Limulus, nur ist es vielleicht noch muvollkomunener. Bei der Hummel, von der ich spreche, konnte ich dieses Bildchen allendings nicht sehen, und zwal deshalb nicht, weil die Oeffnung in Pignente, oder die Spitzenfläche der Kegelzellen zu klein war. Bei Fliegen (Musca 
vomitoria) kounte ich es wiederholt sehen. Es ist das nicht etwa jenes Bildchen, das Leenvenhoek und Gottsche schon gesehen hatten. Diese lıatten ja das Auge abgepinselt, d. h. alle Kegel entfernt, und sahen das allein durch die Corneafacetten entworfene Bild. In meinem Falle abel waren die Kegel sorgfältig erhalten und durch Gefrieren in situ belassen.

Dass bei der Hnmmel die Pigmentöffnung zn klein war, nm ein Bild zu zeigen, ersah ich daraus, dass ein belenchtender Punkt zwar den Brennpunkt an der genannten Stelle entwarf, ein zweiter beleuchtender Punkt aber bis anf wenige ( 2 bis 3 Centimeter in einer Entfernung von circa 60 (entimeter) an den ersten herangerïckt werden konnte, ohne dass sein Bild neben dem des ersten anfgetreten wäre. Brachte ich den zweiten noch näher, so schien der Brenmpunkt des ersten heller zu werden, d. h. die beiden schlechten Bilder verschwammen ineinander.

Man konnte aber mit Hilfe des zweiten Objectpunktes eine andere Erscheinung beobachten, die von grösserer Wichtigkeit ist. Es tritt nämlich neben der ersten Gruppe heller Flecken, eine zweite anf. Man hat also von zwei Objectpmnkten zwei Bilder in derselben gegenseitigen Lage, und jedes Bild besteht in der Erhellung einer Gruppe ron Facettenghiedern, deren Sehstäbe dasselbe aufzunehmen vermögen. Man kann die Objectpunkte recht nahe bringen, bis die beiden Gruppen miteinander verschmelzen. In diesen Gruppen von belenchteten Netzhantelementen, welche verschiedenen Punkten des belenchteten Sehfeldes angehören, haben wir also das wahre Netzhautbild vor uns. Es entsteht ganz analog, wie das von Limulus. Die Aufgabe des dioptrischen Apparates jedes Facettengliedes besteht nicht so sehr darin, ein Bild zu entwerfen, als vielmehr darin, so viel Licht als möglich, das von den an der Axe gelegenen Punkten des Sehfeldes ausgeht, dem Sehstab zuznfïhren, und Licht, das von anderen Stellen des Sehfeldes kommt, von demselben abzuhalten. Wie bei Limulus, konnte ich auch bei der Stubenfliege den eigenthïmlichen Strahlenverlauf nach der Brechung beobachten; anch das in gefrorenem Zustande abgekappte Auge der Stubenfliege zeigte mir nämlich ein Bildchen an der Spitzenfläche des dioptrischen Apparates, und wenn ich die Strahlen von zwei Bildpunkten, welche von zwei sehr nahe aneinander liegenden Objectpunkten entworfen wurden, nach hinten verfolgte, so sah ich, dass die Axen der Strahlenkegel nicht nennenswerth divergirten.

Diese Bilder des Fliegenanges gaben anch ein Mittel an die Hand, die dioptrische Wirkung der Cornea von der der Kegel zu tremmen. Ich benützte zunächst zwei belenchtende Lichtpunkte (Kerzenflammen) und sah die zwei Gruppen erhellter Facettenglieder; damn rïckte ich die Lichtpunkte näher, bis jene Gruppen zu verschmelzen anfingen. Die, beiden Gruppen gemeinschafthichen, Facettenglieder zeigten jetzt je zwei Bildpunkte. Die Entfermung derselben voneinander wude gemessen und betrug 0.003 bis 0.004 Millimeter für den Fall, dass die Objectpunkte 50 Centimeter vom Fliegenange entfernt waren, und ihr gegenseitiger Abstand 30 Centimeter 
betrug. Nun pinselte ich das Ange ab und brachte die so ron den hegelzellen, dem l'igment etc. befreite Cornea wieder mnter denselben Verhialtnissen wie früher an den hängenden 'l'ropfen. Jetzt war, za meiner Ueberraschnng, die Entfernung der beiden Bildpunkte merklich dieselbe. ${ }^{1}$ Bei den Fliegen also wird die Lage des Bremnunktes eines Facettengliedes durch den Krystallkegel nicht merklich beeinflusst, woraus freilich nicht hervorgeht, dass er gar keine optische Wirkung hat. Da er voraussichtlich doch einen höheren Brechungsindex hat, als Insectenblut, und sich direct an die Hinterfläche der Cornea anschliesst, so miisste er, wenn er sellst keine strahlensammelnde Kraft lä̈tte, das Bild nach hinten verschieben, was er nicht thut. Bedleutend aber kann seine optische Wirkıng allerdings nicht sein.

Grenacher rechnet das Fliegenange zn den psendokonen Augen, und, wie dieser Versuch lehrt, mit Recht, da die optische Wirkung durch die Cornea zum allergrössten Theil besorgt wird und die Kegelzellen, wie der Glaskörper des Wirbelthieranges, keine wesentliche Rolle bei der Strahlenbrechung erzielen.

Bei anderen Appositionsbildern freilich ist es ganz ander's.

Aelnliche Erfahrungen wie am Fliegenange habe ich an dem Ange einer grossen Libelle gemacht. Der Ban des Auges dieser beiden 'Thiere ist sehr ähnlich, es liess sich erwarten, dass die dioptrischen Leistmngen auch einander nahe stehen. Am in gefrorenem Zustande abgekappten Ange sieht man wieder, wenn dasselbe in der correcten Weise untersucht wird, die lichten Oeffnnngen der Facettenglieder, sieht, wie dieselben bei Vorbeibewegung eines Gegenstandes im Simne eines aufrechten Netzhantbildes nacheinander verschwinden nnd wieder auftanchen. Ein heller Objectpunkt erleuchtet eine ziemlich grosse Gruppe von Oeffumgen im Irispigment, welche Gruppe im selben Simne wandert, in dem der Objectpunkt verschoben wird. Ein zweiter Objectpunkt erzengt eine nene Gruppe, die beiden Gruppen fallen noch nicht zusammen, wenn man die Objectpunkte bis auf wenige Centimeter aneinanderriickt (in einer Entfermung vom Ange $=$ circa 60 Centimeter), und doch kann man in dem einzelnen Facettenglied, wie bei der Hummel, noch nicht die Bilder beider Objectpunkte unterscheiden. Es ist allch hier die Pigmentöffnung zu klein. Deshalb lässt sich anch der Versuch, die optische Wirknng der Cornea von der cier Kegel zu trennen, nicht ausfiuhren. Es leuchtet ein, dass die Gruppen der von zwei Punkten des Sehfeldes erhellten Facettenglieder ceter. par. um so grösser sein werden, je grösser der Krümmungshalbmesser des Gesammtallges ist, und dass sie anch $n$ m so weiter voneinander entfernt sein mïssen. Es hängt von diesen Umständen die Sehschärfe des Auges ab, worauf ich hier nur verweisen will. Dass bei vielen Libellen das Auge in

1 Die Cornea der Fliegen wird von Ciaccio (Journ. of Micrographie 1889) als convexconcav gesehildert. 
zwei ungleich gebaute Abschnitte zerfällt, soll unten genau besprochen wrerden.

In älnlicher WVeise, wie ich das hier geschildert habe, sah ich noch die Merkmale des Appositionsbildes bei zalılreichen Insecten. Von Käfer'n fülı'e ich an Dorcadion aethiops und einen der Schnellkäfer (Elateriden).

Bei Limulus labe ich auf die optische Bedentung der gegen die Corneabberfäche schief gestellten Kegel anfmerksam gemacht und gezeigt, wie, dank dieser Einlichtung, trotz einer flachen Cornea das Selıfeld ein grosses sein muss. Diese Eigenthiumlichkeit, dass sowohl die Axe der dicken Hornhantcylinder', als der Kegel nicht senkrecht steht auf die Oberfläche der Cornea, fand ich wieder bei der Hornisse (Tespa crabro), (Taf. 111, Fig. 27), die ähnlich Hache Augen besitzt wie Limulus. Ja anch dieses Ther vielfach in Spalten diurrer Bänme u.dgl. lıelumzuschlüpfen hat, so wïıde eine stark gewölbte Cornea den Insulten nicht widerstehen können, und liegt wohl hierin, ähnlich wie bei Limulus, der Grund für die Entwickelung dieser anscheinenden Uncorrectheit in optischen Ban des Auges, welche aber bei flacher Cornea ein ausgedehntes Sehfeld ermöglicht.

Wie man sieht, habe ich hier unter den Insecten, die ein Aprositionsbild haben, ausschliesslich 'T'agtliere anführen mïssen.

\section{Krebse.}

Ich habe schon hervorgehoben, auf wie grosse Schwierigkeiten die optische Untelsuchung der krebsangen stösst. In Folge dessen kamn ich ansser vou dem schon hesprochenen Limulus mu von einem Thiere dieser Classe auf Grund optischur Prüfung des frischen Auges die Angabe machen, dass es ein Appositionsbild beherbergt.

Nach dem anatomischen bau scheint es mil abel möglich, dass Maja, sowie dass Calcinns maenas ein solches besitzen. Bei beiden reichen die gleichmässig dicken sehstähe bis an die Kegel, und lässt das eingeschaltete Pigment ein Superpositionsbild nicht leicht zu stande konmen. Freilich ist nock eine schwache Lichtwirkung auf das Jrispigment zu bemerken, die vieder unter der Voraussetznng des Appositionsbildes nicht verständlich ist.

1)as 'Thier, bei dem ich ein unzweifelhaftes Appositionsbild fand, ist Srfuilla mantis. Jedes Facettenglied von dessen Auge zeigt ein, wenn anch nicht sehr schönes verkehrtes Bildchen äusserer Objecte, zeigt also bei Verwendung zweier Objectpunkte zwei Bildpunkte im Grunde des Facettengliedes. 1)ie sie zusammensetzenden strahlen gehen nach hinten in zwei spitze Kerstrenungskegel anseinander, deren Axen merklich parallel sind wie bei Limulus. 1)iese optische Wirkung sah ich sowohl an der starken kugeligen líummung des Auges, als auch in dem fast cylindrisch gekrïmmten Antheil desselben.

Die mikroskopische Untersuchung des Licht- und Dunkelanges zeigte min keine sicher nachweisbare Pignentverschiebung, auch reichen die Sehstäbe bis an die Krystallkegel heran, beides entspricht dem Appositionsbilde. 
Von den höehst merkwiudigen Jigenthïnlichkeiten anderer Art, welche dieses Ange zeigt, soll noch unten die Rede sein.

\section{c. Augen mit doppelter Functionsweise.}

Line Anzahl ron 'Thatsachen lassen sich, wie alls dem Vorstehenden schon wiederholt ersichtlich worde, шu dureh die Amahne verstehen, dass es Angen gebe, die inn ])unkeln mit einem Superpositionsbild, an 'Tage mit einen Appositionshild sehen.

Es ist ja eigentlich das Bild im Hydrophilusange, oder im Lampyrisange bei hellem Somnenschein schon ein Appositionsbild, wenn wir ronanssetzen, dass die Pigmentscheide, die sich rom hegel gegen die lietina gezogen hat, enge genug ist, um das duch sie dringende licht mu alt ein Netzhatutelement gelangen zu lassen. Nur hat Lampyris ma Hydrophilus Sehstäbe, die in einer bedentenden Entfernung hinter dem dioutrischen Apparat er'st anfangen.

Die remen 'Tagthiere, z. B. die Fliegen, haben fast ansschliesslich Selstäbe, die bis an den dioptrischen Apparat herameichen. Es gibt aber, wie längst bekannt, eine Menge Fatettenamgen, in denen wir gleichsam eine Vermittelung dieser beiden 'Typen finden, in denen nämlich der sehstab in zwei Abtheilungen zerfällt, eine dicke wohl ansgebildete, welehe in Vereinigung mit ihren Nachbarn der Retina von Lampyris oder Hydrophilus gleichzustellen ist, und einer schmalen rorderen, welche einen morphologischen Rest darstellt, der jene spindelförmige Anschwellung zu dem Iangen Sehstal der Fliege ergänzt. Dieser morphologische Rest braucht nicht functionsunfähig zu sein, ja Grenacher hat wenigstens für gevisse Thiere gezeigt, dass er noch alle Bestandtheile enthält, die in der hinteren Anschwellung des Selistabes vorhanden sind. 'l'rotzdem aber wird man in dieser seiner Anffassung bestärkt, wenn man sieht, wie sehn er an Mächtigkeit und Ausbildung varint. So ist er z. B. bei dem Verwandten von Lalnlyris bei Cantharis fusca ein an den besten Präparaten elsen noch sichtbarer Faden geworden, dem kaum mehr eine Function bei der Lichtempfindung zumschreiben ist, msoweniger, als er beim Lenchtkäferchen gar nicht mehr rorhanden ist; oder ist er bei Palïmon und seinen Verwandten so degenerirt, dass man ihn nicht meln als Analogon der entsprechenden gut ansgebildeten Gebilde bei anderen Crustacen ansibht, sonder'n als Scheide des Fegels betrachtet. Kurz, ein Blick anf die Abbildnngen ron Facettengliedern liefert eine Stufenleiter von Graden in der Ausbildung des vorderen Antheiles der Sehstäbe, die, wie die folgende Reihe lehrt, von Null bis zn der Dicke der hinteren Antheile ansteigt: Fig. 13 ('Taf. II), 47 (Taf. V), 50 (Talf. V), 53 (Taf. T), 15 (Talf. II). 24 (Taf. IV), 37 (Taf. IV), 48 (That. V), 23 ('Taf. 1II), 16 ('Tat. II', 58 ('T'at. VI).

Nun kommt hinzu, dass mir kein Ange bekanut gewolden ist, in welchem der Selostab in diese zwei Abtheilungen getheilt ist (abgesehen von jenen, in denen die vordere ganz fehlt) und das nichl. 
Whotomechanische Wirkung des Trispigmentes zeigte. (Umgekehut wäre der Satz nicht richtig, demn es gibt photomechanische Wirkung an Angen mit langem gleichmässig dicken Sehstab.) Es ist uns die Bedeutung der Pigmentverschiebung vollkommen klar für das Superpositionsbild, bei welchem die empfindliche Schichte rom dioptrischen Apparate entfernt liegt, gerade da, wo sich bei den in Rede stehenden Augen die dicken Antheile der Sehstïbe befinden. Es ist also wohl ausserordentlich nahe liegend, dass diese Sehstabanschwellungen als Netzhaut fungiren, sobald das Ange in Dunkelstellung ist. Es gleicht dann der optische Vorgang und der optische Apparat vollkommen dem des Lampyrisauges.

Am Uebergang des dümnen Antheiles in den dicken bildet der Sehstab eine konische Fläche, welche optisch bedeutungsvoll ist. Hier sollen die von einem Lichtpunkte des Objectes kommenden Strahlen sich wieder in einen Punkt rereinigen. Dabei bilden sie selbst einen Kegel und sollen in das Netzhantelement eindringen. Dafür ist nun die konische Fläche günstig, da jeder der Strahlen dieselbe unter einem kleineren Einfallswinkel trifft, als wenn der Sehstab cylindrisch wäre. Es wird also ein klemerer Antheil reflectirt, als wenn die konische Anschwellung nicht da wäre, ein Umstand, der beim Sehen im Dunkehn sehr wohl in Betracht kommt. Sehr schön wird die Function der Sehstabanschwellung als lichtaufnehmendes Retinalement auch durch folgende Thatsache illustrirt. Beim Uebergang des Auges ron der Tag- in die Nachtstellung geht nicht nur das Irispigment die schon geschilderte Lageveränderung ein: wie noch ausführlicher besprochen werden wird, zieht sich eine Pigmentlage, die bei Tage gerade die genamnte konische Fläche ïberdeckt, bei Nacht ron derselben vollkommen rein nach hinten zurïck, wie man das z. B. bei Pisa (Taf, V, Fig. 48, 49) oder bei Portunus (Fig. 37 แ. 38, T'af. IV) sehr schön sehen kann. Es ist, als enthïllte sich die Fläche zur Aufnahme des Liclites.

Es scheint mir also, man könne nicht daran zweifehn, dass Licht, welches erst an der Anschwellung in den Sehstab eindringt, percipirt wird, somit dass solche Angen ein Superpositionsbild haben.

So ist es im I)unkeln. IVenn das Auge in die Tagstellung iibergeht, also das Irispigment den grössten Theil der Strahlen abfängt, so bekommt es ein Netzhautbild, das dem Tagbild von Lampyris gewiss sehr ähnlich ist. Abgesehen von der eben erwähnten Verschiebung des Pigmentes an und in der Retina selbst, zieht sich jetzt das Irispigment so nach hinten, dass fast nur Licht in der Richtung der Axe des Facettengliedes nach hinten gelangen kann. In dieser Axe aber liegt zunächst der dünne, dann der dicke Antheil des Sehstabes. Man wird nach dem Vorstehenden kamm melı zweifeln, dass der letztere Antheil lichtempfindlich ist; wie aber steht es mit dem dümmen vorderen?

Da dürfte die Annahme wohl am nächsten liegen, dass, so wie die morphologische Ausbildung eine continuirliche Reihe bildet, auch seine 
Functionsfühigkeit als Organ zur Umsetzung der lichtbewegung in Nervenerregung von Null his zu jener Höhe variit, die in den dicken, hinteren Antheile des Sehstabes herrscht. Ist es doch an wahrscheinlichsten, diss anch der Selstah des Appositionsanges nicht umsonst so lange ist, sondern dass er in seiner ganzen Länge fungirt. So mag der theils dicke, theils dünne Sehstab auch in seiner ganzen Länge fungiren, der dünne Antheil aber kann eine geringere, und zwar eine bei verschiedenen Angen in verschiedenem Masse geringere Rolle spielen.

Es wïrde also z. B. bei dem Ange eines Nachtfalters (Fig. 28, 'T'if. IV'), wenn sich dasselbe in Dnnkelstellnng befindet, an die mit a bereichnete Stelle des Sehstabes nicht nur Licht gelangen, welches ans der Richtung seiner Axe, sei es durch den verjüngten Antheil, oder neben demselben eindringt, sondern es wiirde auch eine ganze Menge von Lichtbündelı, die durch andere Facettenglieder gegangen waren, in a radiär zusammenstossen, in den Sehstab eindringen und dadurcl zur Lichtempfindung führen. In der Lichtstellung des Anges gelangen aber nach a nur die in oder hart neben dem dümnen Antheil des Selıstabes verlanfenden Strahlen. Diejenigen, welche im Innern verlaufen, erzengen schon hier Nervenerregung, wobei es nicht ausgeschlossen, vielmehr seln wahrscheinlich ist, dass sie nach Durchsetzung des dümen Antheiles anch noch im dicken Theil des Sellstabes dieselbe Wirkung hervorbringen.

Bei dieser Vorstellungsweise stösst man auf eine Schwierigkeit, die aber wohl nur eine scheinbare sein dürfte. Ist nämlich auch der dünne Antheil des Sehstabes lichtempfindlich, so muss die Schärfe des Netzhantbildes in der Dunkelstellung leiden, denn ein schief nach a gelangender Strahl wird dann im Allgemeinen durch eine Anzahl von dünnen Sehstabantheilen gegangen sein und diese anf seinem Tege anch in Erregung versetzt haben. Demnach wird zwar ein scharfes physikalisches Bild eines Punktes in a entstelren, abel es wird als von einem Zerstremugskreis umgeben empfunden werden. Physiologisch scharf also wäre das Bild nicht, wenn wir uns die vorderen Sehstabantheile empfindlich denken.

Ich kamn nicht umlim, auf die vollkommene Analogie aufmerksan zu machen, die dann mit dem Auge des Menschen vorhanden wäre. Auch wir haben in der Dämmerung noch (abgesehen von der geringen, durch die Pupillenweite bedingten Difierenz) scharfe Netzhantbilder im physikalischen Sinne, wir empfinden sie aber, als wäre das Bild jedes Punktes ron einem Zerstrenungskreis umgeben. Wir erkennen noch Schwarz und Weiss, z. B. auf Papier in grösseren Feldern ganz wohl, können aber nicht mehr lesen, weil die physiologischen Zerstreungskreise die Formen der einzelnen Buchstaben unkenntlich machen.

Ich halte, wie schon gesagt, trotz dieses Mangels in der Schärfe der Perception, die nothwendig gefolgert werden muss, doch die Toraussetzung; dass anch die dünnen Antleile der Sehstäbe bei den meisten Thieren fungiren, für die wahrscheinlichste, ji ich werde unten noch daron zu 
reden haben, dass diese Zerstreumgskreise sogar von functioneller Bedentming sein können, von einer Bedentnng, welche die Nachtheile der mangelhaften Schärfe voll aufwiegt. Sollte aber Jemand lieber die Functionsunfähigkeit annehmen, so würde das an der Theorie dieser Angenformen im Ganzen nichts ändern; anch dann noch wären dieselben in doppelter' Weise zu gebrauchen - oder besser gesagt - gäbe es, wie bei Lampyris und Hydrophilus, eine Menge Helligkeiten, für die sie sich zu adaptiren vermöchten. Ihr Lichtregulirungsmittel wäre nur unvergleichlich viel ansgiebiger als das, welches das Wirbelthierauge in der Iris besitzt.

Denken wir uns also die Sehstäbe auch in ihrem vordersten, an den Krystallkegel anstossenden Theil als lichtempfindlich nnd das Ange in Lichtstellung, so empfängt es ein Appositionsbild; die Grösse dieses Netzhautbildes sind wir gewolnt nach dem vordersten Ende der Sehstäbe zu rechnen. In der Nachtstellung hat das Auge ein Superpositionsbild, das in der Ebene der Anschwellnng der Sehstäbe liegt. Diese beiden Netzhantbilder sind natïrlich von mugleicher Grösse. Es lenchtet aber ein, dass sie in der Empfindung von gleicher Grösse sein müssen, da die Sehstäbe, welche die Bilder zweier Objectpunkte aufnehmen, in beiden Fällen dieselben sind.

Thiere, deren Angen diese doppelte Functionsweise besitzen, sind in erster Linie die Nacht- und Dämmerungsfalter und ein grosser Theil der kurzschwänzigen Krebse. 


\section{CAPITEL.}

\section{Die Netzhaut; ihr Pigment und ihr Tapetum.}

Schon im Vorstehenden war wiederholt von den wesentlichsten Bestandtheilen der Netzhaut, sowie von ilnem Pigment die Rede. Tch verstehe hier unter Retina die Schichte der Selistäbe bis zu jener schon wiederholt beschriebenen MLembrana fenestrata, welche Leydig als „Boden der Sklerakapsel" bezeichnet, und durch welche die Nerven aus den dahintergelegenen nervösen Gebilden, dem Ganglion opticum, zu den Sehstäben treten. Sie lässt sich bei gewissen Thieren sehr schün isoliren. So sah ich sie beim Rosenkäfer, wo sie wie mit einem Locheisen ansgeschlagene runde Lü̈cken in ganz regelmässiger Anordnung zeigt. Der 'Zwischenraum zwischen zwei Löchern ist circa halb so gross wie del' 1) urchmesser einer Oeffnung.

E. Berger' freilich belegt mit dem Namen Retina die Summe der Schichte der Sehstäbe und des Ganglion opticum; er unterscheidet in dieser Retina fünf Schichten, welche bei vielen Thieren in directestem Znsammenhang mit dem Gehim stehen, d. h. durch keinen Nervus opticus ron diesem abgetrennt sind.

Es hat diese Bezeichnungsweise ihre guten Grïnde, und es mag sein, dass wir in den Gebilden des Ganglion opticum die Analoga gewisser Schichten der Wirbelthierretina zn sehen haben. Doch ist nicht zu vergessen, dass das Bestreben, das Facettenange dem Wirbelthierange zu andogisiren, schon viel Verwirrung verursacht hat, und dass wir doch gewohnt sind, mit dem Namen Retina eine nervöse Schichte im Innern des Anges zu bezeichnen. Und das Auge wird doch nach dem Vorgange Leydig's allgemein bis zu jener Membrana fenestrata gerechet. Ls sei mir also gestattet, wiewohl Manches dagegen einzuwenden sein mag, in obigen Simne von der Retina zu sprechen, in welche durch die Membrana fenestrata die Nerven ans dem Ganglion optiom eintreten.

Der schöne Fund Grenacher's, dass das einzige constante Element im Wirbelthierange, sowie im Facettenange das stark lichthrechende

1 Untersuchungen iiher den Bun des Gehims mnd der Retina der Arthoporen. Arbciten aus dem zoolog. Institute der Universität Wien, Bı. 1. Wien 1878. 
Stäbchen, bei vielen Angen der Arthropoden in Form des Rhabdomes ist, muss die Frage wachrufen, worin wohl die Function eines solchen Stäbchens bestehen mag? Nun ist es unmittelbar klar, dass es ein Fangapparat für solche Lichtstrahlen sein muss, welche in einer von seiner Längsaxe nicht zu sehr abweichenden Richtung an dasselbe gelangen: Demn diese Strahlen können zwar in sein Inneres eindringen, können aber erst an seinem Ende wieder aus ihm austreten, im Terlanfe seiner ganzen Lünge werden sie durch totale Reflexionen am Austritte verhindert. Befände sich an seinem hinteren Ende aber ein das Licht reflectirender Körper, so würden die Lichtstrahlen nach demselben Modus wieder dureh das Stähchen oder theilweise durch die näuhsten Nachbarstäbchen zurïckbefördert werden, wie wir das nach den Untersuchungen Brïcke's von den mit Tapetum versehenen Wirbelthieraugen als sicher anzunehmen haben. Anch viele Arthropoden haben ein Tapetum, und bei diesen haben die anf die Netzhant auffallenden Strahlen auch eine Richtung, welche mit der Axe der Sehstäbe, also mit der der Rhabdome, näherungsweise zusammenfällt.

Diese ganze Einrichtung legt den Gedanken nahe, dass während der Leitung des Lichtes in den stark lichtbrechenden Stäbchen der wesentlichste Process des Sehactes, die Umwandlung von Lichtbewegung in Nervenerregung, statt hat, oder doch, sei es auf jhotochemischem Wege oder in anderer Weise, eingeleitet wird. Die zı den Stäbchen gehörenden Retinulazellen (Grenacher), die den eigentlichen Sehstab bilden, sind die Vermittler zwischen Stäbchen und den Nervenfasern, mit denen sie zusammenhängen. Die bedentende Länge, welche die Stäbchen vielfach anfweisen, dentet daranf hin, dass es für den Sehact nicht gleichgiltig ist, ob der einmal gefangene Strahl eine kurze Strecke in Stäbchen verläuft oder eine lange. Und so mag es auch kommen, dass schief durch die Stäbchen gehende Strahlen, die also wieder aus ihnen austreten, eine viel geringere Erregung hervorrufen als jene, welche es ganz durchlanfen (vgl. was S. 93 über den Zerstreuungskreis gesagt ist).

Ich habe bei meinen doch auch zienlich ausgebreiteten Untersuchungen der Arthropodenaugen keine Erfahrung gemacht, welche nicht in bestem Einklange mit der Gre nacher'schen Anffassung des Sehstabes gestanden wäre, der Auffassung, nach welcher derselbe aus, gewöhnlich sieben, langgestreckten Zellen bündelartig zusammengesetzt ist, deren sich berïhrende Flächen jene Stäbchen als eine Art Cuticularbildungen ansgeschieden haben. Soferne dieselben verschmelzen, bilden sie das Rhabdom, das auf seinem Qnerschnitt damu als siebenstrahliger Stern und umgeben von dem nicht modificirten Protoplasma der Retinulazellen Zengniss seiner Entstehnng gibt (Taf. IV, Fig. 37 a, b, Taf. T, Fig. 48, d, Fig. 50, d). Den Zusammenhang dieser Retinulazellen, die freilich gewöhnlich nicht einzeln, sondern nu' in ihrer Zusammengehörigkeit als Sehstab erkannt werden, mit den durch die Membrana fenestrata eintretenden Nerven sieht man bei vielen Thieren sehr dentlich, z. B. bei Maja. An diesem Krebse (er war in Mïller"scher 
Flüssigkeit gehärtet und vor dem Tode in der Sonne gewesen) gehen die pigmentirten Nerven ganz direct in die ebenso pigmentirten Sehstäbe iiber (Fig. 41, 42, Taf. IV. Vgl. auch Fig. 37, 38 derselben Tafel und Fig. 45, 46, Taf. V.)

Neueste Untersuchungen von S. Watase ${ }^{1}$ haben ergeben, dass, so wie die Cornea und die Krystallkegel eine cuticulare Ausscheidung aus den Zellen des Ektoderms sind, auch die Rhabdome im selben Verhältnisse zu den Retinulazellen stehen, welche letztere auch als ektodermale Sinneszellen zu betrachten sind. Demnach wäre Alles, was im Facettenglied dioptrisch oder katoptrisch wirkt, es mag selbst in der Tiefe der Sehstäbe liegen, Cuticulargebilde.

I. Das Tapetum. Im zusammengesetzten Auge kommt, wie im Wirbelthierange, ein Tapetum vor, und wie bei diesem die optische Wirkung, nämlich die Reflexion des Lichtes, auf zweierlei Wegen erzielt wird, so auch bei jenem. Bekanntlich haben gewisse Wirbelthiere (Herbivoren) ein 'Tapetum, das aus Fasern besteht, andere (Carnivoren, Fische) ein solches das aus Zellen zusammengesetzt ist. Die Arthropoden theilen sich in solches, deren Tapetum aus zahlreichen Tracheen besteht: Es sind das natürlich Insecten; dieses Tapetum ist bekannt und zuerst durch Leydig beschrieben worden. Ferner in solche, deren Tapetum aus einer körnigen, das Licht stark reflectirenden Masse bestelit, die wahrscheinlich in Zellen eingelagert ist; es kommt bei Krebsen vor und ist meines IVissens wenigstens als Tapetum noch nicht bekannt. Endlich gibt es, wie bei Virbelthieren, viele Augen, die kein Tapetum haben.

In dem Begriffe jedes Tapetums liegt es, dass es das durch die cmpfindliche Schichte der Netzhaut gegangene Licht so zuriickwirft, dass es ein zweitesmal nutzbar wird, die Netzhauterregung also vergrössert. Deshalb haben ja eben die Nachtthiere, gehören sie den Vertebraten oder Avertebraten an, ein Tapetum.

In allen bekannten Fällen ist dabei dasselbe optische Princip in Verwendung, nämlich das, nach welchem Glaspulver, Seifenschaum etc. weiss erscheint, obwohl die Bestandtheile derselben durchsichtig sind. An jeder Grenzfläche zwischen zwei Körpern von verschiedenem Brechungsindex wird nämlich Licht reflectirt, und zwar umsomehr, je grüsser der Unterschied der beiden Brechungsindices ist. Fällt ein Lichtstrahl z. B. auf einen Glassplitter, so wird ein Theil desselben an der Grenzfläche zwischen Luft und Glas reflectirt, ein anderer 'Theil dringt durch den Glassplitter' und erleidet an der Fläche, durch die er austreten soll, abermals eine Reflexion. Diese kann, wenn die Neigung des Strahles gegen die Glastläche die passende ist, sogar eine totale sein, d. h. von dem Strahl wird gar

1 Johns Hopkin's University. Baltimore. Biological Laboratory, Vol. IV. No 6. 1890. Exner, Facettenaugen. 
nichts melr auf der anderen Seite austreten. T'ritt aber doch noch ein Theil aus, so erfährt dieser an einem nächsten Glassplitter dasselbe Schicksal, so dass schliesslich alles Licht reflectirt ist, und keines durch das Glaspulver hindurch gelangt. Das Auge des Beobachters, das sich auf der Seite befindet, von der das Licht kommt, erhält dann das reflectirte weisse Licht, sieht also das Glaspulver weiss; befände es sich auf der anderen Seite des Glaspulvers, so bekäme es aus demselben kein Licht, würde das Glaspulver also schwarz sehen. Das ist die Ursache, aus welcher weisse Haare, Tracheen etc. unter dem Mikroskope im auffallenden Lichte weiss, im durchfallenden schwarz erscheinen. Es geht daraus auch hervor, dass das so reflectirte Licht nach sehr vielen Richtungen verlüuft. Das weisse Pulver erscheint ja gleichmässig weiss, wenn man das Auge anch hin und her bewegt; wïrde das Licht hauptsächlich nach einer bestimmten Richtung zurïckgeworfen werden, dann wäre dem nicht so, es erschiene das Pulver spiegehd. Das vom 'Tapetum reflectirte Licht ist immer ein zer'strentes.

Es kommt bei diesem Principe der Reflexion erst in zweiter Linie in Betracht, ob die fein vertheilten Partikelchen rundlich sind, wie bei den Krrebsen, ob sie eckige Krystalle sind wie bei gewissen Fischen, oder ob sie lange Fïden sind wie bei dem faserigen Tapetum der pflanzenfressenden Sänger oder wie die 'Tracheen der' Insecten solche darstellen.

Wie gesagt, hat bei diesen letzteren znerst Leydig ${ }^{1}$ das Tapetum beschrieben. Er schildert vollkommen zutreffend, wie man bei Oeffnung des Auges z. B. eines Nachtschmetterlings von der schönen glänzenden Membran ïberrascht wird, die in der 'liefe des Auges liegt, und auf den ersten Blick als eine Art Tapetum erkannt werden nuss. Ich iiberzengte mich von der Richtigkeit seiner Angabe, dass es sich hier um kleine Tracheenäste handelt, welche die Nembrana fenestrata durchbohren und sich alsbald in Büscheln feinster T'racheen auflösen. Je ein solches Büschel umgibt korbfürmig das untere Ende des Sehstabes und läuft an demselben ihn einhüllend, nach vorne. Wie Max Schultze angibt, hören die Tracheen in der Höhe auf, in welcher der Uebergang des dickeren zum dümneren Antheil des Sehstabes stattfindet, Leydig lässt sie in seiner Abbildung weiter hinten endigen. ${ }^{2}$ Merkwürdigerweise scheint Max Schultze gar nicht daran zn denken, dass man es hier mit einem 'Tapetum zu thun habe, vermuthet vielnehr in den Tracheenbüscheln einen Ersatz des Pigmentes. Allerdings wird auch durch 'l'racheen die Diffusion des Lichtes verhindert, aber in der Weise, dass es dem Sehstab, durch den es gegangen war, wieder zugute kommt.

Ich habe in Fig. 10 und 11, Taf. II, ein Stiick einer mit dem Tapetum versehenen Netzhaut eines Nachtschmetterlings, eimmal im auffallenden 1 Vgl. das Auge der Gliederthiere S. 13.

2 Vgl. Tafeln zur vergleiehenden Anatomie, Taf. X, Fig. 1 und 2. 
und einmal im durchfallenden Lichte gezeichnet. Ferner in Fig. 12 derselben 'Tafel zwei zu je einem Sehstab gehörige 'T'racheenbüschel. Alles so wie man es im frischen Zustande zerzupft zu sehen bekommt.

Wenn man bedenkt, dass der im Innern eines solchen Büschels gelegene Selıstab sich in der Stellnng für das auffallende Licht befindet, füı alle Lichtstrahlen, die durch ihn hindurchgegangen sind, sich aber in der Lage für durchfallendes Licht für all jene Lichtstralılen befindet, die ursprïnglich durch andere Sehstäbe gegangen waren, so leuchtet der IV erth dieses 'Tapetums wohl zur Genüge ein. Umsomelır, wenn man weiter im Ange behält, dass das Rhabdom ein Lichtfangapparat auch für das reflectirte Licht ist. Es kann kamm einem Zweifel unterliegen, dass diese Form des Tapetums wohl die vollkommenste ist, die ïberhaupt in der 'Thierwelt vorkommt, oder doch bekannt ist, nicht nur wegen der Anordnung an dem Sehstab, soudern auch wegen der Verwendung von Luft, als einen Körper von sehr geringem Brechungsindex.

Ich kenne diese Art des Tapetums, wo gerade das untere, verbreiterte Ende des Sehstabes von der 'Tracheenmasse mmhïlt ist, also da, wo es für die Reflexion am wichtigsten sein muss, nur bei Nachtinsecten. Leydig hebt aber ausdriicklich da, wo er vom 'lapetum spricht (1.c.S. 14), hervor, dass el den weissen Schimmer' anch bei 'Tagthieren (Argynnis, Volncella) gesehen habe. Ob dieses nicht anf einer auderen Form von Tracheenenden beruht, die allerdings bei Tagthieren vorzukommen pflegt?

Bei 'Tagschmettelingen nämlich sah anch wieder Leydig zuerst; dass zwischen den Selıstäben dicke, wurstartige 'Tracheen verlanfen, die vorne in der Höhe der Krystallkegel fingerförmig enden. Später hat ancl Thompson Lowne bei Syrphidae ähnliche Tracheen beschrieben. ' Sie ungeben, im Kreis herumgestellt, jeden Sehstab. Die von mil in Fig. 35, Taf. IV, von Schmetterlingen und in Fig. 24, Taf. III, von Käfer'n gezeichneten Querschnitte zeigen diese 'Tracheen als runde oder' polygonale Felder zwischen den Sehstäben. Auch Max Schultze bestätigt diese Form von Tracheen, gibt aber an, dass bei 'l'agschmetterlingen nur vier an einem Sehstab entlang laufen. Anch bei Libellen und Fliegen sah er solche vorue blind endende 'Tracheen.

Ich bezweifle nicht, dass diese bis nach vorne reichenden und relativ dicken Tracheen morphologisch mit dem früher geschilderten 'Trachealtapetum enge verwandt sind; functionell aber, glaube ich, ist illre Bedentung eine ganz andere. IVas sollte ein 'lapetum in vorderen 'I'heile des Auges? Hingegen ist es selbstverständlich, dass diese den Selıstab umgebenden Luftröhren durch totale Reflexion jeden Lichtstrahl zurïckwerfen müssen, der sie, in Sehstab verlaufend, trifft, und dass dadurch der Strahl doch nach ein- oder mehrfacher Reflexion an das Rhabdom gelangt, und in diesem gefangeu, den Selıfunctionen dienstbar gemaclıt

1 Transact. of the Linnean Soc. Zool. $188 \pm$. 
wird. Diese Reflexionen erleidet der Strahl aber auf dem Wege nach dem Augenhintergrund; es kann also von einer Wirkung, welche einem Tapetum analog wäre, nicht gesprochen werden.

Die Tracheen dieser Gestalt gehören also functionell der eigentlichen Retina an, nnd sind hier beim Tapetum nur eben wegen ihrer morphologischen Terwandtschaft besprochen worden.

Leider sieht man die feineren Tracheen an den in stark lichtbrechenden Harzen conservirten Präparaten nicht mehr. Es ist das der Grund, ans welchem meine Abbildungen für das Insectentapetum nicht reichlıaltiger sind.

Die körnige Substanz, aus welcher das Tapetum der Krebse bestelit, hat im Allgemeinen dieselbe Lage wie die Tracheenbüschel der Insecten, sie hiillt die hinteren Enden der Sehstäbe ein. Vermnthlich liegt sie in Zellen, doch konnte ich mich hiervon nicht allgemein iiberzengen (vgl. Taf. V, Fig. 48, d); im frischen Zustande unter das Mikroskop gebracht, erscheint sie ans rundlichen Körnern zusammengesetzt, deren Durchmesser z. B. bei Pisa um 0.001 Millimeter schwankt. Im durchfallenden Lichte bildet sie eine schwarze Masse, die erst nach einiger Uebung vom schwarzen Pigment durch die Art der Körnnmg zu nnterscheiden ist. Betrachtet man sie aber im aliffallenden Lichte, so erscheint sie hell und gelblich glänzend. Dic Figuren der Taf. $V$ zeigen Beispiele der Tapetumeinlagerung bei Krebsen. Um das Tapetum in der Zeichnung rom Pigment zu unterscheiden, habe ich den Kunstgriff gebraucht, alle Tapetummasse in der gelblichen Farbe zu zeichnen, wie sie im anffallenden Lichte erscheint, das Uebrige aber ist im durchfallenden Lichte dargestellt. In dieser Beziehung, aber nur in dieser, sind die Zeichnungen also schematisirt. Die Körner dieses Tapetums miissen einen ganz besonders hohen Brechungsindex haben, denn die stark reflectirende Wirkung nimmt nicht merklich ab, selbst wemn man gehärtete Augen in Damar einlegt. Ja, ich sah das Tapetum von Palämon noch als stark reflectirende Nasse, nachdem ich es mit einem Gemenge von Anilin und Nonobrommaphthalin durchtränkt hatte, dessen Brechungsindex nennenswerth grösser als 1.6 war, was auf die Termuthung fïlnt, dass hier ganz besondere optische Verhältnisse obwalten. Man hat den grossen Vortheil, dass man bei hrebsen auch an correct eingeschlossenen Schnittpräparaten jederzeit das Tapetum zu demonstriren vermag, was bei Insecten, deren Tracheen lufteer werden und sich mit Damar füllen, nicht der Fall ist. Was die Substinz dicses Tapetum ist, muss noch durch mikrochemische Untersuchung: festgestellt werden. Torläufig kann ich nur sagen, dass sie sich in den bei meinen Härtungen und Consurvirungen verwendeten Fliissigkeiten nicht löst. Es sind das Pikrinsäm'e, Clronsäure, Sublimat, Müller'sche Flüissigkeit, Alkohol, Aether, Xylol, Wasser, schwache Ameisensäure und stark alkalische Seifenlösung.

Es gehört zn den zierlichsten und iberraschendsten mikroskopischen Bildern, wemn man, am besten bei schwacher Vergrösserung (weil sonst die Objectivlinse zu viel von dem auffallenden Lichte abhält), oder dem 
einfachen Mikroskop, einen Domehschnitt durch ein Klebsange betrachtet, und nnter den gewöhnlichen Verhältnissen die suwar Schichte des Retinapigmentes zu sehen glaubt, damn das durchfallende Licht abulendet und nm an Stelle der Zone des vermeintlichen Pigmentes eine goldgläm\%end. Sclichte ror sich lat (Taf. IV, Fig. 39, $L, A$ ).

Bei stiukeren Tergrösselungen und dünnen Schnitten erkennt man damn, dass das Tapetum eine nach hinten an die Membrana fenestrata anstossende Lage bildet, welche die Enden der Sehstäbe gänzlich verdecht. Nach vorne geht sie in spitze oder kolbenfürmige Fortsätze aus, die zwischen die Selstäbe hineinragen.

An Qnerschnitten der Retina beohachtete ich, am dentlichsten beim 1) unkelange des Palämon, wie das runde Rhabdom von dem auch ziemlich runden Sehstab (den Retinulazellen) ungeben und wie sich an diesen direct in continuirlicher Masse das Tapetum anlegt. So verhält es sich natïrlich nicht mehr an den vorderen Partien der Sehstäbe, an denen das Tapetum keine continuirliche Masse bildet. (Tgl. Taf. V, Fig. 48 c, d, Fig. 49, f, Fig. 50, d.)

Die physiologische Dentung hiervon liegt anf der Hand. Ich komme übrigens bei Gelegenheit des Retinapigmentes auf diese Sehstabenden alsbald wieder zuriick.

Ausser dieser 'Tapetumschichte am hinteren Ende der Sehstäbe und natïllich anch ausser der oben als Tristapetum bezeichneten Schichte findet man bei viłen Krebsen noch eine zweite Tapetmmschichte, welche schon ausserhalb des eigentlichen Anges im Ganglion opticum zu liegen pflegt (Fig. 51-54 t, Taf. T. Tgl. fermer Fig. 47, 49). Sie besteht aus vielfach verfilzten Strängen, welche wohl Zellfortsätze sein diirften. Ihre Anordnung erinnert an die Pigmentvertheilung im Stroma der Choreoidea des Menschen, nur kann man die Einlagerung in Zellen nicht so erkennen.

Diese beiden Schichten pflegen nicht strenge getrennt zn sein, sondern sind häufig durch umegelmässige fadige und knollige Verhindmngen miteinander verknïpft; diese Verbindungen durclsctzen die Membrana fenestrata, so dass mau den Eindruck gewimnt, als wïre die im Ganglion gelegene Schichte gleichsam eine Torrathsschichte, von welcher aus Tapetumsubstanz durch die dazwischen liegende Lage des Ganglion opticum in das Auge wandern kann. ( $\mathrm{Tg}$ l. Fig. 4S, 49, Taf. T.)

Ich habe das Tapetum fast bei allen mntexsuchten Iangschwainzern gefunden, bei unserem Flusskrebs (Astacus fluviatilis), wo es die Sehstäbe etwa bis auf die Hälfte ilırer Länge nmgibt, bei Crangon, bei Palämon, der zwei Schichten besitzt (Fig. 51, 52, Taf. V), bei Palinurns mit einer Schichte (Fig. 50), bei Nica edulis, bei Sicyonia sculpta (Fig. 53, 54, Taf. T, und Fig. 39, Taf. IV) und Peneus membranaceus (Fig. 47, Taf. V), welche drei Krebse eine doppelte Tapetumlage zeigen. Nu Scyllarus zeigte mir kein Tapetum. Ich erinnere daran, dass es die langschwänzigen Krebse waren, bei denen wir die unzweifelhaftesten Superpositionsbilder fanden, bei denen auch die 
Verschiebung des Irispigmentes am ausgesprochensten war. Es scheinen eben die Dunkelthiere unter den Krebsen zu sein, und damit hängt anch die Anwesenheit des Tapetums zusammen. Unter den genannten ist besonders Peneus interessant, da diesem Krebs fast jedes Pigment im Ange felilt. Er hat nur ein Iris- und ein Retinatapetum, allerdings fand ich bei einem Exemplare auch eine Andentung von Irispigment, bei einem anderen aber nichts davon.

Von Halb- und Kurzschwänzern zeigte mir ein Tapetum: Carcinns maenas, Dromia vulgaris (Fig. 55 und 56, Taf. V) und Galathea (Fig. 45 und 46 derselben Tafel), während Maja (Fig. 41, 42, Taf. IV), Portunus (Fig. 37, Taf. IV) und Pagurus kein Tapetum erkeunen liessen. Auch bei Squilla fand ich keines. Doch kann ich nicht umhin zu bemerken, dass, wenn ich an den conservirten Augen (denn ich untersuchte die meisten Thiere auf das Tapetum erst im conservirten Zustande) kein Tapetum fand, daraus nicht liervorgeht, dass kein solches vorhanden war. Es kann das 'Tapetum bei gewissen 'Thieren eine Beschaffenheit haben, bei der' es durch die Präparation zugrunde geht, oder unsichtbar wird. So ist z. B. bei Pisa in meinen Präparaten eine zwar schwache, aber doch wohl merkliche reflectirende Wirkung zu beobachten, so dass ich eine Weile im Zweifel war, ob hier ein Tapetum vorhanden ist oder nicht.

Es ist auffallend, dass - wenigstens so weit mir bekannt wurde noch Niemand das Retinatapetum der Krebse erkannt hat. Ich wiisste nur eine Stelle aus der Literatur anzugeben, welche Zeuguiss dafür gibt, dass es gesehen worden ist, nicht aber als Tapetum erkannt wurde. Grenacher' nämlich sagt, indem er die Rhabdome von Mysis beschreilut: „Das scharf abgegrenzte, mässig spitze Hinterende ist meist wenig kenntlich, weil sich um dasselbe Züge eines eigenen, mit den Nervenfasern des Opticus hinter der inneren Cuticula aufsteigenden erdigen Pigmentes legen, die leider durch Salpetersänre nicht zu entfermen sind." Eine dazn gehörige Abbildung lässt es mir kaum zweifelhaft erscheinen, dass Grenacher hier das 'T'apetum gesehen hat; bestimmt kann ich es nicht sagen, da ich Mysis nicht mntersucht habe. Gezeichnet ist es mit einem gelluen 'Ton, also etwa so, wie man es im auffallenden Lichte sehen wïrde. Uebrigens bildet anch Max Schultze die hinteren Enden der Selıstäbe rom Flusskrebse wie mit gellem körnigen Pigmente umgeben ab, ohne aber weitere Bemerkungen daran zu knüpfen.

II. Das Retinapigment ist lange als hintere Pigmentanlüufung bekamnt, nnd oftmals wurde hervorgehoben, dass die Sehstäbe mehr oder weniger von demselben umgeben sind. Auch dass linter der Membrana fenestrata häufig noch Pigment liegt, hat Leydig schon erkannt. Er sagt hieriber: ${ }^{2}$ "Das Augenschwar" erscheint nicht immer erst

1 Sehorgan der Arthropoden, S. 119.

${ }^{2}$ Auge der Gliederthiere, S. 29. 
innerhalb der Angenkapsel (Sklerotika), sondern sehr häufig sind schon die rom Schlappen kommenden Bündel ron Nervenfasern mehr oder weniger stark pigmentirt. Hierbei zeigt sich daun, dass da, wo die Nerven zun Eintritt in die Augenkapsel sich anschicken, das I'igment gehäuft ist, wodurch schon hinter dem Boden des Sklera ${ }^{2}$ einı starke dunkle Pigmentzone hervortreten kam. So z. B. bei Acherontia Atropos. Die Pigmente liegen, wie ich mich ïberzengt zu lraben glaube, in der von mir nachgewiesenen Matrix des Neurilems."

lch labe den schon vorhandenen Beschreibungen dieses Retinapigmentes, soweit es die Insecten betrifft, nichts Wesentliches hinzuzufügen. Bei allen Angen, die ich als typische Tagangen bezeichnet habe, ist eine scharfe Grenze zwischen Irispigment und Retinapigment nicht vorhanden: an den gleichmässig dicken Selistäben sitzt das Pigment besonder's am volderen und am linteren Ende gehïuft, vorne die Verbindung des Krystallkegels mit dem Sehstab, hinten jene der Nerven mit demselben muliülend. Es pflegt in der Mitte des Selıstabes am spärlichsten vorhanden zu sein. (Vgl. Fig. 32 und 40, Taf. IV.)

Die Quantität der Pigmentkürnchen, die man im Ganglion opticum findet, wie Leydig richtig schildert, hauptsächlich die Nerven von aussen umkleidend, ist eine bei verschiedenen Thieren recht ungleiche. Das Nähele . ïber die Tertheilung und Quantität des Pigmentes zeigen die Abbildungen besser, als ich es beschreiben könnte. (Vgl. Fig. 13-17, Taf. II.)

Doch muss ich hervorheben, dass die Nachtangen in Bezug auf das Pigment recht nennenswerth von den Tagaugen differiren, wenigstens bei den Schmetterlingen. Die Nachtschmetterlinge haben fast mu knrze pyramidenförmige Häıfchen Pigmentes, welche mit ihrer Basis auf der Membrana fenestrata aufsitzen und mit ihren Spitzen zwischen die Sehstäbe hineinragen (Fig. 30 und 31, Taf. IV). So sah ich es bei allen eigentlichen Nachtschmetterlingen, die ich nntersuchte; nur der Taubenschwanz (Makioglossa, 'Fig. 17, Taf. II), der im hellen Sonnenscliein fliegt, bildet eine Ausnahme. Hier gehen lange, fadenförmige Pigmentstreifen ron der Membrana fenestrata nach vorne. Sie liegen natürlich zwischen den dicken Theilen der Sehstäbe und enden in gleicher Ebene in der Höhe, in welcher die Kerne derselben gelagert sind.

Mehr Retinapigment haben die Nachtaugen der Käfer, z. B. Hydrophilus, Lampyris und Colymbetes, bei denen die hinteren Enden der Sehstäbe wirklich von demselben vollständig umhïllt sinct. (Fig. 1, Taf. I, Fig. 13, 16, 'Taf. I1.)

Auch hier nimmt wieder der Rosenkäfer (Cetonia) und seine Verwandten eine älnhliche Stellung ein, wie der T'aubenschwanz unter den Naclitfaltern, indem bei diesen Käfern lange Pigmentstreifen, die so weit reichen, als die dicken Antheile der Selsstäbe das Retinapigment repräsen-

1 D. i. der Membrana fenestrata in der von mir gebranehten Nomenclatur. 
tiren (Fig. 23, 'Taf. III). Doch ist anch bei Käfern, wie bei den Nachtschmetterlingen, das Retinapigment vom Irispigment scharf getrennt. Diese Trennung wird nicht verwischt, wenn das letztere in excessive Lichtstellung iibergeht, wie die Beobachtungen bei Hydrophilus, Lampyris u.s.w. lehren.

Ich bin nicht in der Lage, etwas darïber zn sagen, ob die schwarzen Pigmentpartikelchen in Zellen zu liegen pflegen. Es maclit den Eindruck, dass dem nicht so ist, doch weiss ich aus Erfahrungen an Wirbelthieren, wie sehr man sich hierin täuschen kann, und machen es die sogleich zu besprechenden Pigmentverschiebungen fast undenkbar, dass keine Zellen dabei im spiele sind. Wo sollte die Quelle der bewegenden Kraft sonst sein?

III. Die photomechanische Wirkung am Retinapigment. Es ist mir nicht gelungen, bei Iusecten eine mechanische Wirknng des Lichtes auf das Retinapigment nachzuweisen. Um so sicherer gelingt dieses aber bei Krebsen. Ich kamn die Beschreibung des Pigmentes dieser also am besten vereinigen mit der Besprechung meiner Erfahrungen iiber die photomechanischen Aenderungen an demselben.

Ich beginne mit Palämon (Fig. 51 und 52, Taf. V), einem weit verbreiteten Langschwänzer, dessen Augen sich leicht schneiden lassen und der deshalb zu einer eventuellen Nachuntersuchung zu empfehlen ist.

Im Dunkelange (Fig. 51) gewahrt man die zwei besclriebenen Schichten des Tapetums, und in ihrer Nitte, also gleich hinter der Membrana fenestrata, das Lager schwarzen Pigmentes. Querschnitte durch die hintersten Enden der Sehstäbe zeigen zierliche, durchsichtige Sterne, die Sehstäbe und diese vom Tapetum umgeben. Tm Dämmerungsange ${ }^{1}$ ist ein Theil des Pigmentes aus seiner ursprïnglichen Stellung verschwunden, d. h. das Pigmentlager hinter der Membrana fenestrata ist nicht mehr so dicht, dafür findet sich jetzt Pigment in nennenswerther Menge zwischen den Sehstäben, und insbesondere an deren vorderen Enden angehäuft. Doch ist das 'Tapetum, das die hinteren Enden umgibt, immer noch sehr schön sichtbar. Einzelne Fäden ans T'apetmmmasse durchbrechen, indem sie nach vorne dringen, die Schichte von Retinapigment, treten bis an das Irispigment heran, durchbrechen auch dieses noch, $и$ sich mit dem Iristapetum zn verbinden. Im Lichtange (Fig. 52) sieht man die Sehstäbe in ihrer ganzen Länge reichlich von Pigment umhïllt. Die Zone hinter der Membrana fenestrata, welche ursprïnglich das Pigment enthielt, beherbergt nur mehr spärliche Reste desselben, dafür sieht man jetzt in ihr reichlichere Massen von Tapetmm, die mit der dahinterliegenden Tapetmonschichte

1 So nenne ieh in Kürze das Auge eines Thieres, das im Hintergrunde eines Zimmers am Tage getödtet wurde, „Lichtange" nenue ich das Auge, wenn das Thier im directen Sonnensehein getödtet worden war. 
verschmelzen, so dass diese let\%tere nach vorne allmählich ans\%uklingen scheint. Dieser Zuschuss an 'Tapetumsubstanz ist wahnscheinlich nur ein scheinbarer, indem früher das 'Tapetum im Ganglion theilweise vom Pigment verdeckit war.

Es ist sehr schwer zu sagen, ob diese ver'schiedenen Bilder nur: durch Verschiebung des Pigmentes zu Stande kommen, oder ob aucl das 'I'apetum Lageveränderungen eingelit. lch glaubte \%nerst, letyteres annchmen zu müssen. Je genauer ich aber prifte, desto wahrscheinlicher wurde es mir, dass nur das Pigment Vanderungen macht und dass die verschiedenen Bilder, welche die Tapetummasse darbietet, nur der Ausdruck grösserer oder geringerer Verdeckung durch Pigment sind. Wemn z. B. die vorderste Schichte des Ganglion opticum an Dunkelauge fast kein Tapetum erkennen lässt, so riihrt das wohl daher, dass das Pigment das auffallende Licht absorbirt, elıe es an die Tapetumkörner gekommen ist. Aehnlich ist es mit der 'Tapetumlage am hinteren Ende der Selıstäbe, die an manchen Liclitangen ganz zu verschwinden scheint. Es rïhrt dieses wohl nur daher, dass das Pigment nicht so weit mach vorne gewandert ist, wie in den der Fig. 52, Taf. V zu Grunde liegenden Auge.

Ton besonderem Interesse und für das Verständniss der optischen Wirkung wichtig ist es noch, zu sehen, wo das Pigment beim Uebergang vom Dunkelauge zum Lichtauge nach rorne kriecht. Ich habe erwähnt, dass beim Dunkelauge der sternfömige Querschnitt des Selıstabes am hinteren Ende desselben direct vom Tapetum umgeben ist. Am Dämmerungsauge gewahrt man nun im Innern dieses Sternes, und zwar gerade die Strahlen desselben erfüllend, Pigmentmasse, so dass voll dem ganzeu Stern nur das stark lichtbrechende Centrum, das Rhabdom durchsichtig bleibt (vgl. ein analoges Bild ron Pisa f. in Fig. 49, Taf. T). Um sich hiervon zu ïberzeugen, muss man am ziemlich dümmen Schnitt ẹinen Querschnitt abwechselnd im auffallenden und im durchfallenden Lichte beobachten; im lezteren Falle sieht man nichts von der Sternzeichnung; sondern nur das helle Rhabdom; im zweiten Falle sieht man den Stern dunkel, begrenzt vou dem lsellen Tapetum; ähnlich wie $d$ in Fig. 50, wobei man sich im Centrum noch das helle Rhadom zu denken hat. Durch geschicktes Abblenden des Lichtes kann man sich dann anf das unzweifelhafteste von der Anwesenheit der Pigmentkörnchen in den Strahlen des Sternes iiberzengen. Ja bei Carcinus maenas konnte ich an gewissen Stellen sehen, dass das Pigment noch nicht den ganzen Sternstrahl durchsetzt, sondern da, wo der Strahl liolbig anfgetrieben war, in der Mitte noch eine unpigmentirte Stelle zurückliess. (Man denke sich in $d$ Fig. 50 die beiden horizontalen Sternstrahlen noch stärker kolbig anfgetrieben, als es die Fig'ur zeigt, und in der Mitte ihrer kolbigen Auftreibung durchsichtig.) Ich beobachtete zwei bis vier solche unvollkommen pigmentirte Sternstralılen an einem Sehstab.

Man wird vielfach finden, es sei nicht denkbar, dass das Pigment in den Sehstab selbst eindringt; anch sei es sehr umwahrscheinlich, dass 
dieser am hinteren Ende einen sternförmigen Querschnitt habe. Es mag sein, dass meine Dentung der vorliegenden Bilder eimmal eine Correctur erfahren wird, wenn das Krebsauge genauer erfor'scht sein vird, vorläufig aber scheint mir meine Deutung die nächstliegende zu sein. Denn das stark brechende, glashelle Centrum des Sternes ist doch wohl das Rhabdom, und was darum liegt, hat sternförmige Begrenzung. Nun mag wohl sein, dass das nur ein 'Theil dessen ist, was man gewöhnlich Sehstab nennt, dann müsste eben in dem äusseren Theile desselben das Tapetum, im inneren das Pigment liegen.

Wie die Dentung in morphologischer Beziehung auch sein mag, so ist doch klar, dass, während im Dunkelange das durch Sehstab und Rhabdom nach hinten gelangte Licht hier auf das Tapetum stiess, also reflectirt wurde, schon im Dämmerungsauge sich Pigment zwischen den einfallenden Lichtstrahl und das Tapetum geschoben hat: die Reflexion also verhindert wird.

Es scheint aber, dass nicht nur anf diesem Wege Pigment nach vorne rïckt, dass vielmehr die Hauptmasse desselben zwischen den Sehstäben und den da gelagerten grösseren Tapetummassen hindurch wandert, um die ron Tapetum freien vorderen Hälften der Sehstäbe zu umhiillen; ganz besonders massig liegt es dann im Lichtange gerade in der Ebene der vorderen Enden der Sehstäbe. Zwischen ihm und dem weit nach rückwärts geschobenen Irispigment hleibt aber immer eine freie Zone.

Untersucht man Dunkel- und Liclitange (Fig. 51 und 52) mit dem einfachen Mikroskope, so erhält man den Eindruck, dass in Dunkelange, zwei Tapetumschichten durch eine Pigmentschichte getrennt sind, während im Tagange vorne eine Pigmentschichte und dahinter zwei Tapetumschichten liegen. Es orscheinen bei letzterem aber häufig die beiden Tapetmmschichten zu einer verschmolzen, und das Pigment ist thatsächlich jetzt in einer Zone, in der frïher weder Tapetum noch Pigment war.

Tch will nicht merwähnt lassen, dass ich bei einer Reihe von Individuen von Palïmon, deren mir zwei Species zur Verfïgung standen, das hier geschilderte Verhalten des Pigmentes am Dunkel-, Dämmerungs- und Tagauge beobachtet und mich ron dessen Richtigkeit ïberzeugt habe, dass ich aber andererseits doch auch ein Dunkelange geschnitten habe, bei dem in einer Ausdehnung von etwa zwei Dritttheilen der Netzhaut etwas Pigment vor' dem 'Tapetum lag. Auch bei anderen Krebsen sind mir einige Unregehmässigkeiten in dieser Richtung anfgefallen. Da andererseits aber die geschilderte photomechanische Wirkung des Retinapigmentes eine leicht und sicher nachweisbare ist, so erkläre ich mir die Fälle, in welchen dasselbe nicht die erwartete extreme Stellung eimnimmt, dadurch, dass ich doch fast immer genöthigt war, um die Thiere zu tödten entweder den Dunkelkasten oder das Dunkelzimmer ein wenig zu erhellen, um die Thiere iiberhanpt fangen zu können. (In anderen Fällen hatte ich sie in einem kleinen Behälter, aus dem ich im Dunkeln das Wasser ahgiessen und 
durch Alkohol ersetzen konnte.) Es scheint mir sehr wahrscheinlich, dass diese, weun auch nur kurze und sehr mässige Belichtung ausgereicht hat, in jenen wenigen Fällen das Resultat zu triiben. Ich habe selbstverständlich immer Verschiebungen im geschilderten Sinne gesehen, nur betrefis der extremen Licht- und Dunkelstellungen kann von Unregehmässigkeiten die Rede sein. Eine andere Ursache für dieselben kann man im Gesundheitszustande der Thiere finden. Habe ich ja doch schon erwïhnt, dass die photomechanische Wirkung auf das Irispigment bei matten mnd absterbenden Thieren nicht sicher nachzuweisen ist.

Anch bei der grossen Languste (Palinurus) untersuchte ich DunkelDänmerungs- und Lichtangen und fand im ersteren das Retinapigment hinter dem Retinatapetum (rechte Hälfte der Netzhaut in Fig. 50, Taf. V). Allerdings gab es anch in diesem Ange eine grössere Strecke, an welcher, wahrscheinlich weil es doch einiger Zeit der Belichtung bedurfte, um das grosse und sich ernstlich wehrende Thier zu fangen und ihm dem Kopff abzuschneiden (diesel wude damn erst in Alkohol gelegt), schon einiges schwarzes Pigment vor die 'Tapetumlage getreten war (linker Theil der Netzhant in der genannten Figur). Schon am Dämmerungsange war dies durchaus der Fall. Man sah die vorderen Enden der Sehstäbe nicht oder kaum, weil sie von Pigment umhiillt waren, nnd hinter diesem Pigmente kam die auch von vielfachen Pigmentstreifen durchisetzte Tapetumschichte. Auffallend ist, dass ich bei Palinurus sowohl im Dunkelange als anch im Dämmerungsauge alles Tapetum und alles Pigment in der Schichte der Sehstäbe fand; im Ganglion opticum ist nichts daron. Anch bei diesem Thiere fand ich wie bei Palämon die Querschnitte der Sehstäbe als siebenstrahlige Sterne, und am Dämmerungsange die Strahlen der Sterne pigmentlaltig, nach aussen davon Tapetumsubstanz (d Fig. 50). Uebrigens sah ich in den hintersten Theilen der Sehstäbe anch im Dunkelauge schon etwas, allerdings weniger Pigment, was wohl mit dem erwähnten Umstande zusammenhängen dürfte, dass es kein Dunkelange im strengen Sinne war.

Sehr schöne und schlagende lesultate betreffs der Ausgiebigkeit der Pigmentverschiebung ergab mir Sicyonia sculpta. Hier sind dentliche quergestreifte Sehstäbe vorhanden, welche durch eine ziemlich dicke Membrana fenestrata von der Schichte des Ganglion opticum getrennt sind, in der sich die Nervenverzweigungen befinden (Fig. 53, 54, Taf. V. und Fig. 39, Taf. IV). Hinter dieser Schichte kommen noch sehr wohl ansgebildete Abtheilungen des Sehganglions. Im Junkelange nun liegt alles Retinapigment $(\boldsymbol{r} \cdot p$. $)$ in der Schichte der Nervenverzweigungen, und das Tapetum umhiillt als rordere Schichte ( $\bullet$ t.) die hinteren Enden der Schstäbe, und als lintere Schichte $(t)$ nimmt es die Zone des Ganglion opticum ein, die an die Nervenfaserschichte angrenzt. Beim Dämmerungsauge sowrohl, wie beim Lichtauge ist die Schichte der Nervenverzweigngen vollkommen pigmentfrei geworden, enthält anch kein Tapetum, und das Pigment ist durch die 
vordere 'Tapetmmschichte hindurch an die vorderen Enden der Sehstäbe gewandert, die es umhiillt. Es ist so das Retinapigment, indem es nach vorne wanderte, recht nahe an das sehr stark nach rïckwärts verschobene Irispigment (i. p.) heranger ïckt. In der vorderen Tapetumschichte scheint bei diesem Thiere gar kein Pigment zurïckgeblieben zu sein, so dass hier nicht, wie ich es beim Palämon geschildert habe, im Lichtange eine $A b$ sorption der Strahlen an hinteren Ende der Selistäbe stattfindet, sondern es wird der grösste Theil des Lichtes durch das vorgelagerte Pigment schon absorbirt, ehe er in die Sehstäbe eindringt. Wahrscheinlich gelangt ungeschädigt nur jenes Strahlenbüudel in einen Selıstab, das in der Scheide des zugehörigen Krystallkegels rerläuft. Das Gleiche ist natïrlich anch bei dem Palämon vorauszusetzen, dessen Sehstäbe ja nicht nur hinten, sondern auch rorne ron Pigment eingehült werden, wenn Licht einwirkt.

Es ist nicht daran zu vergessen, dass sich rom Krystallkegel bis zum Sehstab bei diesen Krebsen ein pigmentfreier Strang linzieht, ja es lehrte Max Schultze, der diesen Strang mit zum Krystalliegel rechnete, dass er den Selıstab an seinem vorderen Ende unklammere. Also weder das Irispigment, noch das Retinapigment, wem letzteres auch noch so dicht an dem vorderen Ende des Sehstabes angelüuft ist, kam das Lichtbündel des zugehörigen Krystallkegels ganz abblenden. Beide Arten des Pigmentes aber scheinen sich bei diesen Angen darin zu unterstiitzen, aus dem Superpositionsbild das viel lichtschwächere Appositionsbild zu machen, wie wir dasselbe bei den Tagthieren kemen gelernt haben.

Ein ebenso dentliches Resnltat ergab mir Nica edulis, bei welchem Krebse lie Verhältuisse sehr ähnlich sind wie hei Sicyonia. Im Dunkelauge liegt das Retinapigment wieder hinter der Membrana fenestrata gemischt mit Zügen ron Tapetum. Lie Hauptmasse des Tapetmms ist aber wieder in den beiden Schichten abgelagert, zwischen den hinteren Enden der Selıstäbe und linter der Pigmentlage im Ganglion opticum. Im Lichtange ist das Pigment ans dem Ganglion verschwunden, und findet sich in eigenthümlicher Mischung nit dem Tapetum zwischen den Sehstäben, hamptsächlich an deren vorderem Autleil.

Bei Scyllarus komnte ich ein T'apetum nicht nachweisen. Das Retinapigment verhält sich hier ähnlich wie bei den Kurzschwänzern. Es lag im Dunkelange nm die hinteren Enden der Sehstäbe angehäuft, und rïckt bei Belichtung an die rorderen Enden.

Auch bei mserem Flusskrebs ist es mir, freilich erst nach mehrfuchen vergeblichen Versnchen, gelungen, die Terschiebung des Retinapigmentes auf Lichtwinung nachanweisen. Es zeigte sich da wieder, dass die Thiere in gutem Zustande sein mïssen, soll der Versuch gelingen. Nelırfach nämlich war er mir fehlgeschlagen, anch in Bezng auf das Irispigment, offenbar weil die 'Thiere nicht munter' genng waren. Er gelang erst, als ich die gekauften Thiere mehrere Tage bei gutem Futter in einer Cisterne in fliesseudem Wasser gehalten hatte, dam eine Anzahl derselben 
in dunkler Nacht mit Alkohol tödtete, eine andere Anzahl, narhdem sie dem hellen Somnenschein ansgesetzt waren.

Der Flusskrebs (Astacus) hat nur eine dentliche Tapetumlage, zwischen den hinteren Enden der Sehstäbe. Im Dunkelange liegt das Pigment in der Nerrenfaserschichte des Ganglion opticum. Im Lichtange ist es hier: zum grössten Theile verschwunden und umlü̈lt jetzt in dicken Nassen die vorderen Antheile der Sehstäbe.

Wie oben erwähnt, haben die von mir untersuchten Exemplare von Peneus membranaceus kein oder fast kein Pigment in der Retina, wohl aber die iiblichen zwei Lagen von Tapetum. Mit Rücksicht auf die genannte Schwierigkeit, bei den wechselnden Pigmentmengen anderer Krebse zu beurtheilen, ob anch das Tapetum Verschiebungen erleidet, schnitt ich mehrere Augen dieses Krebses, und fand im Dunkel- und im Dämmerungsange das Terhalten des T'apetums ganz gleich. Bei einem Lichtange aber war die ganze hintere Tapetumschichte $(t$ Fig. 47$)$ verschwunden. Ich will nicht wagen, aus diesem Befunde zu folgern, dass anch Tapetummasse ron hinten mach vorne wandern kamn, erwähne ihn aber doch; vielleicht veranlasst dies einen Forscher, dem diese schönen hrebse lebend zur Verfügung stehen, die Frage nach einer 'Tapetumverschiebmrg an ihm zu beantworten. Möglich auch, dass es sich in meinem Falle nur nm eine individuelle Eigenthïmlichkeit gehandelt hat.

Was mun die halb- und die knizschwänzigen Krebse betrifft, so gestalten sich hier die Dinge etwas anders als bei den Langschwänzerm. Das Pigment pflegt richt in so scharf getrennten Schichten anfzutreten, sondern die Bewegungen desselben haben mehr den Charakter einer Terschiebung der Hauptmasse nach der einen oder nach der anderen Richtung. Wo die Sehstäbe bis an die Krystallkegel heranreichen, rermischt sich das nach rückwärts rïckende Irispigment mit dem nach rorne wandernden Retinapigment, so dass eine Grenze zwischen beiden nicht mehr erkannt werden kann. Es liegt dam das Irispigment vielfach um die vorderen Enden der Sehstäbe (Fig. 49 oder 56), so dass man es fuir Retinapigment erklären küunte. Da sich aber dieses selbe Pigment im Dunkelange zwischen den Krystallkegehn befindet, muss man, glanbe ich, doch bei der Bezeichnung und bei der Unterscheidung der beiden Pigmentarten verbleiben. Im Dunkelange sind sie eben ganz wohl roneinander getrennt.

Bei Dromia vulgaris (Taf. Y, Fig. 55, 56) zeigten mir. Durchschnitte durch Dunkel-, Dämmerungs- und Lichtangen Folgendes: Im Inukelauge sind die linteren Enden der Sehstäbe ron einer Tapetmmlage mmgeben, die rorderen sind frei von Tapetum wie ron Pigment. Twischen dem Tapetum fand sich in einem Dunkelauge anch etwas Pigment, in einem anderen war in dieser Schichte gar kein Pigment vorhanden. J)ieses liegt viehmehr in reicher Anhäufung gleich hinter der Membrana fenestrata im Ganglion opticum. Schon im Dämmerungsange, ebenso im Lichtange, war 
das Pigment von hier gänzlich verschwonden, und fand sich in dichter Lage, die Anschwellungen der Sehstäbe umhïllend.

Pagurus hat kein nachweisbares Tapetum, und an Stelle desselben liegt anch im Dunkelauge zwischen den hinteren Enden der Sehstäbe Pigment. Auch in den anstossenden Theilen des Ganglion opticum ist viel Pigment angeläuft. Beim Lichtauge aber ist dasselbe am letzteren Orte wieder fast ganz geschwunden, dafür sind die Anschwellungen der Sehstäbe nicht nur in ihrem hinteren, sondern anch im vorderen Theile reichlich mit Pigment überzogen. Doch setzt es sich in meinen Fällen nicht so weit nach vorne fort, dass es mit dem Irispigment verschmelzen würde.

Bei Maja (Taf. IV, Fig. 41, 42) konnte ich eine Vanderung des Retinapigmentes nicht sicher nachweisen.

Pisa (Taf. V, Fig. 48,49) hat am hinteren Ende der Sehstäbe eine Schichte, die aus Tapetumsubstanz von schwach reflectirender Wirkung besteht. Thre Lage und Anordnung ist ganz die der vorderen Tapetumschichte anderer Krebse. Im Dunkelange liegt das Pigment wieder in der Faserschichte des Ganglion opticum, und ragt nur mit spärlichen Antheilen durch die Membrana fenestrata in die Retina linein. Im Lichtauge hat es seinen Platz verlassen und umhiillt die Anschwellungen der Sehstäbe. Dabei zielıt es sich in sieben zierlichen Strängen an jedem Selistab hinan, ist aber im Strange selust intermittirend, so dass es dunkle, in Reihen gestellte Punkte bildet. Ein Querschnitt durch den Sehstab an der Stelle des Ueberganges der diinnen in die dicke Abtheilung zeigt einen siebenstrahligen ${ }^{1}$ Stern (e), dessen Strahlen durch Pigment gebildet sind und in dessen Innerem das durchsichtige Rhabdom liegt. Weiter hinten $(f)$ ist das Pigment wesentlich reducirt, und $1 \mathrm{~m}$ dasselbe herum ist Tapetumsubstanz gelagert. Es liegt vielleicht an der schwachen reflectirenden Wirkung dieses Tapetums, dass man gerade bei diesem 'Thiere kernhaltige Zellen als Träger des Tapetums erkennt. (Vgl. den Querschnitt $d$ dureh die Fïsse der Sehstäbe Fig. 48.)

Ganz ähnlich verhält sich Portun us (Taf. IV, Fig. 37, 38). Nur sah ich bei diesem Krebse nichts, was man für Tapetum halten kann; dafür ist schon im Dunkelauge (Fig. 37) die hintere Hälfte der spindelförmigen Verdickung des Sehstabes mit Pigment überzogen $(a, b)$, welches anch wieder dem Querschnitte das Bild eines siebenstrahligen Sternes gibt, in dessen Centrum das lichte Rhaudom liegt. In der Faserschichte des Ganglions ist viel Pigment angehäuft. Dieses wandert beim Lichtange (Fig. 38) nicht vollständig, aber zum grossen Theile in die Retina, wo man es num um die vorderen Hälften der spindelförmigen Anschwellungen recht dicht angehäuft tindet. Es liegt hier jetzt dichter als an der hinteren Hälfte, an der es beim Dunkelauge allein war.

Galathea (Taf. V, Fig. 45, 46) hat ein Tapetum zwischen den hinteren Enden der spindelfö:migen Erweiterungen der Sehstäbe. Aber

\footnotetext{
1 Die Zeichnung ist in der Tafel unvollkommen wiedergegeben.
} 
auch beim Dunkelange fand ich hier schon ziemlich viel Pigment, das den Sehstäben näher liegt als die 'Tapetummassen. Es mag sein, dass dies wieder von einer kurzen Belichtung' ror' der 'l'üdtung herruilnt; vielleicht ist aber bei diesem T'hiere wirklich die Netzhant in der lounkelheit nicht vollkommen pigmentfrei. Hinter der Membrana fenestrata ist im Dunkelange viel Pigment. Das Lichtange zeigt daselbt fast kemes mehr, dafür sind die vorderen Hälften der Anschwellungen reichlich mit Pigment iiberzogen. Ja dasselbe ist auch von den hinteren Enden der Sehstäbe ans nach vorne gewandert, so dass jetzt das 'Tapetmm allein jene Schichte beherrscht. Bei diesem Ange verschmełzen bei Belichtung wieder Iris- und Retinapigment, indem sie gemeinschaftlich den Sehstab in seiner ganzen Ausdehnung mit Ansmahme des eben gemannten hintersten 'Theiles umhïillen.

Bei Carcinus maenas geschain es mir, dass sich im Innern des Auges Sublimatniederschläge bildeten. Diese Angen waren nämlich in Rabl'scher Flïssigkeit gehärtet. In diese Niederschlïge wenigstens theilweise mit Tapetummasse rerwechselt werden können, so sehe ich hier von diesen Angen ganz alo.

Endlich untersuchte ich noch Squilla mantis, mnd fand in deren Angen kein Tapetum mo anch keine Lichtverschiebnng des Retinajigmentes.

Die meisten Dekapoden also, am exquisitesten die Langschwänzer, besitzen in ihrer Netzhant ein körniges Tapetum, das diehinteren Enden der Sehstïbe nmliült mnd als Reflexionsapparat wirkt. Bei Belichtung des Auges schiebt sich erstens zwischen das Rhabdom des Sehstabes und die 'Tapetummase bei vielen Thieren schwarzes Pigment von hinten mach vorne und behindert demuch die Reflexion; anch wo dieses nicht geschieht, lagert sich zweitens die grösste Masse des Pigmentes an die vorderen Enden der Sehstäbe, diese einhiillend, nnd von ihnen das Licht abblendend. In der Regel kommt dieses Pigment aus den vordersten Lagen des Ganglion opticum. 


\section{CAPITEL.}

\section{Augen mit ungleichmässigem Bau.}

Es ist schon gelegentlich erwähnt worden, dass die verschiedenen Antheile eines Auges Differenzen im Baue aufweisen kömnen. Insbesondere am Rande des Auges kömnen Corneacylinder und Kegel, anch die Sehstäbe eine andere Lage gegen die Hornhautoberfläche haben, als im Centrum des Auges. Doch sind dies unbedentende Differenzen, die wir in functioneller Beziehung schon gewürdigt haben. Es kommen aber bei gewissen Thieren viel bedeutendere Unterschiede im Baue verschiedener Abschnitte ihres Auges vor, und diese sollen jetzt mit Rücksicht auf ihre optische Wirkung. besprochen werden.

Ein ganz häufiges Vorkommen, insbesondere bei Krebsen (unter den Insecten sind in erster Linie die Dipteren zu nennen) ist eine sehr nennenswerthe Ungleichheit in der Wölbung des Auges. Die Hornhaut kann in der Mitte des Anges einen weit grösseren Krümmungshalbmesser haben als an den Rändern: das Auge hat stark gekrümmte Ränder.

Nun haben wir oben gesehen, dass die Grösse des Netzhautbildes abhängig ist von dem Krümmungshalbmesser des Auges, sei dasselbe ein Superpositions- oder ein Appositionsbild. Es wird also in einem solchen Auge ein Gegenstand von bestimmter Grösse und Entfernung ein grösseres Bild entwerfen, wenn er mit den centralen Theilen gesehen wird, und das Netzhautbild des gesammten Auges wird in der Weise verzerrt sein, dass die Randtheile desselben in jenen Richtungen verkürzt sind, welche im Allgemeinen radiär zum Centrum des Sehfeldes stehen. Aehnliche Verzerrungen muss das Netzhautbild jedes Anges zeigen, das, wie es bei Krabben, aber auch bei Insecten sehr häufig rorkommt, in verschiedenen Richtungen verschiedene Krïmmungen hat. So hat z. B. auch Squilla, abgesehen von einer ringförmigen Einkerbung (ron deren Bedeutung noch die Rede sein wird), fast walzenförmige Augen mit abgerundeten Enden. Steht die Walze des Auges horizontal, so muss also das Netzhauthild einer. Linie, die anch horizontal ist, um ein sehr bedentendes, wahrscheinlich, um ein Vielfaches grösser sein als das Netrhautbild derselben Linie, in derselben Entfernung, wenn sie vertical steht. Aehnliche, wenn auch nicht so starke 
Differenzen kommen aber vielfach vor; Schmetterlinge, besonders die Nachtschmetterlinge und einige langsthwänzige Krebse, z. B. Palinurus, Homarus, Palämon haben Augen, deren Corneakrümmung sich einer sphärischen sehr nähert, die Mehrzahl der Käfer, der Dipteren, der Kurzschwänzer und noch viele andere haben aber Augen, die von der Kugelform sehr nennenswerth - schon mit freiem Auge erkennbar - abweichen. Diese liaben also sämmtlich Netzhantbilder, die der Projection des Sehfeldes geometrisch unähnlich sind, eine vom simnesphysiologischen Standpunkte aus interessante 'Thatsache, deren Deutung uns noch in Capitel X über das Sehen beschäftigen soll.

Bei manchen Gattungen der Libellulinen, z. B. bei Cordulegaster, sieht man beim Anblick des lebenden Thieres sogleich, dass sich der nach oben gewendete Antheil des Auges anders verhüit als der seitliche und untere. Die Krïmmung ist eine andere, wie man sofort an der Grösse der Spiegelbilder erkenut, die Farbe, und vor Allem ist die Zeichnung eine wesentlich verschiedene. Während man in seitlichen nnd unteren Theile jene optischen Phänomene sieht, die ich mnten als Psendopupillen beschreiben werde, sieht man im oberen Theile nichts davon. (Vgl. die Abbildungen eines Libellenanges Taf. VII, Fig. 66, 67.)

Fertigt man Schnitte lurch das gehärtete Ange an, so gewahrt man, bei grossen Thieren mit freiem Auge, dass die Schichte des Augapfels, welche das eigentliche Auge darstellt, also von der Cornea bis zur Membrana fenestrata reicht, im oberen Theil des Auges dicker ist als im iibrigen; dass der Tebergang ein ziemlich plötzlicher und die Färbung eine andere ist. Bei der mikroskopischen Untersuchung (Taf. VI, Fig. 5s, 59) stellt sich \%. B. bei der genamnten Art heraus, dass jedes Facettenglied im unteren 'Theil des Auges in allen seinen Bestandtheilen kleiner ist als im oberen, dass es anch in seiner Gestalt von dem oberen abweicht; indem es relativ länger ist, dass in ersterem der hintere 'Theil der Krystallkegel, sowie die ganzen Sehstäbe schwarz pigmentirt sind und nur der vordere Theil der Kegel von farbigem Pignent umkleidet ist, während im oberen Augenabschnitt gar kein schwarzes Pigment vorkommt, soudern durchaus von farbigem ersetzt ist. Der Uebergang der beiden Augentheile, was das Pigment betrifft, ist ein so plötzlicher, dass neben einem typisch schwarz pigmentirten Facettenglied vielleicht eines kommt, das weniger schwarzes Pigment enthält, dessen Nachbar aber dann schon gar kein solches mehr besitzt. Der Uebergang, was die Dimensionen betrifft, ist ein etwas weniger schroffer.

Auch Libellula depressa zeigt diese Differenz der Angenabtheilungen. Ich mass die Grösse der Corneafacetten am augepinselten Auge und fand den I)urchmesser, gerechnet als Entfernung zweier gegeniiberliegeuder Winkel des Sechseckes, im overen Theile des Auges =0.059 Millimeter, im unteren Theile 0.033 Millimeter. Sie sind also oben fast doppelt so gross wie unteu. Die Entfernung von der Vorderfïche der Cornea bis zur Spitze 
des Krystallkegels war bei Libellula vulgata im oberen Augenantheil 0216 Nillimeter, im unteren 0.133 Millimeter, die grösste Breite des Kegels oben 0.058, unten 0.023 Millimeter.

Den Unterschied in der Grösse der Corneafacetten und in der mit freiem Ange sichtbaren Färbung des Anges hebt ïbrigens schon Not thaft ${ }^{1}$ hervor, wie es scheint, ohne mikroskopische Durchschnitte gemacht zu haben; auch hat er schon auf die Schärfe der Trenmung der beiden Angentheile hingewiesen und Messungen über die Grösse der Facetten mitgetheilt. So fand er bei einem nicht näher bestimmten Individunm aus der Gattung Libellula die grösseren Facetten $=0.054$, die kleineren 0.028 Millimeter, oder bei Aeschna 0.06 und 0.035 Millimeter. Auch bei Stratiomys, welche zu den Dipteren gehört, fand er analoge Differenzen und macht dann die Bemerkung: „Da nun, soviel mir bekannt ist, Facetten von zweierlei Grösse nebeneinander auf demselben Sehorgane nur bei Raubinsecten vorkommen, da ferner die das schärfere Bild ermöglichende feinere Facettirung fast immer anf die nach unten und vorne zu gerichteten Theile der Angenwölbung beschränkt ist, so liegt die Vermuthung nahe, es möchte diese Einrichtung in naher Beziehnng zum Erjagen und Ergreifen der zn erbeutenden 'Thiere stehen...", welche Bemerkung uns noch unten beschäftigen soll.

Es gibt Vertreter der Familie der Libellulinae, bei denen sich die Verschiedenheit im Ban der beiden Augenantheile schon durch die Färbung verräth, so dass z. B. der obere dunkelblan, der untere lichtgriin ist. Anch bei Henschrecken, z. B. Psophus stridnhus (Lin.), kommt es vor, dass das Ange durch eine scharfe Linie in zwei verschieden gefärbte Hälften zerfällt. Bei Dipteren kehrt ein ähnliches Verhältniss wieder, wie wir es bei Libellen kennen gelernt haben. Die Corneafacetten sind bei vielen Arten im oberen Theil des Auges grüsser als im unteren, und hänfig sind die beiden Antheile anch rerschieden in ihrer Fürbung. Doch ist die Trennung hier keine so scharfe, wie bei Libellen. Girschner ${ }^{2}$ hat die Pigmentirung des Dipterenauges genaner studirt.

Geradezu enorm ist die locale Differenz in den eigenthïmlichen Augen von Phronima. Es werden uns diese alsbald näher beschäftigen, hier seien sie nur als exquisites Beispiel eines ungleichmässigen Banes angeführt. Ja das Ange einer Seite zerfällt in zwei so ungleich gebante Abtheilnngen, dass man fiiglich ron zwei Angen einer Seite sprechen kann, umsomehr, als anch die Netzhant in die entsprechenden zwei Abtheilungen zertheilt ist. Die Krystallkegel des oberen Antheiles sind um ein Vielfaches länger als die des seitlichen nnd unteren Antheiles, denn anch hier ist es der obere, der Scheiteltheil des Auges, der die grosse Abweichnng von dem gewöhnlichen zeigt. Phronima, sowie die Libellen haben also ein besonderes Organ zur Beobachtung dessen, was ober ilmen, wenn sie in sitzender, normaler Stellung gedacht sind, vorgeht.

1. c. S. 23.

${ }^{2}$ Einiges über die Färbung des Dipterenauges. Berl. Entomolog. \%eitsehr. Bd. XXXI, 1887. 
Die Lebensweise der Phronimiden ist mir nahezu mbekannt, bei deu Libellen aber kann man sehr wohl einen Versuch zur Deutung der beiden Angenabtheilungen machen. Man beachte, dass wenigstens die grösseren Libellen eine Vorliebe haben, horizontal zu sitzen; man wird, so habe ich es in Erinnerung, nicht leicht eine finden, welche mit der Längsaxe ihres Körpers vertical oder stark geneigt sitzt, wenigstens nicht, während sie bei Tage ihr unstetes Leben führt; auch setzen sie sich mit Vorliebe tief, auf den Boden oder auf niedrige Pflanzen; nur wenn sie ihre Liebesspiele treiben, habe ich sie längere Zeit hindurch sich zwischen den Bänmen und hoch in der Luft herumtummeln gesehen. Sitzt also eine Libelle, wie das so oft rorkommt, anf einem Wege und will man sie beschleichen, um sie zu laschen, so sieht sie den Feind, oder das Netz mit dem oberen Theile des Auges; sieht sie aber eine andere Libelle oder ein Insect vorbeifliegen, denen sie ans Liebe oder aus Hunger nacheilt, so hat sie dieselben wieder mit dem oberen Theile des Auges erkannt; hat sie aber das Insect gefangen und ist im Begriffe es zu verzehren, so sieht sie diese ihre Beute mit dem unteren Theile des Auges, während der obere das Nahen der Gefahren oder das nener Beute anzeigt. Ich habe schon an anderem Orte ${ }^{1}$ darauf aufmerksam zu machen gesucht, dass die Insecten im Allgemeinen ihre Feinde und wohl auch ihre Freunde und ihre Bente, wenn sie sie durch das Ange wahrnehmen, an ihren Bewegungen bemerken oder erkennen. Immer sind es bewegte Objecte, welche die sitzende Libelle mit dem oberen Augentheil zu beachten hat, und sind es ruhende, die sie im unteren 'l'heile ihres Sehfeldes interessiren.

Ich glaube also, dass die geschilderte Differenz im Bau des Anges darin seinen Grund hat, dass die eine Form günstiger ist zur Wahrmelhmung von Bewegmien, die andere zur Wahrnehmung der Formen ruhender Objecte. Wie das möglich ist, soll besprochen werden, wenn von der Function des Sehens die Rede ist.

1 Das Sehen von Bewegungen und die Theorie des zusammengesetzten Auges. Wiener akad. Sitzber. Bd. JXXII, Abth. JII, 1875. 


\section{CAPITEL.}

\section{Kurze Beschreibung einzelner Augen von Insecten und Krebsen.}

\section{A. Insecten,}

1. 'Tagschmetterlinge.

Pieris rapae (Rübenweissling) (Taf. VI, Fig. 61, und Taf. IV, Fig. 34 und 35). Ein typisches Tagange mit Appositionsbild. Die Basen der Krystallkegel sind nennenswerth kleiner als die Flächen der Corneafacetten. Die vorderen Antheile der auch sehr kurzen Kegel sind in Iristapetum ( $T$ ) eingebettet, der hintere Antheil in Irispigment, das sich in Streifen, welche die Tracheen mmgeben, bis an das Retinapigment fortsetzt. Ein bei " angelegter Querschnitt (Fig. 35) zeigt die Sehstäbe mit je vier nicht zu einem Rhabdom verschmolzenen Stäbchen in ihrer Mitte, und umgeben ron den Leydig'schen dicken 'Tracheen.

Melanargia hat ein Ange, das dem des Kolulweisslings durchaus ähnlich ist. Auch ein Iristapetum, auch vier stark lichtbrechende Stäbchen im Selistah, die anf Querschnitten eine zierliche Quadratstellung zeigen, 11. S. W.

Der Fuchs (Vanessa) (Taf. IV, Fig. 36) hat ein typisches Tagange, ähnlich jenem des Kohlweisslings und anderer Tagschmetterlinge. Sonderbarerweise ist die Cornea, wie man schon mit freiem Auge sieht, reichlich mit langen Haren besetzt ( $a$ der Fig. 36 zeigt ein solches am freien Ende alogeschnitten), die bei ihrer radiären Anordnung das Netzhantbild kaum stark stören werden, so wie sie anch die Psendopupille und die Nebenpupillen ganz gint sehen lassen.

Epinephele (Taf. IV, Fig. 39, und Taf. VI, Fig. 64). Das Auge ist sehr ähnlich dem des Kohlweisslings. Man sieht das Rhabdom durch den ganzen Sehstab ziehen. An den hinteren Enden der Selstäbe sind einzelne Kerne. Die Membrana fenestrata ist an manchen Schnitten isolirt und zeigt sich da mit Pigmentkörnchen besetzt. Hinter derselben liegen eigenthïmliche kolbige Gebilde, die nach vorne in den Sehstab iibergehen und hinten mit den pigmentirten Nerven in Verbindung zn stehen scheinen. Sie entsprechen der Netzhant von 'Thompon-Lowne.

Lycaena (der Wiesenbläuling). Das typische Tagange mit starken Wölbungen der vorderen Hornhantfacetten nud eigenthümlichen Liicken zwisehen den Pigmentscheiden der Krystallkegel. Hinter der Membrana 
fenestrata wieder eine Reihe kernartiger Gebilde, wie bei gewissen Nachtschmetterlingen und Epinephele.

Auch hier wie bei anderen 'Tagschmetterlingen verlaufen die Sehstäbe nicht durchaus radiär, sonderı an den Rändern des Auges in zierlichen Bogen, welche dadurch zu Stande kommen, dass die seitliche Beglenzung: des Auges keine radiäre, sondern eine nach dem Innern des Auges hin convexe ist. Dieser Begrenzung schmiegen sich die Sehstäbe an, so dass sie etwa wie Blumenstengel in einer geschweiften Vase nach vorue auseinanderweichen.

2. Nacht- und Dämmerungsfalter.

Catocala unpta (Rotles Ordensband) (Taf. II, Fig. 15). Die Kegel dieses Anges zeigen Andeutungen einer Schichtung, wie ich sie bei Limulus beschrieben habe. An ihrer Spitze befindet sich ein eigenthümlicher durchsichtiger, auch wieder kegelförmiger Ansatz, den man für eine Erweiterung des vielleicht durch den ganzen Sehstab hindurchgehenden Rhabdomes ansehen könnte, wenn er nicht ein deutliches centrales Ende zeigte. Im dünnen Antheile des Sehstabes sitzen die ihm zugehörigen Kerne, ich zähle sechs bis sieben; es mögen aber immer sieben vorhanden sein, wie dies nach Grenacher zn erwarten ist. Ich habe auf die Feststellung dieser Zahl besondere Aufmerksamkeit zu lenken keine Ursache gehabt. Der dicke Antheil des Sehstabes zeigt im Inmern am Querschnitt (Fig. 15a) das Rhabdom. Nahe der Membrana fenestrata liegen unregelmässig; zwischen den Sehstäben angeordnet, Kerne und etwas Pigment. Die hier unzweifelhaft vorhandenen Tracheen sind durch die Behandlung mit Damar etc. unsiclitbar geworden. Hinter der Membrana fenestrata liegen langgestreckte, sich mit Pikrokarmin gut fürbende kernartige Gebilde (b), die Retinaelemente von Thompson-Lowne.

Ich lhatte nicht darauf geachtet, in welchem Zustande das Thier, dem Fig. 15 entnommen ist, getödtet worden war. Doch befindet sich der grösste Theil des Auges in ausgesprochenster Dunkelstellung, am Rande desselben aber findet sich eine Gruppe von Facettengliedern in ebenso ansgesprochener Lichtstellung; ein solches Facettenglied mit seinem Irispigment ist in die Zeichnung aufgenommen. (Es ist das letzte rechts.)

Dieses Pigment zerfällt hier wie auch in manchem anderen Auge mit doppelter Functionsweise in zwei sich gegen Licht ungleich verhaltende Abtheilungen. Ein feinkörniger dünner Pigmentbelag (c) bleibt nämlich, wie die Abbildung ersichtlich macht, an den Kegelı fixirt, es möge das eigentliche lrispigment was immer für eine Stellung einnehmen. Man könnte diese Pigmentlage dem vergleichen, was ich bei anderen Angen Iristapetum genannt labe, doch wirkt es hier nur insoferne als reflectirendes 'Tapetum, als es Teranlassung zu der dunkelbraunen Farbe des Auges gibt, die um die schwarze Pseudopupille sichtbar ist. 
Leucoma (?) zeigt wieder das typische Auge des Nachtschmetterlings sehr ähnlich dem des rothen Ordensbandes (Fig. 15). Auch hier liegen die Kerne der Sehstäbe in nächster Nähe der Spitze der Krystallkegel, und enthält die vorderste Schichte des Ganglion opticum jene radiär gestellten kernartigen Gebilde. Das optische Verhalten des dioptrischen Apparates dieses Schmetterlings ist in Taf. V, Fig. 57, ersichtlich gemacht. Es ist die Corneafacette, (1) ein Querschnitt durch einen Kegel (2) und ein flach liegender Kegel (3) gezeichnet, wie sie unter dem Mikrorefractometer erscheinen.

Porthesia (Ocneria oder Cnophria? 1) Nachtschmetterling (Taf. IV, Fig. 30, 31). Er hat ein typisches Auge mit doppelter Functionsweise, Sehstäbe, deren dünne Antheile verhältnissmässig lang sind. Die Krystallkegel haben eine Andeutung von Doppelschichtung, und zwar liegt an der Grenze der beiden Schichten bei a etwas Pigment. Dass am Dunkelauge das Irispigment doch noch ïber die Spitze der Kegel vorragt, rührt, wie ich vermuthe, daher, dass ich den Schmetterling kurz, ehe ich ihn tödtete, mit dem Augenspiegel untersuchte, um mich von seinem Augenleuchten zu überzeugen. Ich wusste damals noch nicht, dass die Pigmentverschiebung auf Lichtreiz so rasch eintritt, dass diese kurze Beleuchtung einen schon merklichen Effect hervorruft. Fig. 31 zeigt das Dunkelauge.

Lasiocampa quercifolia (Taf. IV, Fig. 28, 29). Der Bau des Auges entspricht vollkommen dem der schon beschriebenen Nachtfalter. Auch hier demonstriren die Zeichnungen die Verschiebung des Irispigmentes durch Liclitwirkung.

Makroglossa (Der Taubenschwanz) (Taf. II, Fig. 17, und Taf. VI, Fig. 63) hat das Auge eines Nachtschmetterlings, wie er ja auch zu diesen gehört. Er fliegt aber im hellen Sonnenschein. Zwischen seinen Selıstäben finden sich lange Pigmentfäden, wie ich solche bei einem anderen Nachtschmetterling nie gesehen habe. Leider habe ich keinen Versuch iiber die photomechanische Wirkung am Irispigmente dieses Thieres machen können, zweifle aber nicht daran, dass er sich in dieser Beziehung wie die ïbrigen Nachtschmetterlinge verhält, denn ich schnitt die Augen zweier Exemplare und es zeigte sich das Irispigment des einen in ausgesprochener Dunkelstellung, während es bei dem anderen in mässiger Lichtstellung war. Ich habe iu Abbildung (Fig. 17) die Facettenglieder beider vereinigt gezeichnet und durch $a$ und $b$ unterschieden. Leider waren die dïmnen Antheile der Sehstäbe, sowie die Muskelfasern des Irispigmentes nur' im vorderen 'Theile erhalten.

\section{Käfer.}

Cantharis fusca ('Taf. I, Fig. 9) hat ein Auge, das jenem von Lampyris splendidula in hohem Grade ähnlich ist, wie aus dem in vorstehenden Capiteln Mitgetheilten schon hervorgeht:

1 Es ist in der Signirung meiner mikroskopisehen Präparate ein Versehen geschehen, so dass ich nicht sicher weiss, welehem von den genannten drei Schmetterlingen die hier besehriebenen Augen angehören. 
Die Krystallkegel sind mit der Cornea verwachsen, nur sieht man bei diesem Käfer eine Trennungstläche dieser beiden. Sie hebt sich bei Färbung mit Säurefuchsin und Pikrinsäure in gesättigtem Tone ab. Im hinteren Ende der Kegel sieht man kleine, auch kegelförmige Gebilde eingelassen. Grenacher ${ }^{1}$ hält diese für die eigentlichen Krystallkegel, welche hier von einer cuticularen Masse eingeschlossen sind. Es wird dies wohl richtig sein. Functionell wirkt das ganze Gebilde ebenso wie der Kegel in seiner Vereinigung mit der Cornea bei Lampyris wirkt. Man kann sich davon leicht am abgepinselten Auge überzeugen. Wer sich für die Frage nach der morphologischen Bedeutung dieser mit der Cornea vereinigten Kegel interessirt, dürfte bei einem anderen Käfer, nämlich 'Trichodes apiarius, Aufschluss erhalten. Ich sah nämlich bei diesem die hintere Völbung der Cornea anscheinend in eine blätterig-gallertige Masse ïbergehen, die mir eine Vorstufe des Zustandes zu sein schien, der bei Cantharis fusca existirt. Das Leuchtkäferchen, bei dem der eingeschlossene Kegel nicht mehr gesehen wird, dürfte eine weitere Entwickelungsstufe darstellen.

Ich will übrigens hervorheben, dass nicht etwa nur die kleinen unscheinbaren, eingeschlossenen Kegel ein nennenswerthes Lichtbrechungsvermögen besitzen, wie man nach der Abbildung Grenacher's (l. c. Taf. XI, Fig. 127) hätte erwarten können, sondern dioptrisch wirksam ist gewiss der ganze grosse Kegel wie bei Lampyris.

Fig. 9 zeigt Kegel sammt anhaftender Corneafacette von einem Dunkelauge $(A)$ und von einem Lichtange $(B)$.

Colymbetes fuscus (Schwimmkäfer) (Taf. II, Fig. 16). Sein Auge ist dem des Dyticus sehr ähnlich. Es sind dies die einzigen zwei Augen von Insecten, die ich kenne, bei denen eine dentliche Lichtwirkung anf das Pigment besteht und die Sehstäbe doch wie bei Tagaugen in. gleichmässiger Dicke von hinten bis vorne verlaufen. Ihre Kerne sitzen am vorderen Ende, also gleich hinter den Krystallkegeln. Die Corneafacetten wirken als Linsencylinder. Diese Angen bilden ein Gegenstiick zu jenen der Rosenkäfer' und deren Verwandten, insoferne als diese Sehstäbe haben, wie sie bei Nachtaugen vorzukommen pflegen, aber keine Irispigmentver'schiebung, die genamnten Schwimmkäfer aber umgekehrt Pigmentverschiebung, aber Sehstäbe ohne Trennung in die zwei Abtheilungen. Vielleicht lat dieses Vorkommen bei letzteren einen analogen Grund, wie ich ihn für erstere (siehe S. 67) vermuthungsweise ausgesprocluen habe.

Dytiscus (Scliwimmkäfer) ('T'af. I, Fig. 6, 7). Abgesehen von der Grösse ist das Auge dem von Colymbetes so ähnlich, dass die Fig. 16 fast auch als Abbildung des Licht- und Dunkelauges dieses Käfers dienen könnte.

Tropinota liirtella (Taf. III, Fig. 23, 24). Selir kleine und wegen der Pigmenteinbettung schwer sichtbare Krystallkegel, die einer dicken

1 Sehorgan der Arthropoden, S. 130. 
Hornhaut ansitzen. Die Sehstäbe haben einen dicken hinteren Antheil und einen dünnen vorderen, der am Krystallkegel in eine kolbenartige Erweiterung übergeht, in welche die Kerne eingelagert sind. Zwischen den dünnen Theilen der Sehstäbe gewahrt man an Querschnitten eine netzartige Zeichnung; die an jene bei Tagschmetterlingen erinnert und wahrscheinlich auch Querschnitten von Tracheen entspricht. Ein Iristapetum dürfte nur in geringen Andentungen vorhanden sein; ich sah, dass dümne Lagen (bei $T$ ), die zwischen den vorderen Enden der Kegel sichtbar werden, das Licht stärker reflectiren, als das beim schwarzen Pigmente der Fall sein kann. Das Irispigment hört mit scharfem Rande nach hinten auf, ebenso das Retinapigment nach vorne. An keinem der beiden kounte ich in Folge del Einwirkung von Sonne oder Dunkelheit eine Aenderung wahrnehmen.

Ueber die Eigenthümlichkeiten dieses Auges, durch welche es den Augen mit doppelter Functionsweise ähnlich wird, aber doch kein solches ist, sowie über die Augen der verwandten Käfer vergleiche das auf S. 67 Gesagte.

Oryctes rhinoceros (Lin.). (Ich verdanke dieses Thier meinem Bruder Prof. Franz Exner, der es in Indien fing und für mich conservirte.) Das Ange ist durchaus dem von Tropinota hirtella ähnlich, nur sind die Cornea dicker, die Krystallkegel besser ansgebildet, iiberhaupt die einzelnen Elemente des Auges grösser. Die Lage des Irispigmentes, auch die zierlichen Querschnitte durch die Sehstäbe und die Tracheen sind wie bei jenem.

\section{Diverse Insecten.}

Libellula vulgata (Diplex) (Taf. VI, Fig. 58, 59. Vgl. ancl 'T'af. VII, Fig. 66,67). Das Ange zerfällt in eine obere, gelb pigmentirte Abtheilung (Fig. 58) und eine untere, hauptsächlich schwarz pigmentirte (Fig. 59). Schon mit freiem Auge erkennt man an Durchschnitten des ganzen Auges, dass die obere Abtheilung dicker ist, d. h. längere Facettenglieder hat; sie sind anch breiter. Die Messung der sechseckigen Hornhantfacetten ergab als Durchmesser von einem Winkel zum gegeniiberliegenden gemessen für den oberen Antheil 0.059 Millimeter, fuir den unteren 0.033 Millimeter. Der Uebergang der beiden Augenabtheilungen ist, was die Grösse der Facettenglieder betrifft, ein ziemlich unvermittelter. Insbesondere aber geschieht das Auftreten des schwarzen Pigmentes so plötzlich, dass man in den Schnitten neben eimem solchen, das nur gelbes Pigment entlält, eines findet, das schon reichlich schwarzes führt, und an zweiten Nachbar ist der Pigmenttypus schon vollkommen der der unteren Augenabtheilung. Hier kann man ein Iris- und ein Retinapigment unterscheiden, die aber nicht scharf voneinander getrennt sind. Vor dem Irispigment liegen gelbe, den Iristapetum entsprechende Zellen. Diese sowie das gelbe Pigment im oberen Theile des Anges werfen Licht zurïck, wenn anch nicht so reichlich, wie von einem eigentlichen Tapetum erwartet werden miisste. 
Beide Angenabtheilungen entsprechen typischem Tagauge. Gewisse optische Erscheinungen, zu denen sie in ungleicher Weise Veranlassung geben, sind unten noch Gegenstand der Besprechung; sie machen, dass man die beiden Augenabtheilungen am lebenden 'Thiere sofort unterscheidet, nu' erscheint da der Uebergang doch nicht so unvermittelt, wie ihn die Durchschnitte zeigen.

Die Larve einer kleinen Libelle (Agrion) zeigt ein Auge, das durchaus ähnlich gebaut ist und ähnliche Pigmentvertheilung hat, wie der untere Theil des (Taf. VI, Fig. 59) abgebildeten Auges einer ausgebildeten Libelle. Dementsprechend hat es auch ein ähnliches optisches Verhalten, z. B. in Bezug auf•die Pupillen und Pseudopupillen (siehe unten).

Die Stubenfliege (Musca domestica) zeigte mir ausserordentlich zierliche und klare Bilder in Schnittserien. Insbesondere sieht man die Lage der verschiedenen Arten Kerne, ferner die Querschnitte durch die Sehstäbe und Rhabdome sehr gut, wegen Hangels jedes undurchsichtigen Pigmentes am in Alkohol gehärteten Auge. Dieselben waren mit Pikı'okarmin gefürbt. Die Configuration ist die des (Taf. VI, Fig. 60) abgebildeten Fliegenauges von Eristalis, weshalb ich keine besondere Abbildung zu geben nötlig habe.

Eristalis. Stark gekrümmte vordere Corneaflächen und bis an die Krystallkegel reichende Selıstäbe von gleichbleibender Dicke charakterisiren das Auge als solches von einem am Tage munteren Landthiere. Das gelbe Pigment (nicht Tapetum) nimmt an hinteren Theile der Selıstäbe eine melır kirschrothe Farbe an, was in der Zeichnung nicht wiedergegeben werden konnte. Schwarzes Pigment findet sich nur an den Grenzflächen zwischen je zwei Corneafacetten und in kleinen Härchen ( $a$ Fig. 60), welche dem Auge aufsitzen. Am Längsschnitt sieht man nichts von den „w wrstförmigen” Tracheen, welche die Sehstäbe vomeinander trennen. Wohl erkemnt man sie am Querschnitt (Fig. 60 c), am besten allerdings am Zupfpräparat. Da sieht man, dass sie einen llind endenden langen Sack bilden, welcher einer' recht dümmen 'Trachea entstammt. Diese dünnen 'Tracheenstämmchell dur'hbohren die Nembrana fenestrata und stehen mit den hinter derselben liegenden 'Tracheen ( $b$ der Fig. 60 ) in Verbindung.

Die Hornisse (Vespa crabo) (Taf. III, Fig. 27) hat eine sehr dicke Cornea, kleine Krystallkegel, hat als echtes Tagthier gleichmässig dicke Sehstäbe, in deren Innerem man Stäbchenbildungen sieht und die in ihnem ganzen Verlaufe von Pigment umgeben sind. Dasselbe ist an vorderen und hinteren Ende besonders diclıt gelı̈uft. Fig. 27 zeigt drei Facettenglieder aus dem Seitentheile des Auges, wo die optischen Axen derselben nicht senkrecht auf der Oberfläche der Cornea stehen. Die physiologische Bedeutung hiervon wurde S.24 besprochen. Die Sehstäbe reigt die Abbildung in einer Curve verlaufend. Es ist das nicht Resultat von Terschiebungen beim Härten und Schneiden, sondern, wie ans der Configuration des ganzen Auges hervorgeht, die natürliche Lage. 
Locusta viridissima (Grüne Heuschrecke). Das Thier hat ein ausgesprochenes Tagange, recht älnnlich jenem der Hornisse. Nur sind die Kegel bis gegen die Spitze hin in ein grüngelbes Pigment, also wieder eine Art Iristapetum gehüllt, welches das Licht stark reflectirt. Die Spitze der Kegel, sowie der ganze Sehstab und die Schichte der Opticusfasern des Ganglions sind reichlich mit Pigment versehen.

Sirex gigas. Auch das Auge dieses Thieres ähnelt sehr dem der Hornisse. Die einzelnen Cylinder der recht dicken Cornea stehen schief und nicht senkrecht auf der Oberfläche der Cornea, ebenso ist die Axe der Krystallkegel geneigt. Bei Tenthredo instabilis ist das durchaus nicht der Fall.

Tenthredo instabilis hat ein Auge, welches, was die einzelnen Facettenglieder anbelangt, sehr ähnlich ist dem der Hornisse. Nur sind die Cornea dünner und die Krystallkegel grö̈sser.

\section{B. Krebse.}

\section{Langschwänze.}

Palämon (Taf. V, Fig. 51, 52, und Taf. VII, Fig. 69, 70) (ich untersuchte $P$. rectirostris und eine zweite nicht näher bestimmte Species) hat, wie schon Max Schultze abbildet, einen eigenthümlichen haubenförmigen Aufsatz am Krystallkegel, der in eine weiche Schichte hineinragt, die der linteren Corneafläche anliegt. Die eigentlichen Krystallkegel sind, wie bei anderen Langschwänzen, aus vier Stücken longitudinal zusammengesetzt. An dieselben schliesst sich nach vorne noch ein kurzes Zwischenstück zwischen Kegel und Haube, und nach hinten schliesst sich jene Krystallkegelhülle an, die, enger werdend, bis an die Netzhaut reicht und, wie es scheint, mit einer gallertigen, in Tropfen coagulirenden Fliissigkeit gefüllt ist; der sich direct an den Kegel anschliessende Theil dieser Gallerte hat aber noch etwas festere Consistenz, gerinnt deshalb in etwas anderer und wechselnder Form. Zwischen den Hïllen befindet sich auch coagulirende, wie es scheint ziemlich fliissige Masse. Vährend z. B. bei Sicyonia die Krystallkegel kugelig begrenzte Endflächen haben, sind diese bei Palämon eben, so dass der g'össte Theil der optischen Wirkung auf Linsencylinderbau bezogen werden muss. Die vorderen Enden der Sehstäbe sind in meinen Präparaten nicht dentlich, wohl aber die daselbst liegenden Kerne. Querschnitte durch die hinteren Theile der Sehstäbe zeigen diese sternförmig, in Tapetummasse eingebettet. Eventuell noch innerhalb der Tapetumlage eine Pigmentschichte. Typische Lichtverschiebung des Iris- und Retinapigmentes.

Merkwiuxdig sind bei diesem Thiere fadenförmige Verbindungen des Iristapetums mit dem Netzhanttapetum (Fig. 52). Letzteres besteht aus den iiblichen zwei Schichten. Die Facetten der Cornea sind quadratisch.

Crangon hat ein Auge, das dem von Palämon recht ähnlich ist. Auch hier zwei Tapetumschichten der Retina und ein Iristapetum. Die 
Sehstäbe haben eine zierliche Zeichnung, die durch regelmässig an ihrer Oberfläche vertheilte körnige Gebilde entsteht.

Nica edulis hat ein Auge, das durchaus ähnlich ist dem von Sicyonia sculpta und wie dieses Pigmentver'schiebungen zeigt. Ich mïsste die Fig. 53, 54 fist genau wiederholen, sollte ich das Auge zeichnen, was wohl iiberflüssig wäre. Der einzige Unterschied, der etwa anffällt, besteht darin, dass bei Nica mehr Tapetumsubstanz im Ganglion opticum eingebettet liegt, und zwar in Fäden vertheilt.

Der Bärenkrebs (Scyllarus) hat wohl ausgebildete, hinten schön linsenartig abgerundete, im Uebrigen fast cylinderförmige Krystallkegel linter einer in quadratische Facetten getheilten Cornea. Das Irispigment, das den Kegeln in dünner, aber ziemlich compacter Schichte dicht anliegt, sendet einzelue fadenförmige - nicht scheidenförmige - Fortsätze ziemlich weit nach hinten.

Die Krystallkegelscheide ist mit einer sich an die convexe Fläche der Kegel anschliessenden Masse gefüllt, die sich gegen Färbungstlïssigkeit anders verhält als die ausserhalb der Scheiden gelegene Substanz, welche im Präparate den Eindruck coaguhirter Flüssigkeit macht. Die Sehstäbe fand ich im Lichtange mehr in die Länge gestreckt mit spindelförmiger Anschwellung, im Dunkelange näher'n sie sich der Walzenform. Ich halte nach Analogie mit anderen Krebsen die erst genannte Form für die natürliche und die andere, die ich ïbrigens auch bei einem Lichtange fand, für den Ausdruck nicht gelungener Härtung. Sie sitzen auf einer Nembrana fenestrata auf, hinter welcher die Schichte der Nervenverzweigungen folgt. Querschnitte durch die Anschwellung des Auges zeigen am Lichtauge das Rhabdom, dessen eigenthümliche Gestalt noch den siebenstrahligen Stern wohl erkennen lïsst, umgeben von den pigmentirten Retinulazellen.

Am Irispigment konnte ich eine Verschiebung als Lichtwirkung nicht sicher erkenuen, wohl aber an der Retina. Das Pigment liegt hier anch im Dunkelange in der Netzhant, aber nur an den hinteren Antheilen der Sehstäbe, die vorderen bleiben frei. Beim Lichtange dagegen reicht das Pigment auch ïber die vorderen Theile und zeigt eine eigenthïmlich streifige Anordnung, deren Erklärung ein Blick auf den sternförmigen Querschnitt des Sehstabes gibt. Die Schichten des Ganglion opticum fand ich bei diesem Krebse ganz pigmentfrei.

Sicyonia sculpta (Taf. V, Fig. 53, 54, und Taf. IV, Fig. 39) hat ein sehr schönes, leicht zu schneidendes Auge mit drei Lagen Tapetum und dentlicher Verschiebung von Iris- und Retinapigment. Die quergestreiften Selıstäbe beginnen erst eine geranme Strecke hinter den hinteren Euden der Krystallkegel. Diese Strecke ist durchzogen von den Scheiden der Krystallkegel, zwischen denen sich im Präparate coagulirte Flïssigkeit findet. Die Krystallkegel selbst haben schöne vordere und hintere kugelige Begrenzungsflächen. Die Corneafacetten sind quadratisch. 
Das Irispigment wandert bei Lichtwirkung mit dem Iristapetum eine grosse Strecke nach rïckwärts, das Retinapigment kommt aus dem Ganglion opticum und wandert durch die Membrana fenestrata und die Tapetunschichte bis an die vorderen Enden der Sehstäbe, die es einhïllt.

Die grossen kugeligen Angen von Palinurus (Langusta) (Taf. V, Fig. 50) haben einen mit freiem Auge präparirbaren Glaskörperraum, hinter dem, gerade wie beim Wirbelthierange, die Retina liegt. Die Sehstäbe sind hier ziemlich klein. Der Bau des Auges ist ganz ähnlich dem ron Palämon oder Sicyonia. Nur scheint es, dass das Retinapigment anch im Dunkelange in der Netzhaut sellust liegt, aber hinter dem Tapetum. Im Dämmerungsauge schon liegt alles Pigment vor' dem Tapetum. Der linke 'Theil des Netzhautstiickes der Fig. 50 stellt das Stadium dar, in welchem eben das Pigment durch das Tapetum zu treten im Begriffe ist. Es hat die rorderen Enden der Sehstäbe noch nicht erreicht, liegt aber schon zum Theile zwischen ihnen und vor der Tapetummasse. Die seitlichen Theile dieses selben Auges zeigen das Netzhautpigment noch in Dunkelstellung. Ich habe eine solche Stelle rechts in Fig. 50 abgebildet. Dahingestellt muss ich es lassen, ob das Irispigment bei Palinurus auch im Lichtauge die Stellung hat, welche diese Figur zeigt, denn in einem Auge aus diffusem Tageslicht sieht es anch so aus, wie in dem abgebildeten unvollkommenen Dunkelauge.

Die Scheiden der Kirystallkegel, im Querschnitt $b$ gut zu sehen, sind wieder mit einer Substanz gefuillt, die, soweit sie sich an den Kegel anschliesst, stark lichtbrechend und homogen erscheint, weiter nach hinten aber sich in tropfenartige Coagula auflöst. Die Cornea lässt an ihrer vorderen Fläche keine Facetten erkennen; an der linteren scheint eine weiche Hypodermisschichte zu liegen, die deutliche quadratische Facetten zeigt.

Astacus fluviatilis lieferte mir keine linlänglich guten Präparate, dass ich eine Zeichnung nach ilnen anfertigen möchte. Doch sind sie genügend, mit voller Dentlichkeit erkenmen zu lassen, dass das Irispigment in der oft geschilderten Weise in Folge von Lichtwirkung nach rückwärts riickt und dass das Retinapigment im gleichen Falle die vorderen Enden der Selıstäbe einhüllt, während es im 1)unkelange aus der Netzhant ganz verschwunden und in reichlichen Massen hinter der Membrana fenestrata angehäuft ist. Ein Theil desselben bleibt iibrigens anch im Lichtange hier zurück. Ein typisches schönes Tapetum umhüllt die hinteren Hälften der Sehstäbe sowoll im Dunkel- als im Lichtauge.

Peneus membranaceus (Taf. T, Fig. 47, und Taf. VII, Fig. 75). Die schünen Augen dieses Thieres zeichnen sich daurch aus, dass sie kein oder nahezu kein Pigment enthalten, hingegen schönes Tapetum. Ich fand nämlich bei einem Dunkelauge und einem Auge aus diffusem Tageslicht keine Spur von lrispigment, wohl aber sehr schönes Iristapetum. Die Augen waren in Alkohol gehärtet. Dann fand ich bei einem Lichtange, das in Mïller'scher Flüssigkeit gehärtet war, doch Spuren eines bramen 
Pigmentes, welches sich vom Iristapetum aus anf eine kurye Strecke, etwa bis in die halbe Höhe des Kegels erstreckte und im Uebrigen den gewöhnlichen Platz des Trispigmentes eimmahm. Nur mit einiger Mühe war es möglich, sich von der Pigmentuatur des unscheinbaren Belages zı ïberzeugen. Ich konnte demnach nicht entscheiden, ob dieses Individum Trispigment hatte, die beiden anderen Individnen keines oder; was mil niclit unwahrscheinlich schien, dass alle in das Iristapetnm eingesprengt und von diesem rerdeckt etwas Pigment besitzen, sich dasselbe aber nur bei Somnenbelenchtung so weit rom Tapetum trennt, dass es mit Sicherheit erkannt werden kann; oder endlich könnte man denken, dass diese Inifferenz der Angen auf der Härtungstlüssigkeit beruhe. Es wäre aber viel wahrscheinlicher, dass die Mïller'sche Flüssigkeit das Pigment anfgelöst hätte, als dass es der Alkohol thme.

Ueber diese Fragen klärte mich der Anblick einiger Fxemplare desselben 'Thieres auf, welche Herr Custos Kölbel mir aus der Sammlung des kaiserl. naturhistorischen Hofmusemms zu zeigen die Freundlichkeit hatte. Diese Thiere, an der spanischen Küiste gefangen, zeigten, ohwohl seit vielen . Tahren in Alkohol, dentlich und schon mit freiem Ange erkrnnbar, pigmentirte Angen. Es scheint also kein Zweifel, dass hier individuelle Sthwanknngen vorkommen, die vielleicht mit der grösseren oder geringeren Tiefe, in welcher die Thiere leben, zusammenhängen.

Die kurzen yutergestreiften Sehstäbe tamchen nach hinten in das Retinatapetum. Wie bei vielen Krebsen, liegt anch bei Penens im Ganglion opticum und vollkommen von der ersten getrent eine zweite Tipetumschichte, die aber nicht reichlaltig mit 'Tapetummasse versorgt ist. Anffallenderweise finde ich diese zweite Schichte nicht bei dem in Mïllerscher Flüssigkeit conservirten Lichtange.

Schöne, hinten abgerindete Krystallkegel, deren Fortsätze in je zwei Stränge ansgehen, die mit coagnlirter Fliissigkeit erfiillt sind. ('orneafacetten ylladratisch.

\section{Halbschwänze.}

Der Einsiedlerkrebs (Pagurus) (Taf. VII, Fig. 71 und 72) Iat, sechseckige Coneafacetten. Auch bei diesem Thiere lïsst sich die Verschiebung des Irispigmentes auf Lichtwirkung an den mikroskopischen Präparaten nachweisen, wie durch das Terhalten des Angenlenchtens erwartet werden musste.

3. Kurzscluwänze.

Dromia vulgaris (Taf. V, Fig. 55, 56). Hinter der dicken quadratischen Corneafacette liegt ein Krystallkegel, in dessen Innerem man, wie das nicht selten ist, noch einen anders brechenden linsenartigen hörper liegen sieht. Ob dieser auch schon im Leben dasselbe optische Terhalten zeigte, muss ich dahingestellt sein lassen. I)ie Sehstäbe reichen mit ihren Verlängerungen bis an den Krystallkegel. 'Typische Verschiebung ron Trisund Retimapigment. 
Portunus (Taf. IV, Fig. 37, 38). Die Krystallkegel zeigen starke Coagulationen, so dass ich ihre Form zwar gezeichnet habe, wie die Mehrzahl sie zeigen, aber für deren Correctheit nicht einstehen hann. Die Corneafacetten sind sechseckig. Merkwïrdig ist hier das Spiel des Irispigmentes, das am Dunkelange die hintere Wölbung des Kegels durch eine weite Oeffnung frei lüsst und im Lichtauge sich am Sehstab dicht anliegend wie ein Ueberguss nach hinten zieht. Das gewöhnliche ist, dass das Pigment eine Röhre von der Weite des Kegels bildet, in welcher, sie aber beiweitem nicht ausfüllend, der Selıstab oder die Hülle des Kegels liegt.

Sehr schön ist auch das Spiel des Retinapigmentes, das sich von der hinteren Hälfte der Spindeln und dem Ganglion opticum auf die vordere Hälfte zieht, an dem ursprïnglichen Standort nur spärliche Reste zurïcklassend. Man sieht hier direct die Stränge, welche das Pigment führen, die Sehstaibe umgeben und die Membrana fenestrata durchbohrend sich in das Ganglion einsenken. Querschnitte $(a, b)$ zeigen, dass diese Stränge Sterne bilden, d. h. bandförmig sind und mit ihrer Breitseite radiär stehen.

Galathea (Taf. V, Fig. 45, 46, und Taf. VI, Fig. 65). Die Kegelscheiden bilden zwischen Cornea und eigentlichem Kegel lange mit coagulirter Flïssigkeit gefüllte Röhren; Lichtverschiebung am Iris- und Retinapigment. Im Dunkelauge sind die SpindeIn der Selıstäbe wahrscheinlich in Folge der Härtung in die Länge gezogen, so dass das Tapetum nicht anf der Memlorana fenestrata anfsitzt. Corneafacetten quadratisch.

Maja (Taf. IV, Fig. 41, 42) hat Sehstäbe, die bis in die nächste Nähe der Krystallkegel reichen, kein Tapetum und eine nicht bedentende Lichtverschiebung sowohl im Iris- als im Retinapigment. An dem ersteren erkennt man dieselbe fast nur daran, dass die runden Kerne, welche dem vorderen Theile der Selıstäbe ansitzen, am Lichtange von Pigment eingehüllt sind, an letzterem ist eine Wanderung aus dem Ganglion nach vorne wemn auch nicht sicher, so doch recht wahrscheinlich.

Die Corneafacetten sind sechseckig und die Cornea zeigt eine deutliche Schichtung in Lamellen. Ueber die Krystallkegel kamn ich Näheres nicht aussagen, da sie an meinen Augen nicht gut erhalten waren.

Pisa ('Iaf. V, Fig. 48, 49). Die lamellirte Cornea hat sechseckige Facetten, die Krystallkegel an ihrer Spitze von dicht anliegenden Kernen mmgeben. Der Sehstab zerfällt in zwei Al,theilungen und trägt am vorderen Ende die iibliche kernhaltige Anschwellung. Zwischen den hinteren Enden der Sehstïbe, sowie im Ganglion opticum findet sich Tapetum. Querschnitte ( $d$ der Fig. 48) lassen es kamm zweifelhaft erscheinen, dass dasselbe hier in Zellen eingelagert ist, die schöne runde Kerne haben. Dentliche Verschiebung des Irispigmentes, ebenso des Netzhautpigmentes, welches im Dunkelange fast ausschliesslich linter der Membrana fenestrata liegt mo im Lichtange an die vordere Hälfte der spindelförmigen Anschwellung geriickt ist, wo es in zierlich mnterbrochenen Strängen angeordnet ist. An einem Lichtange fand ich übrigens das Pigment anch an der hinteren 
Hälfte der spindelförmigen Anschwellung, wo Querschnitte schöne Pigmentsterne mit dem centralen durchsichtigen Rhabdom zeigten. Die Strahlen der Sterne waren durch die Querschnitte der Pigmentstrïnge gebildet. Das Rhabdom zeigt sich im dümmen und dicken Theile des Selistabes als aus vier Scheiben zusammengesetzt. Auffallend ist, dass das obere Ende des Selıstabes im Lichtange vom Kegel abgezogen, aber noch mit einem Strange an ilm befestigt erscheint. Ich wiirde glauben, dass dies durch Härtung und Schrumpfung bedingt ist, aber beide ron mir geschnittenen Lichtaugen zeigen dieses Verhalten, obwohl das eine in Müller'scher Flüssigkeit, das andere in Alkohol gehärtet worden war.

Nicht nnerwälnt kann ich lassen, dass das Tapetum bei diesem Thiere, wenigstens an den Präparaten, schlecht das Licht reflectirt, so dass es im auffallenden Lichte weniger hell, im durchfallenden weniger dunkel erscheint als bei anderen Thieren.

\section{Diverse Crustaceen.}

Squilla mantis (Taf. III, Fig. 22). Eine Pigmentwanderung durch Lichteinwirkung konnte ich an keiner der beiden Schichten beobachten. Tapetum fand ich keines. Die Corneafacetten sind sechseckig.

Phronima, Copilia, sowie die ebengenannte Sunilla lıaben Augen ron so eigenthümlichem Ban und so besonderer Functionsweise, dass ich sie zum Gegenstand der Besprechung in einem eigenen, dem nächsten Capitel machen will, woselust sich anch Holzschnitte finden.

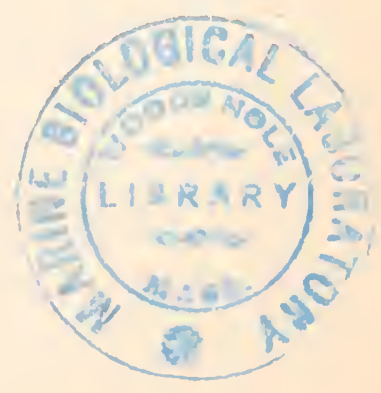




\section{CAPITEL.}

\section{Die Augen von Squilla, Phronima und Copilia.}

Es war bisher fast ansschliesslich vou den Angen der Insecten und der Dekapoden die Rede. Ueber die iibrigen Crustaceen, abgesehen vom Limulus, habe ich sehr wenig Erfahrungen, doch schienen mir die Augen einiger derselben nach den Beschreibungen, die ich ron ihnen las, so interessant, dass ich sie ihres absonderlichen Banes wegen doch in den Kreis meiner Beobachtungen zog und Einiges darïber nittheilen zu künnen glaube.

a) Squilla mantis steht, was den Bau der einzelnen Facettenglieder betrifft, den halb- und knrzschwänzigen Krebsen sehr nahe. Es gelang. mir, am frischen Auge ziemlich gute Bilder iiber den Strahlenverlauf zu erhalten. Derselbe ähnelt durchans dem von Limulıs, d. h. man sieht in der Nähe der Kegeispitzen ein nicht sehr dentliches verkehrtes Bildchen änsserer Objecte. Benïtzt man als solche zwei Lichtpunkte, so erkennt man, dass die Strahlen, welche von jedem derselben ausgegangen waren, sich im Bilde unter einem recht spitzen Winkel krenzen und dass die Axen der beiden weiter verlanfenden Lichtkegel sich wenigstens nicht in einer hier in Betracht konmenden Entfernung kreuzen, sondern näherungsweise parallel verlaufen. Und zwar war das Verhalten der Lichtstrahlen dasselbe, ob die Facettenglieder dem stärkst- oder dem schwächstgekrümmten Theile des Anges angehören. Das 'I'hier' sieht also mit einem Appositionsbild.

T)as Absonderliche an diesem Ange liegt aber in seiner Gestalt. Ich habe schon erwähnt, dass dieselbe einer an beiden Enden abgerundeten Walze zu vergleichen ist, die aber in ihrer Hitte eine ringförmige Einschnürung hat. Einen Schnitt, der auch den Stiel des Auges trifit, zeigt Fig. 22, Taf. III.

Herr Prof. Braner macht mich nach Abschluss meiner Untersuchungen darauf anfmerksam, dass es anch eine Insectenart gibt, deren Augen durch eine tiefe Kerbe in zwei Theile getheilt ist, nämlich Ascalaphus.

Ein Längsschnitt durch das Auge von Squilla würde im Allgemeinen Biscuitform haben, ein Querschnitt Kreisform, wenigstens soferne der Stiel 
nicht mit in den Schnitt fällt. Ich sage Biscuitform, denn thatsächlich kann kein Schnitt, wie das bei einem wahren Cylinder der Fall wäre, eine gerade Begrenzungslinie des Auges ergeben, die Wölbung an Ende der Walze geht direct in die Wülbung der Einschnürung ïber. Es ist das deshalb von Wichtigkeit, weil es im Principe des Eacettenauges liegt, dass die Axen der Facettenglieder gegeneinander genoigt sind.

Ich habe auch schon oben anf die durch die Gestaltung nothwendig bedingte Verzerrung des anfrechten Netzhantbildes hingewiesen; es lohnt sich aber doch, diese Verzerrung etwas genaner ins Auge zu fassen und nach deren möglicher Bedeutnng im Leben des 'Thieres zn fragen.

Fassen wir zmnächst nur die eine Hälfte des Organes ins Auge, also eine Hälfte der Walze, welche vom Ende bis zur Einschniirung reicht. Denken wir uns die Walze horizontal stehend, so ist der Krümmmnsshalbmesser des Auges in der Horizontalen weit grösser als in der Verticalen. Das Netzlantbild eines mit einer Seite horizontal stehenden Quidrates muss also die Gestalt eines langgestreckten Rechteckes haben, dessen lorizontal stehende Seite die lange ist.

Kann nun eine solche Verzerrmng für das 'Thier von irgend einem Nutzen sein? Ich denke wohl. Wir wenden bei unseren physikalischen Versuchsanordnungen eine solche Verzerrung eines Bildes häufig als einen zu dem speciellen Zwecke sehr geeigneten Kunstgriff an. So z. B. wird jetzt oftmals die vordere Fläche von 'Thermometerröhren so zugeschliffen, dass durch die an ihr stattfindende Lichtbrechung der dümme Quecksilberfaden dick erscheint; wir selien ihn dann viel besser wegen des Zuwachses in der einen Dimension. In der anderen Dimension war eine Vergrösserung durchaus kein Bediirfniss. Es ist anch dasselbe Princip, nach welchem wir zur Erzengung eines Spectrums nicht einen hellen Punkt als Lichtquelle, sondern eine lielle Linie verwenden. Das Spectrum wäre ebensolange und enthielte dieselbe Anordnumg der Farben, wenn wir nur einen Punkt verwenden wïrden, wir würden aber viele l)etails nicht sehen, wenn wir nicht die Verzerrung in der Richtnng bewirken wiirden, welche auf die Reihe der wahrzunehmenden Details senkrecht steht.

Gerade ebenso wiude also das Netzhantbild einer Syuilla z. B. ein System paralleler Linien noch als solches erkemnen lassen, wenn die Linien vertical stehen, und wïrde die Auflösung desselben Liniensystemes nicht mehr bewirken, wenn es horizontal stünde. Es wiirde sich also die eigenthïmliche Form des Anges mnter der Voraussetzung erklären, dass es im Haushalte dieses 'lhieres von Wichtigkeit ist, I) Wails, die in einer bestimmten Richtung angeordnet sind, genau zu unterscheiden.

Die andere Absonderlichkeit des Anges, die ringförmnige F'urche, die dasselbe in zwei recht ähnliche Hälften tlıeilt, mus zur Folge haben, dass ein Object, welches näherungsweise in der Ebene dieser Furche liegt, zwei Netzhantbilder in demselben Auge entwirft. Es muss das so sein, weil das 
Facettenauge, abgesehen von hier nicht in Betracht kommenden geringfïgigen Abweichungen, nach jeder der vielen ïber seine Functionsweise aufgestellten Theorien, das Bild eines Punktes durch jenes Facettenglied entwirft, dessen Axe den Punkt trifft. Hier sind aber zum mindesten zwei Facettenglieder, auf jeder Seite der Einschnïrung, deren Axen nach dem Gegenstand gerichtet sind, wenu er in der genannten Ebene liegt. Das Thier sieht also mit einem Auge zwei Bilder, es sieht binoculär. Es hat demnach auch die Vorzüge des binoculären Sehens für jedes Auge speciell. Der wichtigste Vortheil des binoculären Selıens aber ist unzweifelhaft die ermöglichte Schätzung der Entfermungen. Squilla kamn also mit einem Auge Entfernungen schätzen. Wir wissen freilich nicht, wie gut andere Krebse und Insecten monoculial stereoskopisch selıen, das aber ist sicher, dass das Auge der Squilla in dieser Bezielıung iiber einen der wichtigsten Factoren verfügt, der den anderen fehlt.

Dabei ist aber noch Folgendes zu beachten. Es ist nicht gleichgiltig, ron welcher Beschaffenheit der Gegenstand ist, dessen Entfernung geschätzt werden soll. Einer horizontalen Linie gegeniiber wäre diese ganze Einschniirung des Squillaanges fiuchtlos; geradeso wie unser binoculäres Sehen uns bei horizontalen Linien im Stiche lässt, ebenso die Vögel, die sich ja deshalb so häufig an T'elegraphendrähten im Fluge erschlagen, wie das allgemein bekamt ist.

Wir haben oben der Einfachheit der Darstellung wegen vorausgesetzt, dass das walzenfürmige Auge mit seiner -Längsaxe horizontal stehe und sehen nun, dass dies die Richtung eines Liniensystems ist, dessen Entfernung es am schlechtesten schätzt. In der Senkrechten muss es Entfernungen am besten schätzen. Wie nun immer im Leben das Auge stehe, so gelıt daraus hervor, dass diejenige Richtung, welche ein Liniensystem haben muss, um das dentlichste Netzhantbild zn entwerfen, dieselbe ist, die es haben muss, damit seine Entfernung am sichersten erkannt werde. Ein Zusammentreffen, das man kaum ein zufälliges nenuen darf.

Die Eigenthümlichkeiten des Auges befühigen also Squilla Structuren, in deren Anordnung eine bestimmte Richtung hervortritt, schärfer zu sehen und ihre Entfernung genauer zu beurtheilen, als dies ohne diese Eigenthümlichkeiten cet. par. der Fall wäre. Ich bin mit der Lebensweise des Thieres zu wenig vertrant, um auch nur vermuthen zu können, um welche Objecte des Sehens es sich hier handelt.

b) Die Phronimiden haben, wie seit geraumer Zeit bekannt, Augen, die sich von jenen der anderen Krebse recht bedentend unterscheiden. Jedes Ange zerfïllt auch hier in zwei Theile, doch sind dieselben so hochgradig verschieden, dass man füglich jeden als ein Ange betrachten und sagen kam, das 'Thier habe vier Augen. (Vgl. Holzschnitt Fig. 20.) Es sind zwei Seitenangen, deren Schfeld die gewöhnliche Lage und Ausdehnung hat, und zwei Scheitelangen, deren Sohfeld ausschliesslich nach oben 
liegt, wemn man sich das 'Thier, mit seiner Körperaxe horizontal sitzend denkt. Ja, es sind dementsprechend anch vier Retinen volhauden $\left(R^{1}, R^{2}\right)$. Fig. 20 zeigt die rechte Hälfte cines Kopfes von vorne gesehen, bei schwacher Vergrösserung. Diese Thicre sind nämlich fast durchsichtig, so dass man sofort das Seitenange mit den kurzen theil weise in Verkiirzung erscheinenden Krystallkegeln und der Retina $R^{1}$ erkennt, ebenso das ansgedehnte Scheitelange, dessen Kegel in lange Fäden iibergehend von der zweiten Netzhant $R^{2}$ anfgenommen werden, deren Selıstäbe fast wie eine Fortsetzung der Kegel erscheinen und in ihrer Gemeinschaft die Form einer' biite nachahmen.

Ich verdanke anch hier wieder. Herru Prof. Brauer die Mittheilung, dass bei Insecten, und zwar der den Ephemeriden angehörigen Chloëbinoculata, eine ähnliche Theilung der Angen rorkommt.

Indem ich, was den anatomischen Bau des Auges und der Retina ron Phronima betrifft, anf die bekamnten Untersuchungen mnd Abbildungen von Claus ${ }^{1}$ verweise, mit deren Beniitzung auch die beistehende Figur entworfen ist, will ich hier nur das besprechen, was mir von physiologischer Bedentung scheint.

Währeud Gammarus (ich untersuchte G.Rös elii) Krystallkegel hat, deren hintere Fnden in einer nemnenswerthen Entfernung vou der Retiua

1 Vgl. C. C'laus: Der Organismus der Phronimiden. Arbeiten ans dem zoologischen Institute der Universitït in Wien. Tom. II, 1879 .

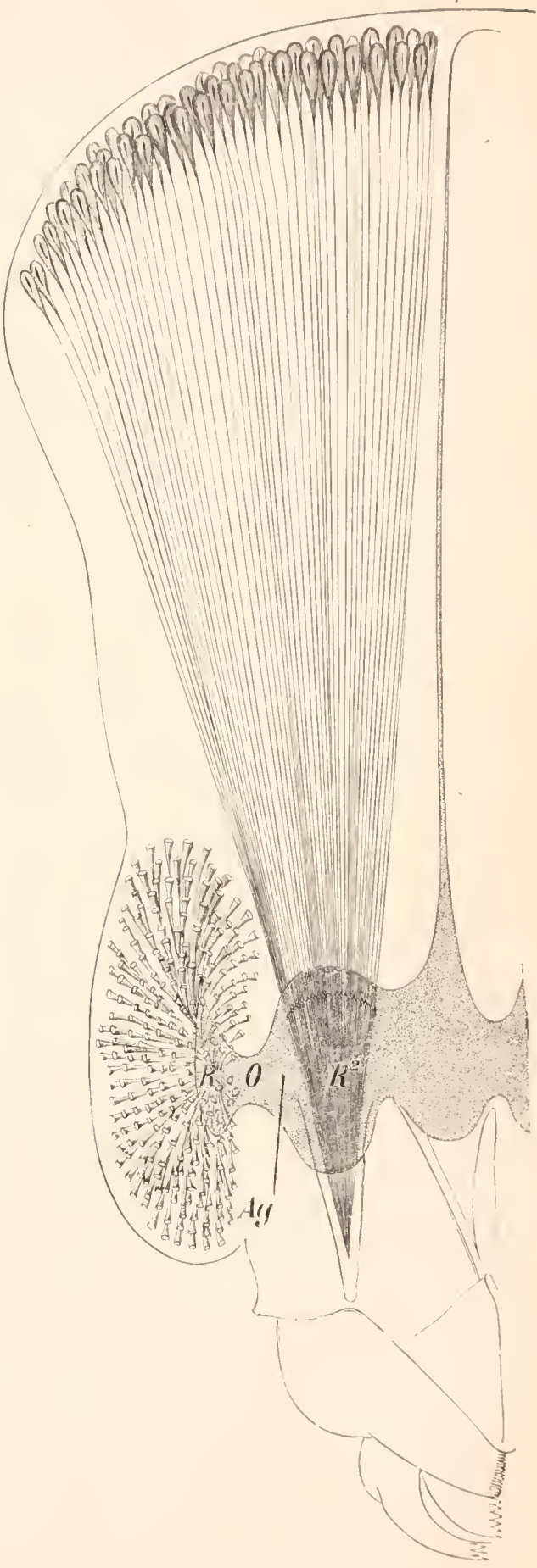

Fig. 20. 
liegen, somit ein Superpositionstrild bei diesem Thier nichit ausgeschlossen ist, ragen bei dem im Uebrigen ziemlich ähnlich gebanten Seitenange von Phronima die Krystallkegel so in die Netzhaut hinein, dass ilıre sehr kleine, aber ebene Endtäche hart an das vordere Ende des Rhabdomes (S) zu stehen kommt, so dass dieses, da es auch fast dieselbe Dicke hat, wie eine Fortsetzung des Kegels wirkt. (Vgl. T'af. IV, Fig. 43.) Die centralen Fortsätze der Netzhautelemente sieht man die Membrana fenestrata ( $m . f$.) durchbohren und sich hier mit Körnern in Verbindung setzen, welche ein primitives Ganglion opticum darstellen, und von diesen Kernen sieht man wieder die Nervenfäden abgehen und den Sehnerven zusammensetzen. Pigment findet sich im Auge keines, abgesehen von einer gelblichen diffusen Färbung der Netzhaut. ${ }^{1}$

Jch kenne kein Facettenange von ähnlicher Einfuchheit und deshalb Verständlichkeit des Baues, in Bezug auf die Gliedermg in den dioptrischen Apparat, die Netzhaut als energiemmwandelnden Apparat und den eigentlich nervösen P'erceptions- nd Leitungsapnarat.

Etwas anders steht es mit der Verständlichkeit der fhysikalischoptischen Vorgänge. Ein Superpositionsbild kann nicht da sein, ans den schon genannten Grunde, aber anch ein Appositionsbild von der Art, wie wir es bisher kennen gelernt haben, ist ausgeschlossen. Denn es erfordert, dass in der Nähe der Spitze jedes Krystallkegels ein, wenn anch schlechtes, dioptrisches Bild der äusseren Objecte entworfen werde. Das ist hier aber so gut wie ausgeschlossen, denn die liegel-sind erstens hier'n in ihn'em Bane nicht regelmässig genug, sie sind, wie O. Schmidt richtig hervorhebt, durchans nicht symmetrisch um eine Axe orientirt, zweitens aber schliesst, wenigstens beim Scheitelauge, die ungeheure Länge des Krystallkegels, sowie seine Dünne den Gedanken an ein gewöhnliches dioptrisches Bild gänzlich aus. Der Kegel des Scheitelanges hat ja im Allgemeinen die Form einer Stecknadel, deren Kopf aber nicht kugelig ist, sondern allmählich in die Nadel iibergeht, und deren Nadel circa fiunfzehmmal so lang ist als die Kopfanschwellung. (Tgl. T'af. IT, Fig. 44, einen isolirten Kegel, dessen Faden aber noch bedeutend ror seinem natïrlichen Ende durchschnitten ist.) Sollte da ein dioptrisches Bild entstehen, so müsste der ganze lange Faden kaum um ein Tausendstel Millimeter von der Geraden abweichen, wenn das Bild nicht zerstört werden dürfte. Nun trifft das gewiss nicht zu, vielmelı sieht man Asymmetrien und Terbiegungen, die ganz gewiss schon im Leben bestanden haben. Aus diesen hat Schmidt gefolgert, dass die Krystallkegel von Phronima das Licht durch totale Reflexion leiten, wie ein Glasstal dies thut, und dass die Theorie vom musivischen Sehen hier nicht zutrifit. Die letzte Folgermng ist, wie schon mehrfach herrorgehoben wurde, falsch, die erstere ist im gewissen Sinne richtig.

1 So zeigten es meine in Alkohol, theilweise auch rorher in osminmsïure, erhärteten Thiere. Frische Angen zu untersuchen, hatte ich keine Gelesenheit. 
In meiner ersten Abhandlung (1875) ïber das zusammengesetzte Ange glaubte ich, die Thooric antstellen zu dürfen, dass jedes facettenglied des zusammengesetzten Anges Lichtstrahlen, welche näherungsweise in der Richtung seiner Axe anffallen, theils durch Brechung, theils durch totale Reflexion an die Spitze des Krystallkegels leitet, wo sie dann vom Netzhautelemente anfgenommen werden. In Grossen und Ganzen war diese meine Theorie falsch. Ich kamnte damals die optische Wirkung der Linsengrlinder noch nicht. Für Phronima aber muss ich sie hente noch anfrecht erhalten, allerdings in einer durch die Kemntniss der Linsencylinder vervollkommneten Form. Die Leitung von Lichtstrahlen in Glasstäben geschieht anch, wenn dieselben gekrïmmt sind, ja es ist dieses Princip in nenester Zeit praktisch verwerthet worden.

Stellen wir uns also zunïchst die radiüre Anordnung der wirklich kegelförmigen vorderen Enden der Krystallkegel vor und setzen wir vorans, dass Lichtstrahlen, welche näherungsweise in Richtung der Axe in einen solchen Kegel eintreten, in den Faden gelangen und von diesem bis zmm Netzhantelement geleitet werden, so ist nur nöthig, dass diese letzteren dieselbe gegenseitige Anordnung haben wie die dazugehörigen vorderen Kegelenden. Es muss damn ein anfrechtes Netzhautbild entstehen, ob die Kegelfïden gerade oder gebogen verlaufen. Wenn die drei Punkte $a, b$, c eines Gegenstandes in den Axen der drei nebenemander stehenden vorderen Kegelenden $a_{1}, b_{1}, c_{1}$ liegen, so miissen die von ihnen ansgehenden Lichtstrahlen den Netzhantelementen $a_{2}, b_{2}, c_{2}$ zugeführt werden. Stehen diese letateren anch nebeneinander, so erhalten sie also ein Bild ron $a, b, c$. Nun stehen sie aber nebeneinander, wie darans mit Bestimmtheit zu ersehen ist, dass auch beim Scheitelange von Phronima die Kegelfäden vollkommen regelmässig, d. h. ohne sich zu verflechten oder zu kreuzen, nach der Netzhant convergiren.

Dass nun wirklich Licht, das nähermusweise mit der Axenrichtung in den Kegel eindringt, in der geschilderten oder einer ähnlichen Weise durch denselben bis an seine Spitze geleitet wird, davon iiberzengte ich mich am Seitenauge ron I'hronima folgendermassen. Das Auge, gefärbt und in Celloidin eingebettet, wurde in dicke Schnitte zerlegt mnd ein Kegel ansgesucht, dessen Axe senkrecht stand, mit dem vorderen Ende dem Spiegel des Mikroskopes zugerrendet. Man sieht nun bei passender Belenchtnng ganz wie bei einem Glasstab dis obere Ende liell und dunkel werden, wemn man das untere Ende behichtet oder beschattet. Das Licht selbst gab den Beweis, dass es den Kregel der Länge nach durchsetzt hatte, denn es war tief roth gefürbt, obwohl die nicht senkrecht stehenden liegel so schwach tingirt waren, dass sie eben nur eine röthliche Farbe erkemnen liessen.

Auf ähnliche Weise überzeugte ich mich num aber auch - es geschieht das wohl jedem Forscher - dass die Dinge doch noch complicirter sind, als man sie sich vorgestellt hat. Anch diese Krystallkegel, die, wie Claus richtig beschreibt. aus zwei longitudinal aneinandergelegten 
Stücken bestehen, sind nämlich wieder nach dem Principe der Linsenrylinder gebant.

Die lichtsammelnde Wirkung der Linsencylinder wird sich also zu der gleichen Wirkung der vorderen convexen Kegelfläche addiren. Es fragt

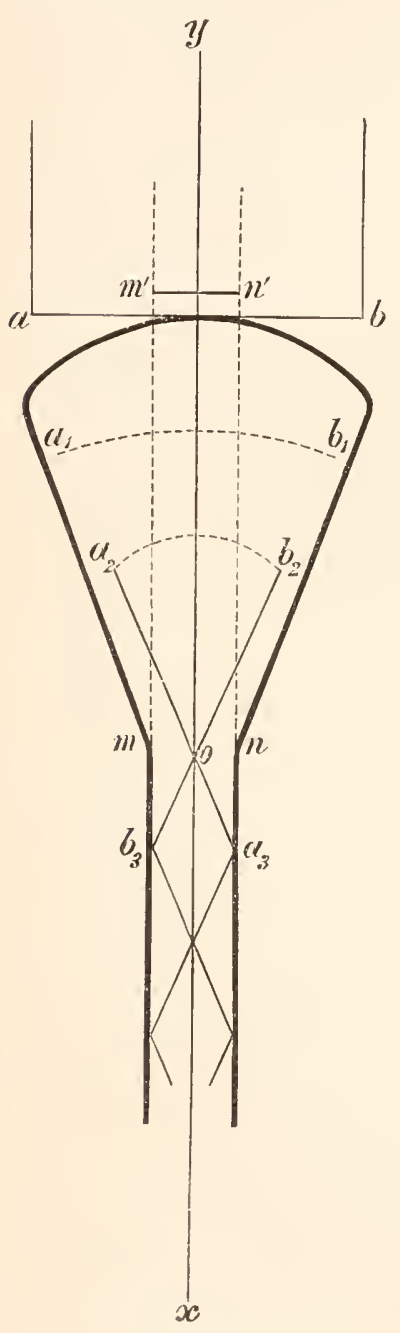

Fig. 21. sich, was für eine Bedentung für das Selien kann diese Sammelwirkung an den Krystallkegeln iiberhaupt haben? Nir scheint dieselbe anf der Hand zu liegen.

Ich liabe oben (S. 59) gezeigt, dass ein Kegel im strengen Simne des Wortes nicht geeignet ist, Licht an seine Spitze zu leiten. Hier handelt es sich aber gerade um etwas derartiges, und speciell um die Lösung der Aufgabe, das aus einer bestimmten Richtung, nämlich der Axe kommende Licht in den Kegelfaden zu bringen. Betrachten wir die Sache in Holzschn. Fig. 21 etwas schematisirt. Wiirde eine Brechung der Lichtstralilen nicht stattfinden, so könnte von einem entfernten, auf der Axe $x$ des Kegels gelegenen Punkte fast nur ein Lichtbündel bei $m n$ in den Faden eintreten, das den Querschnitt $m^{\prime} n^{\prime}$ hat. Etwas von den benachbarten Strahlen wïrde wohl noch durch Reflexion dahin gelangen, aber aus den oben angefiihrten Grïnden würde das bei der Feinheit des Fadens nicht viel sein. Anders ist es, wenn die Strahlen gebrochen werden. Es kann dann das ganze ron demselben Objectpunkte kommende Lichtbündel, dessen Basis $a b$ der Breite des Kegelendes entspricht, den Faden erreichen; denn die Wellenoberfläche von $a b$ wird durch die Brechung an der convexen Fläche nach unten concar $\left(a_{1} b_{1}\right)$, welche Concavität durch den Linsencylinderbau im Fortschreiten der Wellenoberfläche noch vermehrt wird $\left(a_{2} b_{2}\right)$, und bedenkt man, dass die Richtung der Strahlen immer senkrecht auf der Wellenoberfläche steht, so gelangt ein Strahlenkegel $a_{2} o, b_{2} o$ in den Faden, welcher nun durch totale Reflexion $\left(\begin{array}{ll}b_{3} & a_{3}\end{array}\right)$ bis an das Netzhantelement geleitet wird und alles Licht enthält, das aus jener Richtung in die Convexität des Kegels eingedrungen ist.

Die kegelartige Erweiterung am vorderen Ende, ihre convexe Fläche und ilı Linsencylinderbau erzielt also eine selı nennenswerthe Helligkeitssteigerung des Netzhautbildes.

Strahlen, welche schief in den Kegel eindringen, werden, je nach dem Grade ihrer Neigung gegen die Axe, entweder eliminirt (s. oben) oder 
sic werden atuch in den kegelladen gelangen. Is ist dies natündich del kleinere 'Theil, der aine geringe Neiğung gegen die Axe hat. Er muss aber bewirken, dass in einen Kegelfaden nicht nur das Liclit des Axenpunktes, sondern auch das seiner nächsten Umgebung galangt.

Also anch Phonima sieht mit einem anfrechten Netzhantbild, das lem Appositionsbilde verwandt ist, sich von ihm aber dadurch nnterscheidet, dass ansser der Brechung in jedem Facettenglied ancin noch eine Leitung des Lichtes clurch totale Reflexion vorhanden ist. Das 'I'hier sicht wie die Libells nach oben mit einem mehr abgeflachten Auge, was woh] eine ähnliche Bedentung lıaben dürfte, wie bei jener. In Ganzen ist das Auge jedenfalls ein weit unvollkommeneres als das anderer Krebse.

Die bisher besprochenen Angenformen hatten manche Absonderlichkeiten, führten aber doch immer wieder auf den Typus des Facettenauges mit anfrechtem Netzhantbild zuriick.

c) Bei Copilia aber und ihren nächsten Terwandten, besonders Sapphirina, hat man nenerer Zeit eine Angenform kennen gelernt, die in der 'That in höchsten Grade absonderlich ist und in den Rahmen keines bekannten Augentypus zu passen scheint.

Copilia, die ich lebendig und todt zu untersuchen Gelegenheit hatte und von der ich deshall, hier allein zu sprechen habe, ist ein wenige Millimeter grosser, von oben nach unten abgeplatteter Copepode, in der Flächenansicht näherungsweise von der Gestalt eines gleichschenkeligen Dreieckes. Die Basis desselben bildet die rordere Kante des 'Thieres, und an deren beiden Hnden findet sich eine anfillend schöne Linse, deren eine convexe Flächc nach vorne sieht und an IVasser grenzt, und deren hintere Fläche dem Innern des fast gauz durchsichtigen Körpers zugewendet ist. (Vgl. Holzschnitt Fig. 22.)

Grenacher hat bemerkt und ich kann es bestätigen, dass die Linse aus zwei Substanzen besteht, einer cuticularen, welche selbst wieder die Form einer concav-convexen Tinse hat, und einer dahinterliegenden biconvexen stärkeren Linse. Die Linsen bilden die vordersten Theile des ganzen 'Thieres, und hinter denselben ist nicht, wie man erwartet hätte, eine Retina, sondern durchsichtige Körpermasse. Erst weit hinten, etwa in der halben Länge des Körpers, gewahrt man ein Gebilde, das man zunächst gar nicht als mit der Linse in Beziehmng stehend erkennt. Es ist ein krystallkegelartiger Körper, vorne abgerundet, von starkem Lichtbrechungsvermögen, der auf einem knieförmig nmgebogenen gelben Stab aufsitzt, dem einzigen pigmentirten Körpertheil des Thieres. Er endet anf der anderen Seite stumpf. Bei genauerer Betrachtung sieht man, dass dieser Krystalliegel, wenn wir ihn so nennen wollen, durch Aufhängebänder, die bis in die Nähe der Linse reichen, rorne befestigt ist, und dass weiterhin in den gelben Stab seitlich ein Nerv, der Sehnerv (n. o.), hineinfühnt, sich auch 
ein quergestreifter Mnskel an ihn ansetzt. Grenacher, auf dessen Beschreibung ich in anatomischer Beziehung verweise (anch Gegenbauer, Lenckart, Claus und Haeckel haben dieses Auge studirt), und unter Benïtzung ron dessen schöner Abbildung auch die Fig. 22 angefertigt worden ist, beobachtete weiter, dass im Innern des gelben (hier grau gezeichmeten) Stabes die Analoga der Retinulazellen, sowie der Rhabdome zu sehen sind, und zwar wahrscheinlich drei an der Zahl.

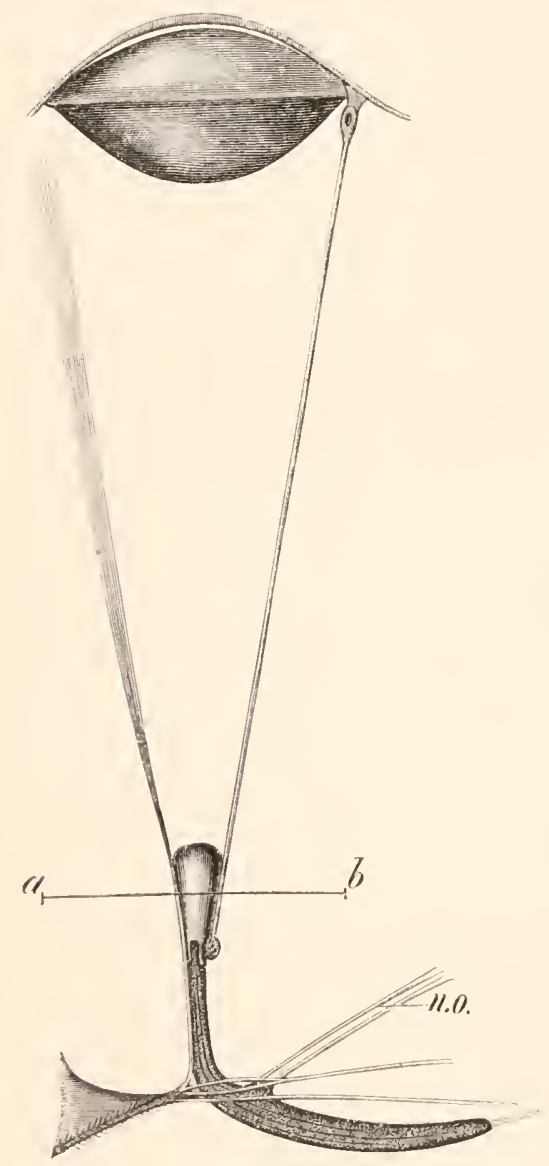

Fig. 22.

Es ist leicht begreiflich, dass ein solches Auge zul Versuchen anregen musste, seiner Functionsweise auf die Spur zu kommen. Es wurde mit einem Ferniohre verglicheu, dessen Objectiv die grosse Linse, dessen Ocular der stark brechende Körper ist, den wir der Einfachkeit wegen Krystallkegel nimnten. Das möchte wolıl gehen, aber wo ist die Netzhant, die das Fernrohrbild aufnehmen soll? Das Bild jener Linse muss ja eine ganz bedeutende Grösse haben; nur der kleinste Theil des Bildes kann ïberhanpt vom Kegel aufgenommen werden, und selbst für diesen wäre doch die hinlängliche Anzahl von Nervenenden nicht vorhanden. Grenacher sagt mit Bezug auf die Leistung dieses Auges: „... hier liegen eine Reihe von Gründen vor, dieselbe fuir die gleiche zu halten, wie die des Einzelanges des facettirten. Freilich wird bei consequenter Durchführung der Begriffe, die in dieser Hinsicht, namentlich bezüglich der Leistung der Stäbchen und der Bedeutung ilırer Zahll fiur die Sehschärfe, in der Wissenschaft zu' Zeit existiren, diese Leistung zu einer minimalen heruntergedrückt, und die grosse U'nvollkommenheit des percipirenden Apparates, dessen anatomischer Ban die Annahme einer Bildperception ausschliesst, contrastirt seltsam mit dem sozusagen kolossalen Aufwand ron Mitteln zur Erzengung eines Bildes, wie sich dieser namentlich im Bau der Linse ausspricht."

Auch ich bin der Meinung, dass eine solche Deutung der Functionsweise nicht eine befriedigende genamnt werden kann. Was könnte auch nach unseren hentigen Kenntnissen ein einziges Facettenglied für einen 
Nutzen bieten, abgesehen von de seln fiaglichen Analogie des banes'? Nur der pigmentinte Sehstah mit seinen Retinulazellen und dem Rhabdom hat die von Grenacher lervorgehobene Aehnlichkeit mit der Retinula eines Facettengliedes, in Tebrigen ist eine Aehnlichkeit kanm anfzufinden. Ich glaube nun, eine ebenso einfache als befriedigende Lösung dieses Angenı̈ithsels geben zu kïmnen.

Nach den Abbildungen und Beschreibungen dieses Auges hatte ich mir schon gedacht, es sei eine mögliche Functionsart im Folgenden gelegen: die Linse entwirft jedenfills ein verkehrtes Bild äusserer Objecte. Dieses Bild kömnte ron einer Netzhant anfgefangen werden, deren Retinaelemente gleichzeitig von den versehiedenen 'Theilen des Bildes erregt werden. Eine solche Netzhant aber fehlt; es ist nur ein Netzhantelement, verbunden nit dem Kegel, da: dieses aber kömnte successive nach der Willkür des 'Thiel'es ron den verschiedenen Theilen des Bildes erregt werden, wenn es am Bilde entlang geführt wird. I)ie eine Retinula wiude dann z. B. angesichts einer horizontalen Reihe von Punkten abwechselnd hell und dunkel sehen und dadurch im Stande sein, die Anorduung derselben zı erkennen; es wiirde bei einer bestimmten Stellıng hell selıen, und durch diese Stellung wiurde die Lage des hellen Zwischemrames geradesogut charakterisirt sein, wie sie es in Wirbelthier-oder Facettenange durch die Lage des erregten Netzlantelementes ist, ja das 'Thier' wïrde mit dem einen Netzhautelement eigentlich genan dasselbe thm, was wir Menschen mit unserer Stelle des deutlichsten Sehens machen; auch wir führen ja die Fovea centralis unserer Netzlaut am optischen Bilde entlang und betrachten uns so des Genaueren die einzelnen, uns interessirenden Stellen: wir machen Blickbewegungen. Oft ist der Vergleich gemacht worden: wir tasten mit unserem Blicke das Sehfeld ab, indem wir die Fovea centralis am Netzhantbilde hin und wider führen; ebenso tastet Copilia mit dem einzigen Netzhantelement das Bild ab, welches die Linse entwirft. Wir haben freilich dabei noch ein indirectes Sehen, dieses fehlt der Copilia.

Sollte diese meine Torstellung von der Functionsweise des Auges richtig sein, so müssten zwei Bellingungen elfüllt sein. Erstens das Retinaelement, also der gelbe geknickte Stab mit dem darangesetzten kegelartigen Gebilde, muss gegen die Linse verschiebbar sein, oder die Liuse, gegen das Retinaelement, aber derart, dass sich die Entfernung der beiden voneinander nicht merklich ändere. Denn das Bild der Linse liegt ja immer in fast gleicher Entfermung von ilı. Zweitens mïsste das Netzhantelement, wenigstens näherung'sweise (wegen des Torhandenseins des Kegels) in der Entfernung von der Linse liegen, in welcher auch deren Bild liegt; das Netzhautelement muss in der Ebene des Bildes liegen und bei den rorausgesetzten Bewegungen in dieser Ebene bleiben.

In der Neapeler' zoologischen Station hatte ich Gelegenheit, Copilia lebend zu untersuchen, lind der erste Blick durchs Mikioskop überzeugte 
mich von der Erfiillung der ersten bedingung. Die geknickten Sehstäbe zeigten die lebhaftesten Bewegungen, welche, wenn man das Thier im hohlgeschliffenen Objectträger mit dem Deckgläscheu eindeckte und es wahrscheinlich deshalb anfing, bei der geringen Nenge Wassers Sanerstoff'mangel zu empfinden, geradezu krampfhaft wurden. Die Bewegungen waren aber immer merklich dieselben mn symmetrisch. Beide Sehstäbe wurden gegen die Medianebene gezogen oder von ilr entfernt nnd blieben dabei immer, soweit man das ohne Mressung bentheilen kann, in derselben Entfermung von den Linsen. Die Bewegung machte den Eindruck jener T'urniibung, bei welcher die in der Faust gehaltenen Hanteln oftmals nacheinander an den Körper gezogen und wieder von ihm entfernt werden. Nur blieben hier die Sehstäbe immer in der gleichen Weise geknickt, inderten überhanpt nur ihre Lage immerhalb der genannten Ebene.

Die Excursionen eines Sehstabes betrugen schätzungsweise ein Tiertheil der ganzen Breite des Thieres. Ob derselbe ansser diesen seitlichen Bewegungen auch solche voll oben nach unten und umgekehrt macht, liess sich nicht mit Bestimmtheit sagen. Bei der geringen Tiefe des, wie erwähnt, flachgedrï̈ckten Körpers könnten diese Elongationen nur von sehr geringer Ausdehnung sein.

Besorgt wird die Bewegung wohl zweifellos durch den von Grenacher beschriebenen und abgebildeten ynergestreiften Muskel; anch die Flinkheit spricht dafür, dass ein quergestreifter Mruskel im Spiele ist. Ob dieser allein wirkt oder ob gewisse Stränge, die sich noch an den Sehstab ansetzen, doch auch Muskeln sind, wie behauptet worden ist, weiss ich nicht. Tm ersteren Falle wüirden diese Stränge als elastische Bänder wirken, die das Zurïckschnellen des Sehstabes gegen die Medianebene bewirken, wenn der Zug des von aussen kommenden Muskels nachlässt. Die Anordnung der Stränge, deren einer sich am fingerförmigen Ende des Sehstabes, der andere in der Nähe des Kegels, den Selıstab umschlingend, ansetzen, würde hiefiir sprechen.

$\mathrm{Es}$ ist mir nicht bekannt, dass diese Bewegungen schon beschrieben worden siud, allein ich gestehe, die einschlägige Literatur nicht genan genug zu kemmen. Doch theilte mir Herr Prof. P. Wayer von der zoologischen Station in Neapel, dem ich ron diesen Bewegungen erzählt hatte, mit, dass sich in seinen Notizen diese seines Wissens nie, auch nicht von ihm veröffentlichte, Beobachtung verzeichnet finde.

Was die zweite Bedinging betrifft, nach welcher das Netzhautelement näherungsweise in der Ebene des Bildes liegen müsse, so ist dieselbe durch Messung zu prïfen. Ich fand mit dem Mikrometer an einem lebenden Thiere die Entfernung der hinteren Linsenfläche ron der Convexität des Kegels $=0.87$ Millimeter.

Die Entfermung des Bildes, von der Linse zu messen, ist weniger einfach. Ich schmitt parallel mit der vorderen Begrenzung des Körpers einen schmalen Streifen des Thieres ab; es gelang mir nach einiger Mühe, 
denselben im Wasser so anf die Kante zu stellen, dass die hintere Fläche der Linsé dem Objective des Mikroskopes zugekehrt war. Nun sieht man ein überraschend schönes und natürlich auch ziemlich grosses Bild, das die Linse entwirft. Seine Entfermmg vom linteren Linsenpol wurde mit der Mikrometerschraube gemessen. Tch fand sie 0.93 Millimeter. Die Differenz der beiden Messungen beträgt also 006 Millimeter', kommt somit bei der Entfernung von fast 1 Millineter nicht meln in Betracht. Sie vermindert sich aber noch, freilich um eine sehr geringe Grösse, wenn man bedenkt, dass die Untersuchmng in einem hohlgeschliffenen Objectträger geschah.

Es ist also kein Zweifel, dass der Kegel fast genan in der Ebene des Bildes liegt. Nun drängt sich aber noch die Frage auf, welche Bedentung diesem stark lichtbrechenden vorne convexen Kegel zukommen mag. Ich glaube, anch diese Frage ist unschwer zu beantworten. Oben bei Besprechung des Phronimaanges habe ich auf den Werth von kegelartigen Gebilden hingewiesen, für die Sammlung aller jener Strahlen, welche näher'ungsweise die Richtung der Axe haben, und für die Abblendung der schief einfallenden Strahlen ist die grosse Bedeutung der Kegel im Abschnitte $C$ des Capitels II, S. 59, anseinandergesetzt worden. Bei der grossen Entfernmg der Linse vom Bilde, beziehmorsweise bei der Kleinheit derselben, werden die sich in einem Bildpunkte schneidenden Strahlen sehr spitze Winkel miteinander bilden. Werden sie von der Convexität des Kegels anfgefangen, so werden sie wohl an seiner Spitzenfläche sämmtlich wieder anstreten und somit in die Retinula gelangen, gleichgiltig ob dieses Auffangen etwas vor oder etwas hinter dem Vereinigungspunkte geschieht. Sie verhalten sich bei den obwaltenden Dimensionen fast wie parallele Strahlen. Damit ist aber schon gesagt, ${ }^{1}$ dass durch Brechung keine anderen Strahlen an die Retinnla gelangen können, als eben jene aus der Gegend der Linse kommenden, um die es sich beim Sehen handelt. Etwa durch totale Reflexion kömnten nocl seitlich einfallende Strahlen störend wirken. Doch diejenigen, welche mit einer geringen Neigung anf den Kegel fallen (also aus der Nähe der Linse kommen), müssen nach ihrer Brechung den hinteren Theil der Mantelfläche des Kegels treffen, wo sie vielleicht von der eigenthïmlichen Pigmentlage absorbirt werden, falls dieselbe die dazu nöthigen optischen Eigenschaften hat, ${ }^{2}$ vielleicht aber anch thatsächlich reflectirt werden und die Reinheit des Bildes trüben. Strahlen von stärkerer Neigung aber werden so gebrochen, dass sie aus dem Kegel wieder anstreten, olne an die Retinula zu gelangen.

Bedenkt man, dass das Thier, abgesehen vom Selıstab, vollkommen durchsichtig ist, dass also auf das vordere Ende der Retinula, selbst wenn sie, wie thatsächlich der Fall, am Boden einer kurzen Pigmentröhre sitzt,

1 Wegen des optischen Gesetzes von der Umkehrbarkeit des Strahlenganges, siehe S. 6.

2 Sie müsste sich zur Kegelsubstanz verhalten, wie z. B. der schwarze Lack zum Glase, mit dessen Hilfe man schwarce Sviegelu zu machen pflegt. 
Licht aus einem immerhin noch sehr grossen Theile des Sehfeldes gelangen würde, so lenchtet der Nutzen des vorgesetzten Kegels sofort ein. Er bewirkt, dass der ans der Linse kommende Stralılenkegel in sehr vollkommenem Masse der Retinula zugeführt und alles oder fast alles Licht, das ans anderer Richtung kommt, von derselben abgeblendet wird. Aus der Linse kommt aber an die eine Stelle des Bildes eben nur Licht von der entsprechenden Stelle des Gegenstandes.

Copilia sieht also, indem sie mit einem lichtempfindlichen Netzhatelemente das Bild, das die Linse entwirft, abtastet. Der psychische Process, der dem Erkennen der Objecte zu Grunde liegt, ist wesentlich jener, der uns zum Erkennen von Formen führt, wemn wir mit einem Finger tastend, den Kanten und Flächen des Objectes entlang fahren und uns so aus dem Nacheinander der Empfindungen die Gestalt construiren. Dieses Sehen hat eine gewisse Analogie mit mnserem Sehen bei bewegtem Blicke. Wegen der Körperform des Thieres ist sein Selıfeld, d. i. die Fläche des Bildes, die es abtasten kann, ein langgestrecktes. Die Ausdehnung desselben ist eine derartige, dass, wie aus den obigen Angaben hervorgeht, das Thier mit einem Auge eine Strecke von 1 Meter Länge noch ganz zu ïbersehen vermag (natürlich successive), wenn sie sich in einer Entfernung von näherungsweise » Meter befindet.'

Das Netzhantbild, das abgetastet wird, ist ein verkehrtes, und der Umstand, dass das Thier symmetrische Bewegungen mit seinen Sehstïben ausfülırt, zeigt, dass es, so wie die Krrebse meistens oder immer, mit jedem Ange besonders sieht, also keinen binocularen Sehact besitzt.

1 Diese Angabe ist natïrlich ganz approximativ; ich kann mich um die Hiilfte geirt lıben; doch gibt sie einen Begrift von der Grössenordıung, um die es sich hier handelt. 


\section{CAPITEL.}

\section{Accessorische optische Erscheinungen am zusammen- gesetzten Auge.}

Soweit ich die optischen Vorgänge in den facettirten Augen bisher besprochen habe, bezogen sie sich auf die Function des Auges als Sehorgan, insbesondere also auf die Entwerfung des Netzhautbildes. Es liegt aber auf der Hand, dass ein so complicirter optischer Apparat, wie dieses Auge einer ist, anch zu Brechungen, Reflexionen, Absorptionen etc. Veranlassung geben muss, die zwar mit der Function des Sehens direct nichts zu thun haben, wegen des gesetzmässigen Banes des Organes aber regelmässige optische Erscheinnngen hervorrufen können, suwie etwa die auf Reflexion beruhenden Purkinje'schen Bildchen des menschlichen Auges oder das Lenchten des Katzenanges anch direct mit dem Sehen nichts zu thun haben. Bei der oft genamnten Mannigfaltigkeit im Bau des Facettenauges sind auch diese Erscheinungen fast bei jeder Species andere; doch treten gewisse Typen immer wieder hervor. Von diesen soll hier die Rede sein und die zum Theil nicht einfache Erliärung derselben gegeben werden. Einzelne Beobachtungen liegen schon vor, aber allgemeine Erklärungsversuche dieser Erscheinungen sind meines Wissens iberhaupt noch nicht gemacht worden.

Ich gehe hauptsächlich ein auf das Lenchten der Facettenaugen und auf die Pseudopupillen derselben.

\section{Das Augenleuchten.}

Leydig ${ }^{1}$ erzählt, er habe vermuthet, dass das von ihm entdeckte Trachealtapetum im Auge ron Schmetterlingen, beim Windenschwärmer (Sphinx convolvuli) besonders stark entwickelt sei, da von diesem „Lepidepterologen (Kleemann) melden, dass die Augen desselben im Dunkeln wie glühende Kohlen leuchten". Es sei ihm aber erst später gelungen dieses Thieres lebend habhaft zu werden, und da sah er Folgendes:

„Als ich das erste lebende Thier in der Abenddümmernng erhaschte und sofort im Freien anf die Beschaffenleit der Augen prifte, war ich

1 Das Auge der Gliederthiere. T'iibingen 1S64. Histologie. S. 255. 
nicht wenig betroffen, auch keine Spur von einem Leuchten zu gewahren. Die Augen hatten dasselbe dunkle Aussehen, wie etwa bei einem Käfer. Zu Hause angekonmen, wende ich meine Anfmerksamkeit wieder auf den Falter im erhellten, sowie im ganz dunklen Zimmer, doch die Angen lenchten eben nicht. Des Experimentirens miide, sperre ich das 'Thier in eine ausgeräumte Commodenschublade. In aller Friile des anderen Morgens sehe ich nach dem Windig; ich ziehe behntsam die Schublade etwas hervor, der Falter sitzt ruhig am Rande, ich blicke nach seinen Augen - und sie leuchten jetzt prächtig "wie glïhende Kohlen". Ich glaubte nun, die Bedingung zu kennen, unter denen das Lenchten auftritt. Der Käfig des Falters stand rom Lichte abgewendet, die Fensterläden waren geschlossen bis auf einen, die Augen leuchteten, als nur durch den Spalt der geöfneten Schublade auf das im Dunkeln sitzende Thier etwas Licht fiel. Unter ähnlichen Verhältnissen sieht man bekanntlich anch an ehesten z. B. an Hunden und Katzen das Lenchten ihrer Augen. Aber seltsam, als ich einige Stunden später das noch immer wie im Schlafe rulig dasitzende Thier beselie, ist trotzdem, dass ich genan dieselben Umstände wieder herbeifülıe, nicht die leiseste Spur von einem Leuchten wahrzumelımen. Die Augen liaben wieder das dunkle, sammtschwarze Aussehen wie Abends vorher. I ieselbe Unbeständigkeit beobachtete ich an anderen frisch eingefangenen Thieren." Leydig sclıliesst aus derartigen Beobaclıtungen mit Recht, dass ausser den entsprechenden Beleuchtungsverhältnissen noch eine andere Bedingung erfüllt sein muss, soll ein Leuchten statthaben, dass nämlich ein gewisser innerer Zustand im Auge statthaben mïsse. El denkt hier' an zwei Mögliclkeiten, entweder eine stärkere Füllung der Tracheen, die das 'Tapetum bilden, oder' „die Contractionszustände der Pupillenschichte wechseln". Unter den Pupillen versteht hier Leydig die engen Oeffnungen in Pigmente, durch welche die Spitzen der Krystallkegel oder die oberen Enden der Sehstäbe hindurchragen und denen er nach gewissen Beobachtungen Verengerungsfähigkeit zuschreibt. Wir wissen nach dem Vorstehenden, dass diese Auffassung, wenigstens fïir die Nachtschmetterlinge, nicht amnelmbar ist, doch werden wir uns überzengen, dass Leydig's zweite Alternative in Principe zutrifft.

Während sich Leydig iiber die Verbreitung des Augenlenchtens bei den Schmetterlingen nicht näher ausspricht, sich nur wundert, dass er bei gewissen Arten, die anch Tracheen im Ange haben, kein Lenchten finden konnte, spricht Max Schultze den Satz aus, diss die Augen der Nachtschmetterlinge im Dunkeln leuchten, die der Tagschmetterlinge nicht. Dieser Satz; soferue man ilın aussprechen will, ohne ron den 'Tausenden von Schmetterlingen, die es gibt, mehr als einen sehr kleinen Bruchtheil untersucht zu haben, ist, wie wir sehen werden, wenigstens unter gewissen Bedingungen richtig, unbegreiflich abel ist, dass Max Schultze der leicht zu bestiatigenden Beobachtung Leydig's widerspricht, dass die Augen eben um zeitweilig leuchten. Er stellt die liehauptung auf, lass sie jeder- 
zeit lenchten, wenn man die Thiere in den dunklen lianm bringt, und schreibt den vermeintlichen Irrthm Iseydig's der Unzweckmässigkent der Beleuchtung zu. Die Ursache des Lenchtens sieht er nicht in der Schichte der 'Tracheen, sonder'n in der von ilım beschriebenen Blättchenstructur der' Selistäbe.

Endlich lat K ïhne ${ }^{1}$ nach Beobachtmngen hauptsächlich an einem 'Todtenkopf (Acherontia atropos) ansser / /weifel gestellt, dass stärkere Belenchtungen das Angenlenchten zun Schwinden bringen und dass sich der Zustand des Anges, in welchem es lenchtet, wiederlerstellt, wenn das 'Thier längere Zeit in Dunkeln gehalten wurde. Er sil nämlich während der Belenchtung des Auges nit dem Aıgenspiegel das Leuchten vergehen. Ans der Iangsamkeit, nit der die entsprechende Verändernng im Ange vor sich geht, vermuthet er, dass dieselbe auf Vorgängen an Pigmentzellen ber'ulıe, da sie für eine Muskelaction zu langsam, für eine Aenderung an den Tracheen zu rasch erfolge.

Eigene Beobachtungen. A. Insecten. Mit Hilfe des Augenspiegels untersucht, zeigen nicht alle, wohl aber die meisten Facettenaugen die Fïhigkeit zu leuchten, d. h. das eingedrungene Licht nach bestimmten Gesetzen zurickzuwerfen und aus dem Auge wieder austreten zn lassen, in voller Analogie zu dem sogenannten Augenlenchten der Wirbelthiere. Wie bei diesen die Pupille lenchtet, so beschränkt sich auch bei den Facettenaugen das Leuchten auf ein kreisförmiges Stiick derselben, welches ganz oder nahezu identisch ist mit dem Sitze jener optischen Erscheinung, die wir unten ảs Pseudopupille kennen lernen werden. Es sei mir deshalb jetzt schon gestattet, von der leuchtenden Pseudopupille zu sprechen, obwohl ich die Rechtfertigung des Namens Pupille erst später bringen werde. Ein wesentlicher Unterschied aber zwischen dem Lenchten der beiden Augenarten zeigt sich sofort, wenn man das Facettenauge drelit, während die Richtung der Beleuchtung und die Stellung des Beobachters dieselbe bleibt. Es behält nämlich dann anch die lenchtende Stelle des Auges dem Beobachter gegenüber immer dieselbe Lage, d. l. während der Drehung des zusammengesetzten Auges wechselt die lenchtend erscheinende Gruppe von Facetten. Ist die Beleuchtung des Auges eine möglichst vollkommene, so erscheint dem Beobachter leuchtend die Facette, deren optische Axe in der Richtung seiner eigenen Augenaxe liegt, und deren kreisförmig begrenzte Umgebung. Wie gross dieser leuchtende Kreis ist, lüngt vom feineren Bau des Auges, sowie von der Stellumg der beiden Pigmentlagen ab: er kann, wie das bei Nachtschmetterlingen und Dunkelstellung des Pigmentes geschieht, mehrere Millimeter im Durchmesser haben, und das sind die Fälle, welche von Ley dig, K ï hne und Anderen beschrieben worken sind; er kann aber auch, und so verhält es sich normalerweise bei l'agschmetterlingen, so klein sein, dass er nur unter besonders günstigen Tel-

1 Eine Beobachtung iiber das Lenchten der Insectenaugen. Untersuchungen des phys. Institutes der Universität Heitelberg. Bi. I. Heft 3. Heidellerg, bei Winter. 
hältnissen ïberhaupt und da fast nu unter Lupenvergrösserung wahrgenommen wird, und wenn es mir bei manchen Insecten und bei den meisten Krebsen in Lichtstellung iiberhanpt ummöglich war, den leuchtenden Kreis zu selıen, so beruht das offenbar wenigstens zum Theile darauf. dass seine Grösse eben jenseits der Grenze der Wahnehmbarkeit fällt. Ich vermuthe das darum, weil ich iln bei manchen Insecten erst vergebens gesucht, später aber doch als kleines leuchtendes Pïnktchen gefunden habe. Die Farbe des lenchtenden Kreises ist gewöhnlich looth, kimn aber anch bei gewissen Arten eine weissliche bis grïnliche sein, und während der Dauter der Belichtung des Anges ihren 'T'on ändern.

Ich gebe keine Abbildung von dem wenigstens theilweise bekannten Leuchten der Jnsectenaugen, doch kömnen die Krebsen angehörigen Figuren 68 und 70 der Taf. VII als Beispiele engeren und ausgebreiteteren Augenlenchtens dienen, welches dem der 'Tag- und Nachtschmetterlinge recht ähnlich ist.

Gerade wie beim Wirbelthierange die optischen Vorgänge zwar wesentlich dieselben sind, ob das Auge ein 'Tapetum enthält oder nicht, man aber' doch der auffallenderen Lichterscheinung wegen hauptsächlich von den mit Tapetum rersehenen Augen als ron leuchtenden Augen spricht, so kann man es auch bei Facettenaugen lalten. So wie das menschliche Ange unter gïnstigen Umständen eine leuchtende Punille zeigt, hat auch das Fliegenange unter analogen Bedingungen eine leuchtende Psendopupille; dieses Leuchten ist aber in beiden Fïllen ein unscheinbares gegenïber den mit 'Tapetum versehenen Angen einerseits der Raubthiere, gewisser Wiederliäler u. s. w., andererseits der Nachtschmetterlinge und der Nachtkrebse, letzterer für den Fall, dass sie im Dunkeln gehalten worden waren.

Ich beginne mit der Besprechung des Augenleuchtens der Nachtschmetterlinge als jener 'Thiere, bei denen diese Erscheinung schon bekannt ist und in rollkommenstem Masse auftritt. Die Erklärung des Phänomens ist für die velschiedenen 'Thiel'classen wesentlich dieselbe, so zahlreich auch seine Tariationen sind. Es wird also auch für diese genügen, wenn ich mich zunächst an die Nachtschmetterlinge halte.

Es ist Regel, dass ein nach Anbrucl der Dunkelheit gefangener Nachtschmetterling, den man so hinter eine Lichtflamme hält, dass das beobachtende Auge, Flamme und der Kopf des Sclmetterlings fast in einer Geraden liegen (letzterer also hart an der Flamme rorbei geselıen wird), leuchtende Augen zeigt. Die Art des Leuchtens ist mit Recht dem glïhender Kohlen verglichen worden. Schöner noch und bequemer ruft man die Erscheinung herror, wenu man einen Augenspiegel zur Beleuchtung verwendet; ich pflegte denselben mit einer Convexlinse, die ich als Lupe benïtzte, zu rersehen. Man erkennt dann leicht, dass nicht das ganze Auge lenchtet, sondern nu eine kreisrunde Scheibe desselben, dass bei Drehung des Thieres diese Scheibe am Auge so wandert, dass sie ihre Fläche stets dem Beschaucl zuwendet und dass sie, an den Rand des Auges geschoben. 
hinter demselben nach und nach zo verschwinden scheint. Botrachtet man das 'Thier von vorne, so sieht man beide Augen lenchten, aber entsprechend der Randstellung der leuchtenden Pseudopupillen in jedem Auge nu einen linsenförmigen Abschnitt.

Die Erklärnng des A g genleuchtens sehliesst sich rollkommen an die des Irirbelthieranges an. Das hinter und zwischen den Sehstäben gelegene 'Tapetum wirft, wie wil sahen, das Licht, nachdem es die Sehstäbe durclsetzt lat, wieder zurïck. Auf diesem Rückweg wird es lıaptsächlich die schon einmal duchlanfenen Sehstäbe, beziehungsweise Rhabdome zum zweitenmale durchdringen und dadurch die Selnfähigkeit des Auges bei geringen Helligkeiten erhöhen. Es ist aber bei der Structur des 'T'apetum kanm ander's denkbar', als dass ein 'Theil des Lichtes anch diffus zerstreut wrd. Bei geringen Helligkeiten, also unter den normalen Verlältnissen für das Dunkelauge, wird dieser kaum in Betracht kommen, bei grossen Helligkeiten, also dem besprochenen Fall, dass das Dunkelange in die Nähe einer Lichtflamme gebracht wird, muss sich auch dieses diffus gewordene Licht bemerkbar machen.

Erinnern wir uns an den normalen Strahlengang im Dunkelauge cines Insectes, wenn ein lenchtender Punkt als Gegenstand fungirt. Das Irispigment steht zwischen den Krystallkegeln, die Strahlen eines mächtigen Lichteylinders (vgl. Holzschnitt Fig. 11 anf S. 40) werden durch die Facettenglieder so gebrochen, dass sie sich im Bildpunkte $B$ treffen. Dieser, in der stark reflectirenden Netzhautschichte liegend, wirkt nun selbst als lenchtendes Object und die von inm ausgehenden Strahlen, soferne sie in die Krystallkegel ein- und durch dieselben hindurchdringend in das Auge des Beobachters gelangen kömnen, werden gerade so gebrochen, wie die einfallenden Strahlen gebrochen worden waren; es zeigen also die Linien der Fig. $11 x^{\prime} B y^{\prime}, p B q$, sowie alle dazwischen liegenden jetzt den WVeg an, welchen die von der belenchteten Netzhaut ausgehenden Strahlea durch den dioptrischen Apparat einschlagen, um wieder nach Aussen \%ı gelangen. Das Resultat ist wieder ein Strahlencylinder, der denselben ITeg zurïckgeht, den er, von dem belenchtenden Lichtpunkt kommend, nach dem Auge gegangen war. Würden die Verlültnisse mathenatisch genan die eben geschilderten sein, so künnte man (wie beim Wirbelthierange) mit nnbewaffnetem Auge das Leuchten nicht selıen, sondern nur mit Hilfe des Augenspiegels, denn das beobachtende Auge miisste sich genan an dem Punkte im Raume befinden, an welchem gleichzeitig der beleuchtende Lichtpunkt sein muss. Noch weniger als beim Wirbelthierange ist aber dieser ideale Zustand im Facettenange verwirklicht, und deshalb geniigt es, wenn man, wie oben beschrieben, das Auge des Beobachters und die Lichtquelle nur näherungsweise mit dem beobachteten Facettenange in dieselbe Linie bringt. Andererseits aber ist das geschilderte Verhalten doch die Ursache, aus welcher das Augenlenchten bei ungeeigneter Einfallsrichtung des Lichtes gar nicht und am rollkommenston mit Hilfe des 
Angenspiegels heobachtet werden kamn; denn dieses Instrument ermöglicht eben Lichtinelle (heziehmosweise deren Spiegelbild), beobachtendes und beobachtetes Auge in eine Linie zu stellen.

Wäre nämlich jener ideale Zustand verwirklicht, so müsste das Angenkuchten, falls ein Punkt als Lichtquelle dient, sofort verschwinden, wenn der. Beobachter sein Auge aus der genannten Richtung briugt. Das ist nun, wie wir sahen, erst bei recht merklicher Verschiebung der Fall. Untersucht man mit dem Aug*uspiegel, indem man diesen sammt dem eigenen Auge um das Facettenauge als Centrum bewegt, und merkt sich eine Stelle, z. B. die Nitte des untersuchten Auges, so kann man gewahren, dass, auch wenu die Lichtquelle als punktförmiges Object zu betrachten ist (7. B. das Spiegellild der Sonne durch einen Helmholtz'schen Angenspiegel als Object beniitzt wird), diese Stelle schön lenchtend erscheint, während man einen Bogen von ziemlich viel Winkelgraden um das Ange beschreibt. Die leuchtende Psendopupille ist eben recht gross nnd die Stellung des lipobachters, bei welcher die Mitte des Auges in dieselbe hineinrüickt, demnach recht, resschieden von der Stellung, bei welcher sie wieder herausrïckt. Gemessen habe ich die Anzahl dieser Winkelgrade nicht, da sie verschieden ist bei verschiedenen Species und anch bei demselben Indiridum unter verschiedenen Pigmentzuständen des Auges.

Diese Beobachtung lehrt, dass auch bei punktförmiger Lichtquelle die ans einer Facette anstretenden Lichtstrahlen nicht nur, wie es jener ideale Znstand voraussetzte, nach einer Richtung verlanfen, sondern dass sie einen Lichtkegel bilden. Dieser Lichtkégel ermöglicht es also anch, dass wir das Auge leuchten sehen, ohne Zuhilfenahme des Augenspiegels, und es frägt sich num, woher kommt es weiter, dass beim Facettenange, indem es lenchtet, an jedem Punkte seiner Oberfläche (oder doch an jeder Hornhantfacette) ein ganzer Lichtkegel austritt. Beim Wirbelthierauge ist das nur der Fall, wenn das Netzhautbild eine merkliche Ausdrhomung hat.

Diese Frage ist leicht zu beantworten. Fs mag hierbei in Betracht kommen, diss nnter den gemannten Unständen, wo ein grelles Netzhautbild hei voller l'nukelstellung des Pigmentes im Ange entworfen wird, dieses eben durch biffusion des lichtes seine Punktform verliert. Man hedenke, dass sowohl die stark lichtbrechenden Khabdome als das Trachealtapetum so stark Licht zerstrenen und rellectiren muss, dass das Netzhautbilachen der punktförmigen Sonne so wenig punktförmig sein wird, wie etwa das sommenbildchen, durch eine Linse auf Milch entworfen, seine richtige Grösse zeigen wïrde. Mehr aber dürfte ein anderer Umstand in Betracht kommen. Die Netzhant des Facettenauges ist im Vergleiche zu Ier des Wirbelthieranges sehr dick, anch das 'Tapetum liegt in sehr verschiedenen Ebenen. In welcher Ebene immer die Perception des Netzhantbildes geschehen möge (wenn sie überhaupt in einer Ebene geschieht), so ist kein Zweifel, dass sowohl die Netzhant als hauptsächlich das Tapetum 
in sehr verschiedener Tiefe des Auges erlenchtet wird, somit auch die zuriicklaufenden Strahlen ans sehr verschiedenen kntfernungen aul den dioptrischen Apparat stossen. Wem der Punt B in Fig. 11, S. 40, den vordersten Enden der Sehstäbe entsprechen wïrde, so miisste nicht nur von diesem aus Licht nach den Krystalkegeln zuriickkehren, sondern auch von weiter hinten gelegenen Stellen, z. B. von den 'l'acheen, welche das hintere Ende dieses Selistabes umfassen, und da diese 'l'racheen von hinten nach vorne verlaufen, auch wieder von den rerschieden tief gelegenen Antheilen derselben. Es ist aber klar, lass diese Strahlen damn mnter einem anderen Winkel gegen die Axe desselben Krystallkegels, z. B. nach $n$, gelangen müssen als der Strahl $B n$, somit auch unter einem anderen Winkel aus der Hornhantfacette anstreten. Das ist offenbar die hanptsächlichste Ursache dafür, dass an jeder Facette ein ganzer Strahlenkegel das Auge verlässt, dessen Spitze in der Facette gelegen ist. Ton der Grösse dieses Strahlenkegels, d. l. von der Grösse seines Spitzenwinkels lıängt ceteris paribus aber direct die Grösse der leuchtenden Psendopupille ab.

Die Erscheinungen des Augenleuchtens erklären sich also nach denselben Principien wie bei Wirbelthierangen, sie unterscheiden sich aber insoferne, als an Stelle der Pupille eine mit der Stellung des Beobachters ihre Lage ändernde Psendopmpille tritt und die erhellten Objecte im Angenhintergrunde nicht in einer, sonder'n in sehr verschiedenen Ebenen liegen, demnach die an einem Punkte das Ange wieder verlassenden Strahlen in einem Strahlenkegel divergiren, auch wenn die belenchtende Lichtquelle eine punktförmige ist.

Das Verschwinden des Augenlenchtens in Folge ron Lichteinwirkung ist bei Nachtthieren eine allgemeine Erscheinung. An jedem der vielen von mir daranf geprüften Nachtschmetterlinge habe ich beobachten können, dass die am Abend gefangenen Thiere lenchtende Augen halien und dass dieses Lenchten verschwindet, wenn man sie in einen hellen Raum bringt. Die Geschwindigkeit, mit der das geschieht, ist woll] von sehr verschielenen Unständen abhängig, vor Allem von dem Grade der einwirkenden Helligkeit; eine Enle, die des Abends in mein Zimmer geflogen kam, zeigte nach 25 Minuten kein Angenleuchten mehr, wenigstens nicht in jenen 'Iheilen des Anges, die ich in dieser Zeit wiederholt mit dem Augenspiegel beleuchtet hatte. Das ist also ungefähr die Zeitdaner, in welcher der Zustand des Auges den Wechsel durchmacht. Langsamer gelıt die Unwandlung in entgegengesetztel Richtung vor sich. Nach meinen Erfahrungen braucht es immer mehr wie eine Stunde, bis das nicht lenchtende Ange wieder lenchtend geworden ist. Zweifellos hängt die Lebhaftigkeit dieser Vorgänge auch von dem Gesundheitszustand der Thiere ab. Matte, im Absterben begriffene Schmetterlinge verlieren die Fähigkeit, leuchtende Augen zu bekommen. Der Uebergang hingegen in Nichtlenchten scheint anch noch bei recht kranken Thieren verhälnissmässig gut abzulaufen: ich habe schon gesagt, dass ich wiederholt hei der Glucke (Lasio- 
campa quercifolia) folgenden Versuch gemacht habe. Dem dem Dunkeln entnommenen Thiere wird sagittal eine Kopfhälfte sammt dem Auge abgeschnitten und dann wird es in die Sonne gebracht. Das zurïckgebliebene Ange, zmüchst wunderschön lenchtend, war nach circa einer Viertelstunde vollkommen dimkel geworden.

Was das Hervorrufen des Leuchtens bei Tage anbelangt, so muss ich bemerken, dass man für sorgfältigen Abschhuss des Lichtes sorgen muss. Man täuscht sich eben leicht iiber den Grad der Dunkelheit in der Nacht, und eine kleine Spalte am Kä̈ig des Thieres reicht hin, das Ange am Uebertritt in die Dunkelstellung zn verhindern.

Die Art, wie das Augenlenchten erlischt, hat, wie gesagt, Külıne nach Beobachtungen an einem Todtenkopf vollkommen zutreffend beschrieben : die leuchtende Kreisscheibe wird kleiner und kleiner, blasst dabei etwas ab, zeigt anch Unregehmässigkeiten in der Helligkeitsvertheilung besonders am Rande, bis endlich nichts mehr von ihr zu sehen ist.

Dem ist noch hinzuzufügen, dass, wenigstens bei gewissen Schmetterlingen, die klein gewordene lenchtende Scheibe zunächst von einem schwarzen, weiter nach anssen von einem bräunlichen Hofe umgeben erscheint (es sind das die Phänomene der später zu besprechenden Psendopupille) und dass die grösseren Unregelmässigkeiten wohl von ungleicher Beleuchtung der verschiedenen Angenantheile herriihren.

Den physiologischen Vorgang, der dem Erlöschen des Augenleuchtens zu Grunde liegt, wird der Leser schon ans dem Nitgetheilten entuommen haben. Er besteht in den oben ausführlich besprochenen Pigmentverschiebungen in Folge der Lichteinwirkung. Bei den in Rede stehenden Nachtschmetterlingen kommt nur die photomechanische Wirkung des Irispigmentes in Betracht. Es ist klar, dass, wenn dasselbe in die Lichtstellung übergetreten ist, nicht nur das Netzhantbild um Vieles weniger hell, deshalb anch das aus dem Ange riickgestrahte Licht entsprechend vermindert sein muss, sondern dass anch die leuchtende Kreisscheibe mit zunehmender Tichtstelhung an Grösse bis zmm Verschwinden abnehmen muss. Denn (vgl. Holzschnitt 19, S. 64) so wenig wie Lichtstrahlen durch die von ab entfernteren Krystallkegel noch nach h, dem Bildpunkte, gelangen können, um sich an der Erzengung des Bildes zn betheiligen, wenn das Irispigment in Lichtstellung ist, ebensowenig können, von dem immer noch in $b$ liegenden Bildpunkte aus, Strahlen durch diese seitlichen Facettenglieder austreten. Sie werden rom mach hinten geschobenen Irispigmente aufgefangen. Rïckt das Pigment im ganzen Auge gleichmässig nach hinten, dann sind es die von " $b$ entferntesten Strahlen, welche znerst am Austritt gehindert werden: es verschwindet die periphere Zone der leuchtenden Scheibe znerst, und mit successiver Zumahme der Lichtstellung werden ebenso snccessive die $a b$ näher gelegenen Strahlen abgeblendet: die Scheibe geht ein, bis endlich nur wenige, vielleicht nur mehr eine Facette Licht nach anssen treten lïsst: das Lenchten ist verschwunden. 
Man ersieht hieraus, dass man sich jederzeit nit Hilfe des Augenspiegels von dem '/ustande des Irispigmentes am lobenden Thiere iiberzengen kann, ein Unstand, der mir bein studim der Pigmentverschiebungen sehr dienlich war.

Ich komme zur Besprechung eines weiteren Verhaltens, durch welches sich die leuchtende Psendopmpille von der lenchtenden Wirbelthierpupille unterscheidet. Es besteht darin, dass die Lichtwirkmng auf das Irispigment eine locale ist. Während sich also die Sängethierpupille bei Lichtwirkung im Ganzen contrahirt und dabei r'und bleibt, kann die lenchtende P'sendopupille verschiedene Gestalten ammehmen, indem auf einen Theil des Auges Licht eingewirkt hat, anf einen anderen keines oder doch weniger. Ich wage nicht zu behampten, dass die nicht beliehteten Theile des Anges vollkommen unberührt bleiben, doch sind, wemn sie überhaupt in Mitleidenschaft gezogen werden, die Wirkungen an ihnen mit den von mir benützten Hilfsmitteln nicht zu bemerken.

Man kann sich von dieser localen Lichtwirkung anf das Augenleuchten und somit auf das Irispigment leicht dadurch iiberzengen, dass man ein in der Dunkelheit gefangenes 'Thier von einer gewählten Richtung aus mit dem Augenspiegel untersucht. Wem dann die betreffende Angenstelle ihr Leuchten eingebiisst hat, so lenchten noch andere Stellen des Auges, die man nun, indem man das Thier dreht, der Beobachtung zugänglich macht.

Am schlagendsten habe ich mich von der localen Lichtwirknng durch folgenden Versuch äberzeugt. Ein grosser Windenschwärmer (Sphinx convolvuli) wurde an einem Abend, sährend seine Augen lenchteten, auf einer Korkplatte fast unbewegrich so bufestigt, dass eines seiner Angen in der oberen Gesichtsfeldhälfte die Lampe und von dieser belenchtetes weisses Papier sah, während die untere Hälfte des Anges einem möglichst dunkel gehaltenen Raume gegenüber stand. Die beiden Sehfeldhïlften stiessen in einer scharfen horizontalen Linie aneinander Nach circa 10 Minuten zeigte das Auge, mit dem Angenspiegel untersucht, in der obereu Hälfte kein Leuchten mehr, während die untere Hälfte noch schön lenchtete. Bei passender Stellung des Auges zum Beobachter konnte man die Grenze der beiden Hälften einstellen, und gewalnte nun einen correcten Hallomond mit scharfer horizontaler Grenze und nach unten gewendeter ('onrexität. Es entspricht dies also dem in der eben genannten Zeichnung (Fig. 19, S. 64) dargestellten Schema der Pigmentstellung; wo ams der unteren Hälfte des Auges noch Licht austreten kamn, während in der oberen Alles von dem nach hinten geschobenen Trispigment absorbirt wird. Diesen Tersuch habe ich zweimal mit demselben Erfolg ansgefülnt.

Auch labe ich iln in folgender Weise modificirt. Ich sorgte datiï: dass die ganze Umgebung der Lampe und das z'immer möglichst dunkel waren und das Thier, r'uhig gehalten, die Lampe immer mit derselben Facettengruppe sehen musste. 
Das Resultat war, dass, während das ganze Ange noch lenchtete, eine beschränkte Stelle dunkel geworden war. Untersuchte man, indem das Thier hin und her gewendet wurde, mit dem Angenspiegel, so gab diese photomechanisch modificirte Stelle zu eigenthïmlichen optischen Effecten Veranlassung, sobald man die leuchtende Pseudopupille in ihre Nähe schob.

Das Verschwinden des Leuchtens geht in der Regel mit einer recht nemnenswerthen Farbenveränderung einher. Während anfangs, wie so oft beschrieben wurde, die Pseudopupillen zwei glühenden Kohlen gleichen, geht die rothe Farbe allmällich in ein matteres Orange und einen weisslichen 'T'on ïber', um selbst bisweilen, d. lı nach meiner Erfahrung bei gewissen Species, in einem Grünlichweiss zu enden. Leider ist es mir nicht möglich, für diesen Farbenwechsel eine genügende Erklärung zu geben. Es läge freilich nahe, das ursprüngliche Roth dem in den Sehstäben enthaltenen Sehpurpur ähnlichem Farbstoffe zuzuschreiben und das Erblassen dann dem Ausbleichen des Farbstoffes in Folge der Lichtwirkung. Doch ist es mir, wenigstens bei Tagsclunetterlingen, wo ich alsbald eine analoge Erscheinung zu besprechen lraben werde, nicht gelungen, ein Ausbleichen des Farbstoffes anch im directen Sonnenlichte unter dem Mikroskope zn beobachten.

Was num die Taginsecten betrifft, so erstrecken sich meine Untersuchungen auch hier hauptsäichlich auf Schmetterlinge. Ich muss dem Späteren vorwegnehmen, dass viele 'Tagfalter eine sclon mit freiem Ange sichtbare dunkle Psendopupille zeigen, die von einer Gruppe Nebenpupillen umgeben ist. Alle diese erscheinen, mit cder olne Augenspiegel untersucht, als dnnkle Flecke. Es soll muten noch ansführlich von ilnen die Rede sein. Die Pseudopupille, die uns hier allein inter̀essirt, ist vou den Nebenpupillen gewöhnlich leicht durch ihre tiefere Schwärzung und ihre centrale Lage zu unterscheiden. Sie wandert mit der Drehung des Auges wie die leuchtende Pseudopupille der Nachtsclmetterlinge. Nimmt man nm z. B. unseren gemeinen Rübenweissling (Pieris rapae) in die Hand und untersucht sein Auge mit dem Augenspiegel, indem man als Lichtquelle die Sonne beun̈tzt, so sieht man im Centrum der Hauptpupille einen sehr hellen, roth glänzenden Fleck. Derselbe ist so klein, dass ihn nicht Jeder mit unbewaffnetem Auge erkennen wird - ich pflege den Augenspiegel mit einer Convexlinse von 2 bis 8 Zoll Brennweite zn armiren -, und anfangs bekommt man den Eindruck, als würde er nur zeitweilig aufblitzen, um alsbald wieder zu rerschwinden. Es rührt dies ron zwei Umständen her. Erstens sieht man den lenelitenden Punkt nur, wem das Licht recht genan ans der Richtung des beobachtenden Anges kommt. Der concave Augenspiegel entwirft einen Reflex, in welchem man die centrale Oeffnming als Lücke sieht. Man muss nun dieses Spiegelbild der Oeffnung, durch welche man durchblickt, hart neben die Pseudopmpille oder doch neben das Ange werfen, soll man den roth leuchtenden Punkt sehen. Bei Nachtschmetterlingen genügte es roll- 
kommen, wenn nu ïberhant rom spiegel reflectiotes lirht ins Ange drang. 'Zweitens verliert der lenchtende P'unkt seine rothe t'arbe schon nach einer oder doch sicher nach einigen secunden ler intensiven Belluchtung und wird weisslich und unscheinbar, so dass ar der Beobarlitung leichter entgeht. Die Schmetterlinge fflegen sich bei diescr Untersuchung nicht ruhig zu laalten, sie bedrolit sie an Leben (mir sind sie wiedteldolt todt in der Hand geblieben, ob in Folge von Hitze, lasse ich dahingestellt.), und deshalb machen sie mit dem Kopte mmonge Bewregungen. Sowie num die T'seudopupille in Folge dessen ihren Plat\% ändert, lenchtet anch wied(r. der helle Fleck in derselben in grellem Roth auf, um sofort wieder abznblassen und in Folge nenerlicler Kopfdrehungen an einer anderen stelle anfzutanchen. Dies sind die Ursachen der Unstetigkeit der Erscheinung am Tagsschmetterling. 1

Die Erklärung dieser Form des Angenlenchtens ergibt sich aus der Erklärung des Augenlenchtens der Nachtschmetterlinge sofort, wenn man die anatomischen Verlältnisse in Betracht zieht. In der 'That habe ich erst die Vermuthung gehabt, man müsse anch bei Taginsecten eine, wenn anch sehr kleine lenchtende Scheibe finden und, indem ich nach ihr suchte, fand ich das beschriebene Phänomen. Demu wenn anch ein Tapetum von der Art, wie wir es bei Nachtschmetterlingen liennen geelernt haben, hier nicht vorkommt, so wissen wir doch, dass ein solches zum Zustandekommen des Angenlenchtens nicht nothwendig ist, und betrachten wir das Auge z. B. des Ruibenweisshings auf dem Durchschnitt (Tiaf. IV, Fig. 34), so verhält es sich, was die Pigmentlagen betrifft, recht ähnlich dem Auge eines Nachtschmetterlings in Lichtstellung oder in anmähernder Lichtstellung. Letzteres leuchtet noch, und wem ersteres nicht meln lenchtend geînden wurde, so liegt das gewiss nur an ungenügenden Untersuchungsmitteln. Es war deshalb recht waluscheinlich, dass aluch Taginsecten mutatis mutandis Lenchten zeigen, und wirlich hat der helle Fleck in der Psendopupille des Rübenweisslings recht viel Aehnlichkeit mit dem letzten Reste des Lenchtens an Nachtschmetterlingen, bei denen man anch schon mu den lenchtenden, punktförmig gewordenen Kreis die dunkle Psendopupille sielıt. Dass die dioptrischen Terhältnisse im Ange der Tag- und Nachtschmetterlinge niclut dieselben sind, wie wir sahen, kommt hier nicht in Betracht, dem in jedem Falle müssen die Strahlen von einem Netzhantelement, das durch eindringendes Liclit leelenchtet wurde, wesentlich anf demselben Wege zuriicklichen, den sie anf dom Wege nach dem Netzhautelement zuriickgelegt hatten. Fs lïsst sich nun freilich in der genannten Fig. 34 nicht genaner angeben, wo Licht zurickgeworfen wird, ob elst an der Membrand fenestratal uder schon friilere etwa an den die Sehstäbe begleitenden 'Tracheen oder' noch spätc' oder'

${ }^{1}$ Ieh will nicht merwähnt lassen, dass nan hei jenen Insecten, die Nebenaugen besitzen, diese in der vorziiglichsten Weise lenehten sieht, wenn man mit dem Angenspiegel untersucht. 
aucl an allen drei Orten. Das aber ist sicher, dass wegen der bis unten reichenden Pigmenthüllen alle Strahlen absorbirt werden müssen, die auf ilırem Rückwege nicht in der Richtung nach den Spitzen der Krystallkegel verlanfen. Diese aber dringen dann nalıezu genan in der Axe des Facettengliedes in den dioptrischen Apparat ein und erleiden hier eine ganz analoge Brechung, wie die einfallenden Strahlen erlitten haben.

Stellen wì uns nämlich einen Querschnitt des Sehstabes als belenchtete und somit lenchtende Fläche vor, so wird von diesem ungefähr an der rorderen Corneafläche ein rerkelırtes Bildchen entworfen (sowie normalerweise ron einem kleinen äusseren Objecte an der Spitze des Krystallkegels ein verkehrtes Bild entworfen wird), dessen Lichtstrahlen aber wegen der Linsencylinderwirkung so wenig divergiren, dass sie in ihrer Verlängerung nur ein ganz kleines Stiickchen des Sehfeldes treffen. Haben wir ja geselıen, dass der dioptrische Apparat jedes Facettengliedes seinem Sehstab nur Licht aus einem sehr beschränkten Gebiete des Sehfeldes, dieses aber in verhältnissmässig grosser Intensität zuführt. Oder correcter ausgedrückt: nach den obigen Darlegungen ïber den Strahlenverlauf in den Tagangen gelangen in das Netzhautelement eines Facettengliedes nur Strahlen, welche von einem engbegrenzten Antheile des Sehfeldes ausgingen, diese aber in relativ grosser Intensität. Der Querschnitt des vordersten 'Theiles eines Netzhautelementes enthält also Punkte, welche entsprechenden Punkten jenes Stückes des Sehfeldes conjugirt sind. Alle Strahlen, welche diesen Querschnitt passiren, mïssen also auch an die zugehörigen Punkte des Sehfeldes gelangen. Nun mïssen aber alle zuriickkehrenden Lichtstrahlen, soferne sie überluant das Auge verlassen, jenen Querschnitt des Netzhautelementes durchsetzen.

Was wir mit dem Angenspiegel beobachten, ist also eine volle Be stätigung der im dioptrischen Theile dargelegten Verhältnisse. Es beweist, dass ans jedem Facettenglied nur in einer sehr bestimmt eingehaltenen Richtung Licht zuriickstrahlt, dieses aber auffallend intensir ist; demnach müssen wesentlich dieseluen Verhältnisse auch fü̈ das eindringende Licht obwalten. Beobachtet man im dunkeln Zimmer nnter Benïtzung einer Kerzenflamme zur Belenchtung, so gewahrt man, dass der leuchtende Punkt im Imneren der schwarzen Pseudopupille kleine Verschiebungen erleidet, wenn man den Spiegel ein wenig dreht. Der Sinn dieser Verschiebungen entspricht der jeweiligen Richtung des einfallenden Lichtes, indem \%. B. bei Verschiebung des Spiegelbildes der Kerze nach rechts eine Facettengruppe ius Leuchten geräth, die anch (spurweise) weiter nach rechts liegt.

So gibt die Kleinheit des leuchtenden Fleckes in der Psendopupille einen Massstab für die Schärfe des Netzhautbildes ab, ja man kann den Lichtpunkt bei Beleuchtung geradezu als das von Aussen gesehene Netzhautbildchen der Sonne auffassen. Sielıt man doch auch mit Hilfe des Augenspiegels ein Netzhautbild in menschlichen Ange. 
Das Verblassen des Augenlenchtens bei 'L'agschnetterlingen bin ich, wie schon erwähnt, nicht zu erklären in Stande, da ich ein Schwinden des rothen Farbstoffes in den Sehstäben nicht beobachten konnte. Ich zerzupfte das Auge eines Ruibenweisslings mo sah unter dem Mikroskope die rothen fadenartigen Gebilde der Sehstäbe. Dann brachte ich das gaine Mikroskop sammt dem Präparate in die Somne, wo letzteres nahezn im Brennmulte des beleuchtenden IJohlspiegels lag. 'Trotzdem war auch nach einer Viertelstunde keine Aenderung in der Intensität der Farbe zu erkennell.

Nachdem ich nun das Augenlenchten der Insecten im Grossen und Ganzen besprochen habe, will ich gewisse Einzelnheiten, sowie meine Erfahrungen an verschiedenen 'Thieren mitheilen.

Zunächst, dass ich nicht unterlassen habe, mich divon zu iiberzeugen, dass das Angenlenchten eine rein dioptrische Erscheinnng ist, wie beim Wirbelthiere und dass keine Lichtproduction im Ange stattfindet. Schon aus dem beschriebenen Verhalten des Anges ist mit Sicherheit zu entnelımen, dass nicht etwa leuchtende Körper wie im Lenchtorgan von Lampyris vorhanden sind, aber an etwas anderes konnte gedacht werden. Es könnten Stoffe im Augenhintergrunde sein, welche nachlenchten, d. l. wemn auch nur kurze Zeit nach der Belichtung selbst Licht produciren. Thun dies ja selbst die fluorescirenden Stoffe, und sind solche im menschlichen Auge nachgewiesen.

Ich construirte mir einen Apparat (nach Art des Phosphoroskopes von Becquerel), der mit Hilfe eines rotirenden Zahnrades gestattete, das Auge eines Nachtschmetterlings in Dunkelstellung zu beleuchten, wälırend es für den Beobachter verdeckt war und gleich nach Abblendung der Beleuchtung sichtbar werden zu lassen. Durch rasches Rotiren kounte sich dies oftmals in der Secunde wiederholen, so dass ein Nachleuchten, selbst wenn es ron sehr kurzer Dauer wäre, hätte bemerkt werden müssen.

Der Taubenschwanz (Makroglossa), als ein bei Somnenschein fliegender Nachtschmetterling, hat, wie wir sahen, Augen, die sich sowoll von jenen der Tagschmetterlinge wie der Nachtschmetterlinge im feineren Bane unterscheiden. (Vgl. Taf. II, Fig. 17 und Taf. TI, Fig. 63.) Anch sein Augenleuchten ist eigenthümlich. Nit dem Augenspiegel betrachtet, zeigt sich ein auffallend grosser, schün griün glänzender Fleck im Inneren der Pseudopupille. Ich salı dieses wiederholt, und zwar am Tage, bei diffusem oder directem Sonnenlicht.

Auch der Bärenspinner (Enprepria) ist ein am Tage sich herumtreibender Abendfalter. Er zeigte mir aber ein Lenchten, das dem der Tagschmetterlinge entsprach, also nur einen ganz kleinen hellen Fleck.

Sehr gut eignete sich zum Studium des Augenlenchtens bei Nachtschmetterlingen auch das rothe Ordensband (Catocala nupta). dessen Augen gross genug sind, um das Lenchten an einem Theile zmm Schwinden zu 
hringen (durch Lampenbeleuchtung in circa einer Viertelstunde), während es noch an anderen weiter besteht. Ich brachte ein solches Thier am Tage, wemn seine Augen gleichmässig dunkel erschienen, il einen lichtverschlossenen Raum und nalım es nach zwei Stunden heraus. Die Augen zeigten das schünste Leuchten.

Was die 'Iagschmetterlinge betrifft, so glanbte ich anfangs nur bei jenen Species eine lenchtende Psendopupille zu finden, die keine schwarzen Augen haben. Denn der nächste Verwandte des oben behandelten Riibenweisslings, der schwarze Angen hat (ich kamn nicht sicher sagen, ob es Pieris crataegi oder brassicae war), zeigte nir trotz mancher Bemïhungen kein Leuchten. Ebenso viele andere schwarzäugige Insecten, insbesondere Käfer. Doch fand ich später bei dem eben genannten Bärensuinner trotz seiner schwarzen Augen ein Leuchten wie bei Tagschmetterlingrn, und habe seitdem an mehreren schwarzäugigen echten Tagschnetterlingen die Erscheinung beobachtet. So z. B. beim WViesenbläuling (Lycaena).

In meinen Notizen finde ich, dass ich die typische Form der leuchtenden Psendopupille bei folgenden Tagschmetterlingen geselen und angemerkt habe: bei Tanessa urticae, C-album und cardui, dem Bärenspinner (Enprepia): Lycaena corydon, Coenonymplia Pamplilus, Argynnis Latonia, Polias, Coleas Hyale, Polyomatus phlaeas, dem Rübenweissling (Pieris lapae) und einer Hipparchia (Medea?), welche alle einen rothen Augenreflex zeigen, während mir Pararge megarea, Melanargia galathea, sowie Epinephele grïnes Augenlenchten zeigten; rom 'T'aubenschwanz habe ich dasselbe schon angeführt, und ganz ähnlich diesem verhält sich Hesperia coma. Plusia gama zeigt bei 'l'ag'e in Inuelen der schwarzen Hauptpupille nu' einen helleren Fleck, der erst am Abend in die lenchtende Psendopupille ïbergeht. Es liegt der Gedanke nahe, dass diese griine Farbe des reflectirten Lichtes der Ausdruck längeren Aufenthaltes im Sonnenschein ist, doch liegen die Dinge nicht so einfach, dass sie ohne genauere Untersuchung bentheilt werden können.

Ich habe natiorlich anch andere Insecten anf die Anwesenheit der leuchtenden Psendopupille untel'sucht, und, wie zu erwarten war, gefunden, dass sic eine in der Insectenwelt recht verbreitete Erscheinung ist. Nur bei Käfern kounte ich sie niemals sehen. Auch wemn ich z. B. Hydrophilus piceus im Dunkeln gehalten Iatte, in welchen Falle das Irispigment ja eine Stellung einnimnt, welche der bei Nachtschmetterlingen durchans ähnlich ist, konnte ich ein Leuchten nicht sehen. Als Trsache hiefür kann das massige und dichte Retinapigment der Kïfer angesehen werden, ob das aber die alleinige Ursache ist, muss ich dahingestellt lassen.

Schön sieht man das Algenlenchten, und zwar nach den 'Typus der 'Tagschmetterlinge in den muteren Hälften der Tibullenaugen. Ich labe es bei verschiedenen Arten gesehen, hebe hier aber Libellula rulgata (Diplex) 
als bestimmt besonders hervor. Anch bei unseren grossen griinen Henschrecken (Locusta riridissima oder caudata), die eine sehr kleine dunkle Pseudopupille haben, kann man, unter gewissen gleich zu besprechenden Bedingungen, noch im Inneren derselben das hellglänzende Pünktchen erkennen.

In anderer Art zeigt sich das Augenlenchten bei Untersuchung mit dem Augenspiegel und directem Somnenlicht an allen jenen Insecten, deren Augen arm an schwarzem Pigment sind. Eine Stubenfliege z. B. zeigt einen ziemlich grossen roth glänzenden, aber nicht scharf begrenzten Fleck, in dessen Mitte eine viel hellere Stelle besonders auflenchtet. Ebenso verhält sich im Allgemeinen das Auge der iibrigen Dipteren. Bei manchen ist der centrale hellste Fleck, den ich als das Analogon der lenchtenden Psendopupille betrachten muss, besonder's schön ausgebildet, z. B. bei Eristalis. Sehr schön zeigt sich bei dieser Untersuchungsart wieder die Differenz der beiden Augenhälften der Libellen, indem auch hier del obere Augenautheil das Verhalten des Fliegenauges, der untere der des Auges der Tagschmetterhinge zeigt. Nan denke sich in Fig. 67 (Taf. VII) den grossen schwarzen Fleck, abgesehen von einem schmalen Randstreifen, voll lenchtend, und in Fig. 66 die mittlere schwarze Hauptpupille mit einem leuchtenden Fleck versehen, so lıat man einen Begriff von den beiden Formen des Augenleuchtens.

Man kam aber mit Hilfe des Augenspiegels am Libellenange noch eine andere physiologisch bedeutsame Beobachtung machen. Dreht man das Thier, indem man die untere Augenhälfte beobachtet, und achtet auf die Geschwindigkeit, mit welcher die leuchtende Pseudopupille wandert, und macht dam dasselbe mit der oberen Augenhälfte, so wird man nicht im Zweifel darïber sein, dass im letateren Falle die Bewegung eine weit raschere ist. Erimnern wir uns daran, dass die Lichterscheinung in gewissem Simne als das von aussen sichtbare Netzhautbild betrachtet werden kann, so ersieht man, dass ein Object ron gewisser Winkelgeschwindigkeit im oberen Theile des Sehfeldes ein Netzhantbild entwirft, das sich schneller iiber die Netzhant bewegt, als wenn dasselbe Object sich im unteren Theile des Selıfeldes bewegen würde. Oben habe ich auf Terhältnisse hingewiesen, die dafür sprechen, es sei der obere Theil des Libellenauges wesentlich zum Sehen ron Bewegungen bestimmt, der untere zur Erkenmung ron Formen. Das geschilderte Verhalten am Augenspiegel dient als kräftige Stiitze hiefür.

Die Verwaschenheit und Grüsse des Netzhantreflexes bei allen nach dem Typus des Fliegenanges gebanten Insectenaugen erklärt sich von selbst, wenu man die Lichtzerstreung auf der Netzhaut wegen des mangelnden schwarzen Pigmentes in Betracht zielit. Tch habe oben ron der Diffusion des Lichtes an der Netzhant als Ursache der grossen leuchtenden Pseudopupille ron Nachitschmetterlingen gesprochen. Am Fliegenauge muss diese Diffusion eine viel stïrkere sein, und da auch das typische schwarze 
Irispigment mangelt, so wird der helle Kreis auch keine so scharfen Ränder haben. Immerhin aber ist zn elwarten, dass das eigentliche Netzhautbild als Centrum des verwaschenen Fleckes sich mit besonderer Intensität abhebt, wie wir das thatsächlich selen.

\section{Die gegenseitige Lage des Corneareflexes und der Psendo- IIlille.}

Wie gesagt, sieht man das Lenchten der Psendopupille bei sehr vielen Insecten, aber nicht bei allen. Eine vermuthete Ursache fïr den Wegfall der Erscheinung labe ich schon erwähnt, es ist die Kleinheit und Lichtschwäche derselben. Bei anderen Thieren aber diurfte noch eine andere Ursache im Spiele sein, deren Besprechung einiger physikalischer Erlïuterungen bedarf und auch fïr das Folgende noch von Bedeutung ist. Ich will die Sache hier also besonders behandeln.

Ich habe gezeigt, dass und warum die leuchtende Pseudopupille im Grunde jener Facettenglieder gesehen wird, deren Axen in ihrer Verlängerung genau oder näherungsweise das Auge des Beobachters treffen. Sie erscheint also (in der Regel) an jener Stelle des Insectenanges, an welcher die Gesichtslinie des Beobachter's die Insectencornea senkrecht schneidet. Nun bildet aber die Cornea selbst eine mehr oder weniger kugelfürmige Wölbung, die als Convexspiegel wirken kann. Sie entwirft also wie die Cornea des Menschen ein Spiegelbild ron jeder Lichtquelle. Die Lage dieses Spiegelbildes der Somne bei Untersuchung mit dem Augenspiegel muss nun aber wieder durch die Richtung gegeben sein, in welcher die Gesichtslinie des Beobachters die Hornhautoberfiäche des Insectenanges senkrecht trifft, denn der Werth des Augenspiegels beruht ja eben darauf, dass die Lichtquelle mit dem beobachtenden Auge von den beobachteten Auge aus in derselben Richtung liegt.

Man sollte also zunächst glamben, dass die Psendopupille ïberhaupt nicht Gegenstand der Beobachtung sein kömne, da sie von dem starken Corneareflex zugedeckt werden miisse. Und in der 'That glaube ich, dass dies die Ursache ist, aus welcher bei vielen 'Thieren eine leuchtende Psendopupille nicht gesehen werden kann.

Es frägt sich nun, wieso sieht man sie bei anderen Thieren? Aus zweierlei Ursachen. Erstens, weil viele Insecten gar keinen Corneareflex in Form eines Bildchens haben. Es sind das alle jene, deren rordere Corneafläche nicht eine gekriimmte Fläche darstellt (wie z. B. bei den im Wasser lebenden Käfern und Krebsen in Taf. II, Fig. 16 und Taf. V, Fig. 45 bis 56), sondern in Facetten zerfällt, deren jede eine kleine, nach vorne convexe Fläche bildet (z. B. bei den Schmetterlingen, 'Taf. IV, Fig. 28 bis 36). Eine solche Cornea entwinft kein einheitliches Spiegelbild der Lichtquelle, sondern jede Facette wirkt als selbstständiger Convexspiegel: die mikroskopisch kleinen Spiegelbilder dieser aber bilden in ilıer Gesammtheit 
nur einen Schimmer iiber das Ange, der die Wahmehnung der lenchtenden Pseudopupille nicht stört. Werden die Krïmmungshalbmesser der einzelnen Facetten aber recht gross, d. h. nähert sich die Gestalt der Fläche einer einfach gekrïmmten, so entsteht doch ein Corneareflex, cihnlich dem an einer glatten Hornhautflïche, nur weniger scharf (z. B. bei Libellen, Taf. VI, Fig. 58). Man kann also in dieser Weise schon mit freiem Aúge bestimmen, welcher Art die vordere Hornhautfläche eines 'Thieres ist.

Zweitens aber sieht man oft die leuchtende Pseudopupille trotz starken Corneareflex aus folgender Ursache.

Oben (S. 24) wurde gelegentlich der Dioptrik des Limulusauges auseinandergesetzt, dass, wenn die anatomische Axe des Kegels die Corneaoberfläche nicht senkrecht schneidet, der Kegel also geneigt auf der Cornea aufsitzt, an der Kegelspitze Strahlen zur Vereinigung gelangen, die nicht von jenem Antheile des Sehfeldes stammen, der durch eine auf die Cornea errichteten Senkrechten getroffen wird, sondern von einem Sehfeldantheil, der mit diesem einen recht bedentenden Winkel einschliessen kann (vgl. Holzschnitt Fig. 9, S. 25). Wir erkannten in dieser Einrichtung ein Mittel, das Sehfeld des Thieres bedentend zu vergrössern, ohne der Cornea eine gefährlich starke Wülbung zu geben Dieses Nittel ist in der 'Thierwelt viel verbreiteter, als man nach der groben mikroskopischen Untersuchung erwarten könnte, wie die feinere Untersuchung der leuch. tenden oder nicht leuchtenden Psendopupille mit Hilfe des Augenspiegels beweist. Da gewahrt man nämlich als eine ganz gewöhnliche Erscheinung die örtliche Verschiebung des Corneareflexes gegen die Psendopupille, erkennt auch wieder, wie uns das die anatomische Untersuchung von Limulus und ron einigen anderen Thieren erwarten liess, dass diese Verschiebung an den Rändern des Anges ihr Maximum erreicht. Bei gewissen grossen Libellen and Heuschrecken z. B. wäre es wegen des Zusammenfallens von Pseudopupille und Corneareflex nicht möglich, erstere zu sehen, wenn nicht eine gegenseitige Verschiebnng der beiden Phänomene einträte, sobald man die Beobachtung vom Centrum des Auges gegen den Rand hin fortsetzt. Hier fallen die beiden Lichterscheinungen rïumlich gan\% auseinander, indem der Corneareflex peripherer liegt als die Psendopupille, ja ersterer schon am Rande des Auges verschwunden sein kann, während man die letztere noch iibersieht.

Die Erklärung hiervon ist nach dem gemachten Hinweis kaum mehr nöthig. Man brancht sich nur wieder zu erimnern, dass der IVeg der Strahlen in einem dioptrischen Systeme, wenn er gegeben ist fïr die eine Richtung des fortschreitenden Lichtes, auch für die entgegengesetzte Richtung zutrifft. In Holzschuitt Fig. 9, S. 25, wird also der Strahl, der von dem beleuchteten Punkte $a^{\prime}$ ausgeht, den Weg $a^{\prime}$ oc zurücklegen, da ein von $c$ nach o verlaufender Strahl, wie wir sahen, den Weg co $a^{\prime}$ gegangen war. Ist also die Netzhant bei $a^{\prime}$ durch den Augenspiegel erleuchtet, so wird die lenchtende Pseudopupille in der Richtung co zu 
sehen sein; der Corneareflex aber wird bei $x$ oder einem Punkte, der von o noch weiter als $x$ gegen die Peripherie des Auges gelegen ist, sichtbar sein, nämlich an jener Stelle der Corneaboberfläche, an der diese von der Gesichtslinie des untersuchenden Auges senkrecht getroffen wird.

Im Centrum des Auges, dem der Kegel A der Figur entspricht, fallen Psendopupille und Corneareflex zusammen, da der Weg des nach a gelangenden Strahles senkrecht auf der Hornhautoberfläche steht.

Dieses örtliche Auseinanderfallen von Pseudopupille und Corneareflex gibt also in theoretischer Beziehung eine schöne Bestätigung der auf anderem Wege gefundenen Art der dioptrischen Erweiterung des Sehfeldes; in praktischer Beziehung ist sie von Wichtigkeit, weil sie ermöglicht, die Psendopupille noch bei Thieren zn sehen, wo ein starker Corneareflex dies sonst ummöglich machen wïrde. Es gilt dies nicht nur für die leuchtende Pseudopupille, sondern in noch höherem Grade für die schwarze, die nnser Interesse später noch in Anspruch nehmen wird.

B. Krebse. Es war zu erwarten, dass bei der Aehnlichkeit im Bane der Angen von Insecten und Krebsen auch bei diesen letzteren Erscheinungen, welche dem Augenleucliten entsprechen, vorhanden sein werden. Ich kannte dieselben schon, ehe ich wusste, dass die Aehnlichkeit sich bis anf die Verschiebung des Irispigmentes und die Anwesenheit eines Tapetums erstreckt. So viel mir bekannt, ist das Leuchten del' Krebsaugen bisher nicht beschrieben worden. Es hängt das wohl mit der grösseren Unzugänglichkeit des lebenden Materiales zusammen.

Zuerst salı ich an einem der kleinen, in unseren Seen und Bächen vorkommenden gemeinen Krrebse (Astacus) mit Hilfe des Augenspiegels und bei Sonnenbeleuchtung eine roth lenchtende Pseudopupille. Das Thier war vorher im Dnnkeln gewesen. Indem das Lenchten verschwindet, bleibt eine schwarze Psendopupille zurïck. Ich habe den Versuch bei Sonnenbelenchtung, sowie bei künstlicher Beleuchtung am Abend oder des Morgens ausgefïhnt, im Allgemeinen mit demselben Erfolg. Freilich fand ich bisweilen die Angen nicht leuchtend, wemn ich sie lenchtend erwartet hatte (nie umgekehrt), was, wie ich jetzt weiss, mit dem Gesundheitszustande des Thieres zusammenhing. Das Auftreten des Zustandes, in welchem die Augen leuchten, ist bei Krebsen viel mehr vom Wohlbefinden des 'Thieres abhängig als bei Insecten - so weit man dieses Wohlbefinden beurtheilen kamn. Ich habe schon auf dieselbe T'hatsache betreffs der Verschiebung des Irispigmentes, das ja mit dem Augenleuchten in ursächlichem Zusammenhang steht, lingewiesen.

Obwohl die mikroskopische Untersuchung des Flusskrebses (Astacus fluviatilis) ein Tapetum an der Netzhaut erwies, so steht sein Leuchten doch weit hinter den mancher Neerkrebse zurück. Taf. VII, Fig. 71 und 72, zeigt die Angen eines Einsiedlerkrebses (Pagurus); Fig. 69 und 70 das Auge einer Species von Palaemon, dessen Leuchten dem von Nachtschmetterlingen nicht nachsteht, und Fig. 73, 74 die Augen von Sicyonia sculpta. 
In jedem Paare dieser Abhildungen ist Licht- nnd Dnnkelauge desselben Thieres nebeneinander gestellt und bei Lmenvergoüsserung abgebildet, sämmtlich so wie man sie bei Beleuchtung mit dem Angenspiegel sieht. Das Lenchten der'Dunkelthiere verging im Lanfe von Minnten, wenn sie ans Licht gebracht wurden, so dass das in Fig. 70 dargestellte Auge in das der Fig. 69, Fig. 72 in 71, Fig. 74 in 73 iiberging.

Ein ähnlich intensives Augenlenchten sah ich nach Einwirkung der Dunkelheit bei Dromia rulgaris - ich verweise anf die ausgesprochene Dunkelstellung, welche Iris- und Retinapigment bei diesem 'Thiere eingelit, wie Taf. V, Fig. 55 und 56, zeigt; ferner bei Nica edulis, Sicyonia sculpta und Anderen. Während bei diesen Thieren das Ange eine grosse lenchtende Scheibe zeigt, wie bei den Nachtschmetterlingen, nähert sich das Pild bei anderen Krebsen insoferne dem der 'Tagschmetterlinge, als die leuchtende Pupille kleiner ist und im Inneren einer schwarzen Psendopnpille sichtbar wird, oder es ist die lenchtende Fläche nicht so scharf begrenzt und nicht so intensiv wie bei den erstgenannten Thieren. Immer aber ist es ein unzweifelhaftes Leuchten, das im hellen Ramme rasch rergeht. Olme anf das Verhalten der einzehnen Thiere näher einzngehen, führe ich an, dass ich derartiges Angenlenchten bei Careinns maenas gesehen und Taf. VIT, Fig. 68, abgebildet habe; ferner bei Innachus, Scyllarms arctus, Pisa, Galathea strigosa, Herbstia und Maja verrucosa. Waren die Thiere am Lichte, so verschwand das Lenchten vollkommen bei Innachus, Galathea, Pagurus, den verschiedenen Species yon Palaemon, Sicyonia sculpta, während ein sehr kleiner Rest einer lenchtenden Pupille, wie bei 'Tagschmetterlingen, bei Carcinus maenas zurïckblieb. Wir wissen, dass diese Krabbe sich wirklich wie ein Tagthier benimmt nud anch im Sonnenschein ihr Wesen treibt.

Eine eigenthïmliche Stellung nehmen Palinurus (die Langusta), Homarus (der Hummer) und Scyllarıs arctus (der Bärenkrebs) ein, indem ihre Angen, wenn sie im Dunkeln waren, ein muweifelhaft rothes, ansgedehntes, aber nicht scharf begrenztes Imenchten zeigen, das am Lichte schwächer wird, anch die Farbe ändert, aber doch als ein ansgebreiteter weisslicher Schimmer bestehen bleibt. Von einer Psendopmpille kann mau wegen der schlechten Begrenzung nicht sprechen.

An Portunus kounte ich bei Uutersuchung mit dem Angenspiegel iiberhaupt kein Augenlenchten und keine Verändermng in Folge von Lichteinwirkung beobachten. Wie die spätere mikroskopische Untersuchnng lehrte, hat diese Krabbe wirklich kein Tapetum, wohl aber eine Lichtverschiebung von Tris- und Retinapigment. (Siehe Taf. IV, Fig. 37 und 38.) Es liegt wohl an dem Mangel reflectirten Lichtes, dass mir der optische Effect dieser Verschiebungen entgangen ist.

Ebenso hatten die Augen der frisch aus dem Dunkelkasten entnommenen Exemplare dasselbe Aussehen, wie der in der Sonne gehaltenen, bei Penens membranacens nnd Squilla mantis. Bei diesen stimmte die 
mikroskopische Untersuchung vollkommen mit dem Augenspiegelbefund, denn keiner dieser Krebse zeigte an den Schnitten Verschiedenheiten bei Licht- und Dunkelauge. Der erstere hat, wie wir sahen, überhaupt kein oder fast kein Pigment. Fast bei allen von mir mutersuchtẻn Crustaceen habe ich wieder das oben bei den Insecten besprochene Phänomen beobachtet, dass gewölnnlich am Rande des Anges der Corneareflex von der leuchtenden Pseudopupille örtlich abweicht, und zwar natürlich wieder in dem Sinne, dass der Corneareflex peripherer liegt als die Pseudopupille. Ja man kann hier die Pseudopupille in der Regel nur dann gut sehen, wenn man solche Stellen des Auges aufsucht, wenigstens wenn sie klein ist. Es weicht also anch hier die optische Axe des Facettengliedes von der auf der Corneaberfläche desselben errichteten Senkrechten nennenswerth ab, und wird auch bei diesen Krebsen so wie es bei Limulus und manchen Insecten besprochen wurde, das Selıfeld durch diese Eimrichtung weiter gemacht, als es der Colneawölbung entsprechen würde.

Finige weitere Beobachtungen über die Physiologie der Pigmentverschiebungen will ich hier noch anfiihren, mehr um dadurch zu eingehenderen Versuchen anzuregen, als um Fertiges mitzutheilen.

Der Uebergang von der Dunkelstellung zur Lichtstellung geschieht viel rascher, als der Uebergang von der Licht- zur Dunkelstellung. Ich latte anfangs geglaubt, dass die Krebsaugen ïberhaupt nur des Nachts leuchten, weil ich sie gewöhnlich nur des Norgens, indem ich sie aus dem Dunkelkasten nahm, leuchtend fand. Später iiberzengte ich mich, dass das Leuchten doch auch bei Tage eintrit, wenn man die Thiere nur lange genug im Dunkeln hält. Das Leuchten verschwindet an der Somne im Laufe von Minuten und tritt im Dunkelkasten wieder auf im Laufe von Stunden. Auch überzeugte ich mich z. P. an verschiedenen Species vou Palämon, dass die Oeffnung des Dunkelkastens, die so kurz dauert, dass das Augenlenchten beim Schliessen noch nicht verschwunden ist, doch bewirkt, dass noch nach einer Stunde kein Auge leuchtet. Erst nach drei Stunden fand ich wieder schönes Augenleuchten.

Es ist eine naheliegende Frage, ob die Pigmentverschiebungen im Krebsauge directe Lichtwirkungen oder ob sie reflectorisch ausgelöste Bewegungen sind. Ich habe auf verschiedenen Wegen versucht, diese Frage zu beantworten, bin aber zu keinem mich befriedigenden Resultate gekommen. Bei einer Reihe von Thieren (ein grosser Palinurus, zwei Scyllarus, drei Maja, ein Pagurus) bohrte ich auf einer Seite den Augenstiel an und entfernte aus dem centralen Canal alle VVeichtheile, also auch den Sehnerv. Es zeigten sich dann wohl Unterschiede der beiden Augen, wenn man mit dem Augenspiegel prüfte und die 'Thiere vorher in der Sonne oder im Dunkeln gehalten hatte, nur waren dieselben nicht eindentig genug. Nur das ging aus den Versuchen hervor, dass das operirte 
Ange gar nicht, oder doeh weit geringer ant Hell und Dunkel reagirte als das nolmale. Wie leicht einzusehen, könnte das ganz wohl von der gestörten Ernährung herrïhren.

Ferner, habe ich eine ganze Reihe ron Versmehen gemacht (Paliunon eignet sich dazu am besten), in denen ich dem im Dumkeln gehaltenen 'Thiere ein Auge, natürlich sammt dem Angenstiel, abschnitt, 'l'hier und Auge dann an die Somne brachte, oder momgekehrt. Es zeigte sich, dass in ersteren Falle das dem 'Thiere gelassene Auge natürlich zu leuchten anthörte, während das abgeschnittene fortlenchtete. In einem Falle fand ich die Argen (ich machte den Versuch immer zugleich an mehreren 'l'hier'un) nicht nu' nach einer Stunde, sondern noch am nächsten Morgen. nach 17 Stunden leuchtend, obzwar ich sie anch da wieder in der Sonne liegrend antraf. Andererseits hatte ich bei mehreren Palaemonen, die in der Abendsonne gehalten waren, je ein Alge abgeschnitten, diese wie die 'Thiere dann in den Dunkelraum gebracht; am nächsten Morgen fand ich die am Thiere gelassenen Angen natürlich leuchtend, während die abgetrennten Augen in voller Lichtstellung verblieben waren. Es ist selbstverständlich, dass die abgetrennten Augen vor Vertrocknen geschützt sein müssen.

Diese Versuche sprechen wohl dafür, dass man es hier mit reflectorisch ausgelösten Pigmentbewegungen zu thum hat. Sie sind aber durchaus nicht einwurfsfrei, hätten auch nur zur vorläufigen Orientirung über die Müglichkeit der experimentellen Prüfung dienen sollen. Leider war mir nicht genügend Zeit in Neapel gegönnt, die Frage definitiv zu beantworten. Es liegt nämlich auf der Hand, dass eine hinlänglich rasche Abnahme der Erregbarkeit mach Abtrenmung des Auges auch die Ursache für das Tel' bleiben des Auges in dem Zustand sein kann, in welchem es sich im Nomente der Exstirpation befindet.

Auf die Nothwendigkeit, dass die Thiere in gesundem Zustande sein müssen, sollen sich die Pigmentverschiebungen correct vollziehen, habe ich schon wiederholt hingewiesen. Es ist mir z. B. vorgekommen, dass aus einer ganzen Reihe von im Dunkelkasten gehaltenen Krebsen einer aus dem Aquarium herausgesprungen war. Er war nicht ins 'Troekene gerathen, sonder'n sass in einer 'Tasse, die einige Centimeter hoch Wasser' enthielt. Trotzdem war er der einzige von allen Krebsen, der keine leuchtenden Augen zeigte, obwohl man ihm im Uebrigen ein Unbehagen nicht ansehen konnte.

Endlich habe ich mich bemüht, zu ermitteln, ob die Pigmentverschiebungen durch elektrische Reizung erzielt werden köunen. Auf diese Weise müsste man erfahren, welcher der Ruhezustand der Pigmentlagen ist. Leider haben mir auch diese Versuche keine befriedigenden Resultate ergeben. Aeussere Verhältnisse zwangen mich, die meisten an Hydrophilus anzustellen, bei welchem Thiere erst durch die mikroskopische Untersuchung ein Urtheil ïber die Pigmentstellung zu gewimnen ist. Am meisten wäre zu erwarten von Reizung des leuchtenden und des nicht leuchtenden 
Auges eines grossen Nachtschmetterlings. Solche bekam ich aber nur während meines Landaufenthaltes, wo mir die elektrischen Reizmittel nicht zur Verfügung standen.

\section{D)as Phänomender Pseudopupillen.}

Ich komme zur Besprechung eines merkwürdigen optischen Phänomens, dessen Enträthselung mir manches Kopfzerbrechen gekostet hat. Anch hier war, meines Wissens, wieder Leydig' ${ }^{\prime}$ der Erste, der eine Beschreibung und zutreffende Beobachtung brachte, sonst ist kaum von dem Gegenstande die Rede gewesen, abgesehen von einer Bemerkung Thompson-Lowne's, auf die ich alsbald zurückkomme. Die allgemeine Verbreitung der Erscheinung - sie wird an den meisten Facettenangen beobachtet - die Einheit in der Mannigfaltigkeit ihrer zahlreichen Formen, wurde bisher freilich nicht hervorgehoben, und eine Erklärung kaum angestrebt.

Leydig sagt richtig, dass man bei Lmmulus einen dunklen, einer Pupille ähnlichen Fleck im Auge sieht, der sich aber von einer Wirbelthierpupille dadurch wesentlich unterscheidet, dass er mit dem Beschaner die Lage im Ange ändert. Er nennt ihn schon eine Pseudopupille. Auch hebt er hervor, dass man bei Schmetterlingen gelegentlich mehrere solche schwarze Flecken im Auge bemerken kann. Thompson Lowne ${ }^{2}$ bemerkte bei einem Schmetterlinge (Cabbage Butterfly) sechs schwarze Flecken um einen siebenten centralen angeordnet, welche mit dem Beschaner den ort inder'n, und die, wenn el sie mit einem ophthalmoskopisch armirten Mikroskope betrachtete, hell erschienen. (Ich zweifle nicht, dass hier ein Irrthum vorliegt und nicht alle sieben, sondern nur der centrale Fleck hell erschienen war, d. h. dass das im vorstehenden Abschnitte behandelte Phänomen vorlag.) Als Erklärung denkt er an ein Diffractionsbild.

Ich habe im Vorstehenden schon wiederholt von der Pseudopupille zи surechen gehabt, aber hamptsächlich insoferne sie oder ein centraler Kern in ihr lenchtete. Im Folgenden bitte ich den Leser, von dieser Frscheinungsweise der Pseudopupille, dem das Lenchten des Wirbelthierauges entspricht, abzusehen und sich viehmehr einen pupillenähnlichen schwarzen Fleck als solche vorzustellen.

Man kann als Regel anfstellen, dass jene zusammengesetzten Augen, die zwischen den vorderen Antheilen der Krystallkegel eine Licht reflectirende Substanz (Iristapetum) haben, Pseudopupillen zeigen. Als solche Substanz fungirt in der Regel ein gleich hinter der Cornea gelegenes Pigment, das die verschiedensten Farben und Helligkeiten besitzen kann. Te dentlicher eine Farbe vom Schwarz absticht, desto deutlicher ist auch die Psendopupille; so sieht man sie auf rothem (Taf. VI, Fig. 65), blanem (Taf. VII, Fig. 71 und 76), gelbem (Taf. VI, Fig. 61), blangrünem (Taf. VII

1 Müller's Areh. f. Phys. 1855, S. 431.

2 Transact. of the L'nnean Soe. Zool. 1SSt, S. 407. 
Fig. 66, 71, 75), lichtbraunem ('T'af. VI, Fig. 64, 'T'at'. VII, Fig. 68), braunem ('T'af'. VI, Fig. 62, 63, mu 'Taf'. VII, Fig. 69) und dunkelbraunem ('Taf. Til, Fig. 73) Grunde, welcher Grund schliesshich so dunkel werden kann, diss man die Psendopupille, wie bei vielen nichtlenchtenden Augen von Nachtsthmetterlingen oder bei Hydrophilus piceus und Dyticus, ${ }^{1}$ kaum mehr sieht, ähnlich wie man bei recht dunkler Iris auch in manchem IIenschenauge die Pupille schwer unterscheiden kann. Bei jenen Insecten, es sind hauptsächlich Käfer, bei welchen auch die vordersten Pigmentlagen im Auge schon schwarz sind, sieht man gar keine Psendopupille mehr. Krebse dieser Art sind mir nicht bekannt geworden. ${ }^{2}$

Alle Psendopupillen haben die Eigenschaft, mit dem Beschauer den Ort zu ändern, indem sie im Allgemeinen da erscheinen, wo das Facettenauge von der Gesichtslinie des Beobachters senkrecht getroffen wird. Die sehr häufig und insbesondere an der Peripherie des Auges auftretende Abweichung ron dieser Stelle ist oben schon ausfïlnrlich besprochen und für die leuchtende Pseudopupille erklärt worden.

Die Pseudopupille ist durchaus nicht immer kreisrund. Entsprechend der Abweichung der Corneaoberfläche von der Kingelgestalt nimmt auch sie häufig die Form eines Oval an, welches bei Insecten, deren Facetten sechseckig sind, bisweilen Neigung zeigt, in ein umregelmässiges Sechseck iiberzugehen, bei Krebsen, deren Facetten quadratisch sind, gewöhnlich, wenigstens bei mässiger Vergrösserung in deutliche Viereckform iibergeht. (Taf. VI, Fig. 65, und Taf. VII, Fig. 69 und 73.) Auch unsere Flusskrebse zeigen die Psendopupille. Peneus membranaceus, der, wie wir sahen, kein oder fast kein Pigment im Auge hat, zeigt in Folge seines Iristapetums doeh in seinem, herrliche Farben spielenden Auge eine deutliche quadratische Psendopupille, die durch die Krenzung zweier dunkler meridionaler Streifen entsteht (Taf. VII, Fig. 75). Auch er hat, wie dieses Phänomen erwarten liess, quadratische Hormhautfacetten.

Die eigenthïmliche Wölbungsart der Cornea bewirkt, dass manche Krabben, z. B. Carcinus maenas (Taf. VII, Fig. 6S), nach einer Seite hin spitzzulaufende Pseudopupillen haben.

Ausser dieser Pseudopupille sieht man aber bei sehr vielen Thieren noch andere schwarze Flecke am Auge, die zwar nicht so dunkel, auch weniger scharf begrenzt als jener sind, aber doch viele Aehnlichkeit mit ihm haben, sich vor Allem auch wie die Pseudopupille am Auge verschieben, wenn sich die Stellung des Beobachters zu demselben indert. Hat man einige Thiere, am besten Tagschmetterlinge, genal angesehen, so erkennt man bald, dass in der anscheinend unregelmässigen Grupue

1 Man muss in diesen Fällen kräftige Belenchtung des Auges mit dem Augenspiegel rornehmen, dann überzeugt man sich auch an diesen dunkeln Augen von der Anwesenheit der Psendopupille.

2 Bei der Tangnsta und dem Hnmmer sind die Psendopupillen aus anderen Úrsachen nicht dentlich. 
dunkler Flecke eine Gesetzmässigkeit herrscht. Um die eigentliche Psendopupille liegt nämlich zunächst ein Kranz von sechs dunklen Flecken, die in ihrer Schärfe der Pseudopupille am nächsten stehen, weiter nach Aussen kommt ein zweiter Kranz noch schlechter ausgebildeter Flecken, deren zwölf zu sein scheinen. Bei gewissen Libellenlarven habe ich auch noch Flecken unterschieden, die einem dritten Kranze angehört haben. Alle zusammen bilden das Phänomen der Pseudopupillen. Es besteht aus der bisher allein besprochenen Ha utpupille, ferner aus (bei den Thieren mit sechseckigen Facetten) sechs Nebenpupillen erster Ordnung und wahrscheinlich zwölf Nebenpupillen zweiter Ordnung, endlich solchen dritter Ordnung, die sich alle über das Auge verschieben, wenn man es dreht.

Die meisten Augen zeigen das Phänomen nicht in dieser Vollständigkeit. Wie etwa das Plänomen des Regenbogens aus äusseren Gründen fast nie in seiner 'Totalität gesehen wird, so ist es anch mit dem der' Psendopupillen. Freilich ist mir die Theorie dieses letzteren, somit die Kenntniss alles dessen, was dazu gehört, nicht in jener Vollkommenheit lekannt, doch glanbe ich das Gesagte vertreten zu können.

Am vollkommensten sah ich die Erscheinung bei reifen, im Wasser lebenden Larven von Agrion, deren Angen wie ïbersäet mit Punkten waren, an denen ich zuerst die geschilderte Anordnung und Zahlenvertheilung bemerkt habe. Dreht man das Auge so, dass die Hauptpupille gegen den Rand rückt, so verschwinden die Nebenpupillen auf der einen Seite, indem sie gleichsam iiber den Rand linausrïckeñ, wälırend anf der entgegengesetzten Seite nene Nebenpupillen aufzutauchen Platz finden. So ist es bei jedem Thiere, das ïberhaupt Nebenpupillen hat. Der untere Augenantheil grosser Libellen (Taf. VII, Fig. 66) lässt das Phänomen auch noch in ziemlicher Vollkommenheit erkennen, wenn man die Hauptpupille an den richtigen Ort bringt. Nan sieht dann die verzerrten, zum Theil miteinander verschmrelzenden Nebenpupillen erster Ordnung, auf der einen Seite ziemlich vollkommen die Reihe der Nebenpupillen zweiter Ordnung, und sieht zeitweilig an einzelnen Randstellen auch noch die eine oder andere Nebenpupille dritter Ordnung auftauchen (bei a). Bei jeder Bewegung des 'Thieres oder' des Beschaners geräth das ganze Bild in ein Fliessen, das dem Auge jenen räthselhaften Schimmer verleiht, der noch unverständlicher wird, wenn man die Hauptpupille gegen den oberen Antheil des Auges verschiebt, wo sie schliesslich halbmondförmig wird, und in die grosse schwarze Hauptpupille des oberen Augenantheiles iibergeht, unter Wegfall aller Nebenpupillen.

Immer noch sehr schön, aber schon enger begrenzt tritt das Phänomen am Auge vieler 'Tagfalter auf, z. B. an dem des Rübenweisslings (Pieris rapae) Taf. VI, Fig. 61. Eine schöne Hauptpupille, sechs gut ausgebildete Nebenpupillen erster Ordnung und einige Andeutungen von jenen zweiter ordnung sind bei einer gegebenen Stellung des Auges zu erkennen. Die letzteren treten anf einer Seite dentlicher hervor, wemn man die Haupt- 
pupille nach der anderen Seite verschiebt. Ganz ähnlich verlanlten sich Pupille und Nebenpupille beim Citronenfalter (Colias rhamni).

Auch Epinephele zeigt die Nebenjupillen bis zur zweiten Ordnung. Jiese lıaben hier eine Neigung, miteinander und mit der Hamptpupille zusammenzufliessen, so dass das Auge ein eigenthïmliches Aussehen erhält ('Taf. VI, Fig. 64) und erst nach einigem Drehen und Wenden das Gesetzmässige der Anordnung erkennen lässt. Man darf nämlich bei Betraclıtung dieser Abbildungen nicht vergessen, dass eine solche das Auge nur bei einer Stellung und von einem Gesichtspunkte aus darstellen kann. Bei kleinen Verschiebungen schon ändert sich Lage, For'm und gegenseitige Entferuung der Pupillen.

In ähnlicher Ausdehnung, aber mit anderer Anordnumg tritt das Phänomen bein Distelfalter (Tanessa cardui. Fig. 62) auf. Auch hier sind noch einzelne Nebenpupillen zweiter Ordnung andeutungsweise zu erkennen. Bei Melanargia, und noch mehr beim Táubenschwanz (Makroglossa stellatarum) hat das Pliänomen grössere Dimensionen angenommen, so dass selbst die Nebempupillen erster Ordnung nicht mehr ganz auf dem Auge Platz finden (Taf. VI, Fig. 63). Die Hauptpupille ist bei letzterem verlältnissmässig gross, es ist dieselbe, welche bei Untersuchung mit dem Augenspiegel so intensiv grïn aufleuchtet. Würden, wie Thompson-Lowne angibt, die Nebenpupillen auch leuchten können - bei diesem Schmetterling wäre mir das sicher nicht entgangen.

Man denke sich diese Hauptpupille noch grösser und die Nebenpupillen über den Rand des Auges hinausgeriickt, dann liegt das Bild vor, das, wie oben gesagt, die nicht leuchtenden Augen von Nachtschmetterlingen und manchen Käfern zeigen.

Die grossen Heuschrecken, z. B. Psopluts stridulus, zeigen scharfe, aber kleine schwarze Pupillen olne Nebenuupillen.

In allen diesen Fällen ist, wie die Abbildungen zeigen, der ringförmige Raum zwischen der Hauptpupille und den Nebenpupillen erster Ordnung von besonderer Helligkeit. Bei manchen Thieren, z. B. Hesperia coma, die ein dem Auge des 'Taubenschwanzes sehr ähnliches Auge hat, ist dieser lichte Hof un die Hauptpupille so ausgeprägt, dass man geneigt ist zu sagen, diese sei vol einem sechsstralıligen, weisslichen Stern umgeben.

Ein auffallender Unterschied zwischen der Hauptpupille und den Nebenpupillen erster Ordnung einerseits, den Nebenpupillen zweiter und dritter Ordnung andererseits bestelıt darin, dass die Lage der ersteren nur von der Stellung des beobachtenden Auges, die Lage der letzteren aber ausserdem noch von der Richtung der Beleuchtung abhängig ist. Ich beobachtete das bei Pieris rapae. Benutzt man eine Kerzenflamme als Lichtquelle im sonst dunkeln Ramme, iiberzeugt sich unter Benützumg des Augenspiegels, dass man die Hauptpupille richtig erkannt hat (indem ihr Kern bei passender Belichtung roth leuchtet) und wendet das Ange so 
dass wenigstens einige Nebenpupillen zweiter und dritter Ordnung sichtbar werden, so sieht man, wie sich diese im Krreisbogen um die Hauptprupille drehen, wenn man die Kerze anf und ab bewegt. An der Hauptpupille, sowie an den Nebenpupillen erster Ordnung habe ich nie auf diese Veise eine bemerkbare Bewegung hervorufen können.

Es ist nothwendig bei diesen Beobachtungen eine Lupe zu benützen.

Die Hauptpupille steht also, wie gesagt, fest, insoferne als ihre Lage unabhängig von der Richtung der Belenchtung ist. Anders aber ist es mit dem centralen leuchtenden Theile derselben. Diese, die „leuchtende Pseudopupille", erleidet wenigstens bei dem genannten Schmetterling - und bei anderen Tagschmetterlingen wird es sicher ebenso sein - kleine Ortsveränderungen im Inneren der schwarzen Psendopupille, wenn die Richtung der Beleuchtung durch den Augenspiegel sich ändert. Ich habe das oben schon hervorgehoben und erklärt.

Aehnlich wie bei den Insecten, ist auch bei vielen Krebsen (z. B. Carcinus mänas, 'Taf. VII, Fig. 68) die dunkle Hauptpupille von einem auffallend hellen Hof umgeben.

Bei den Krebsen habe ich, so dentlich, wenn auch klein, die Hauptpupille ist, niemals unzweifelhafte Nebenpupillen gesehen, ausser beim Einsiedlerkrebs (Pagurus, siehe Fig. 71). Dieser Krebs hat wie die Insecten sechseckige Corneafacetten, und hat wohl ãuch sechs Nebenpupillen. Sie sind aber sehr undeutlich, nur unter den gïnstigsten Verhältnissen mit Sicherheit zu erkennen, und es gelang mir nicht, sie zu zählen. Man ist nie iiberzeugt, das ganze Phänomen zu iibersehen. Wohl aber glaube ich noch Nebenpupillen zweiter Ordnung erkamnt zu laben.

Bei den Krebsen mit quadratischen Corneafacetten, bei denen sich vier Nebenpupillen erster Ordung erwarten lassen, habe ich niemals solche von ähnlicher Dentlichkeit wie bei Insecten gesehen. Vier dunkler gefärbte Stellen, wie man sie z. B. bei Galathea ('Taf. VI, Fig. 65) sieht, oder die eigenthümliche Zeichnung bei Palaemon (Taf. VII, Fig. 69) und ähnliche Erscheinungen an Palinurus und Homarus halte ich fiir den Ausdruck von Reflexen, die an den in Reihen gestellten Corneafacetten, beziehungsweise den darunter liegenden Kegeln erfolgen; sie laben also einen anderen Ursprung als die Pseudopupillen. Am ersten könnten mit diesen noch die Arme des dunklen Kreuzes identificirt werden, das man am Auge von Peneus membranaceus (Taf. VII, Fig. 75) sieht.

Erklärung des Phänomens der Psendopupillen.

Diese Erklärung ist nicht ganz einfach, anch nicht für jene Theile des Phänomens, für die ich sie iiberhanpt zu geben vermag. Ich werde mich nämlich darauf beschränken mïssen, die optischen Grundlagen für 


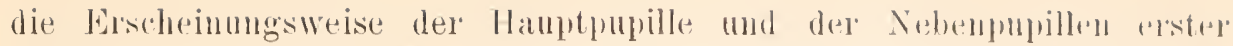
Ordmung klarmlegen. Die Nebenumpillen höherre ()'dnungen sind so schwach entwickelt, dass sie einer eingehenderen physikalischen l'ntersuchung zu grosse Schwicrigkeiten entgegensetzen. Ich musste hier also auf eine experimentelle Prifung meiner Vermuthungen verzichten, glaube deshalb auch die Mittheilung dieser Vermuthungen unterlassen zu könueı, unsomehr, als der Weg, auf dem man die I)entung der Nebenpunilun zweiter und dritter Ordnung zu suchen lat, durch die Erklärung jener erster Ordnung schon in seiner Richtung bestimmt ist.

Die grosse Manigfaltigkeit, die wir in Form und Grösse des Phänomens kennen gelernt haben, und die auf den zahlreichen Variationen in Bane der Facettenaugen beruht, zwingt uns zunächst eine Exklärung des typischen Phänomens anf Grund eines typischen Auges zu suchen und die einzehen Variationen damn an der Hand der zu Grunde liegenden anatomischen Verhältnisse besonders in Betracht zn ziehen. Wir setzen also im Folgenden ein rollkommen regelmässig gebautes (z. B. kugelig gekrümmtes, mit senkrecht aufsitzenden Krystallkegeln versehenes etc.) Insectenauge voraus.

Das Phänomen hat ein Centrum, um das es angeordnet ist. 1)asselbe ist die Mitte der Hauptpupille, welche, wie oft erwähnt, dadurch charaktelisirt ist, dașs in ihl die Gesichtslinie des Beschaners das Facettenange senkrecht trifft. IVir wollen diese Linie die Axe des Phänomens nennen. Dasselbe, soweit wir es zu erklären beabsichtigen, besteht dam ans der die Axe umgebenden Hauptpupille und sechs von der Axe gleichweit entfernten, im Sechseck gestellten Nebenpupillen.

Die Hauptpunille. Man sieht dieselbe, wie schon Leydig beohachtet hatte, sehr schön am Limulus, selbst an einem getrockneten Exemplare komnte ich sie noch erkemnen. Nebenpupillen fehlen bei diesem Thiere, doch zum Studium der Hauptpupille eignet es sich besonders, nicht nur wegen der Grösse dieser — sie misst mehrere Millimeter in Durchmesser - sondern vor Allem wegen der Grösse der einzelnen Facettenglieder. Betrachtet man am lebenden Thier mit der Lupe die Grenze der Hauptpupille, so gewahrt man eine Lichtrertheilung an den einzelnen Facetten, die ich durch Taf. I, Fig. 8, wiederzugeben versucht labe. $A$ liegt noch im Bereiche der Pupille, $B$ liegt schon ansserlialb derselben. Man hat sich diese Lichtrertheihng an den Facetten rund um die Pupille vorzustellen. Diese verdankt somit ihre Schwärze dem Unstande, dass in der Nähe der Axe des Phänomens aus den Facetten kein Licht in das Auge des Beobachters gelangt, und die Grenze der Prpille ist dadurch gegeben, dass aus Facetten, die ron der Axe weiter entfernt sind, wohl Licht in der Richtung nach dem beobachtenden Ange helausdringt. Die Abbildung zeigt weiter jede dieser Facetten auf der der Axe abgrwendeten Seite hell, und dass die mit der Entfermung von der Axe zmnehmende Helligkeit der Augenoberflache darauf berulıt, dass in jeder cinzelnen Facette die helle, fast halbmonoförmige \%one an Breite und Intensität wächst. 
Ich habe mich ïberzengt, dass lei Thieren, welche Nebenpupillen haben, die Lichtvertleilung in und um die Hauptpupille dieselbe ist, wie hier bei Limulus. Libellen und der Rübenweisshing, bei schwacher Vergrösserung unter dem Mikroskope untersucht, dienten zu dieser Controle. Die Richtung der Beleuchtung kommt, wie aus dem Vorstehenden schon hervorgeht, hier in der Regel nicht in Betracht.

Die Ursache dieser Lichtvertheilung und somit der Entstehung der Hauptpupille geht aus Holzschnitt Fig. 23 hervor. Zum Verständnisse des-

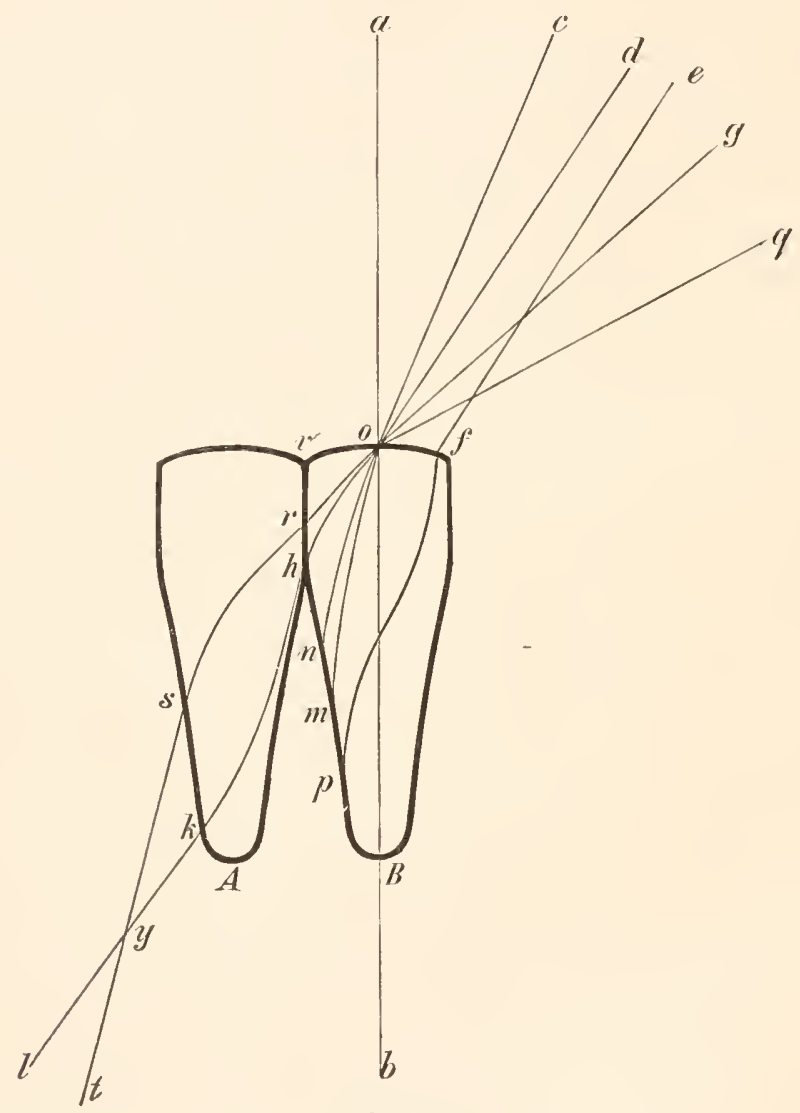

Fig. 23.

selben ist festzuhalten, dass das von einem Punkte ausgehende Licht die Oberfläche des Facettenauges nur an einer Stelle senkrecht trifft, und dass es auf die ïbrigen Corneafacetten unter um so grösserem Einfallswinkel anffällt, je weiter diese, bei gegebenem Krïmmungshalbmesser des Auges, von der ersten Stelle entfernt sind.

Gestatten wir uns, der Bequemlichkeit der Darstellung wegen, dats Ange des Beobachter's als lenchtenden Punkt vorzustellen, und zu fragen, wohin die von diesem Punkte ausgehenden Strahlen im Facettenange gelangen werden. Haben wir den Weg dieser Strahlen gefunden, dam 
wissen wir allch, von welehen Punkten des Fateettenauges aus Licht in das Auge des Beobachters gelangen kann. Haben wir ja doch den Satz von der Umkehrbarkeit des Strahlenganges schon wiederholt in Anwendung gebracht.

Es seien $A$ und $B$ (Fig. 23) zwei Facettenglieder, deren Form ich dem Lampyrisauge entnehme, ohne damit einen anderen Zweck zu verfolgen, als das mir bekannteste Auge den Betrachtungen zu Grunde zu legen. Bui den anderen Augen müssen die Verhältnisse in den wesentlichen Punkten dieselben sein. Befindet sich das lenchtende Auge des Beobachter's in der Verlängerung von $b$, also in der Axe des Phänomens, so dringt Licht durch das Facettenglied $B$ und beleuchtet eine in der Axe gelegene Stello der Retina. Ist diese Stelle nicht mit schwarzem Pigmente ausgekleidet, sondern vermag sie eine genügende Henge Licht zuriickzuwerfen, so dringt dieses in der Richtung von $b$ a in das Auge des Beobachter's, und dieses sieht - wie das für Tagschmetterlinge, Libellen und manche Krebse oben beschrieben wurde - das Centrum der Hauptpupille leuchtend. Ist eine solche reflectirende Schichte nicht da, so kann aus dieser Facette kein Licht in das Auge des Beobachters zurückgelangen, es sieht das Centrum der Psendoptupille schwarz, wie das bei Käfern, Krebsen, deren Augen sich in Lichtstellıng befinden, etc., besprochen wude.

Fällt aber vom Ange des Beobachters ein Strahl etwa unter der Neigung von $c$ o auf eine Facette - dieselbe stünde dann in einiger Entfernung von der Axe des Phänomens - so gelangt er, wie wir (S. 25) silhen, nach $m$, und wird, wenn sich daselbst schwarzes Pigment befindet, wie das bei fast allen Augen der Fall ist, absorbirt. Aus allen Facettengliedern also, deren Axen zu der Axe des Phänomens, eine gewisse Neigung haben, könnten in das Auge des Beobachters nur Strahlen gelangen, die von dem schwarzen Pigmente ausgegangen sind, d. h. es gelangen keine Strahlen in sein Auge; er sieht das schwarze Pigment, das die Krystallkegel umgibt, in Form eines schwarzen Ringes um die leuchtende Pupille (Fig. 72, Taf. VII), oder wenn an der Retina kein Licht reflectirt wurde, als äussere Zone des schwarzen Fleckes, der durch die erst besprochenen Strahlen bedingt ist. Beide zusammen bilden dann das, was wir die Pseudohauptpupille genannt haben. Dieser äussere, von dem Kegelpigment herrührende schwarze Ring ist deshalb immer vorhanden, es mag die Beleuchtung welche immer sein, denn das Pigment absorbirt eben immer alles Licht, das auf dasselbe fällt.

Ein Strahl, der, rom Auge des Beobachters kommend, unter einer noch grösseren Neigung ein Facettenglied trifft, z. B. do, gelangt nach dem Punkte $n$ in das daselbst liegende Pigment. Wir haben aber gesehen, dass bei vielen Facettenaugen vor dem şchwarzen Irispigment ein lichteres, häufig schön gefärbtes Pigment, das Iristapetum, liegt, z. B. beim Rïbenweissling ein gelbes ('T) Fig. 34, Taf. IV). In das Ange des Beschaners gelangt also jetzt in diesem Falle reichlich gelbes Licht, und zwar nur solches, denn ans allen 
Filcettengliedern, welehe die bestimmte Neigung gegen die Axe des Phänomens labben, dringt nach der kichtung des beobachtenden Anges eben nur dieses gelve Licht. Hierdurch ist die äussere Grenze der Hauptpupille gegeben, und zugleich die Ursache des hellen Hofes, den man um dieselbe zu sehen pfiegt ('Taf. VI, Fig. 62, 64).

Auch die Lichtvertheilung an einer Corneafacette, die oben beschrieben und Taf. I, Fig. 8, abgebildet wurde, erklärt sich in dieser Weise sehr einfach, dem es ist klar, dass ein Lichtstrahl ef, der aus derselben Richtung wie $d v$, also auch aus dem beobachtenden Auge kommend, die Corneafacette bei f trifft, den Kegelrand erst etwa bei $p$, also im Bereiche des schwarzen Pigmentes erreichen muss. Die Corneafacette wird also auf der der Axe des Phänomens zugewendeten Seite noch schwarz erscheinen, während die andere Seite schon hell ist.

Diese Deutung der Hauptpupille bedarf noch einiger Ergänzungen. Nach in kamn eine Pseudopupille überhaupt nur in jenen Augen sichtbal sein, in denen vor dem schwarzen Pigment, das wir Irispigment genannt laben, noch eine andere das Licht nicht oder doch nicht vollständig absorbirende Masse liegt. In dieser Beziehung stimmt meine Erfahrung vollkommen mit der 'Theorie. Es liegt ja eben hierin die Ursache, ans welcher man bei Schmetterlingen mit schwarzen Augen (zwar mit Hilfe des Augenspiegels eine lenchtende, aber ohne diesen) keine Psendopupille sieht, ebenso bei den meisten Käferm. Viele freilich haben nicht vollkommen schwarze, sonder'n dunkelbrame Augen; das entsprechende P'igment hat dann anch die Lage wie das Iristapetum bei anderen Thieren (c, Taf. II, Fig. 15). 1)amn aber sieht man auch die Hauptpupille. Eine scheinbare Ausnahme macht Limulus, bei dem man gerade die Pupille auffallend schön sieht, obwohl er ansser dem schwarzen kein Pigment in Auge hat. Hier wild das vordere lichte Pigment, das Iristapetum, in ganz exquisiter Weise vertreten durch die stark reflectirenden Stellen der Corneasulustanz, die wir zwischen den einzelnen Kegeln kemnen gelernt haben. Da liegen (s. a auf Taf. III, Fig. 20) zalhheiche feinste Porencanälchen, welche die Substanz von rorne nach linten durehzieheu und mit Luft gefiillt zu sein scheinen. Es ist klar, dass diese mm die vorderen Antheile jedes Kegels (soferme er optisch als solcher wirkt) angeordnete modificirte Chitinsubstanz ilırer Lage, sowie dem Reflexionsvermügen nach das helle Pigment anderer Angen nicht nur ersetzen, sondern iibertreffen kamn.

Wenn der obere Theil des Libellenanges, anch wo er kein schwarzes Pigment enthält, doch eine grosse diffuse Psendopupille zeigt, so rührt das dalrer, dass das betreffende braune Pigment eben doch recht dunkel ist. Es ist das Leuchten dieser Psendopupille eben wegen dieses nicht ganz schwarzen Pigmentes anch ein ausgedehntes und diffuses. Im mnteren Theile des Libellenauges ist die Pupille dunkelschwarz und scharf begrenzt, weil hier schwal'zes Pigment vorhanden ist und die liegel relatir liunger und schmäler sind, wie im oberen Theile (s. oben Cap. VI und Fig. 59, Taf. VI.) 


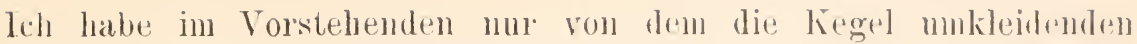
Pigmente als Ursache der Hamptpupille gesprochrol. Es ist aber kain \%weifel, dass bei jenen Thieren, deren bis an die Kegelspitzen reichende Sehstähe mit Pigment umhïllt sind, dieses Retinapigmont in derselben Weise wirken muss. Es bildet dann in Bezug auf die Psendopupille elsen nur eine Fortsetzung des Irispigmentes nach hinten.

Einer besonderen Bemerkmg bediurfen noch die Augen mit Superpositionsbild und sehr ausgiebiger Verschiebung des lrispigmentes. An besten erkennt man an jenen mserer Nachtschmetterlinge bei 'Tagstellumg eine auffallend grosse, von einer brämnlichen Imgehming sich schwach abluebende Psendopupille. Wo ist da das notlıwendige vordere Pigunentlager?

Eine solche vordere differenzirte Pigmentlage ist in der 'T'hat volhanden, wenn sie sich auch am mikroskopischen Präparate nur wenig in der Färbung vom Irispigment unterscheidet. Man erkennt sie doch als unzweifelhaft dunkelbraun. Auch verhält sie sich physiologisch anders als das Irispigment. Dieses Pigment bildet eine dïnne, dem Kegel sich eng anschmiegende Lage, welche schon in der Dunkelstellung von dem eigentlichen Irispigmente leicht zu nnterscheiden ist und beim Uebergang in die Lichtstellung vielleicht nicht immer, aber jedenfalls bisweilen in seiner Lage am Kegel verharrt (vgl. die Abbildung vom rothen Ordensband, Taf. II, Fig. 15). Bei den Krebsen, deren Irispigment ansgiebige Terschiebungen eingeht, macht das Iristapetmm, das Analogon der lichten Pigmentschichte der Insecten, dieselben mit (vgl. Taf. IV, Fig. 39, nnd Taf. V, Fig. 51 bis 54), ohme die Lage gegen dasselbe zu ändern; bei anderen Krebsen, deren Irisverschiebungen weniger ausgiebig sind, rerlaart das analoge Pigment an seinem Platze (so z. B. bei Portunus, 'Taf. IV, Fig. 37, 38 it.).

Aber auch die Pupille bei Nachtschmetterlingen bedarf einer Bemerkung. Bei vielen dieser Thiere, sowie wohl bei den meisten Insecten und Krebsen, die ein Superpositionsbild laben, ist bei Lichtstellung des Auges die Mantelfläche des Krystallkegels ganz oder zum grossen Theile vom Irispigment entkleidet. Man könnte nun fragen, wie entstelıt da eine Pseudopupille, wo die Stralılen co, do und of des Holzschnittes Fig. 23 anf gar kein Pigment stossen? Die Antwort hieranf ergibt sich, wenn wir zunächst die regelrecht gebrochenen Strahlen ins Ange fassen. Bei diesen Thieren, deren Facettenglied einen Tinsencylinder ron der doplelten Länge seiner Brennweite darstellt, werden die gegen die Axe desselben mässig geneigtru Strahlen noch an die Spitze des Kegels geleitet, wo sic anf derselben Seite der Axe austreten, anf der sie eingetreten sind. Es ist das oben ausfiilulich besprochen worden. Vgl. Strahl $p b^{\prime} \rho^{\prime}$ auf Holzschnitt Fig. 12, S. 44. Diese Strahlen aber gelangen dann auch nocls an das nach rïckwïrts geschobene Irispigment, werden also absorbirt, so dass das ganze Geliet dieser schief einfallenden Strahlen der Hauptpupille angehört, obwohl der 
Verlauf derselben von dem bisher geschilderten recht verschieden ist. Der Beschauer sieht dann in der Pupille ein Schwarz, welches nicht den der Axe des Phänomens alogewendeten Seiten der Kegelmantelumhüllungen angehört, sondern den der Axe zugewendeten Seiten der Pigmentscheiden, die zwischen Kegel und Retina liegen. Strahlen aber, welche so verlaufen wie co oder ef des Holzschnittes Fig. 23 miissen, nachdem sie aus dem Fiegel ansgetreten sind, doch früher oder später auf schwarzes lrispigment stossen, das jetzt aber weit rïckwärts geschoben ist.

Je grösser also die Anzahl der Facettenglieder ist, welche zur Bilderzeugung eines Punktes bei voller Dunkelstellung des Auges verwendet wird, desto grösser muss ceteris paribus auch die Psendopupille dieses Auges wälırend der Lichtstellung sein. Und das dürfte mit der Erfahrung auch stimmen.

Die Nebenpupillen erster Ordnung. Zum Verständnisse dieses Theiles unseres Phänomens werden uns hauptsächlich zwei Beobachtungen führen.

Die erste besteht in Folgendem. Untersucht man das lebende Auge eines Thieres, das gut entwickelte Nebenpupillen hat (Riibenweissling; unterer Theil des Libellenauges), indem man die Corneafläche desselben bei auffallendem Lichte unter dem Mikioskope betrachtet, und eine Vergrösserung wählt, bei welcher die sechseckigen Facetten schon gut zu sehen sind, so bemerkt man, dass die Lage einer Nebenpupille gegen die Hauptpupille gegeben ist durch eine Gerade-; die, vom Centrum der Hauptpupille ausgehend, je zwei Seiten der sechseckigen Facetten senkrecht schneidet. Denken wir uns nämlich eine ebene Fläche in regelmässige Sechsecke getheilt, so liegt auf der Hand, dass rom Mittelpunkt eines derselben sechs Linien (von denen je zwei in derselben Richtung liegen) zı ziehen sind, die alle Sechseckseiten, die sie schneiden, rechtwinkelig treffen. Das sind die Richtungen, nach welchen von der Hauptpupille aus die Nebenpupillen erster Ordnung zı finden sind.

Da das Auge gewölbt ist, auf einer kugelig gekrïmmten Fläche aber eine vollkommen regehmässige Eintheilung in Sechsecke bei gegebener Grösse der letzteren im Allgemeinen nicht möglich ist, so weicht die Richtung correspondirender Sechseckseiten am Auge häufig recht beträchtlich von der an der supponirten ebenen Fläche ab. Das ist die Ursache, aus welcher die sechs Nebenpupillen erster Ordnung in der Regel von einer regelrechten Anordnung recht weit entfernt sind, also durchaus nicht in gleichen Abständen voneinander und rom Centrum der Hauptpupille stehen. Es zeigen das die Figuren auf 'Taf. VI zur Genïge.

Ich mache noch darauf aufmerksam, dass die genamnten Linien auf der in Sechsecke getheilten Ebene kurze Durchmesser der Sechsecke bilden, wïhrend sie um 30 Grad gedrelıt, indem sie die gegenüberliegenden Ecken der Sechsecke miteinander verbinden, lange Durchmesser darstellen. 
Wemn schon von voluherein kaum daran zu zweifeln wal, dass die Sechszahl der Nebenpupillen erster Ordung in einem urä̈hlichen Zusammenhang mit der Sechszahl der Facettenseiten steht, so wird diese Vermuthung durch diese weitere Bezielıng der Iagen beider noch rerstälkt.

Die zweite Beobachtung, die uns zum Verstïndniss der Nebenpupillen fïhren soll, bezieht sich anf eine recht übermaschende dioptrische Èscheinung, von der ich im einschlägigen Abschnitte noch nicht sprach, weil sie zwar ihre Entstehnng der Dioptrik des Anges verdankt, für das Sehen des 'Thieres aber bedeutungslos ist; ich meine die Erscheinung der Nebenbilder, wie ich sie nennen möchte.

Hat man das Auge von Lampyris spl. abgepinselt, und so unter das Mikroskop gebracht, wie man es thun muss, m den Verhältnissen im Leben möglichst nahe zu kommen ("correct montirt") und das normale Netzhautbild zu sehen, so gewahrt man unter güustigen Verhältnissen nm dasselbe herum sechs weitere anfrechte Bildchen von wesentlich gleicher Art wie das Hauptbild, nur nemenswerth weniger scharf. Wie beim Hamptbilde kann man auch hier, unter Beniitzung eines Punktes als Gegenstand, die Strahlen nach dem betreffenden Bildpunkt convergiren sehen, und zwar ist es sehr evident, wie - geschieden durch sechs radiare Tremungslinien - die Strahlen eines Sectors nach je einem Bildpunkte convergiren, also Strahlen, welche aus den Trennungslinien nahe gelegenen Kegeln austreten, untereinander divergiren. Die Nebenbilder sind ebenso angeordnet wie an anderen Augen die Psendopnpillen erster Ordnung, verhalten sich insoferue ihnen ähnlich, als man gewöhnlich nicht gleichzeitig alle sechs iibersielıt, ihre Abstände roneinander und vom Hauptbild kleinen Variationen unterliegen, und indem die Lage derselben gegen das Haupthild wieder gegeben ist durch die sechs Linien, die rom c'entrum des ersteren ansgehend gedacht werden, und die Seiten der Sechsecke senkrecht schneiden. ${ }^{1}$

Die Nebenbilder sind immerhin noch dentlich genug, um die Finger einer mahe gehaltenen Hand, besonders wenn sie bewegt wird, unterscheiden zu lassen. Sie liegen in einer etwas anderen Ebene als das Hanptbild, haben aber näherungsweise dieselbe Grüsse. Ich sah sie nicht nur bei Lampyris und jenen seiner Verwandten, deren Krystallkegel auch mit der Cornea rerwachsen sind, sondern auch bei Tropinota hirtella und dessen Verwandten. Ich habe oben hervorgeholen (S. SO), dass bei diesen

1 Beim Lampyrisauge kann man in der oben gesehilderten Anordnung die sechseckigen Facetten nicht sehen; um mich iiber die Lage der Nebenbilder zu den Seehseekseiten zu orientiren, benutzte ich den Kunstgriff, das Prïparat wie es war umzudrehen. Man sieht, wie oben S. 39 gesehildert wurde, auch dann in der Ebene der Netzhaut ein Bildehen, und sieht nun auch die Nebenbilder. Jetzt aver kann man durch Hebung des Vikroskoptubus auch die sechseckigen Facetten zur Anschaung bringen und sich ïber die gerpenseitige Lage unterrichten. 
Thieren der Hauptantheil der dioptrischen Leistung des Facettengliedes der dicken Corneafacette zufält, und man deshalb bei ihnen, auch wenn die unscheinbaren Krystalliegel mit dem Pigmente weggepinselt worden sind, noch ein allerdings schlechtes aufrechtes Netzhautbild sieht, dessen Zustandekommen den bei Lampyris ganz ähnlich ist. Diese Thiere zeigten mir nun auch Nebenbilder, immer natïrlich erst nach Abpinselung des Pigmentes. Die Anordnung entsprach der bei Lampyris.

Diese Nebenbilder nun geben ein Mittel an die Hand, den Strahlengang im Auge zu verfolgen, und dadurch einen Rückschluss auf die Nebenpupillen zu machen.

Hat man bei Lampyris en Nebenbild unter dem Mikroskope eingestellt und als Object einen Lichtpunkt verwendet, so gewahrt man bei Annäherung' des 'l'ubus an das Object, ganz ähnlich wie beim Hauptbilde, dass die Strahlenbündel - die freilich lange nicht so scharf begrenzt, sondern stark verzerrt sind - auseinanderweichen und jedes derselben in das Bild eines schief gesehenen Krystallkegels ïbergeht, wemn man den Focus des Mikroskopes bis an den dioptrischen Apparat herangeschoben hat. Es erscheint eine r'undlich begrenzte Gruppe von Kegeln, ungefähr von derselben Anzahl wie jene in der Verkiirzung gesehenen des Hanptbildes, hell erlenchtet. Hier ïberzeugt man sich nun, dass alles Licht, das das Nebenbild zusammensetzt, aus der Mantelfläche der Kegel austritt. Diese Mantelfläche ist aber im Leben vom Irispigment iiberkleidet, absorbirt ${ }^{\prime}$ also das ganze Nebenbild. Deshalb ist dieses für das Sehen des Thieres bedeutungslos.

Kehren wir aber jetzt wieder zu unserer Vorstellung zurück, nach welcher das Auge des Beobachters lenchtet, so ist klar, dass die von diesem ausgehenden Strahlen an jenen sechs Gruppen ron Krystallkegeln, und zwar an der der Axe des Pupillenphänomens abgewendeten Seite derselben durch das Irispigment absorbirt werden müssen, während wir volläufig keinen Anhaltspunkt dafür haben, eine ähnliche Absorption für die 7wischemrämme zwischen jenen sechs Gruppen anzunehmen. Der Beobachter sieht also jedenfalls ausser der Hauptpupille auch jene sechs Stellen am Ange schwarz: die sechs Nebenpupillen erster Ordnung.

Also die Existenz der Nebenpupillen folgt nothwendig aus der Existenz der Nebenbilder, und die physikalische Erklär'ung der ersteren fällt mit der der letzteren zusammen. Wir haben uns demnach zu fragen, wie kommen die Nebenbilder zu Stande?

Denken wir uns das kugelig gewölbte Auge von parallelen, z. B. im Raume senkrecht verlanfenden Strahlen getroffen. Es ist dann jener Strahl, der dessen Oberfläche senkrecht schneidet, die Axe des Phänomens. In der Nachbarschaft dieser Axenfacette schliessen die einfallenden Strahien

1 Oder dasselbe liegt bei Lichtstellung tiefer unten und fängt demnach das austretende licht auch, nul etwas später, anf. Bei 'T'ropinota tritt das Licht dureh die seitlichen Theile der huteren Corneafliche ans. 
Winkel mit den Facettenaxen ein, die nu so grösser werden, je weitel die Facette von der Axenfacette entfernt ist. I)ie so in das Ange tretenden Strahlen com der Fig. 23, S. 168, werden erst vom Irispigment ausorbirt, dann $(d \circ n)$ rom lichten Pigmente reflectirt (theilweise anch absorbirt) und veranlassen so, wie wir sahen, das Phänomen der Hanptpupille und des sie ungebenden hellen Hofes. In noch grösserer Hutferung ron der Axenfacette ist der einfallende Strahl noch stärer geneigt (go), und dringt deshalb anch nicht mehr in das lichte Pigment des Anges, sondern passint die 'Iremmungstiche zweier' Corneafacetten, bei $h$, gelangt so in den benachbarten Krystalikegel und nimmt daselbst einen Weg, den wir nach unserer Keuntniss rom optischen Bau desselben zwar nicht genau, wohl aber näherungsweise angeben können; er dürfte $o h k l$ sein. Bei $l$ selıen wir diese Strahlen aus den Kegeln austreten, wemn wir mach Beobachtung der Nebenbilder den 'Tnbus so weit verschieben, dass die Krystallkegel sichtbar werden. Bedenkt man, dass bei k: Irispigment liegt, so ist klar, dass die Facetten der betreffenden Antheile des Anges für den Beschaner schwarz erscheinen mïssen. Mau künnte also einen schwarzen Ring erwarten, da eine ringförmige Zone Facettenglieder die supponirte Neignng gegen die Axe des Phänomens hat. In der That sieht man bei gewissen Thieren mnweifelhafte Andentungen dieses Ringes, z. B. bei Epinephele (s. 'Taf. VT, Fig. 64). In der Regel aber hat dieser Ring nicht nur wie bei diesen 'Thiere die Neignng, in sechs Stücke zn zerfallen, sondern er' besteht wirklich ans sechs Stïcken, den Psendopupillen, beziehungsweise den Nebenbildern. Diese Zerfïllung geschient augenscheinlich durch die Corneafacetten.

Ein Umstand, der hielzn beiträgt, ist leicht zn nennen. Wir sahen, dass die Richtungslinie für die Pseudopupille jede sechseckige Facette in einem kmren Durchmesser schmeidet. Stellt also v $f$ (Holzschnitt Fig. 23) einen Durchschnitt durch die Corneaborfläche dar, welcher im kurzen Durchmessel geführt wurde, so müsste die l)istanz $v$ f grössel sein, wemn der Schnitt durch den langen Durchmesser ginge. Damn aber wiirde der gebrochene Strahl o h noch, nicht in den Nachbarkegel gelangen, sondern er miisste (ähnlich wie $o n$ ) das lichte Pigment zwischen den Kegeln tretien. So erklärt sich, weshalb der lichte Hof mm die Hauptpupille in den sechs Meridianen, welche die Facettentiächen senkrecht treffen, schmäler ist als in den um 30 Grad dagegen verschobenen Meridianen, weshalb er also, einen sechsstrahligen Stern bildend, die centrale Begrenzung der Psendopupillen erster Ordnung herstellt.

Das ist die Ursache, aus welcher die Strahlen, welche die TremnungsHäche zweier Corneafacetten passiren, ein Phänomen erzengen mïssen, das in seiner kreisförmigen Anordnung sechsmal seinen Charakter ändert, in der Weise, dass die Grenze zum mindesten vom Centrum weggeschoben wird.

Aber auch eine periphere Glenze muss das Phänomen laben, die ebenso leicht zn erklären ist. Die Nebenbilder zeigen, wie gesagt, dass 
Strahlen, wie yo, bei $k$ die Mantellläche des liegels verlassen. Ein noch geneigter auf die erste Facette auffallender Strahl $q$ o wird etwa so gebrochen werden, wie es der Weg or $s t$ augibt; bei $s$ aber liegt wieder das lichte Pigment. Das Auge des Beschaners also sieht peripher von der schwarzen Stelle (der Pseudopupille erster Orduming) wieder das lichte Pigment, sowie es dasselbe central von dieser Stelle sieht. Dieses aber ist nun die äussere Begrenzung der Pseudopupille.

So weit wir die Sache bisher betrachtet, könnte man erwarten, die Gestalt der Pseudopupille, beziehungsweise der Nebenbilder, mïsste ein mit sechs Wellenbergen versehenes Band sein, das die Hauptpupille kranzförmig umgibt. Jeder nach Aussen gerichtete Wellenberg entspräche der grösseren Breite, in welcher die Facetten vom Lichtstrahl durchsetzt werden müssen. Dass nun das Phänomen kein fortlaufendes Band ist, dieses vielmelır thatsächlich in sechs Stïcke zerrissen wird, beruht nun darauf, dass die Lichtstrahlen, indem sie die Trennungsflächen zweier Hornhautfacetten durchsetzen (bei $r$ oder $h$ der Fig. 23), eine seitliche Ablenkung erfahren, wenn diese Tremnungsflächen nicht in einem der sechs bevorzugten Meridiane liegen.

Das sowohl, wie die Entstehung der Nebenbilder iiberhaupt, geht ans folgender Betrachtung hervor. Wir denken uns durch die Axe des Phänomens und eine jener Linien, welche die Facettenseiten senkrecht schneidet, eine Ebene gelegt, die somit, unserer obigen Voraussetzung entsprechend, im Ramme senkrecht steht und Meridianebene heissen soll. Die ebenfalls vertical einfallenden Lichtstrahlen, so weit sie jener Zone des Anges angehören, in der sie die Trennungsfläche zweier Corneafacetten passiren, convergiren nach der Brechung untereinander, und zwar näherungsweise nach einem in der Meridianebene gelegenen Punkte. Im ganzen Ange sind das also die sechs Convergenzpunkte, die Nehenbilder. Die Convergenz kommt für jene Strahlen, die in der Meridianebene verlanfen, dadurch zu Stande, dass sie sämmtlich 'l'heile des dioptrischen Apparates passiren, die im Wesentlichen Linsencylinder sind. Diese werden schief durchsetzt, und nach Allem, was wir vom Linsencylinder wissen, dürfte der im Holzschnitt Fig. $23 g \circ h k l$ und $q \circ r s t$ angegebene Weg ziemlich richtig sein. Denn die Richtung der austretenden Strahlen ist Gegenstand der Beobachtung, wenn ich auch nicht ïber genauere Messungen verfüge. Die Zeichnung zeigt, dass, wie das bei jedem regelmässigen Durchtritt des Lichtes durch einen Linsencylinder geschehen muss, die in das Facettenglied eintretenden Strahlen im Bogen abgelenkt werden. In Bezng anf den Verlanf nach dem Austritte spielt freilich auch die Form des Kegels und die Eintrittstelle des Strahles eine Rolle. Die austretenden Strahlen kreuzen sich, wie das die directe Beobachtung lehrt.

Die Strahlen st und $k l$, welche verschiedenen in der Meridianebene gelegenen Facettengliedern angehören, convergiren also hinter dem dioptrischen Apparate und geben dadurch die Möglichkeit zur Entstehung des 
Nebenbildes. Ws ist dazu aber weiter nöthig, dass aud Strahlen, velche die ansserhalb der Merialianebene gelegenen Faretten trolfen, zur Meridianehene hin abgelenkt werden.

'l'rägt man sich in mögliclıst regelnäissigex Anordnung Sechsecke anf eine Kugelfläche auf, so gewahrt man - wie am Insectenange - dass in einiger Lntfernung von jener Linie, in der die Meridianebene die Augenoberfläche schneidet, die Sechsecke nicht nehr ihre Seiten, sondern ihre Ecken der Axenficette zukehren, wic das natürlich anch in der Ebene der Fall ist. Jede der Seiten des Sechseckes ist aber nur das freie Ende jener Trennungsfäche zwischen zwei Hornlautfacetten, in der die Punkte $h$ und $r$ der Fig. 23 liegen. Denkt man sich auf einer dieser lremungsfläehen ein Loth ervichtet, so fällt dasselbe in die Meridianebene, wenn die Facette dem Meridian angehört, liegt sie aber ausserhalb derselben, so ist das Loth gegen die Meridianebene geneigt. Denken wir uns den Fusspunkt desselben von einem senkrechten Lichtstrahl getroffen, so muss derselbe, er mag was immer für eine Brechung an der Trennungsfläche erfalnen, in der Ebene bleiben, welche durch den Strall und das Toth gegeben ist. Diese senkrechte Ebene schneidet aber die Meridianebene. Er wird demnach dieser zugefiihrt, da im Uebrigen seine Brechung im Kegel der jener Strahlen ähnlich ist, welche in der Meridianebene selbst einfallen. Fs wäre demnach ganz wohl denkbar, dass die beiden oberen 'Tremnungslïchen einer' Corneafacette das durch sie aringende Ticht so trennen, dass der eine Theil dem einen Nebenbilde zugefülnt wird, der andere dem anderen Nebenbilde. Bei den Thielen, die ich nntersuchte, trifft das aber nicht zu, da ist immer zwischen zwei Kegelgruppen, die sich an der Erzengnng von Nebenbildern betheiligen, eine Strecke, leren Kegeln gar kein Ticht so austreten lassen, dass es in das Mikroskop gelangt. Hier tritt alles Licht, das man den dioptrischen Apparat passiren sieht, zwischen den Basen der Kegeln hervor, da also wo sonst das Tristapetmm liegt. Wir haben ja sclon einsehen gelernt, dass der Zwischenramm zwischen den Psendopupillen deshall, von der Faube dieses Pigmentes ist.

Dass jene Ablenkung, welche die Strahlen an den T'rennungsfächen zweier Corneafacetten elleiden, m so grösser sein muss, je weiter imerlatb gewisser Grenzen die Facette von der Meridianebene entfernt ist, dass sie anch imnerhalb des Meridians mit der Entfernung von der Axe des Phänomens wäehst, geht aus dem Dargelegten wohl hervor; dass die Nebenbilder nicht dentlicher sind, wird wohl ancl Niemanden Wunder nehmen; eher dass sie so deutlich sind, wie man sie thatsächlich sieht. Mit dieser Erklärung der Nebenbilder ist aber auch die Erklärung der Nebenpupillen erster Ordnung erledigt, denn wir branchen uns eben wieder nur die Richtung des Strahles umgekelıt zu denken und zu erwägen, dass die Strahlen, welche die Nebenbilder znsanmensetzen, sämmtlich an der im Loben pigmentirten Mantrolfïrbe des Kogels austroten, so lenclitet ein, 
dass sechs getremnte schwarze Flecke mm die centrale Hauptpupille gesehen werden müssell.

Eine eingehendere Theorie des Phänomens zu geben bin ich nicht in der Lage. Ich weiss wohl, dass das hier Vorgelegte in vieler Beziehung mangelhaft ist, iclı habe \%. B. anf die Wölbungen der Corneafacetten keine Riicksicht genommen, doch dürfte der richtige Weg zur Erklärung des complicirten Plä̈nomens eingeschlagen sein.

Die dargelegte 'Theorie der' Nebenpupillen postulirt, dass kein 'Thier solche zeigt, bei welchem sich zwischen den Corneafacetten undurchsichtiges Pigment befindet ('T'if. VI, K'ig. 60). In der That habe ich niemals bei einem solchen Insect Nebenpupillen gesehen. Dasselbe gilt natiirlich für die Nebenbilder. Das Leuchtkäferchen, die Verwandten der Cetonia, zeigen Nebenbilder, aber keine Nebenpupillen. Letzteres aus demselben Grunde, aus dem sie keine Hanptpupille zeigen. Hauptpupille und Nebenpupille sind da, aber von ihren Zwischenräumen nicht zu unterscheiden, weil diese Thiere eben nur schwarzes Pigment im Ange haben. Aus derselben Ursache kamn anch ein anderer Effect eintreten. Ich habe hin und her gesomnen, weshalb wohl die grossen grünen Heuschrecken (Locusta viridissima) keine Nebenpupillen zeigen, obwohl sie so hellgefärbte Angen haben. Die mikroskopischen Schnitte belehrten mich, dass bei diesen 'Thieren das lichte Pigment fist bis an die Spitze des Krystallkegels reicht. Unter diesen Umständen kann sich natiirlich auch die Pseudopupille von der Ungebung nicht abheben, obwohl sie virtuell vorhanden ist. Diese Pigmentyertheilung ist zugleich die Ursache, aus welcher die Hauptpupille dieser Thiere so ausserordentlich klein ist. Wie leicht einzusehen, muss diese cet. par. um so grösser sein, je höher das Irispigment am Kegel hinaufreicht, beziehungsweise je weniger tief das Iristapetum herabreicht.

Es ist selbstrerstindlich, dass Alles, was ich ron der gegenseitigen Verschiehmg des Comeareflexes zur lenchtenden Psendopupille gesagt habe, Giltigkeit lat für das ganze Phänomen der Psendopupillen. 


\section{CAPITEL.}

\section{Das Sehen mit den Facettenaugen.}

a) Schärfe des Netzhautbildes.

Eine Angabe ïber die Schärfe des dioptrischen Netzhautbildes bin ich mit Sicherheit nur für Lampyris zn geben in der Lage. Sie ist in der Photographie des 'Titelbildes enthalten, und zeigt, dass dieses Thier, soferne es sich mu das Netzhantbild handelte, noch im Stande wäre, Schilderschrift in der Entfermung von einigen Netern zu lesen. Die Dicke der Hanptstriche des an der Fensterscheibe angebrachten $R$ betrug 4.9 Centimeter, die Entfermung desselben rom Ange 2.25 Meter. Das „R" ist, obwohl die Plotographie und die weitere Vervielfältignng desselben gewiss das Bild nicht gebessert, sonder'n nntr gesclädigt haben kann, noch erkenntlich. In der Ausdrucksweise der Oplithalmologen entspü̈che also das Netzlautbild ron Lampyris einer Selıschïrfe ron $\frac{6}{400}$ bis $\frac{6}{500}$ Snellen.

Der senkrechte Stal des "R" war 4.9 Centimeter breit. Ein Gitter aus so dicken Stäben wïrde also das Lenchtkïferchen ans einer Entfernung ron 225 ('entimeter noch als Gitter erkennen. Fin Netzhanthild von derselben Grösse würde es auch erhalten, wenn Gitter und Entfernung sich proportional verkleinern würden. Es unterscheidet also auf die Distanz von 1 Centimeter noch die Stäbe des Gitters, wem diese nur 022 Millimeter breit sind. Wie man sieht, eine Leistnng des Anges, die nicht gering genamnt werden kann, und dem T'hiere beim Aufsuchen von Nahrung u. dgl. sehr wohl dienen dïrfte.

Nach dem Bane der Augen ist kaum daran zu zweifeln, dass andere Insecten und Krebse mit Superpositionsbild selır viel schärfere Netzhautbilder haben; schon ilne Grösse deutet in lrohem Masse darauf hin. Ich glanbe, es wï̀de mit einiger Mühe gelingen, diese Netzhantbilder entweder auch direct sichtbar zn machen, wie ich es bei Lampyris und dessen Verwandten gethan habe, oder auf Grund des Angenspiegelbefundes ein Nass für die Schärfe derselben zu gewinnen.

Aehnliches gilt von den Appositionsbildern. So könnte man z. B. für Limulus ans den obem mitgetleilten Daten die Sehschärfe theoretisch ermitteln. 
remn der Durchmesser der einzelnen Retimnla am lebenden 'Thiere (oder an Schnitten durch das gefrorene Ange) ermittelt wiude.

IIan kann die Frage anfwerfen, oh die Scllärfe des Netzhantbildes anch wirklich ein MLaass für die Selıschärfe ahgibt. Es wäre ja möglich, dass die Netzhant so unvolliommen ist, dass sie die im Bilde enthaltenen Details nicht wahrzunelmen gestattete. lch glaube nicht, dass irgend Jemand ernstlich das Zutreften einer solchen Möglichkeit in ausgiebigem Masse annelınen wiirde. Demn erstens entspriclıt die Anzahl der Netzlıntelemente, die so gross ist, wie die Anzahl der Facettenglieder (wenn wir mit Grenacher ein Rhabdom als eine physiologische Einheit anffassen), durchans der Schärfe des Bildes, zweitens wäre es doch wohl absurd, zu denken, die Natur habe einen so complicirten dioptrischen Apparat zm Herstellung eines Bildes construirt und dem Thiere keine Netzhant gegeben, dieses Bild zn verwerthen. Freilich, dass das Bild in seiner rollen Schärfe percipirt wird, kann auch nicht behauptet werden; ich werde selbst sofort einen Umstand anzuführen haben, der dies zweifellaft erscheinen lässt.

\section{b) Verzerrungen am Netzhanthild.}

Eine besondere Beachtnng verdient der Umstand, dass das Netzhantbild des facettinten Anges häufig, ja vielleicht in der Melnzalıl der Species Aer Projection des Objectes nicht geometrisch ähnlich ist. Wir sind das beim Wirbelthienange nicht oder doch mur in sehr geringem Grade zu finden gewohnt. Beim Facettenange aber haben wir Einrichtungen kennen gelernt, welche pino solche Verzerrung des Netzhantbildes zu Gunsten einer Erweiterung des Selnfeldes bewirken. Es sind das die Schiefstellungen der Kegel am Rande des Auges. Ausserdem aber lernten wir vielfach selır beträchfliche Abweichungen der Connea ron der Kugelgestalt kennen, sehr mennenswerthe I)ifferenzen der Krimmmgshahmesser in den rerschiedenen Meridianen, welche dam naturlich auch eine Terzerung der Psendopupille bewirken (Libellen, Carrinus). T)as Maximum solcher Abweichung zeigte mns squilla, ron deren Consequenzen oben schon die Rede war.'

Sei es also, dass die Corneaoberfläche nicht eine Kungelschale um die kugelig gokrümmte Netzhant bildet, sei es, dass hei kingeliger Krïmmung der Cornea die Axen der Facettenglieder nicht ladiär gestellt sind, jmmer muss ('ine Verzerrung des Netzhantbildes entstehen, durch welche es seine geometrische Aelmbichkeit mit dem Selnfolde verliert.

So muss \%. B. die stärkere Kriimmmng des Anges an seiner Peripherie bewirken, dass cin (onadrat, dessen eine Seite horizontal steht nnd das in

1 Sehon J. Müller hat die Alweiehung des Anges von der Kugelgestalt bemerkt und besprochen (zur vergl. Physiologie des Gesichtssinnes, S. 379), liebt aber nun hervor, dass die Dentlichkeit des Netzhathildes in Folge dessen an verschiedenen Stellen eine ungleiche sein miisse. 
einer kugeligen Fläche um das Auge bewegt wird, ain Nelzhauthild antwirft, das, wemn das Quadrat nach oben odel nuten vorschoben ist, die Form eines Rechteckes laat, dessen horizontale seite länger ist; befindet sich das Quadrat aber rechts oder links, so bildet das Netzhautbild ein Rechteck, dessen verticale seite die längere ist. In den / wischenstellungen bildet es Rhomben. Kur\%, das Netzhantbild rines solehen Auges wird an seinem Rande Velzerrungen zeigen, die dadurch zu stande kommen, dass die Dimensionen desselben in radiärer Richtung (wobei die Mitte des Sehfeldes Centrum ist) verkiiut sind.

Analoges muss sich auch im Centrum des Netzhauthildes finden, wenn der Kriümmugshalbmesser desselben in verschiedenen Meridianen verschieden ist. Ist er z. B. im verticalen kiirzer, so wird auch das in der Mitte des Sehfeldes stehende Quadrat als Rechteck abgebildet, dessen horizontale Seite die längere ist.

Es frägt sich nun, ob diese geometrische Unähnlichkeit des Netzhautbildes mit dem Sehfeld nicht etwa das Sehen schwer schädigt.

Vom physiologischen Standpunkte aus ist eine solche schädigung nicht zu erwarten. Erkennen doch auch wil die Grösse eines Objectes ziemlich gut, ob das Object nahe oder ob es ferme, d. h. ob sein Netzhautbild gross oder ob es lilein ist. Iter Mensch, wem er es nicht in der Sclıule gelernt hat, weiss nichts davon, dass er ein Netzhauthild besitzt und wie es gestaltet ist, der Arthropode noch viel weniger. Der Werth aller simesorgane bei der Wahnehmung der Anssenvelt beruht viehmehr dal'auf, dass unter gleichen äusseren Bedingungen gleiche Nervener'egungen zum Centralorgan gelangen. Aus der Jifferenz der Nachrichten, die dahin gelangen - unter sonst gleichbleibendem Zustand des 'Thieres und seiner' Organe - wird eine Differenz der Verhältnisse in der Aussenwelt erkannt. Nun ist das Netzhautbild bei einem gegebenen Auge, z. B. am . Rande immer in der bestimmten Weise verzerrt. Es hat das betreffende Insect. einen Vogel, der am Rande seines Sehfeldes vorbeilliegt, immer mittelst eines langgestreckten Netzhautbildes gesehen, und wem nun wieder ein solches langgestrecktes Netzhantbild in demselben Theile des Sehfeldas auftritt, so wird es, vom Netzhautbild nichts wissend, den Vogel erkennen und sich zu verbergen trachten.

Es kann natürlich keine Rede davon sein, dass dieses Individumm das Netzhautbild zu deuten gelernt hat, wohl aber ist der ganze centrale Mechanismus von Instincten etc. auf Grund dieses so und nicht ander's geformten Netzhantbildes im Laufe der Generationen alsgebildet worden.

Ein in der angefïhrten Alt verzerrtes Netzhiutbild ist also durchaus nicht als schlechter betreffs der Erhaltung des Individumus zu betrachten, es wird vielmehr gewöhnlich gerade wegen seinel Branchbarkeit diese Form erhalten haben. Nenn alwh am Rande weniger Details im Netzhatbilde entlialten sind, so kann die Erweiterung des Selffeldes doch einen grösseren Werth für das Thier haben; demn wemn es Details an einem 
Objecte beobachten will, so kalln es jat das C'entrum des Anges nateh denselben richten. Machen wir es doch alleh so. Unser Netzhantcentrum dient uns zur genauen Beobachtung: wir richten unseren blick nach Objecten, die wir bis dahin in den seitlichen Theilen des Sehfeldes hatten und die unser Interesse erweckt haben.

\section{c) J)as Selien von Bewegungen.}

Ich habe in Tolstehenden mit Absicht nu von der Scluärfe und der Verzerrung des Netzhautbildes gesprochen, dem so wenig die Thiere die Verzerrung des Netzlantbildes als Terzerrung der Objecte selien, so wenig ist von vornherem die Sulärfe des Netzlıantbildes als directex Ansdruck für die Schärfe des Selıens zu betrachten. Es ist numöglich, dass die 'Thiere Einzelnheiten sehen, die nicht im Netzlatutbild enthalten sind, es ist aber, wie schon benerlit, wohl möglich, dass sie solche nicht sehen, obwoln sie im Netzhautbilde enthalten sind. Tier liommt es aucls auf die Leistungsfähigkeit der Netzhant an, sowie auf die ganze Art ilırer Finction.

Die Netzhaut des Facettenanges ist im Allgemeinen absolut dicker als die des Wirbelthierauges, eine Difterenz, welche mit Riicksicht auf die kleinen Dimensionen des dioptrischen Apparates eine ungeheme wird. Wiirden wir uns vorstellen, dass nur eine dïnne schichte dieser Netzhant lichtempfindlich ist, so könnte das Bild in seiner vollen Schärfe percipirt werden. Eine dïnne Schichte, der man eine solche Function zuschreiben könnte, ist aher nirgends zu finden, und es geschieht gewiss mit Recht, dass wir die Sehstäbe, beziehungsweise die Rhabdome für dieselbe in Anspruch nehmen. Die Sthichte der Sehstäbe ist aber eben recht dick, und ist bei vielen Augen immer, bei anderen in der 1)unkelstellung des Netzhautpigmentes, noch bei anderen allerdings wohl gar nicht oder nur in gerjngem Grade ('Tagschmetterlinge) fï̀ solches Licht durclıgängig, das nicht genau in der Richtung der Axe des Facettengliedes eindringt. Dadurch aber kann es geschehen, ja es ist nicht einzuselıen wie es nicht geschehen sollte, dass das von einem hellen Punkt ansgehende Licht nicht nur einen Sehstab, sondern, allerdings in geringerem Grade, auch noch die benachbarten reizt. Ein Blick anf Holzschnitt Fig. 11, S. 40, macht es klar, dass, wenn der Bildpunkt $B$ z. B. anf dem rorderen Ende cines Selistabes vom Lampyrisange liegt, die nach rïckwärts divergirenden Strahlen auch noch in Nachbarstäbe eindringen miissen. Die oben geschilderte Art, wie die Rlabdome das gefangene Licht festhalten, wird diese Diffusion des Lichtes in der Netzhant gewiss sehr beschünken, aber gänzlich wegzuschaffen rermag sie sie wohl nicht. Es wird deshalb ein heller Punkt, wenn sein mikroskopisch beobachtetes Netzhanthild anch scharf wäre, immer noch in der Empfindung als nit eimem Hofe mmgeben erscheinen, der an Tntensität nach Anssen rasch abfällt. Würde der Bild- 
punkt nicht au dem rorderen bude des Selstabes liegren, sondern an seincus hinteren, oder irgendwo in seinem Terlaufe, so wiirde das in Verhalterl dieser Lichtdiffusion nichts Wesentliches äudern.

Die ganze Lichtverschiebung des Retinapigmentes bei krebsen scheint mir, nu' von diesem Standpunkt betrachtet, eine physiologinche bedeutumg zu haben; es ral schon oben davon die Rede, dass anf diesem Wroge das Netzlautbild, soferne es percipirt wiod, bei Nacht eine grosse relative Helligkeit auf Kosten seiner Schäufe gewinnen muss. Es scheint das um so winschenswerther; als das Netzhantbild des Facettenanges, ganz im Allgemeinen gesprochen, sehr viel lichtschwächer ist als das des Wirberthieranges. Man bedenke nur die grosse Ebente der Pupille des Säugethieres als Basis jedes einem Bildpunkte zugehörigen Strahlenkegels und die kleine Gruppe von Facetten, welche beim zusammengesetzten Auge die Basis dieses Strahlenkegels bildet, ron dem Appositionsbild ganz abgesehen.

Die Schärfe des Netzhautbildes gibt also mu die obere Grenze fii die Schärfe des Unterscheidungsvermögens; der physiologischeZerstrenungskreis drïckt dieses herab. Doch ist dieser Zerstreungskreis gewiss nicht so bedeutend, dass er es ummöglich machte, die Sehschärfe nach der Schärfe des Netzhautbildes näherungsweise zu beurtheilen.

Ith bin auf den wahrscheinlichen Zerstrenungskreis und seinc physiologische Entstehung hier eingegangen, weil ich mit denselben einen Lmstand in Beziehung bringen möchte, der mil von bedentung scheint.

Es ist ja eine sehr naheliegende Frage: was bedenten die beiden 'Typen von Augen, die im Thierreiche vorkommen? Haben sie wirklich ganz gleiche Functionen, und hat die Natur hier dasselbe Ziel auf zwei grundverschiedenen Wegen erreicht, eimmal mit einem Linsensystem nnd dem verkehrten Bilde, das anderemal mit Hunderten von Linsensystemen und einem aufrechten Bilde? Wenn ja, was bedeutet es damn, dass viele Thiere nebst den grossen Facettenaugen kleine einfache Augen haben? Wozu die kleinen, wenn die grossen gemau dieselben Functionen, nur ihrer Grösse wegen in vollkommenerer Weise erfüllen?

Ich stehe in der Beantwortung dieser Fragen noch auf dem Standpunkt, den ich schon in meiner ersten Abhandhung iiber das zusammengesetzte Alge (1875) angegeben habe; die genauere Begriindung dessellen muss nacl meinen heutigen Kemntnissen rom Facettenange freilich eine andere Gestalt annehmen, und wird dadurch wohl an Festigkeit gewimnen.

Meine Ansicht geht dahin, dass der Typus des Wirbelthierauges in vollkommenerer Weise dem Erkennen von Formen der äusseru Objecte, der Typus des Facettenauges in vollkommenerer Meise dem Erkennen von Veränderungen ${ }^{1}$ an den Objecten dient.

1 Ich habe früher gesagt „von Bewegungen der Ohjecte". Es scheint mir hereehtigt, den Begriff zu dem der Veränderumgen zn erweitern. Ls geschieht anf Grund ron Stmlien iiher die Fähigkeit des mensehlichen Auges, Bewegungen und Verïndermngen im Allgemeinen wahrunehmen. 
Ich muss bemerken, dass die Wahrmehmung von Terändermugen, insbesondere von den Bewegmgen ämsserer Objecte, in Leben der Thiere eine viel grössere Rolle spielt, als man gewölnlich anzunehmen scheint. Es steht das in Zusammenlang mit den lebendigen Feinden. vor denen sie sich zu hiiten, oder mit der lebendigen Bente, die sie zu erjagen haben. Ich habe mich zu wiederholtenmalen davon überzengt, dass Rehe oder Hasen den Menschen an seiner Gestalt nicht erkemnen; wemn er sich vollkommen ruhig verhält, so kommt es vor, dass er ihnen als etwas Absunderliches anffällt, dass sie iln lange und anfmerksam betracliten, dass sie aber ganz nahe kommen, und sich schlliesslich vollkommen über den fremden Gegenstand beruhigen. Sellostverständlich würde das lieh in liöchsten Grade erschrecken, wenn es so unter den Wind käme, dass es Gernch vom Menschen empfinge - nebenbei bemerkt - ein Zeichen, un wie viel sicherer diese Thiere nach dem Geruchsinn, als nach dem Gesichtssimme, wenigstens bei ruhenden Objecten urtheilen. Wer je eine Katze genan beobachtet hat, weiss, wie sehr die leiseste Bewegung in ilnem Gesiclıfsfeld sie aufzuregen, oder doclı iln'e Aufmerksankeit zu wecken vermag, während sie für ruhende Objecte verlällnissmässig stumpfsimnig ist. Eine Natter sieht den Frosch in ihrem Kä̈lig nicht, so lange er ruhig ist, beim ersten Sprung, den er macht, ist er geselen und erhaselit. Aehnliches beobachtet man bei Fröschen, wenn sie Fliegen fangen, oder bei Fischen. Der Angelfischer weiss, dass sich seine künstliche Mü̈ke an der Wasseroberfläche bewegen muss, soll die. Forelle nach ihn schnappen. Solche Beispiele liessen sich ron Wirbelthieren in grosser Menge anfïhren; noch viel mehr aber ist das für die Insectenwelt der Fall. Ich branche nur daran zu erimner'n, wie man einen Schmetterling oder eine Libelle fängt. Alles kommt anf die Behutsamkeit der Annäherung an, jede rasche Bewegung schreckt das 'Thier auf, bei linlänglich langsamer Bewegung aber kann man sich oft nähern, bis man es greifen kann. Die Gestalt des sich bewegenden Objectes scheint dabei ziemlich gleichgiltig, es fliegt auf, ob ein Togel vorbeifliegt, ein Schmetterlingnetz ilnm unvorsichtig genähnt wird, ein Mensch oder ein Hund rorbeigeht n s. w. Das Insect kemnt seine Feinde nicht mach Fonmen, sondern nur nach Bewegungen, die Fliege setzt sich ungeschent auf jeden ausgestopften Vogel, und der' ganze Schwarm ron Fliegen steigt in die Luft, wemn im Zimmer ein Sacktnch geschwungen wird. Andererseits erkennt die Libelle anch ihre Beute lauptsächlich an Bewegungen, denn sie stürt sich anf ein in die Luft geworfenes Papierkïgelchen, sowie sie es bei einem fliegenden lusect thut.

Dieses Alles sollte nur die Anfmerksamkeit anf die Bedentung lenken, welche die walıgenommene Bewegung im Simesleben der Thiere hat.

Nun war ich, ehe ich nich mit den Facettenangen zu beschäftigen begann, anf Grund physiologisch-optischer Studien zu der Anschaung gelangt, dass die Walunehmung von Bewegungen mit dem Ange anf einer minitiven Empfindung berube, einer so prinitiven Enpfindung etwa, wie 
die Emptindung lioth oder Hell in Gegensatze za einer anderen Firloe oler zu 1)nkel ist. Ws ist hier nicht der Ort ant diesen Gegunstand näher einzugehen, ich will nu erwähnen, dass diese Empfindung der Bewegrung ebenso eine obere und untere lntensitätsgrenze hat, wie die Empfindung der Farbe, dass sie wie diese ein negatives Nachbild hinterlässt, welches sich wie bei dieser auf die gereizte Netzhantstelle beschränkt u. s. w.

Fïr uns von Wichtigkeit ist nun der Unstand, dass die Empfindlicllkeit fiir die Bewegungen an den verschiedenen Stellen der menschlichen Netzhant durchaus nicht gleichen Schritt hält mit der Localisationsfäligkeit derselben. Jiese ist in Centrum am grössten und nimmt nach der Peripherie hin rasch ab. Die Bewegungsemptindlichkeit aber nimmt so viel weniger rasch ab, dass man geneigt ist zu sagen, die Function der Netzhautperipherie besteht in erster Linie in der Wahrnehmumg vou Bewegungen, oder, wie ich mich später ïberzengt habe, in der Walı'nehmung von Veränderungen iiberhaupt. ${ }^{1}$ In der That lehrt die tägliche Erfahrung, dass wir ruhende Objecte nie bemerken, wenn sie nicht recht nahe dem Blickpunkt liegen, dass aber die leiseste Veränderung an der. P'eripherie des Sehfeldes, ein vorbeitliegender Vogel, die Bewegung eines \%weiges, das Herabgleiten eimes Kleidungsstïckes von einem seitlich stehenden Stuhl, den wir vorher gar nicht benerkt hatten, u. dgl. n. msere Aufmerksamkeit sofort rege macht und uns fast reflectorisch nöthigt, den Blick dahin zu wenden. v. Fleischl hat eine sinnreiche Hypothese iiber die Structurverhältnisse der menschlichen Netzhaut aufgestellt, weluhe, anknüpfend an meine Anschamungen iiber die Functionsweise des Iusectenalıes, diese relative Ueberempfindlichkeit für Bewegungen bei Unterempfindlichkeit für räumliche Auffassung zu erklären vermag.

Ich bin nämlich der Anschaumug, dass das Facettenauge ïlnlich functionirt wie die Netzlautperipherie des Mensclien, dass also das Hauptgewiclıt der Wahrnehmung von Teränderungen zufällt, die Wahrnehmung der Formen erst in zweiter Linie in Betracht kommt. liervor:

Warum ich diese Ansicht hege, geht aus folgender Betrachtung

IVie eben besprochen wurde, wird durch das Superpositionsbild eines hellen Punktes, auch wemn das optische Bild so vollkommen als möglich wäre, nicht nur ein Sehstab in Erregung versetzt, sondern eine ganze Gruppe derselben. Es entsteht eben ein kleiner Empfindungszerstreungskreis. In diesem Zerstreungskreis aber ist der Grad der Erregung nicht gleichnässig vertheilt, sondern das Maximum der Erregung trifft den im Centrum gelegenen Selıstab; um diesen herum liegt eine Zone Sehstiibe, deren Erregung geringer ist, nm diese Zone eine zweite, deren Erregung noch geringer ist u. s. w.; kurz es ist ein Zerstremungsieis rorhanden,

1 Wenn man z. B. eine Gruppe dunkler Punkte aul hellem Grunde so weit an die Peripherie des Sehfeldes schiebt, diss man sie anch nicht mehr anuähernd zihlen kann, so hemerkt man es doch sofort, wenn einer von ihnen versehwindet oder ein never auftancht. 
innerhalb dessen die Erregung nicht gleichmässig vertheilt ist, sondern rom Centrum nach anssen continnirlich bis auf Null absinkt. Jenken wir mns jetzt den lenchtenden Punkt nur um so weniges verschoben, dass sein Bild sich auf der Netzhant nur um den Durchmesser eines Sehstabes verschiebt. Es muss sich dann der Erregungsgrad aller dem Zerstreungskreis angehöriger Selıstäle geändert lıaben. Es leuchtet ein, dass diese Erregungsänderung in einer grossen Anzahl ron Tervenendigungen in hohem Grade geeignet ist, die Aufmerksamkeit auf sich zu lenken, d. l. ein Benerken der stattgehabten Bewegung sowie ihrer Richtung zu veranlassen, ebenso dass jede Veränderung, also das plötzliche Auftreten eines vorher unsichthar gerresenen Objectes (es ist ein solches ohne sehr merkbare Bewegung möglich), älmlich starke Simesreizung veranlassen muss.

Der Zerstreungskeis eines correct gebauten Wirbelthieranges würde nicht in gleicher Weise wirken, weil er durchaus von gleicher Helligkeit ist. Es treten im selben Falle dann Veränderungen im Erregungszustande nur in der relativ geringen Anzahl vou Netzhantelementen ein, welche die Peripherie des Zerstreumgskreises bilden. Die beiden 'T'ypen der Zerstremugskreise verhalten sich also recht versehieden und die physiologische Wirkung gleicher Verschiehmugen gleich grosser Zerstreumgskreise diirfte sich verhalten wie die Peripherie zum Fliicheninhalt. Es ist also der Zerstreunngskreis des Facettenauges in dieser Beziehmug selı bedentend in Vortheil. Eine Vergleichung der Bewegungsempfindlichkeit beider Augentypen muss natürlich auf der Voranssetzung basiren, dass in beiden Fällen die Netzhant gleich empfindlich für Helligkeitsditterenzen ist. Auf dieser Toraussetzung beruht natïrlich jede Schätzung der Leistungen eines Auges nach seinem dioptrischen Verhalten.

Es ist aber nicht wahrscheinlich, dass nur die mit Superpositonsbildern begabten Augen einen derartigen physiologischen Zerstreumgskreis haben. Er ist wohl anch beim Appositionsbild rorhanden.

Mau erimnere sich, dass bei diesen Augen in der Nähe der Spitze des Krystallkegels ein Bild ron einem kleinen Stiick Sehfeld entstelıt (vgl. Holzschnitt Fig. 9. Seite $25 \mathrm{ab}$ ), welches von der da liegenden Retinula aufgenommen wird. Es wird nicht als Bild percipirt, sonderu liefert einen einheitlichen Eindruck, da ja die Retinnla einem Sehelement entspricht. Nun ist die Aussenfläche der Retimula, wie die Mantelfäche des Kegels ron Pigment umgeben. Ein wie grosser Theil des Bildes ab anf die Retinula fällt, hängt von der Lage dieser und des einhiillenden Pigmentes ab. Es wäre sehr unzweckmässig und deshalb nicht wahrscheinlich, dass der percipirte Antheil des Bildes kleiner wäre, als es dem zugehörigen Bruch. theil des Selıfeldes entspriclıt. Wäre er nämlich kleiner, so würde das Thier nicht Eindrïcke von allen Objecten des sehfeldes erhalten, sondern

1 leh sage: eines correct gebanten Anges, denn thatsïchlich kommen Helligkeitsdifferenzen vor, die aber moregelmässig sind, und deshalb nicht wie die des oben geschilderten 7erstrenungskieises in Facettenauge der geschilderten Funetion dienen können. 


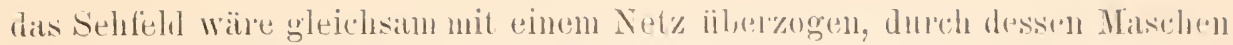

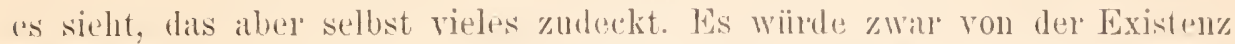
dieses Netzes so wenig eine Empfindung haben, wic wir von der Existen\% unseres blinden Fleckes, doch erlitte es rine bedentende Schädigung seines Sehens. Man wird also wohl voraussetzen, dass die percipirten Antheile des bildes ab so gross sind, dass sich die correspondirenden Anthoile des Sehteldes mindestens beriihren. Nin aber brancht man nur anzunchnen, dass diese Antheile norh etwas grösser sind, so hat anch dieses Angu Zerstremnglireise, welche sich ebenso verhalten wie die des Auges mit Superpositionsbild. Denn es gelangt dann zu der Retinula cines Ficettengliedes nicht nur das Licht, welches von den ilm dumeh Projection zugehörigen 'Theile des Sehfeldes ausgeht, soudern anch noch solehes aus den Nachbartheilen des Sehfeldes, aber in geringerer Mengr, und zwa in um so geringerer Menge, je weiter dieser Nachbartheil von dem in der Axe des Facettengliedes gelegenen entfernt ist.

Aus den oben geschilderten Beobachtungen an aligekapnten Augen mit Appositionsbild geht hervor, dass man diese Tolanssetzung aber gar nicht brancht und dass es keine Hypothese, sondern Thatsache ist, dass an der Spitze einer gauzen, wenn auch kleinen Gruppe ron Kegeln die. verkehrten Bildchen desselben leuchtenden objectes geselıen werden; und die anatomischen Terhältnisse der Retinula lassen es kitum möglin elscheinen, dass auf jede mur das Licht des geometrisch zugehörigen Antheiles des Selıfeldes gelangt. Es ist also nur - vielleicht übelgrosse Torsicht, wenn ich mich iiber das Torhandensein des nach der Peripherie an Intensität abnehmenden Zerstreungskreises mit so geringer Entschiedenheit ausspreche. Wenn sich die Beobachtung Leydig's und 'Thompson Lowne's bestätigt, mach welcher das Pigmentlumen zwischen Krystallkegel und Retinula seinen Durchmesser im Leben zu ändern vermag, an welche Möglichkeit freilich nur fïr gewisse Thiere gedacht werdell kann, so haben wil auch hier, wie bei den Augen mit Superpositionsbild, ein Mittel vor uns, nicht nur die Helligkeit des Netzhantbildes, sondern auch die Grösse des Zerstreumngskeises, somit die Schärfe des Bildes zu variiren.

Dass ich beim Sehen der Insecten ein grösseres Gewicht anf das Erkemnen ron Veränderungen lege, geschieht, weil ich darin die wesentlichste functionelle Differenz rom Sehen mit dem rerkehrten Netzluatbild erblicke; ich bin aber weit daron entfernt, das Erkennen ron Formen zu nntel'schätzen, ${ }^{1}$ wie man wohl geglaubt zu haben schunt. Die schönen V'lsuche ron Plateau haben hinlänglich festgestelit, dass die Insecten Objecte und deren Lage sehen, und die Schärfe, mit der das geschieht, stimmt recht gut mit der iiberein, die ich seit Langem relmuthet und anch angedentet habe.

1 Vgl. das ohen hei Bespreehung des Anges vou Synilla Mitgetheilte. Ks schrint mir übrigens selbstrerständlich, dass bei rerschiedenen Thierarten das Verbältniss der Follkommenheit des Form- und Bewegnnassehens hedentenden Variationen unterworfen ist. 
Man lnamcht nu einen schmetterling zn beobachten, wie er von Blune zn Blume fliegt, un sich zu ïberzengen, dass er diese aus mässiger Entfermug sieht, nnd man braucht andererseits nu' zu sehen, dass er sich nicht zu selten von Objecten älnlicher Gestalt mnd Farbe tänschen lässt, diese Täuschung aber erst bemerkt, wenn er fast bis zur Beriihlung nahe gekommen ist, un die Ueberzengung zn gewimnen, es sei dieses Sehen etwa von jener Vollkommenheit, deren Giössenorduung durch das Netzlautbild ron Isampyris gegeben ist.

Anch dass die Thiere Farbenempfindung haben, kamn man so ohne weiters beobachten, hanptsächlich an der Art, wie sie sich täuschen lassen; doch ist das durch die exacten Versuche Lubbock's längst bekannt, nnd die ganze bunte Welt der Schmetterlinge und blumen legt Kengniss davon ab.

d) Accommodation.

Dass es in zusammengesetzten Ange eine Accommodation gebe, ist mir sehr unwah'scheinlich. Erstens ist dieselbe beim lppositionsbild überflïssig, denn es kommt eine geringe Verschiebung des an der spitze des Krystalliegels entworfenen Bildes physiologisch kam in Betracht. Zweitens findet man weder in den Angen mit Appositionslibl, noch bej jenen mit Superpositionsbild ilgend eine Eimrichtung, welche als Accommodationsmechanismus gedentet werden kömnte. Bei den Angen letzterer Art rïckt das Bild bei Annäherung des Objectes nach vorne, im Gegensatze zu den Wirhelthierangen. Ieln mass diese Terschiebung in einem Falle bei Jamuyris. sie betrug 0.092 Millimeter, wenn der Gegenstand ans der Entfernung von 810 Millimeter in die von 1.2 Millimeter gebracht wude. Un den Gegenstand so nahe zu bringen, benntzte ich den Kinnstgriff, von demselben durch den Abbéschen Beleuchtungsapparat ein Rild zu entwerfen. Dieses fungirte als abzubildender Gegenstand. Die Nessungen sind ans nalıeliegenden Gründen mu approximativ, doch zeigen sie zur Genüge die Grössenordnung der Verschiebung, um die es sich bei diesem Ange handelt. Man wird wohl kanm zweifeln, dass das herumfliegende Lampyrismännchen mit dem Ange das im Grase sitzende lenchtende Weibchen sucht, dass es also diesen lichtpunkt mit nähelungsweise anf Unendlich eingestelltem Ange sieht; ob es aber noch dentliche Bilder von 1.2 Millimeter entfernten Objecten zn bekommen nüthig hat, mag wohl fraglich elscheinen.

Wäle ein Accommodatiousapparat da, so mïsste er bein Fixilen naher Objecte eine Annäluerung des dioptrischen Apluarlates und der Netzlaut elzielen. Doch ist nichts ron eiuem solchen zu finden. Es ist anch seh" leicht begreiflich, dass ein Accommodationsalpanat diesen Angen fehlt. Denn die grosse Dicke der Netzlant vermag ihn vollständig zn ersctzen. Wenn das Bild anch etwas nach vorne oder nach rïckwärts riuckt, es liann dabei immer noch in Inneren der Netzhant verbleiben. Beim Wirbelthierauge ist es unter gleicher. Verschiebung les Objectes längst schon vor oder hinter die Netzhant gewandert. 
Noch ein anderer lTustand kommt in Betracht. We betrilit anch das Wirbelthierange. Ie kleiner die Jimensionen des Auges werden, desto entbehrlicher wird die Accommodation, unter der im Grossen und Ganzen zutreftenden Voraussetzung, dass die empfindliche Sulichte der Netzhaut eine absolnt gleichbleibende Dicke hat. Die Grösse der Verschiebung des Netzhautbildes ist, gleichen Bau der Augen vorausgesetzt, proportional den linearen Dimcnsionen des Anges.' Fiir diese gibt die hintere Brennweite ein Mass ab. Nieselbe ist z. B. beim Elephanten vielmals grösser als bei der. Mans; und da die beiden empfindlichen Netzhantschichten, sowie die Netzhautelemente nu' gering'e Grössenunterschiede zeigen (beim Frosche sind sie sogar viel grösser als beim Elephanten), so ist die Accommodation bei der Maus viel entbehricher als bei den grossen Säugethielen. Hier ist freilich unter entbehrlicher nu verstanden, dass das 'Thier in einer Entfernung noch scharfe Bilder bekommt, für welehe der Elephant schon stark accommodiren muss. Dabei könnte allerdings für die Maus die Beobachtung wenige Millimeter entfernter Objecte noch Bedeutung haben, die für den Eleplanten bedentungslos ist.

Ganz ähnlich aber verhält es sich auch bei den Insecten und Krebsen mit Superpositionsbild, deren Augen durbans nu die Grösse von denen kleiner Sämgethiere lıaben.

\section{e) Das Sellen in der Tiefendimension.}

Dass Insecten und Krelse nahe von fernen Gegenständen interscheiden, wird wohl nicht zu bezweifeln sein; es lassen sich, besouders an Insecten, leicht Versuche anstellen, die zeigen, dass sie sich vor einem nahen Gegenstand melı fürchten, als vor einem formen, auch wenn scheinbare Grösse und Winkelgeschwindigkeit dem letzteren giinstig sind.

Wir Menschen und offenbar alle Wirbelthiere erkennen Entfernungen hauptsächlich auf Grund der Verschiedenheit, welche die beiden Netzhantbilder desselben Gegenstandes in den beiden Angen zeigen, und anf rrund der Convergenzanstrengung, die wir bein binounlaren Fixiren eines regenstandes anfwenden müssen. Letzterer Punkt kommt bei sehr vielen Thierm, welche mit Facettenaugen sehen, sicher nicht in Betracht, denn ihre Aigen sind unleweglich am Kopfe befestigt. loie Angen anderer allerdings sind beweglich (viele Krebse), doch sind ihre Bewegmaen so nuablängig roneinander, dass es schwer ist, zu glauben, ein Mpclunismus binocularel Fixation spiele in inlem Sehen eine grosse Rolle. Auch ist vielfach die Stellung der Angen am Kopfe eine solche, dass dieser Gedanke zuriickgedrängt wird.

Doch ist kein Grund anzunelmen, dass das erste Moment bei Facettenaugen niclıt dieselbe Rolle spiele, wie bei Wirbelthierangen. Auch hier ist,

1 Denn die Entfernung des Bildos vom zweiten lirenupmulst $f_{2}-F_{2}=1$ ergibt, da $f_{2}=\frac{F_{2} f_{1}}{f_{1}-F_{1}}$ ist, $D=\frac{F_{1} F_{2}}{f_{1}-F_{1}}$ 
z. B. bei Libellen, ein grosses genteinsames Gesichtsfeld, muveifellaft viel grösser als das des Menschen, denn es erstreckt sich nicht nur nach vorne, sondern auch nach oben, hinten und unten. Auch hier müssen die Bilder beider Augen verschieden sein, und die beiden Netzhautstellen, welche von dem Bilde desselben Objectpunktes getroffen werden, bestimmen eindentig die Entfernung und Lage des Objectpunktes bei gegebener Stellung des Kopfes.

Die binoculare Tiefenschätzung des Wirbelthieres ist eine nm so genauere, je grösser die Distanz der beiden Angen voneinander ist, wie dies jüngst Berlin ${ }^{1}$ alsgeführt hat. Diese Distanz ist bei Insecten allerdings lecht gering, obwohl sie so gross zu sein pflegt, als es die Dimensionen des Kopfes nu immer zulassen. Daraus geht aber nicht hervor, dass diese 'Thiere mit dieser Art der 'Tiefenwahrnehmung nicht auskommen, sondern nur dass sie bei gleichel und ziemlich grosser Entfernung der Objecte unvollkommener ist. Bei geringer Entfernung aber kann das Princip der 'Tiefenwahrnehmung genall so fungiren wie bei den Wirbelthieren. Und wenn ein solches in wenigen Centimetern ron seinen Augen schon gar keine branchbare T'iefenwalnuehmung mehr hat, schon

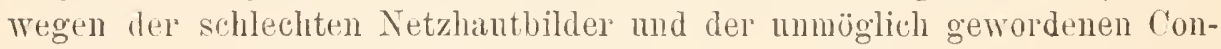
vergenz, so wird eine Libelle vielleicht gerade in dieser Entfernung die schärfste 'T'iefenwahrnehmung' besitzen, und diese kann ilı' vortheilhafter' sein, als eine genane Suhätzmng grosser Entfernungen.

Es ist sehr wohl möglich, dass manche Insecten, wie dies Platean beobachtet hat, leshalb erst kurz vor einem Hinderniss iluen Weg änder'u (Platta) und answeichen, weil sie das Object zwar vorher gesehen, seine Entfernung und damit seinen Charakter als Hinderniss aber erst erkannt haben, als sie nahe genug waren, um einen branchbaren binocnlaren Tiefeneindruck ron ilnm zu bekonmen. Wenn viele Insecten an ein Papierblatt erst anstossen mussten, um auszuweichen, so kann das auch darin seinen Grund haben, dass die Thefenwahnehmung (anch hein Wirbelthiere) nu' dann möglich ist, wenn hetails in Objerte geselen werden. Ein Blatt Papier könnte also nur anf Grund der Wahrnelmung seiner Begrenzungshinien in die richtige Entfernung verlegt werden, wenn es selbst vollkommen gleichmässig gefärbt wäre.

Wie gesagt, ist es bei der Unabhängigkeit voneinander, mit der sich die Angenstiele vieler Krebse bewegen, schwer, bei diesen Thieren an einen binocularen Sehact der geschilderten Art zu denken. Doch drängt sich bei der Betrachtung eines solchen Krebses mit seinen lebhaften Augenbewegungen eine andere Vorstellung auf. Jedelnann weiss, dass es eine für das schwierige Erkennen und Enträthseln eines Gesichtsobjectes charakteristisclıe Bewegung ist, wenn Jemand mit vorgestreckten Hals und fixirtem

1 Ueber die Sehïtzung der Entfernungen bei Thieren (Festschrift zur Feier des XXV. Regierungsjubiläums sr. Mijestiit des Konigs Karl ron Württenherg), Stuttgart 1889. 
Blicke den Kopf nach rechts mol links hin mol her bewegt. Anch Thiere mathen es bisweilen so. Lis handelt sich darum, das Object ron etwas verschiedenen Richtumgen aus zu betrachten. Die nacheinander erhaltenen Bilder gewähren dann nicht nur eine correctere Anscluaung der f'ornen, sonder'n vor Allem anch der Entfernungen der verschiedenen 'l'heile. v. Helmholtz füht einen sehr treffenden Fall all, ${ }^{1}$ in dem man sich von der Wirkmng dieser Succession von Bildern über"zengen kamn: Wemn man den binocularen Sehant beseitigt, indem man ein Ange schliesst, mo blickt dann bei ruhig gehaltenem hopfe in die Zweige eines Bammes oder in das Astwerk eines Gebüsches, so sieht man nur ein wïstes Gewirre von Zweigen und Blättern, in dem man sich nicht zurechtfindet und vor Allem kein Urtheil ïber die Entfernung und gegenseitige Beziehmng der einzelnen Aeste zu einander gewinnt. Sowie man aber nun den liopf etwas nach rechts und links bewegt, so geht das ganze Gewire in räumlicher Klarheit auseimander, es scheiden sich Aeste und Wipfeln, kurz es stellt sich ein plastisches Bild des Ganzen dar. Es beruht das natiirlich darauf, dass das Netzhantbild eines nahegelegenen Gegenstandes sich während der Koptbewegung rascher auf der Netzhant verschiebt, als das eines fernen, nnd dass der nahe Gegenstand eben dadurch als solcher erkannt wird.

Ich halte es nun für möglich und wahrscheinlich, dass Krebse, deren Angenstiele keine coordinirten Bewegungen machen, sich aber, fast wie in gewohntem Spiele, hin und her zn bewegen pflegen, nach diesem Principe Wahrnehmungen der Tiefendimension gewinnell. Es ist dieses freilich eine Hypothese, die leider nicht leicht wird verificirt werden künnen, deren Priifung aber doch nicht ganz ansgeschlossen erscheint. Sie findet ihre Stuitze auch darin, dass diese fast continuirlichen Augenbewegungen keinen anderen einsehbaren Grund haben.

1 Physiologische Mptik. 1. Auflage, S. 655. 


\section{CAPITEL.}

\section{Einige Bemerkungen über die Phylogenese des facettirten Auges vom functionellen Standpunkte betrachtet.}

Grenacher lat neuerdings die genetische Terwandtschaft der beiden Augentypen einer Discussion unterzogen, des zusammengesetzten und des einfachen, nach dem Typus des Wirbelthieranges gebauten Stemmas.

In der That, man findet bei verwandten Thieren, ja an einem und demselben Kopfe nebeneinander die zwei Augenformen, das eine Auge sieht mit verkehrtem, das andere mit aufrechtem Netzhantbilde. Wo ist da das Bindeglied, nach dem wir doch stets zu suchen pflegen, wie kamn iiberhaupt ein Bindeglied zwischen einem aufrechten und einem verkehrten Bilde, zwischen dem Pilde einer Camera obscula und dem Superpositionsbilde. rieler astronomischer Fermrohre aufzufinden sein?

Ich will zum Schlusse hieriiber noch ein Paar Worte vom optischen Standpunkte sagen, umsomehr, als mich meine Betrachtungen zu wesentlich demselben Resultate geführt haben, das Grenacher auf Grund seiner morphologischen Untersuchungen gefunden hat.

Eine warzenartige Verdickung der Cuticula mit einer oder einigen darunterliegenden Simneszellen, die im Stande sind, Aetherbewegungen als solche oder vielleicht nach ihrer durch ein schwarzes P'igment bewirkten Umwandlung in Wärmebewegung, zu Nervenerregung umzusetzen, kann wohl in den rohesten Zïgen als Urauge betrachtet werden. Solche Uraugen sehen wir auch noch heute bei niederen 'Thieren. Sie sind hei gegebener Stellung des Thieres im Stande, Fell und Dunkel, sowie die Richtung zu muterscheiden. Fin im Wassel' schwimmendes 'Thier wird dureh dasselbe erkennen könmen, mach welcher Richtung die leuchtende Oberfläche liegt.

Nun sind zwei Arten der Verrollkommnung dieses einfachsten Sehapparates möglich. Erstens die Verdickung der Cuticula (auch die Linse des Menschen entwickelt sich noch aus dem äusseren Keimblatt) nimmt immer mehr die Gestalt einer optischen Linse an, und die Sinneszellen nähern sich der Bremweite derselben. Schon bei der einfachsten warzenartigen Verdickung wird im Allgemeinen die in der Axe derselben gelegene 
Sinneszelle, dann die intensivste Erregung elleiden, wenn diese Axe der Sonne zugekehrt war; es wäre also da schon ein Beginn der Localisirnng vorhanden, wenn mehrere Simeszellen im Urauge angenommen werden. Denken wir uns diese Zellen allmïhlich an Kahl zunehmen und gegen die Brennweite der Linse rïcken, so wird, da der ron der Sonne stammende Lichtkegel in immer intensiveren Partien von den Simneszellen aufgefangen wird, die Localisirungsfähigkeit stetig zunehmen, und wir gelangen so ohne Sprung - und daranf kommt es hier ja ausschliesslich an - bei ebenso stetig zunehmendem Werthe des Organes für' seinen 'Träger zu den einfachen, aber hoch entwickelten Augen der Spiunen u. dgl., sowie der Wirbelthiere. Die Simneszellen breiten sich in grosser Anzahl in der Bremnebene der brechenden Medien, also in einer nach vorne concaven Fläche aus und empfangen das verkehrte Bild.

Zweitens kann sich das Urauge durch Multiplication vervollkommnen und so zum zusammengesetzten Auge werden. Das Thier, das ein Urauge besitzt, bekommt in einem gegebenen Momente nur Nachricht darïber, ob in der Richtung, welche der Axe und deren Ungebung entspricht, helle Objecte sind; will es über eine andere Richtung Erfahrungen einziehen, so muss es den Körper wenden. Soll das Thier zu gleicher Zeit ïber melırere Richtungen orientirt werden, so müssen sich melırere Augen entwickelt haben, deren Axen divergiren. Zwei solcher Augen geben dann in ihrer vereinten Wirkung schon den ersten Anfang eines aufrechten Bildes. Je grösser die Anzahl dieser primitiven Augen geworden ist, desto vollkommenere Localisirung ist möglich. So entstehen, wieder olıne Sprung, die zahlreichen radiär angeordneten Facettenglieder des zusammengesetzten Auges, von denen jedes noch die ursprünglichen Elemente birgt. Bei der Kleinheit der Cuticularlinsen wird die Quantität des in ein Einzelange dringenden Lichtes eine geringe sein, es werden sich Structurverhältnisse ausbilden, welche diese geringe Menge Lichtes wenigstens in so vollkommenem Masse als möglich dem nervösen Elemente oder den nervösen Elementen zuführen, sei es durch die Bildung kugeliger brechender Flächen, sei es durch Schichtung von Medien ungleichen Brechungssvermögens. Wir kommen auf diesem Wege direct zu dem Auge, das wir als mit einem Appositionsbilde ausgestattet kennen gelernt haben.

Morphologisch haben wir diese Entwickelungsreihe im Vorstehenden kennen gelernt, ausgehend vom Trilobitenkrebs und durch das Auge ron Limulus zu dem der Taginsecten fortschreitend. Man sieht in dieser Reihenfolge deutlich, wie das verkehrte Bildchen des Einzelauges (beim Trilobitenkrebs) verkümmert, um dem aufrechten Bilde des Gesammtanges, das auch bei diesem Thiere schon in der Aggregation der Augen vertreten war, Platz zu machen und es zur rollkommensten Ausbildung gelangen zu lassen.

Es fragt sich nun, ob auch vom Appositionsbild zum Superpositionsbild eine phylogenetische Brïcke führt, $d$. h. ob eine continuirliche Reilıe von Zwischenglieder'n denkbar ist, deren jedes gegenüber dem vorher- 
gehenden im Kampfe ums Dasein Vortheile gewährte, und sich dadurch ansbilden konnte. Es scheint mir, dass diese continuirliche Reihe unschwer zn finden ist:

Das Facettenglied in dem mit einem Appositionsbilde begabten Auge enthält, wie wir sahen, einen Linsencylinder, näherungsweise von der Länge seiner Bremnweite. Er bewirkt, dass an seiner Spitze ein Bildchen eines engbegrenzten Antheiles des Sehfeldes entsteht, welches dadurch einen verhältnissmässig intensiven Lichtreiz hervorruft, dass die Hauptstrahlen der verschiedenen Punkte des Sehfeldes sämmtlich fast parallel mit der Kegelaxe in die Retinula eindringen. Der einem Bildpunkte angehörende Strahlenkegel zeigt dabei eine nicht unbeträchtliche Divergenz. Stellen wir uns vor, der 'Träger dieses Auges sei aus biologischen Motiven gedrängt, ein Dämmerungs- und ein Nachtthier zu werden. Dann brancht sich der Linsencylinder nur zu verlänger'n, und die Retina in entsprechendem Maasse vom dioptrischen Apparat zurïckzwweichen, um das Auge für geringeres Licht sehtïchtiger zu machen. Durch die Verlängerung, beziehungsweise Verstärkung des Linsencylinders, nämlich verringert sich die Divergenz jedes einem Bildpunkte zugehörigen Strahlenkegels, was jedenfalls für das Centrum des „Elementarselıfeldes” (s. S. 31) eine Erhöhung der Perceptionsintensität bedeutet; zugleich aber hören die Hauptstrahlen der peripherischen Punkte des Partialsehfeldes auf, parallel der optischen Axe des Facettengliedes der Retina zuzustreben; sie bilden mit dieser einen Winkel in demselben Sinne, wie sie das beim Superpositionsbilde thun. Wenn also, wie roransgesetzt, die Retina zurïckgewichen ist, so trifft jetzt ein Theil des Strahlenkegels dieser peripheren Sehfeldumkte schon das benachbarte Netzhautelement, geht also anch fiir die Perception nicht mehr verloren. Ich habe schon S. 84 und S. 91 ron solchen Angen gesprochen, welche Uebergangsformen zwischen den beiden Typen darstellen.

Auf diesem Wege kann die relative Helligkeit des Bildes zum Nutzen der betreffenden 'Thierclasse allmählich steigen, ohne dass ein Superpositionsbild in vollkommenster Weise entsteht; dieses in der Form, wie wir es oben besprochen haben, ist erst vorhanden, wenn der ursprüngliche Linsencylinder an Stärke oder Länge 1 m das Doppelte zugenommen, also die doppelte Länge seiner Brennweite hat, und die Netzhaut sehr beträchtlich zurüickgewichen ist.

Dieses Ziel also, so scheint mir aus dem Dargelegten mit Wahrscheinlichkeit hervorzugehen, kann unter continuirlicher Steigerung der Leistungsfähigkeit des Auges bei Lichtmangel erreicht werden; dabei ist $\mathrm{zu}$ bedenken, dass die Lichtverschiebung des Irispigmentes jederzeit aus dem unvollkommenen Superpositionsbild ein Appositionsbild zu machen vermag, sollte ein Ueberfluss an Licht das erheischen. 


\section{Sachregister.}

A.

Accommodation 188.

Acherontia atropos 143.

Agrion-Larve, Bau 121.

- Pseudopupillen 164.

Agrypuns moertus, Netzhautlild 77.

Appositionsbild 17, 18.75, 86 .

Argynnis latonia, Augenleuchten 154.

Ascalaphus, Zweitheilung der Augen 128.

Astacus, Augenleuchten 158.

- Ball 124.

- Jrispigment 73 .

- Retinapigment 108

- Tapetum 101.

A ugen mit doppelter Functionsweise 91 .

- mit ungleichnässigem Bau 112.

Augenleuchten 141, 153.

- der Krebse 158.

- der Nachtschmetterlinge 144.

- der Taginsecten 150.

- Verschwinden desselben 147.

Augenschema 45

\section{B.}

Bärenkrebs, s. Scyllarus.

Berechnung d. Lampyrisauges 52.

Bewegungen der Augenstiele von Krebsen 190

- ihre Wahrnehmung 182.
Bild, verkehrtes von Jampyris 39,46 .

Bilder durch Linseneylinder $2 \mathrm{u}$. folg.

Bildschärfe 37.

Bombus terrestris, Netzhaut- Cornea für Wasser und Iuft 9. bild 87 .

\section{c.}

C-album, Augenleuchten 154. C-cardui, Augenleuchten 154.

Cantharis fusea, Ball 118.

- Irispigment 67.

- Netzhautbild 77.

Cantharis rustica, Netzhautbild 77 .

Careinus maenas, Augenleuchten 159.

- Irispigment 74.

- Pseudopupillen 163, 166.

- Tapetum 102.

Catocala nupta, Augenleucliten 153.

- Bau 117.

- Irispigment 71.

- Pseudopupillen 171.

Cetonia, optiseher Bau 80.

- Irispigment 67.

- Retinapigment 103.

Chloe binoculata, Ball 131.

Cnoplria quadria, Netzhautbild 81 .

Coenonympha Pamphilus, Augenleuchten 154.

Coleas hyale,Augenleuchten154. - Irispigment 73.

Colymbetes fuscus, Bau 119. - Retinapigment 109.

- Irispigment 68.
Colymbetes fuseus, Retinapiginent 103.

Copilia 135.

Cordulegaster, Augenwölbung 113.

- der Wasser- und Luftthiere 9 .

- der Krebse 82.

Corneafacetten, Grössendifferenz 113.

Corneakrümmung, unrege!mässig 113.

Corneareflex 166.

- der Libellen 157.

- und Pseudopupille 156.

Corneaschichtung 8 .

Crangon, Bau 122.

- Tapetum 101.

\section{D.}

Dioptrik des Lampyrisauges $39,52$.

Diplex, Bau 120.

Dipteren, Augenleuchten 154.

-- Corneakrüımmung 113.

Doppelte Functionsweise der Augen 91.

Dorkadion aethiops, Netzhautbild 90 .

Dromia vulgaris, Augenleuch. ten 159.

- Tapetum 102. 
Dytiseus, Bau 119.

I.

- marginalis, Irispigment 68.

E.

Einsiedlerkrebs, s. Pagurus 73. Elater, Kegel desselben 77.

Epinephele, Augenlenchten 154.

- Bau 116.

- Pseudopupille 165.

Fristalis, Bau 121.

Etagenlupe 8, 58.

Euprepria, Augenleuchten 153, 154.

\section{F.}

Flusskrebs, s. Astacus.

Fuchs, s. Vanessa.

G.

Galathea strigosa, Augenleuchten 159.

- Augenzeichmung 166.

- Bau 126.

- Irispigment 74 .

- Retinapigment 110.

- Tapetum 102.

Gammarus 131.

Gastropacha, Irispigment 70 .

H.

Hauptstrahlen der Linsencylinder 5 .

Helligkeit, relative, des Netzhantbildes 32 .

Helligkeitsregulirung des Bildes 65 .

Herpstia, Augenleuchten 159.

Hesperia coma, Augenleuchten 154.

- Pseudopupillen 165.

Hipparchia, Augenleuchten 154

Homarns, Corneakrimmung 113.

- Augenleuchten 159.

Hornisse, s. Vespa. crabo

Hummel, Netzhautbild 87.

Hydrophilus piceus 13.

- Netzhautbild 78.

- optischer Bau 78.

- Irispigment 68.

- Retinapigment 103.
Innachus, Augenleuchten 159. lrispigment 63.

- Function 59.

- locale Lichtwirkung 149.

- locale Wirkung 66.

- Verschiebung und Wirkung 63, 160 .

Iristapetum 61, 62 .

- dunkles 117, 171.

- von Catocala 117.

- Wanderung 171.

\section{$\mathbf{K}$.}

Käfer, Corneakrümmung 113

Katroptrische Wirkung der Kegel 59.

Kegel der Krebse 82.

- optische Wirkung 83, 134.

Kegel, katoptrische Wirkung 59.

- optische Wirkung 43, 133.

- optische Wirkung der Schiefstellung 24.

- von Lampyris 44.

Kegelmantel 27.

Krebse, Corneakriimmung 113

Krystallkegel, s. Kegel.

\section{I.}

Lampyris splendidula 35 .

- Nebenbilder 173.

- Retinapigment 103.

Lampyrisauge, Dioptrik 39, 52.

Languste, s. Palinurus.

Lasioeampa quereifolia,Bau11s.

- Irispigment 70.

Leuchten der Augen 141.

Leuchtkäferchen, s. Lampyris.

Leucoma, Bau 118

- Irispigment 70.

Leucoma salicis, Netzhautbild 81 .

Libelle, Netzhautbild 89.

Libellen, ihr Sehen 115.

- Augenleuchten 154, 155.

- Corneareflex 1507.

- Pseudopupillen 164.

Libellula depressa, Differenzen im Bau 113.

Libellula vulgata, Augenleuchten 154.

- Ball 120.
Libellulinen, Differenzen im Ban 113.

- Augenwölbung 113.

Lichtschimmer im Auge 61.

Lichtwirkung auf das Irispigment 64 .

- auf das Retiuapigment 104

Limulus 18.

- Pseudopupille 167.

Linsencylinder 2. u. folg.

- von der Länge ihrer Brennweite 5 .

- von der doppelten Länge der Brennweite 7.

- im Facettenauge 7.

Locusta caudata, Augenleuchten 155.

Locusta virdissima, Augenleuchten 155.

- Ban 122.

- Pseudopupillen 178.

Lueiola italica, Netzhautbild 77.

Lyeaena, Augenteuchten 154.

- Bau 116.

Lyeaena eoridon, Angenleuchten 154.

\section{M.}

Maja verrucosa Augenleuchten 159.

- Irispigment 74.

- Ban 126.

- kein Tapetum 102.

- Retinapigment 110.

Makroglossa, Augenleuchten 153.

- Ban 118.

- Netzlıautbild 81.

- Psendopupillen 165.

- Retinapigment 103.

Melanargia, Bau 116.

Melanargia galathea, Augenleuchten 154

Müller'sche T'heorie 11.

Mnsca, Angenleuchten 154.

Musea domestica, Bau 121.

Musca vomitoria, Netzhantbild 87 .

N.

Nebenbilder 173.

Netzhaut 95. 
Netzhautbild, Grösse von Lam- Phacops feeundus 34. pyris 37.

- Lage 38.

- Sehärfe 37, 179.

- unähnlich 112, 129.

- Verzerrungen 180.

Netzhautfunetion 95 .

Nica edulis, Angenleuchten 159.

- Ban 123.

- Irispigment 72.

- Tapetuin 101.

- Retinapigment 108.

\section{0.}

Ocneria rubea, Netzhautbild 81.

Ordensband, rothes, s. Catocala.

Oryetes rhinocerus 81 .

- Bau 120.

\section{P.}

Pagurus, Augenleuchten 158.

- Bar 125.

- Irispigment 73.

- Pseudopupillen 166.

- Retinapigment 110.

- Kein Tapetum 102.

Palaemon, Augenleushten 158.

- Augenzeichnung 166.

- Bau 122.

- Corneakrümmung 13.

- Irispigment 72.

- Retinapigment 104.

- Tapetum 101.

Palinurus, Augenleuehten 159

- Bau 124.

- Corneakrümmung 113.

- Irispigment 72.

- Retinapigment 107.

- Tapetum 101.

Pararge megarea, Augenleuchten 154 .

Peneus membranaceus, kein Augenleuchten 159.

- Augenzeichnung 166.

- Ball 124.

- Irispigment 73.

- Tapetum 101, 109.
Photomeehanische Wirkung an Irispigment 63.

Plironima, Ban 130.

Phylogenese der Augen 192.

Pieris rapae, Augenlenehten $151,154$.

- Bau 116.

- Nebenpupillen 172.

- Psendopupillen 164, 165.

Pisa, Retinapigment ('Tapetum) 110.

- Augenlenchten 159.

- Bau 126.

- Irispigment 74.

Plusia gama, Augenleuchten 154.

Polias, Augenlenchten 154.

Polyommatus phlaeas, Augenleuebten 154.

Portunus, Kein Augenleuchten 159.

- Bau 126.

- Jrispigment 74.

- kein Tapetum 102.

- Retinapigment 110.

Porthesia, Bau 118.

- Irispigment 70.

- Netzhautbild 81.

Pseudopupillen 18, 162.

- Erklärung 166.

- ihre Form 163.

- quadratische 163, 166.

Pseudopupille und Corneareflex 156.

Psophus stridulus, Augenabtheilungen 114.

- Pseudopupilien 165.

R.

Reflexion im Auge 61.

Retina der Dekapoden 85.

- beim Superpositionsbild ". Appositionsbild 75

Retinapigment 102.

- Lichtwirkung 104.

- Versehiebung 104.

Retinatapetum 97.

Retinula, s. Rhabdom.

Rhabdom, optische Wirkung 31 .

- Funetion 96.

- Retinapigment 105.
Rhagonyeha melanura, Kegel und Netzhautbild 77.

Rosenkiifer, s. Cetonia.

Rübenweissling, s. Pieris rapae.

\section{s.}

Schärfe des Netzhautbildes 37, 179.

Sehema des Insectenauges 45.

Schiefstellung der Kegel 24, $90,121$.

Schimmer im Auge 166.

Scyllarus aretus, Mugenleuchteu 159.

- Ban 123.

- Irispigment 73.

- Retinapigment 108.

- kein Tapetum 101.

Sehen von Bewegungen 182.

- in der Tiefendimension 189.

Sehen, Theorie des, s. Theorie des Sehens.

Sehstäbe 91 .

Sieyonia seulpta 107.

- Augenleuchten 159.

- Irispigment 72.

- Retinapigment 123.

- Tapetum 101.

Sirex gigas, Bau 122.

Sphinx eonvolvuli, Augenleuchten 149.

- Netzhautbild S1.

Spillosoma, Irispigment 70 .

Squilla mantis, kein Iugen lenchten 159.

- Ban 127.

- optiseher Bau 112, 128.

- Irispigment 74.

- Netzhautbild 112.

- Verzerrung des Netzhautbildes 112, 129.

- Retinapigment 111

- kein Tapetum 102.

Stereoskopisches Sehen 189

- bei Krebsen 190.

Stubenfliege, s. Musea domestica.

Superpositionsbild $35,75,84$.

T.

Tapetum 67.

- körnig 100. 
Tapetum im Ganglion opticum Trichodes apiarius, Cornea- Verkehrtes Bild im Insecten101. kegel 119. auge 46 .

- der Krebse 100.

- der Retina 97.

- aus Tracheen 98.

'T'rilobitenkrebse 33.

T'ropinota hirtella, Irispigment 67.

Taubenschwanz, s Makroglossa. - Bau 119.

Telephorus, Irispigment 67.

Tenthredo instabilis, Ban 122.

'Theorie des Sehens, von J. Müller 11, von Grïiel und Gottsche 11, von Max Schultze 12, von Grenachel 12, von 0 . Sehmidt 14, von Notthaft 15, von Thompson-l lowne 16 Tracheen im Auge 99.

U.

Uebergangsformen des Auges 85.

\section{v.}

Vanessa, Ball 116

- Psendopupillen 165.
Verzerrungen des Netzliautbildes 180.

Vespa erabo, Ball 121.

- Hornhaut und Kegel 90.

- Schiefstellung der Kegel 121.

$\mathbf{w}$.

Wasser- und Luftaugen 9.

W'iesenbläuling, s. Lyeaena.

$\mathbf{Z}$.

Zertreuungskreis 182.

- als Tapetum 98.

154. 


\section{Erklärung der Tafeln.}

\section{Tafel I.}

Fig. 1. Meridionaler Durchschnitt durch den seitlichen Antheil des Auges von Lampyris splendidula. Alkoholhärtung; Einbettung in Celloidin; Färlung mit Satfranin, Vergrössorung der Zeichmug (auf diese, nicht auf die Mikroskopvergrösserung, bei welcher grezeichet wurde, sind die Augahen ïber Vergrisserung in Folgenden zu bezichen): 120. c. Corneafacetten.

I. P. Irispigment in llunkelstelhung, ans welchen nach rïckwärts lieransragen:

$\boldsymbol{K}$. die Spitzen der Krystallkegel. Die hier nicht sichthare Gestalt eines Krystallkegcełs und einer Homhantficette ist im Holzschnitt S. 41 wiedergegeben.

G. Glaskörperram der Autoren, hier mit durehsichtigen spindelförmigen, radiär gestellten Zellen erfïllt.

\section{$R$. Retina.}

$R P$. Retinapigment.

m. f. Hembrana fenestrata, an welche von hinten die Nervenbündel herantroten, welche anls dem

G. o. Ganglion opticum kommen.

Fig. 2 bis 5 zeigt die optischen (querschnitte der ans den Krystallkegeln des Lamugris- Anges anstretenden dünnen strahlenbünlel (beziehnngsweise ilıer Verlängerungen), wie man sie bei schwacher Vergriisserung sieht, wem als Object ein heller Punlit in Verwendung steht und das Mikroskop snecessive anf versehiedene Ehenen eingestellt wirl. Der Vurlanf der Strahlen, sowie die vier Ebenen, bei deren Einstellnng die vier in Rerdr stehenden Bilder geselien werden, sim in Holzselnitt, Fig. 11, S. to des Textes, gezeichnet. Fig. 2, 3, 4, 5 entsprechen der Einstellumgsebene $A A_{1}, C C_{1}, D D_{1}, E E_{1}$. Fig. : zeigt die strahlen (richtiger ihre Verlängerungen), wenn man ant eine im Innevin der Krystallkegel oder norh vor denselben gelegene Ebene eingestollt hat. Riickt man mit der Focalebene von da ans gegen die Netzhaut, so nähern sich die einzelnen strahlenhündel und gewähren etwa in der Ehene, welche die spitzen der Kegel tangirt $\left(C C_{1}\right)$, das libl der Fig. 3. Ist das Auge frisch dem Thiere entnommen (die Figuren 22 bis 5 sind nach einem in Alkohol conservirten Ange gezeichnet), so sind die durch lieflexe 11 , dgh. hedingten IJöfe weniger ansgeprägt. Rï̈ckt man die Foealehene noch writer nach rïckwärts $\left(D D_{1}\right)$, so nälem sich die strahlenbïnlel, bis sio an de Ehene der Netzhant zu dem bilde des punktförmigen ohjectes den kleinen hellen Fleck der Fig. 4 rerschmelzen. Noch weiter nach hinten $\left(E E_{1}\right)$ gehen sie in den Zerstremugskreis. Fig. i, anseinander, der zierliche Iniffractionserscheinmenen zeigrt. 
Fig. fo und 7. Jiystallkegrel nut vorderer Antheil des Sehstalues von Dyticus marginalis. Die Umisse sind mit dem Zeichenprisma anfgenommen. Vergrössemug 5ó. Fig. 6 zeigt das Irispigment in der Lichtstellung, Fig. 7 dasselbe in der 1)unkelstellung.

Fig. s. Fin Streifen ans dem Ange eines lebenden Limulus. Das Ende der Zeichmmg A liegt im Bereiche der schwazen Pseudopupille, $B$ liggt ausserhalb derselhen, so dass die $\Lambda \mathrm{b}$ bildung die Art der Lichtvertheilung in den einzelnen Facettengliedern wiedergibt. Das belenchtende Jicht kam von der rechten Seite des lieschauers.

Fig. 9. Comeafacette mit dem daranhaftenden Krystalliegel von Cantharis fusca. $A$ einem im Dunkeln, $B$ einem im Sonnenscheine getölteten Thiere angehörig.

\section{Tafel II.}

Fig. 10 nud 11. Beide Ablibungen betreffen dassello frische Zupfpräparat der Netzlaut von der Messingenle (Plusia chrysetis). Es zeigt die hei den Nachtschmetierlingen ras 'Tapetum bildenden 'l'racheenlüischeln, welche die Selstäl,e von hinten her umkleiden und im durchfallenten Lichte, Fig. 10, dunkel, im anftallenden Lichte, Fig. 11, hell erscheinen. Hinter dem Tapetum sieht man bei Fig. 10 die Pigmentsehichte der Netzhaut und in dieselbe eiutretende Nerven. S. die im frischen Zustande undentlichen vorrleren Hailten der dicken Antheile der Sehstähe.

Fig. 12. Zwei solcher 'Tracheenbüschel desselben Thieres isolirt. Man erkennt, wie jerles derselben ans einer kileinen Trachea hervorgeht.

Fig. 13 und 14. Durchschnitte diuch das Ange von Iydrophilus picens. Die Comea ist nicht gezeichnet. Die Umrisse der einzenlen Schichten sind mit dem Zeichenprisma aufgenommen. Vergrüsserumg 210.

R. Retina.

m. $f$. Membrana fenestrata.

Zwischen dioptrischem $\Lambda$ p] arat und Netzhant betindet sich ein von Fasein iturehzogener Glaskörperraum. Die Fasern inseriren sich an kegelartigen Vorsprïngen des Irispigmentes. Fig. 13 gehört einem im Dumkeln gehaltenen und daselbst getïrlteten Thiere an, Fig. $1 t$ einem in sonnenschein getörteten.

Fig. 15. Einige Facettenglieder emes rothen Ordensbandes (Catocala nupta) (Nachtfalter) links in Dunkelstelhug, rechts ein Facettenglied mit seinem Irispigment in Lichtstellumg. Vergrössernng 216. Man sielıt, dass bei $c$ eine dem Kegel eng anliegende Pigmentschichte zutülkbleiht, wem das Irisjigment mach riekwäts wandert. Es ist das das Analogon des "Hristapetums". Es reflectirt, wie das eigentliche Iristapetum der Krebse, das Licht, und gibt dadureli zu der hramen Farbe Veranlassung, die das Ange des Ordensbandes hat, und von der sich am 'Tage die schwarze Pseulopupille abhebt.

a. Querschuitt Aurch die Anschwellung eines Sehstabes.

b. Netzhant in Sime von Thompson Lowne.

$m$. $f$. Memlirana fenestrata.

Fig. 16. Facettenglieder von Colymbetes fusens, Vergrisserung 160. A gehört einem Thiere an, das im Junkeh gehalten mul daselhst getibltet, $B$ einem solchen, das dem Somenselieine ausgesetat mul in diesem getüdtet wurle; beile durch Alkohol.

i. p. Irispigment.

$r$ p. Retinapigment.

Fig. 17. Facettenglicher eines Tauhenschwanzes, Makroglossa (Abendfalter). Vergriisserumg 166. $a$ gehiut dem anf' 'Tafel VT, Fig. 63, ahgehihleten Auge an. Es zeigte, mit dem Augenspiegel untersucht, schönes grimes Lenchten im Immem der I'sendo-1Ianptpupille. Das Irispigment befiudet sich in lonnkelstellumg.

6 gehört einem anderen Hxemplare an. Sein Irispigment nähert sich der Liehtstellumg: $r$. p. Das Retinapigment ist in langen streifen zwisehen den Selstaiben angeorlnet.

$m$. f. Membrama fenestrata. 


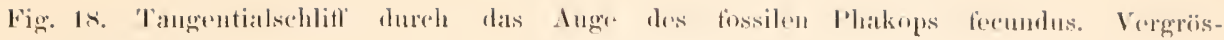
serung 2.2.

Fig. 19. Meriolionalsehlift durch dasselhe Auge. Vergrösserung 22.

\section{Tafel III.}

Fig. 20. Ein Facettenglied von Limnlus polyphemns. Vergrisssemug 170. lis ist nu insoferno combinirt, als gerade an dem hier alogebildeten r'acettengliede die l'orencan alchen in der Comea bei a nicht mit Luft gefüllt waren, die wenigen hier lufthältig gezeichnetrn also einem anderen entnommen sind. Die wellenartige Streifung der Chitinsubstanz ist in der Natur viel reicher und regehmässiger, als dies die Abbildung wiedergeben konute. 1. Stäbchen im Inem der Retinula.

Fig. 21. Querschnitt durch die Retimula desselben Thieres. Vergrösserung 170. Die ratiäı gestellten Gebilde im Centrum sind die Querschnitte der in Fig. 20 der Länge nach sichtbaren Stabchen. Der Querschnitt trift' die Retimula etwas tiefer als rer mit $R$ hezeichneten punktirten Linie der Fig. 20 entspräiche.

Fig. 22. Uebersichtlicher Durchschnitt eines Auges von Squilla mantis bei Vergrösserung 30. Der Schnitt geht parallel zul Längsaxe des walzenfürmigen Anges und durch seinen grössten Umfang.

c. Cornea.

$k$. Krystallkegel.

I. $P$. Irispigment.

s. Sehstäbe.

$m$. $f$. Membrana fenestrata und in ihrer Umgebung das Netzhautpigment.

g. Ganglion opticum.

Fig. 23. Drei Facettenglieder von Tropinota hirtella. Vergrösserung 280.

c. Cormea.

T. Ein krystallkegel der vom Irispigment vollkommen umlüllt ist, während die beiden henachbarten wenigstens in ihren oberen Antheilen freigelegt sind. Die Sehstäbe hahen knopfartige kernhaltige Anschwellungen, die den Kéegeln anliegen, und eine längere verdickte Strecke an ilıren hinteren Enden.

$m$. $f$. Membrana fenestrata.

$a$ gibt den Ort an, wo der Schnitt gefuilurt ist, welcher

Fig. 24 ergibt. Die Sehstäbe sind durch die Färbung dunkel geworden, nud zwischen ihmen sieht man polygonale Felder, die wahrscheinlich Querschnitte von Tracheen sind; am Läingsschnitte (Fig. 23) sielit man dieselben nur als scharf gezeichnete parallele Streifen. Vergrösserung 1000.

Fig. 25 und 26. Facettenglieder vom Bärenkrebs (Scyllarus arctus). Vergrösserung 85. Fig. 25 gehört einem Dunkelauge an. Das Thier war uiber Nacht his gegen Mittag im Dunkeln gewesen, wurle in Alkolıol abgetörtet, nach Verlauf ron drei Viertelstundeı wurden die Augen abgetrenut und in $0 \cdot 1$ procentige Chromsäure gelegt. Fig. 26 entstammt einem Lichtauge. Das Thier warl in der Soune gehalten und dann ebenso behandelt wie das erste.

a. Querschnitt eines Sehstahes an der bezeichneten Stelle bei stärkerer Vergrösserung. m. $f$. Membrana fenestrata.

Fig. :27. Einige Facettenglieder der Ilonisse (Vespal crabo). Vergrösserung 132. Dieselluen sinr dem Rande des Auges entuommen und zeigen die Abweichung der optischen Axe der Facettenglieder von den anf der Corneaberfläche errichteten Loth. Comea und Kogel zeigen Schattirungen, wie man sie unter Zuhilfenahme des Mikrorefractometers sicht. so dass die Grenzen der einzehnen Corneatacetten und dadurh die sonst selwwer walunehmbare Zuordnung der Kegel zn denselben kenntlich wird. 


\section{Tafel IV.}

Fig. 28. Einige Facettenglieder von Lasiocampa quercifolia (Nachttalter). Vergrösserung 145. I ie Selstibe bestehen ans einem diunen, vorderen und rinem dicken hinteren Antheil. m. $f$. Membrana fenestrata.

$n$. Die Elemente der Netzhint im Sinne von Thompson-Lowne.

n. o. Bïuleh der Selmerventasem.

Dis Irispigment befindet sich in Lichtstellung, die diulurch erzielt wurde, dass dis thier etwa eine Viertelstunde im Somuenschein gehalten wude; vorher aber war es im Dunkelı gewesen, nud daselbst latte ich ilm die eine Itilfte des Kopfes mit einem Auge abgeschnitten, und diese Jälfte sogleich in Alkohol gegeben. Jhr entstanmt

Fig. 29, welche nur den vorderen Theil der Hacettenglieder zeigt; das Irispigment in Dunkelstellung. In beiden Abbildungen sieht man die muskelartigen Stränge, welche sich an die l'igmentzellen ansetzen und augenscheinlich dieselben in Folge der Erhellung nach hinten ziehen.

Fig. 30 und 31 zeigt Licht- und Dunkelange eines kleinen Nachtfalters, von dem ich in Folge rines Versehens bei der signirung (wie schon in Texte erwälnt) nicht weiss, ob es Porthesia, Ocneria rubea, Lencoma salicis orler Cuophria quadra ist. Das Thier dem Fig. 31 angehört, wurde des Nachts gefangen und noch wïhrend der Nacht in der Dunkelheit getödtet, das andere (Fig. 30) wurde nächsten Morgen in directes Somerlicht gesetzt und daselbst getödtet. Vergrössermug 208.

Fig. 3:2. Lin Facettenglied von Epinephele (Tagfalter). Vergrösserung z40.

m. f. Membrama fenestrata.

$a$ Kolbige Erweiterungen augenscheinlich analng $n$ der Fig. 28 und $b$ der Fig. 15.

Fig. 33. Ein Facettenglied einer 13lattwespe (Tenthredo instahilis). Vergribserung :20.

Fig. 34. Zwei Facettenglieder des Rübenweisslings (Pieris raphe). Vergrösserung 180. Macht man bei a einen Quersehnitt, so erhält man das Bild der

Fig. 35, wo die dunkleren kireise die Querschnitte der Sehstäbe, die hellen jene von salckartigen Tracheen bilden. In den ersteren sieht man je vier stähchen, die nicht zu einen eigentlichen Rhabdom verschmolzen sind. Vergrösserung 300.

Fig. 36. Zwei Facettenglieder eines Fuchses (Vimessa) (Tagfalter). Vergrösserung 208. bas Auge ist behaurt.

a. Lin Stidek eines llatures, das der Cornea anfsitzt.

Fig. 37. Facettenglierler eines Portums, der in Dunkeln gehalten war. Vergrösserung 125.

i. $t$. Iristapetum zwar dunkel, aber doch denthich unterscheidbar von

i. p. dem lris]igment.

r. p. Retinapignent, dis sich den Nervenfasem folgend his hinter die Grenzsehichte dos Auges,

m. f. die Membrana fenestrata, erstreckt und dadureh den Zusammenhang der Nerven mit den Sehstäben sehr dentlich hervortreten lässt.

$a$ ı. $b$. Zwei verschieden hoch gelegene Quersehnitte des Sehstahes mit seiner Pigmenthille.

Fig. :38. Zwei Facettenglieder derselben Krebsspecies, doch von einem Individum, das in diffinsem Tageslicht gehalten worden war. Vergrösserung und Bezeichnungen wie in Fig. 37. Man sieht eine Verschiebung des Trispigmentes, sowie das Vorwandem des Retinapigmentes, in Folge dessen die hinteren Enden der Selıstäbe, sowie die Nervenbiindeln des Ganglion opticum fast ganz jigmentfrei geworden sind.

Fig. 39 zaigt in den Altheilungen $D$ und $L$ zwei Angenaluschnitte vou sieyonia sculpta, die erstere in der Dunkelstellung, die zweite in der Lichtstellung. Sie sind so aneinandergeriickt, dass sie einen Augenalselunitt zu bilden scheinen, damit die Unugerungen der Pigmentichichten augenfilliger zu 'Tage treten. Die dritte Abtheilung $A$ zeigt das Priparat $L$ im inffallenden Lichte und ist anch als die Fortsetzmng des Anges dargestellt. Schematisirt ist also nur die Zusammenstelhung der drei Bilder zn einem grösseren Angenalsschnitte, im Uebrigen ist alles genan nach der Natu gezeichnet; Vergrössemng 60. 


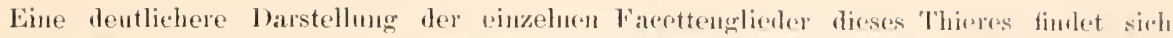

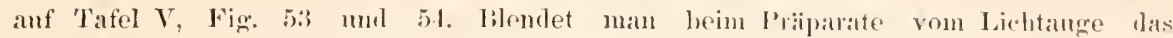
durchfallende Licht ab, so erkout man, dass dem Irispigmente vome oin Iristapetmm (i. t.) anfsitzt, und dass die hinteren Enden der Sehstibe blos vom lietinatanetum (r. t.) umgeben sind; in Ganglion opticum findet sich eine dritte lage Tapetumsulstan\% (t), weleho auch im durchfallenden lichte vom Pigmente kam zu unterscheiden ist. liei Voregleich

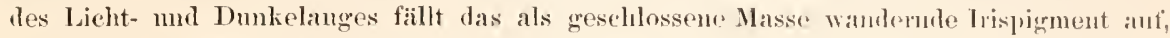
sowie das Retinapigment, welehes das Retinatapetum duchsetzend vom Ganglion opticum bis an die vorderen Ende der. Selsstäbe wande.t.

C. Cornea.

i. p. Irispigment.

R. Retina.

m. $f$. Membrana fenestrata.

i. t. Iristajuetum.

$r$. . lietinatapetnm.

t. 'Tapetmuschichte im Ganglion opticum. Das Jichtange gehört einem Thitere an, las nicht an iler Somne, sondern mur im hellen diffisen 'Tageshichte verweilt latte.

Fig. 40. Facettenglieder von Lycaena (Tagfalter). Vergrössemug :3:).

$m$. $f$. Membrana fenestrata. Damuter die kemartigen Gelilde wie bei vielen anderen schmetterlinger.

Fig. 41 und 42. Facettenglieder von Maja. Vergrossermg 126. 1)ie erste Figur gehürt einem Lichtange, die zweite einem Dunkelange an. Am lrispigment ist eine nur geringe Verschiebung zu beobachten; anfallender ist dieselbe am lietinapigmente. Schön sieht man. den Zusammenhang der Sehstibe mit den Nerven.

Jig. 43. Ein Kégel mit der Comea (c) und seinen centralen Verbindungen, dem Sehstal, (S) und dem Ganglion optienm ans dem Seitenange von Phronima. Vergröserung 157.

Fig. 41. Ein Kegel, dessen fadenfirmiger centraler Antheil noch nicht in voller läuge gezeichnet ist, aus den Seheitelauge von Phronima. Vergrösserung 1;7.

\section{Tafel V.}

Auf dieser 'Tatel ist alle Tapetmmasse gell gezeichnet. Sellustverstandlich erseheint sie unter dem Mikroskope nicht so, es soll die gelhe Farbe vielmehr mur ein Zeiehen datïr sein, dass die betrefienden Stellen im durchfallenden Jichte dumkel, wie Pigment, im aufallenden Lichte aber liell, im Gegensatz zmm Pigment, erscheinen.

Fig. 45 und 46. Fafettenglieder von Galathea. Vergrössemng 92. Fig. 45 golört einem Dunkelthiere an; das 'Thier, dem die Fig. 46 entnommen ist, war in der some getödtet. Wanderung des Iris- und Retinapigmentes. Gehärtet in Miiller'selier Fliissigkeit.

Fig. 17. lacettenglieder von Penens monlmanacens. Vergrissemng 114. In ganzen Ange ist kein Pigment (bei einem anderen mikroskopisch untersuchten Individmum dioser species fanden sich Spmen von ligment, wie im Texte crlantert ist) sondern mm die drei liagen von Tapetum, wie sie hei anderen Krebsen auch rorkommen. Hartung in Alkohnl.

i. t. Iristapetum.

$r . t$. lietinatapetum.

t. 'Tapetummasse im Ganglion opticum. n. $f$. Membrama fenestrata.

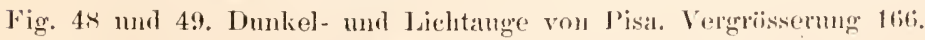

m. $f$. Membrana fenestrata.

$a, b, c, d, e, f$ Querschnite dureh die heveichneten Stellon dre liegel und selstaibe bei staikerer Vergrösserung gezeichnet. Die Zeichnumg ist znsammengestellt theils ans Praiparaten, die in Müller'scher Flüssigkeit gehärtet waren, theils nach solelıı ans Alkohol. 
Fig. jo. Facettenglieder einer Langusta (Palinurus). Vergrösserung 46.

In dem durch einen Strich getrennten rechten Theil des abgebildeten Netzhautstïckes befintet sich das Retinapigment in Dunkelstelluug. Jiartung in Rabl'scher Flïssigkeit.

$a, b, c, d$ Qnerschnitte Iurch die bezeichneten Stellen der Facettenglieder; die beiden letzteren bei stärkerer Vergrüsserung.

Fig. 51 und 52. Dunkel- und Lichtange von Palaemon. Vergrösserung 146. Exquisite Lichtverschiebung beider Pigmentlagen.

Härtung in Rabl'scher Flïssigkeit, und nathträgliche Behandlung mit Alkohol.

c. Cornea.

i. $t$. Iristapetum.

i. $p$. Irispigment.

$r . p$. Retinapigment.

$r$. t. Retinatapetum.

m. f. Membrana fenestrata.

t. Tapetumlage des fangtion opticum.

Fig. 53 und 54. Dunkel- und Lichtange von sicyonia sculpta. Vergrïssenung 1:21. Alkohollıärtung.

Bezeichnung wie in dem vorstehenden Figurenpar.

Fig. 5: und 56. Te ein Facettenglied aus dem Dunkelange und dem Lichtange von Dromia vulgaris.

Das Thier, dem Fig. 56 angehört, war nur in diffusem 'Tageslichte, nicht in der Soune gehalten gewesen. Vergrösserung 104. IIärtung in Alkohol und spätere Entkalkung in Rabel'scher E'liissigkeit.

c. Cornea.

i. $p$. Irispigment.

$r . p$. Retinapigment.

m. $f$. Membrana fenestrata.

Fig. 57. Um das dioptrische Verhalten der brechenden Medien eines Nachtschmetterlings zu zeigen, bilde ich in dieser Figur Krystallkegel und Coneafacette von Lencoma salicis al, wie sie mit dem Mikrorefiactometer erscheinen. Der Schirm des Instrumentes steht rechts.

1. Wine Corneafacette, in welcher sich ein Kern durch seine stärkere sammelnde Kraft (infolge von Schichtung) abhebt von einer Randzone, dio andere optische Beschaffenheit lat.

2. Fin trommelartiges Stück les Kegels dureh zwei Querschnitte isolirt zeigt immer noch dir strahlensammelnde Wirkung (als Linsencylinder). Herum seine Hülle.

3. Der Kegel sammt Itiille der Lä̈nge nach gesehen. Er ist in der Gegend seiner Spitze von dunklem Pigment umgeben, erscheint deshalb hier heiderseits dunkel.

\section{Tafel VI.}

Fig. is und 59 zeigen je zwei Facettenglieder, erstere ans dem oleren, letztere ans dem unteren Theile des Auges ron Libellula vulgata (Diplex). Vergrïsserung beider Zeichnungen 15s. Man sieht die Grössenverschiedenlıeit, sowie den Mangel schwarzen Pigmentes in der oberen Augenabtlieilurg.

m. f. Membrana fenestrata.

t. Tracheenquerschinitte.

Fig. 60. Einige Facettenglieder einer Fliege: Eristalis. Vergrösserung 180.

a. Ein Haar.

b. 'Tracheen.

c. Querschnitt der Sehstähe (die dunkel erscheinen) mit den zwischen ihren liegenden dicken Tracheen. 
Fig. 61. Das Ange eines Rühenweisslings (Pieris rapae) im Lehen mit der lunje hetrachtet (Fig. 3t und 35 zeigen Durchselunite dureh dasselhe Auge.) 1)er grösste schwarze Fleck ist die Hauptpupille, in deren lnuerem man bei benutzung des Angenspiegels und directen Sounenlichtes noch ein roth lenchtendes Piinktehen sehen wiirde. Un die Hamptpupille in etwas unregelmässiger Auordnung die sechs Nebenpupillen erster Ordnung der Manptpupille am nächsten stehend. Noch weiter nach Aussen sieht man eine Anzahl Nebenpupillen zweiter Ordmung, deren regelmässige Anordnung aber nicht mehr zu nrkennen ist.

Fig. 62. Ange des lebenden Distelfalters (Vanessa cardui) unter Lupenvergrösserung. 1Iauptpupille mit den sechs Nebenpupillen erster Ordnung uml einigen am Rande eben noch bemerkbaren Nebenpupillen zweiter Ordnung.

Fig. 63. Ange eines lebenden Taubenschwanzes (Makroglassa) unter Lupenvergrösserung. Die Hauptpupille. Die Nebenpupillen erster Ordnnng sind bis an den Rand des Auges geriickt und, obzwar sechs an der Zahl, nicht mehr mit Sicherheit hei einer Stellung des ljeolyachters zu iibersehen. Wiirde die Zeichnung bei Benutzung des Angenspiegels und directen Somenlichtes aufgenommen sein, so wiirde der dunkelste Theil der Hamptpupille nit grünem Glanze leuchten丸 zu zeichen sein.

Fig. 64. Lebendes Ange von Epinephele (Tagfalter) mit der Lupe betrachtet. Die Hauptpupile ist dureh eine dunkle spange mit zwei dej seclss Nebenpupillen erster Orłnung verbunden, und diese wieder sind untereinander durch einen dunklen ling in Communication. Andentungen von Nebenpupillen zweiter Ordnung.

Fig. 65. Lebendes Ange von Galathe: in diffusem lichte mit der lupe betrachtet. Die IIanptpupille ist entsprechend der quadratischen Gestalt der Corneafacetten viereckig. Schimmernde Streifen, den Seiten der Pujille parallel durchziehen das Augo in einer Feinheit un Regolmässigkeit, wie dieses die Zeichnung nicht wiederzugehen vermag.

\section{Tafel VII.}

Fig. 66. Auge einer grossen Libelle (Cordulegaster), von seitlich vorne und unten mit freiem Auge gesehen. Manptpupille; theilweise ineinanderfliessende Nebenpupillen erster Ordnung und eine Anzahl Nebenpupillen höherer Ordnung.

Fig. 67. Auge derselben Libelle von oben gesehen. Die grosse Hauptpupille des oberen Augenabschnittes und einige Nebenpupillen erster und zweiter Ordnung am seitlichen Theile des Anges.

Fig. 68. Auge eines im Dunkeh gehaltenen Carcinus maenas mit dem Angenspiegel hei schwacher Lupenvergrösserung untersucht. In der lïnglichen dunkeln Psendopupille sieht man den roth lenchteuden Kem (lenchtende Pseudopupille). Um das Ganze ein heller Ilof. Die Flecken in der Ungebung des Phänomens haben nit diesem nichts zu thuu, wandern nicht mit der Blickrichtnng des Beobachters, sondern sind Pigmentflecken.

Fig. 69 und 70 sind Augen von Palaemon, beiłe mit dem Angenspiegel und bei schwacher Vergrösserung untersucht. Fig. 69 gehört einem in diffusem 'Tageslicht gehaltenen Thiere an, Fig. 70 einem eben der Dunkelheit entnommenen. Nach Minuten lauerndem Aufenthalte im Lichte geht das 13ild der Fig. 70 in das der Fig. 69 über. Durchschuitte dieser Augen siehe Fig. 51 und 52.

Fig. 71 und 72. Licht- und Dunkelauge von Pagurus, in derselben Weise betrachtet. Ersteres (Fig. 71) zeigt um die dunkle Hauptpseudopupille einigo eben merkbare Pseudopupillen erster Ordnung, die zum Theile doppelt erscheinen. (Pseudopupillen zweiter Ordnung?)

Fig. 73 und 74 . Licht- und Dunkelauge von Sicyonia sculpta in terselben Weise betrachtet. Durchschnitte dieser Augen siehe lig. 39, 53 und 54. 
Fig. 75. Das Ange von Penens membranacens im diffisen Tageslichte bei schwather Lupenveraroösserung. Die Psendopupille bildet den Kern eines vierstrahligen Stemes. Durchschnitt dieses Anges Fig. 47.

Fig. 76. Das Ange von Nica edulis bei schwacher Lupenvergrösserung unter Wasser betrachtet. Benützt man zur Belenclitung den Angenspiegel und directes Somnenlicht, so leuchtet die sehwarze Pseurlopupille oder ein centraler Fleck in ilır hell auf. Die weissen Streifen stellen einen Reflexionsschimmer von einer Zartheit und Zierlichkeit dar, die die Zeichnung nicht wiederzugeben vermag. 
Fig. 1
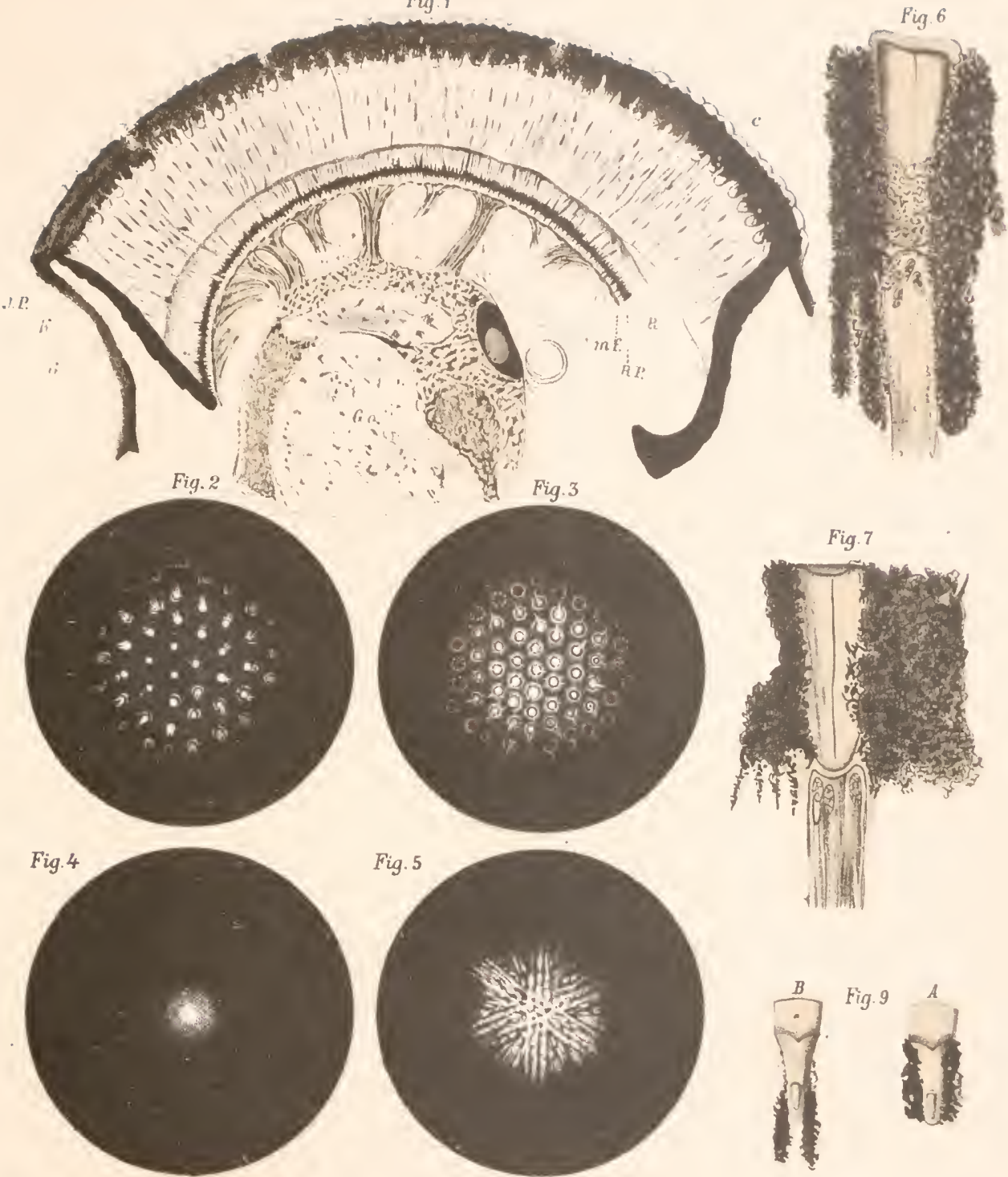

Fig. 8

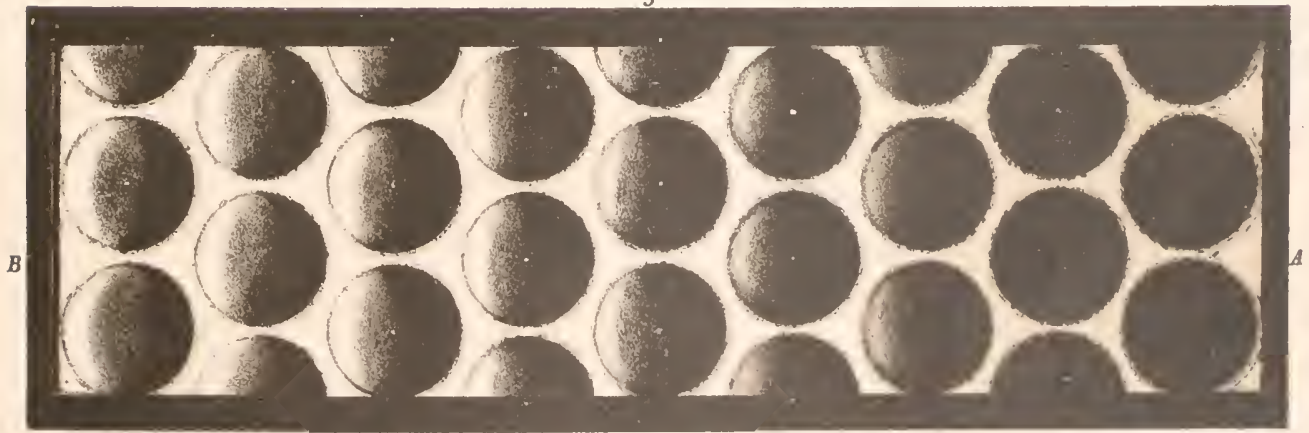



Fig. 10
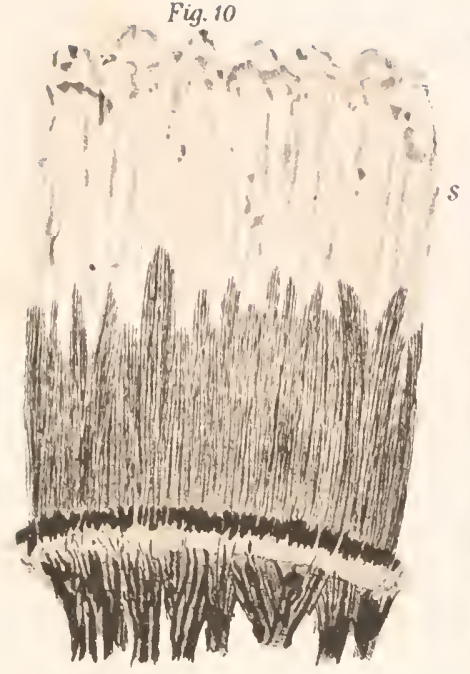

Fig. 13
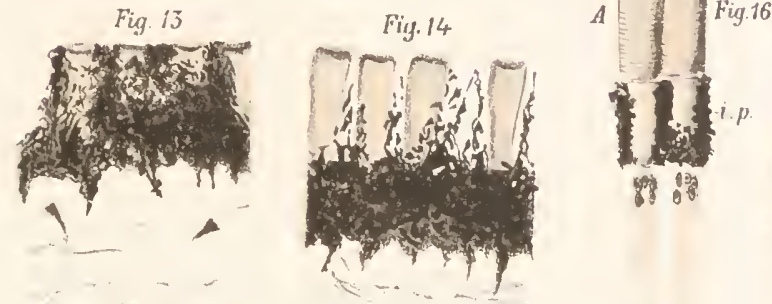

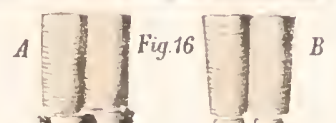

57

Fig 11
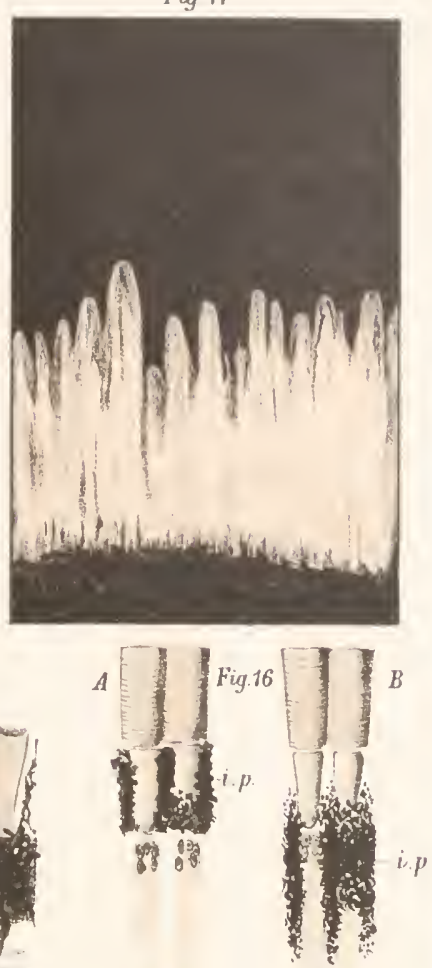

$\{a$

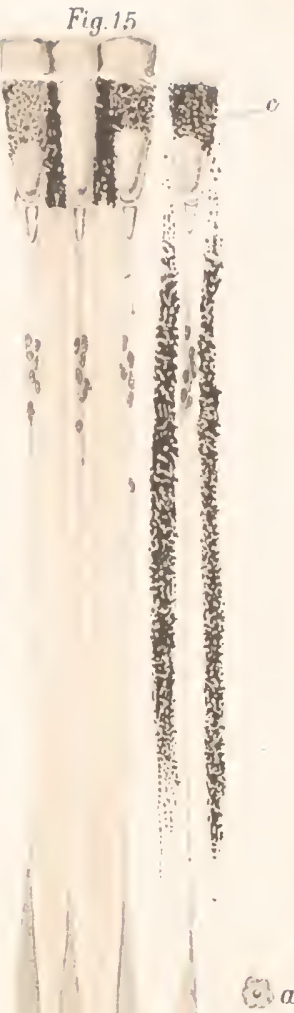

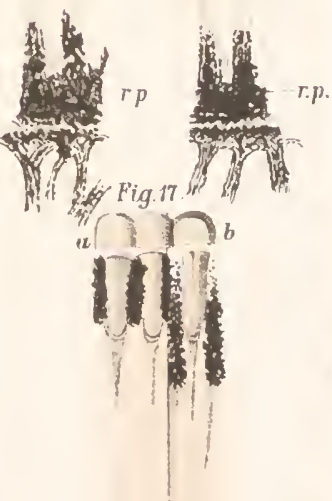
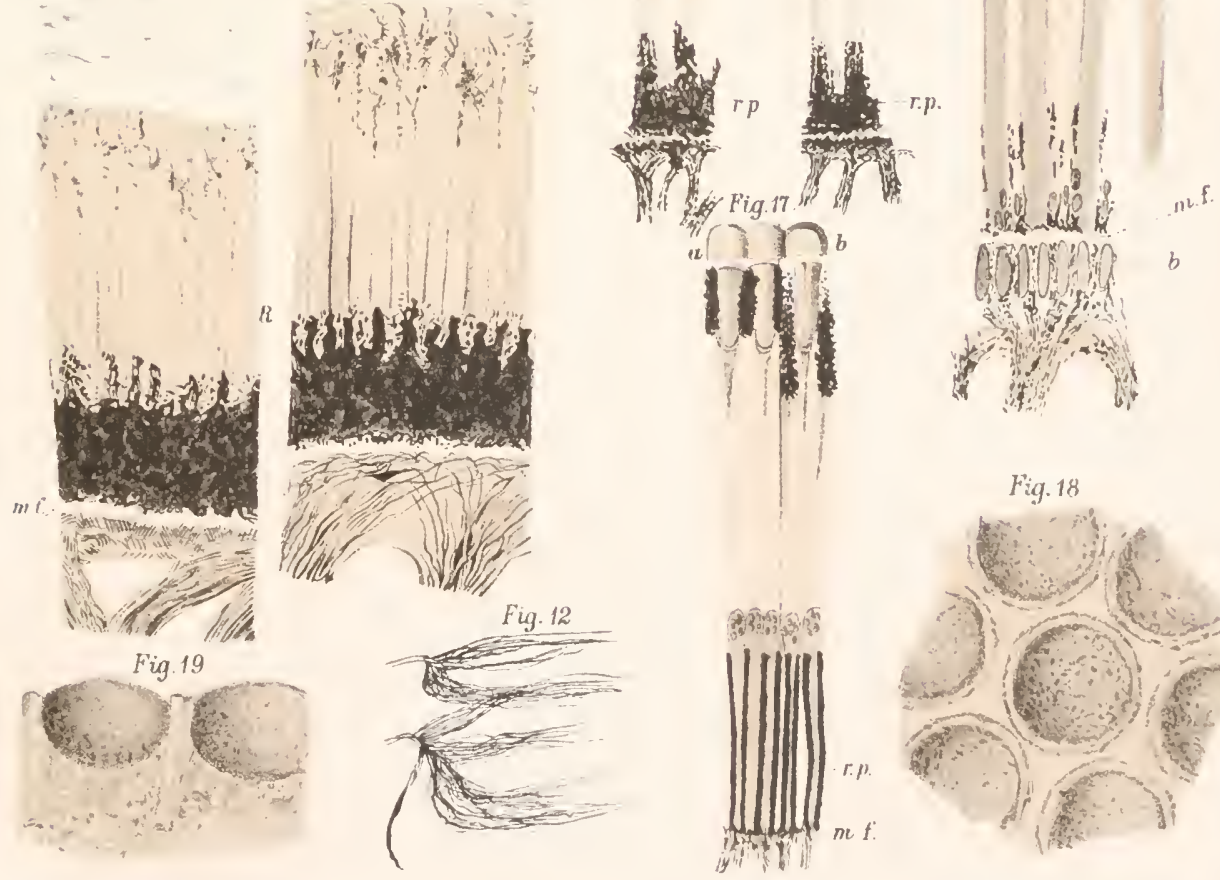

Fig. 18

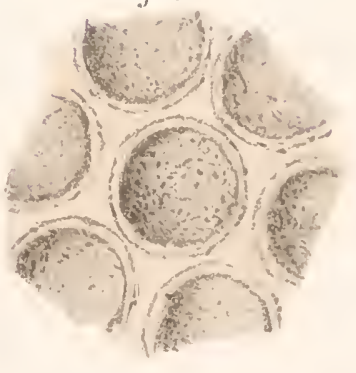

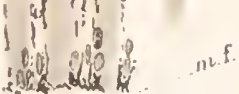
(f) 
Fig. $20 \quad a$

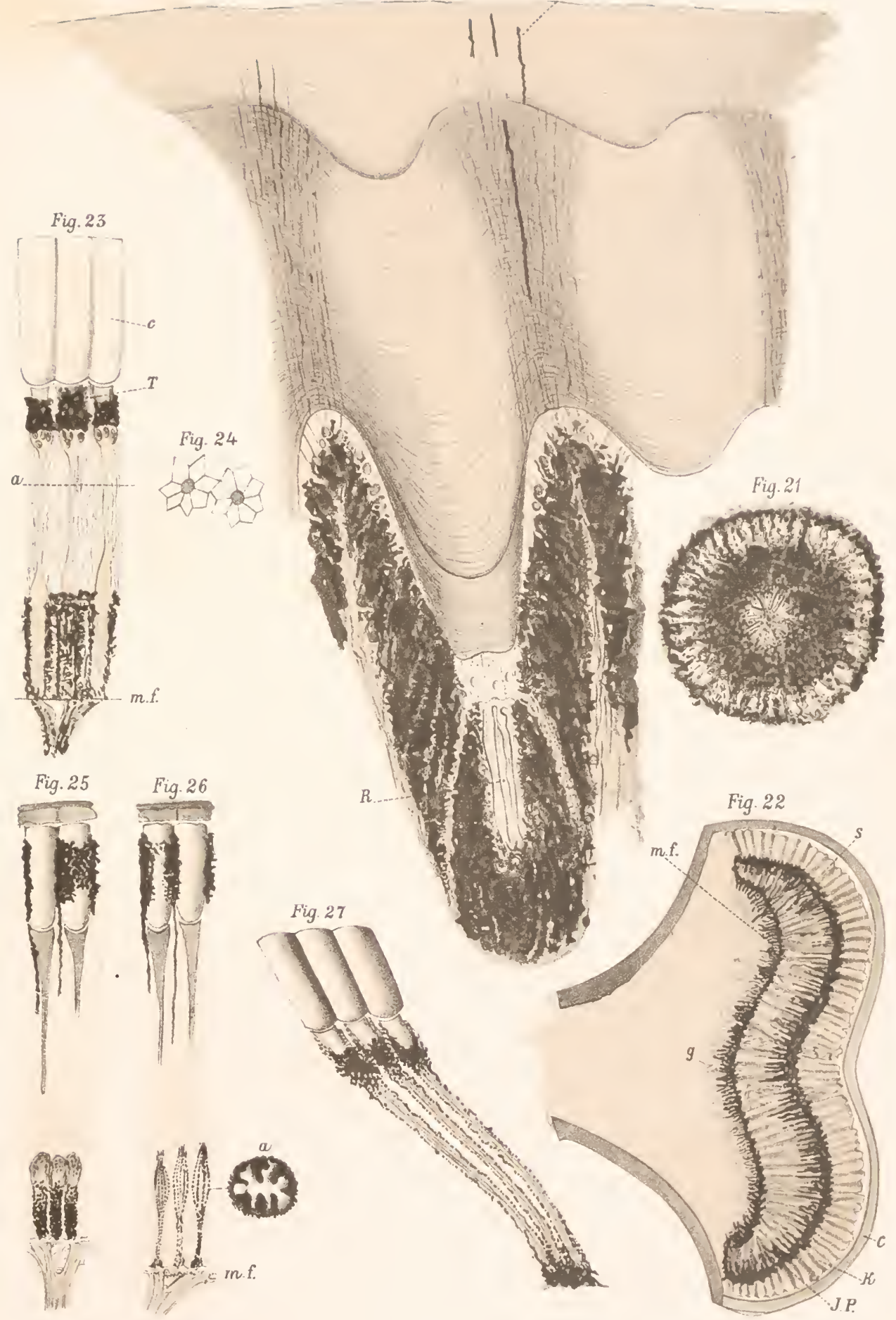




$$
\text { . }
$$




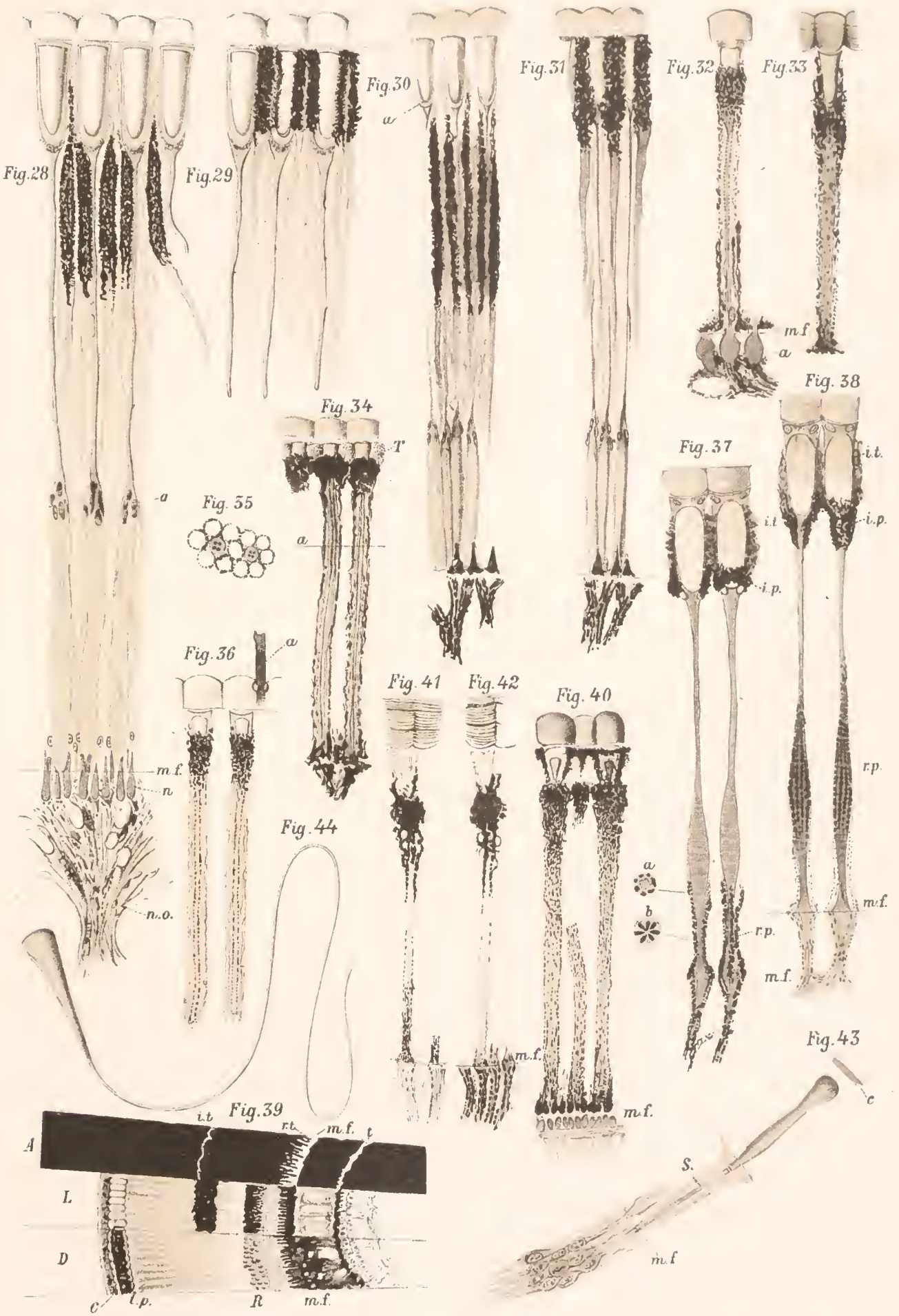





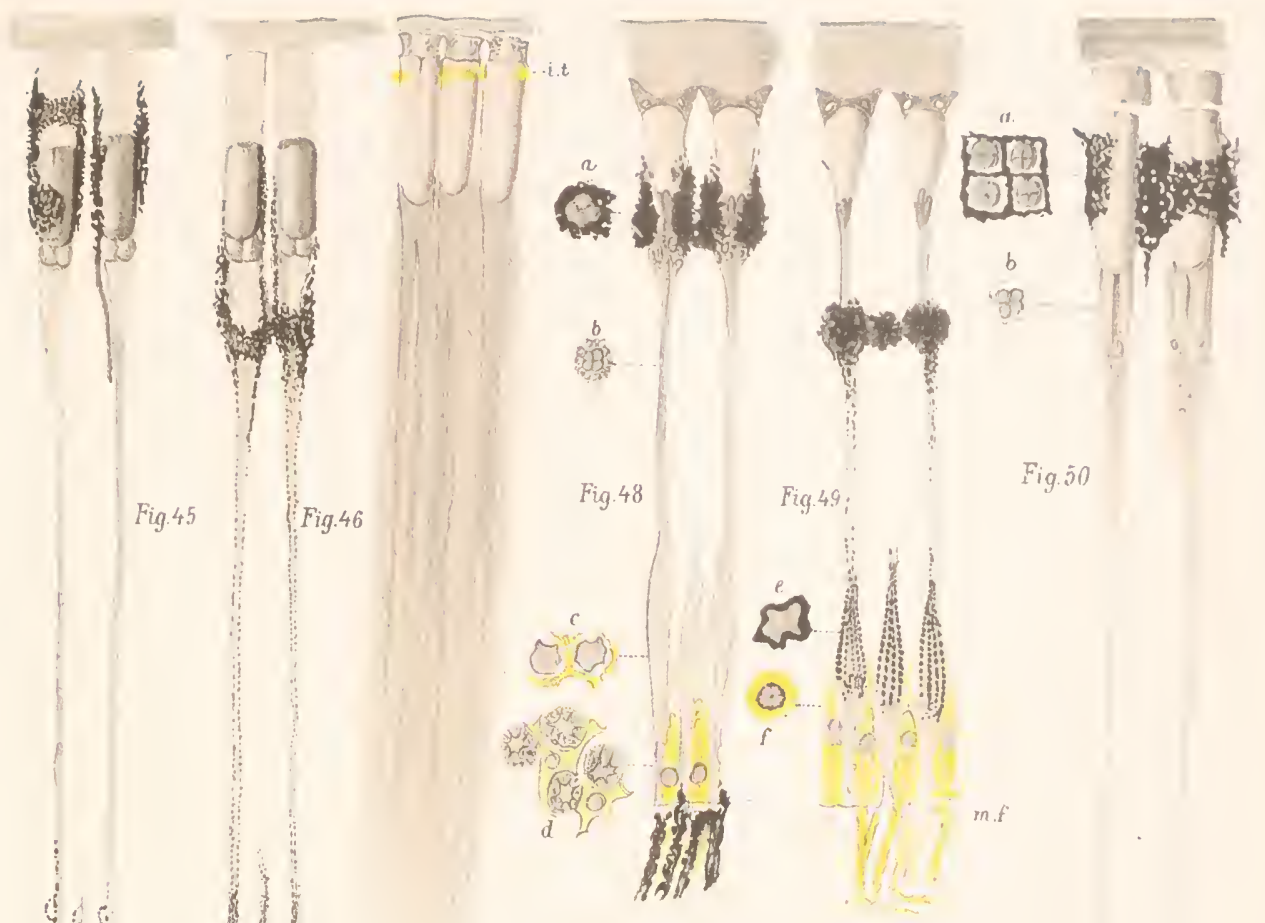

Fig 47

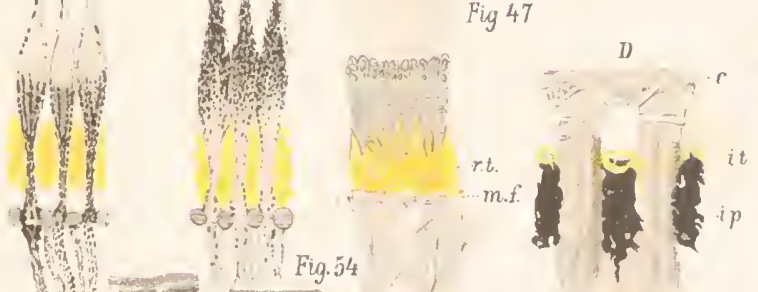

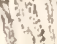

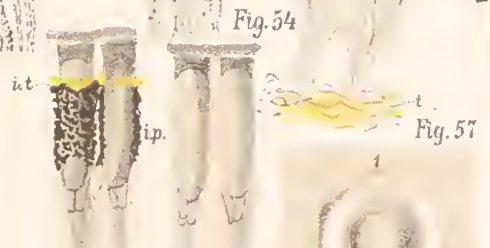

Fig. 53
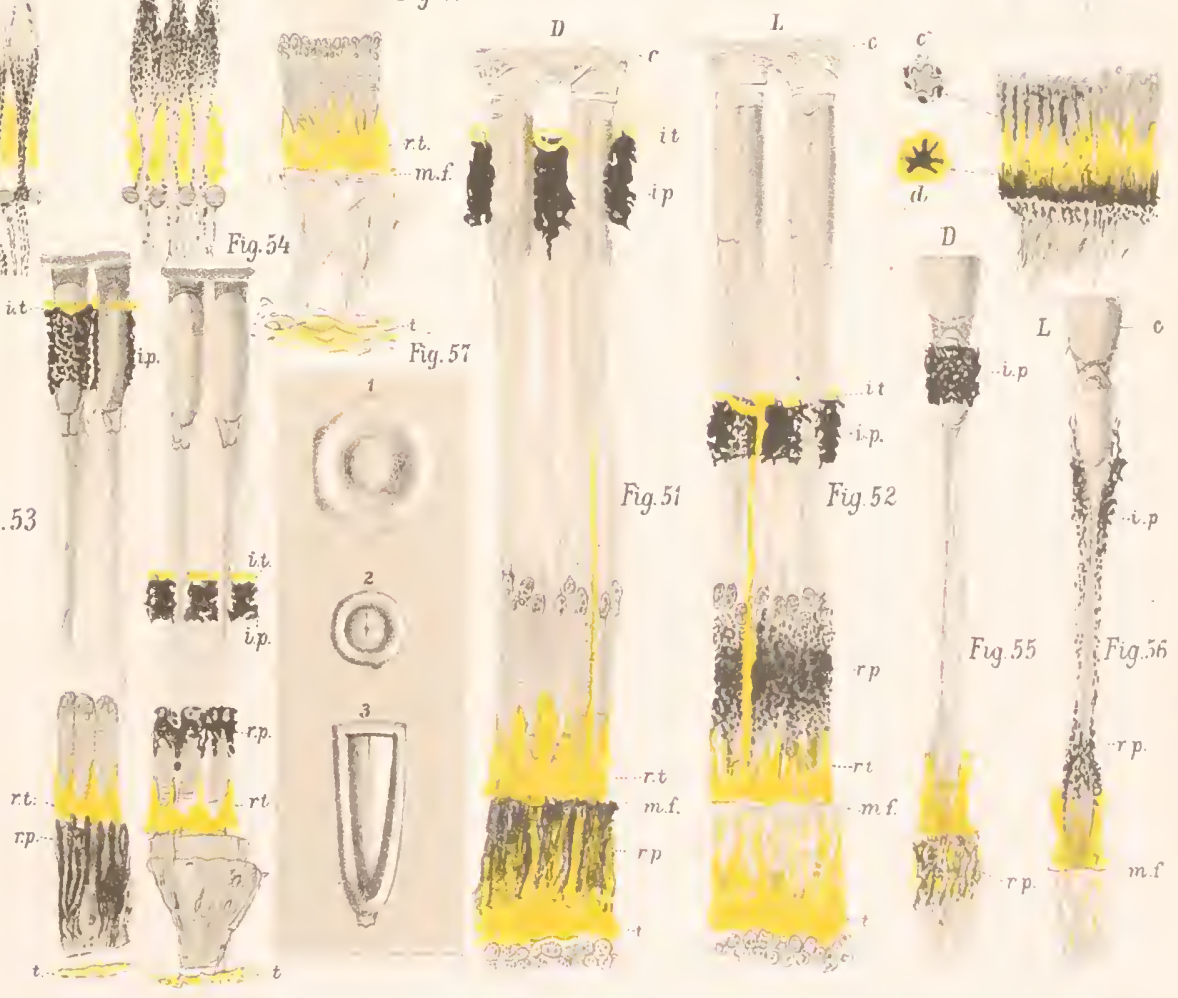



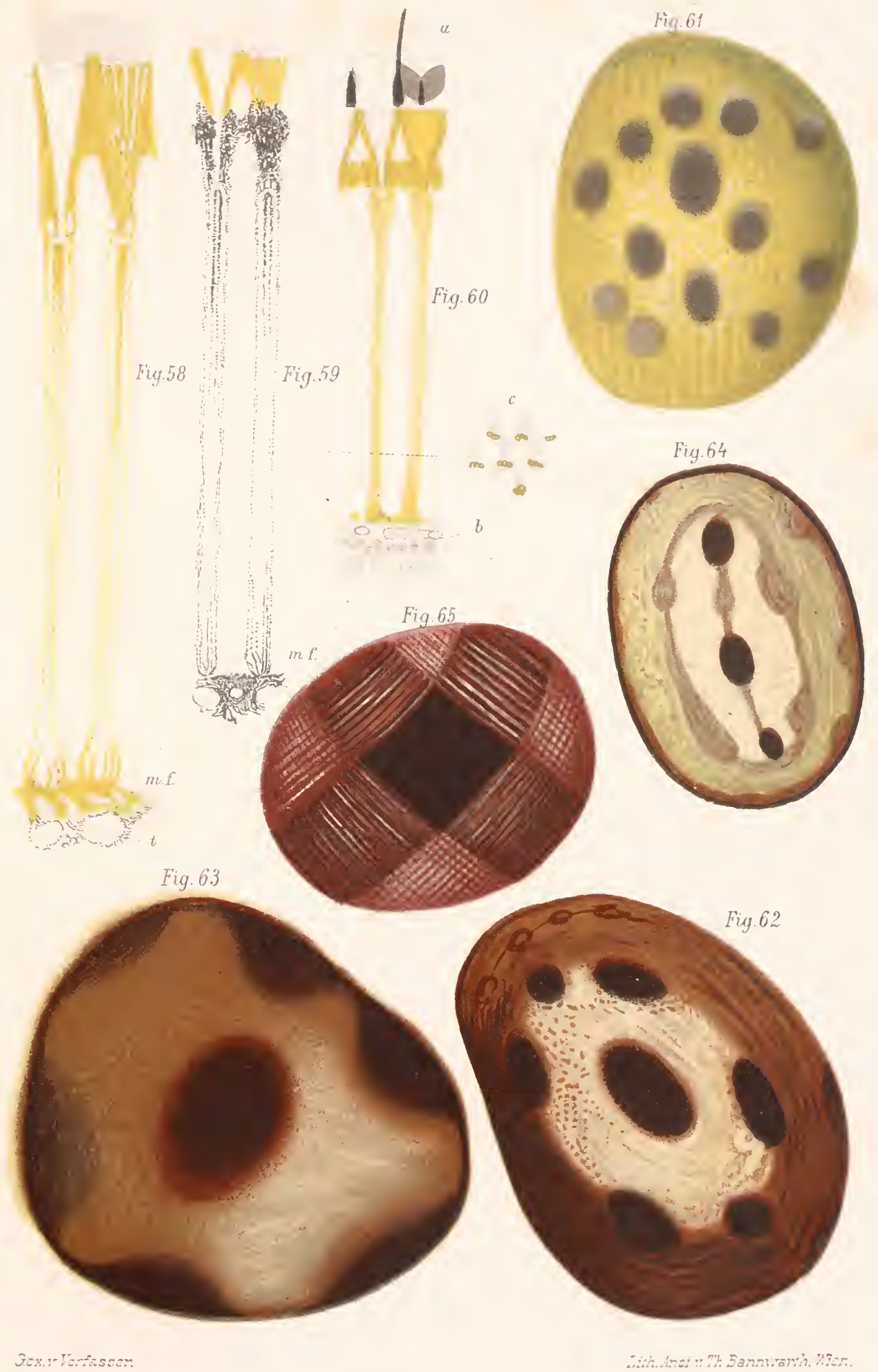

Verlay von Franz Irosticke in Vhion und l.eiprig 

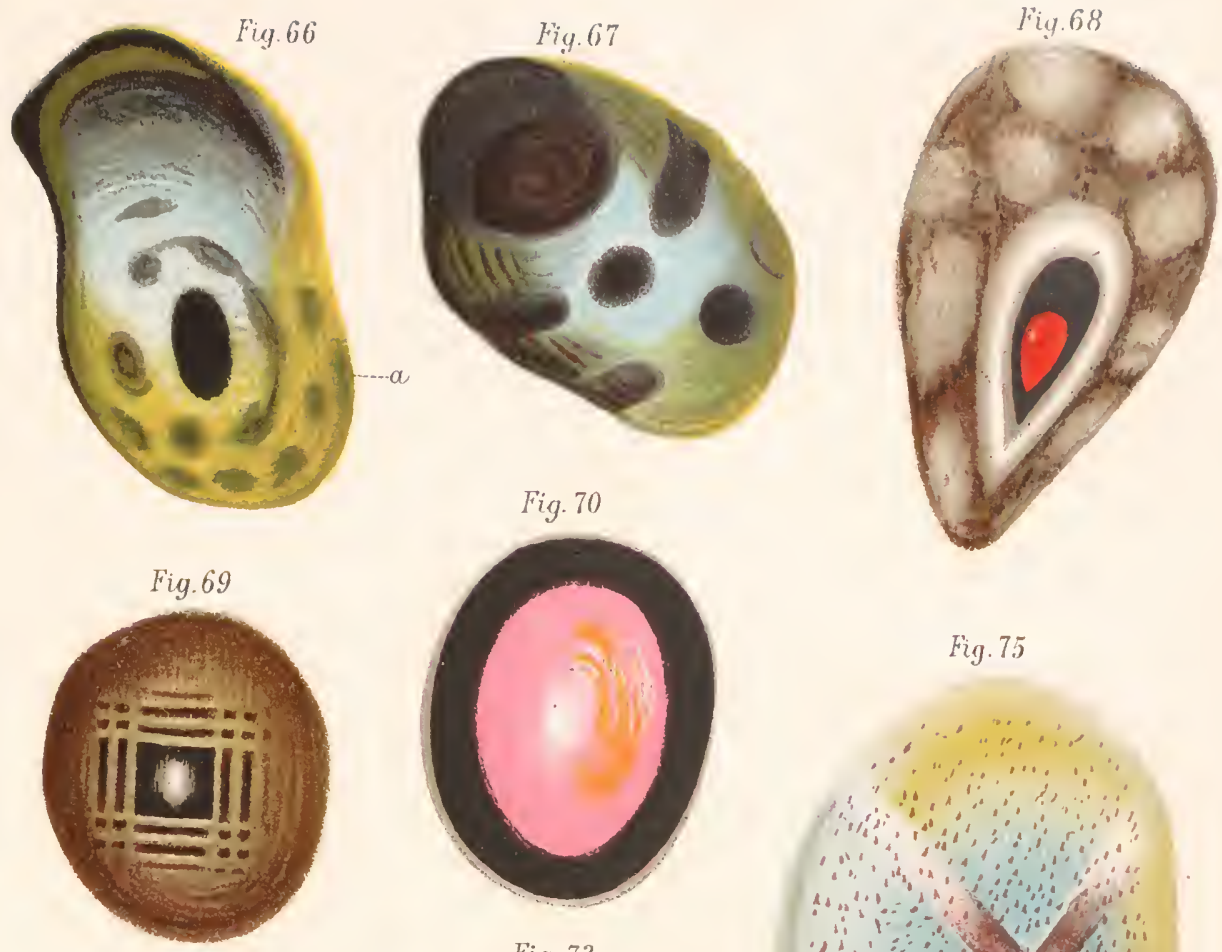

Fig. 75
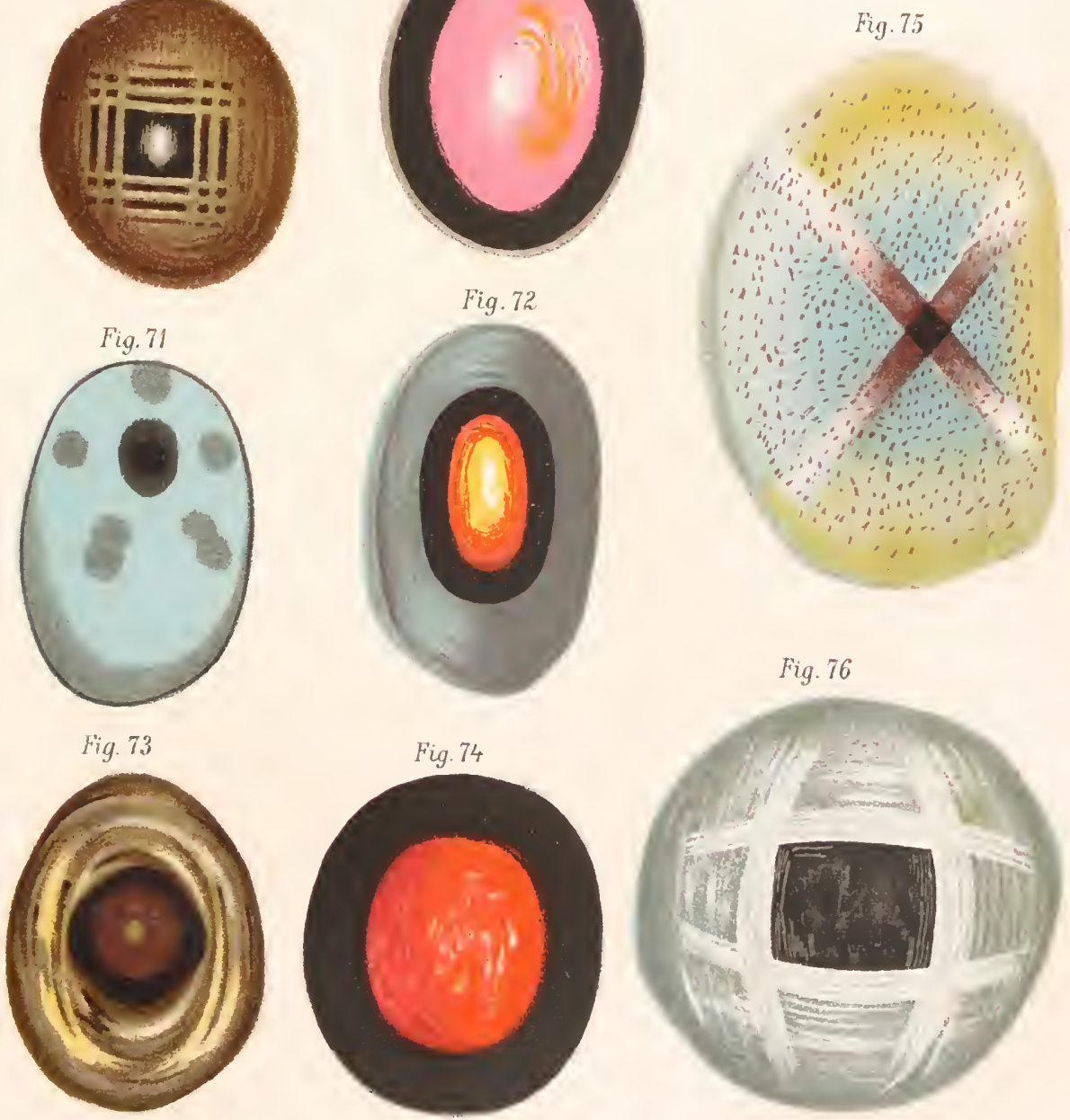


$$
\text { . }
$$





